Iwona Witczak-Plisiecka

\title{
From Speech Acts to Speech Actions
}


$\frac{3}{40}$ 


\section{Iwona Witczak-Plisiecka \\ From Speech Acts to Speech Actions}

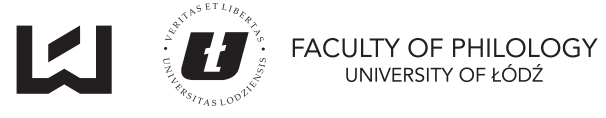

ŁóDź 2013 
Iwona Witczak-Plisiecka - University of Łódź, Faculty of Philology Institute of English Studies, Department of English and General Linguistics 90-514 Łódź, 65 Kościuszki Ave

REVIEWER

Hanna Pułaczewska

TYPESETTING

Iwona Witczak-Plisiecka

\title{
COVER DESIGN
}

Barbara Grzejszczak

Printed directly from camera-ready materials provided to Łódź University Press by the Faculty of Philology

C Copyright by University of Łódź, Łódź 2013

Published by Łódź University Press

First Edition. W.06456.13.0.M

ISBN 978-83-7969-092-3

\author{
Łódź University Press \\ 90-131 Łódź, 8 Lindleya St \\ www.wydawnictwo.uni.lodz.pl \\ e-mail: ksiegarnia@uni.lodz.pl \\ phone (42) 66558 63, fax (42) 6655862 \\ Print and setting: Quick Druk
}


to my family with love $\delta$ 



\section{Table of contents}

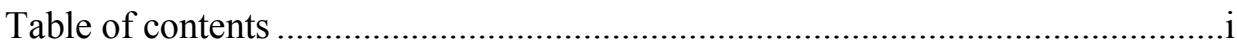

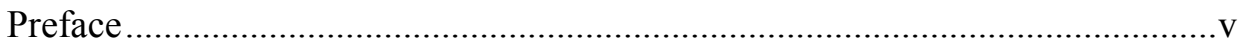

INTRODUCTION

\section{CHAPTER ONE}

The concept of language as action in retrospect ...........................................

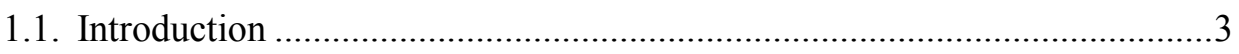

1.2. Religious, magic, ritual, and institutional performative utterances of the past

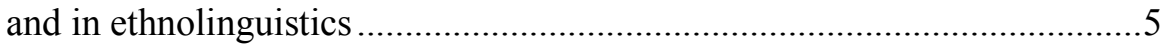

1.3. Aristotle and the later philosophical-linguistic perspective..........................

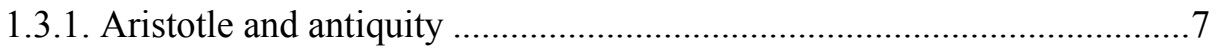

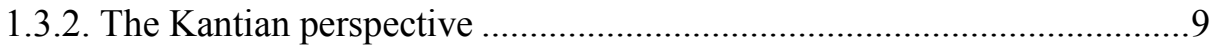

1.3.3. Reid and the concept of 'social operations' ............................................11

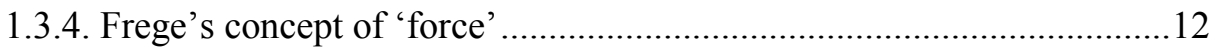

1.4. Wittgenstein and the concept of a language game.....................................14

1.4.1. The concept of 'meaning as use': Wittgenstein, his contemporaries and

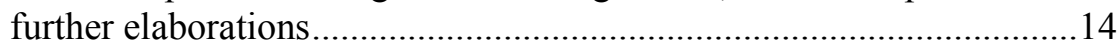

1.4.2. Wittgenstein and the concept of a language game and 'family

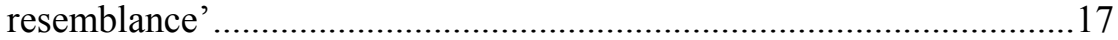

1.5. Husserl and the phenomenologist perspective............................................19

1.5.1. Brentano's physical and psychological phenomena …………………....19

1.5.2. Edmund Husserl and mental activities.................................................20

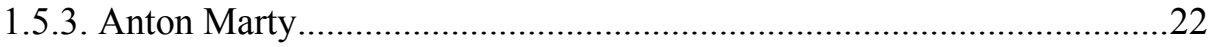

1.6. Reinach's 'sociale Akte' in language and law and the beginning of speech

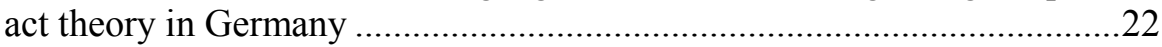

1.7. Research into functions of language in the linguistics tradition .................24 
1.7.1. New voices of the twentieth-century Europe: Ferdinand de Saussure and John R. Firth

1.7.2. Karl Bühler's and Roman Jakobson's models of the functions of language

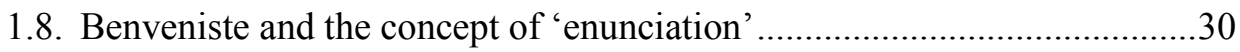

1.9. Slavic languages and research in speech actions ........................................33

1.10. Habermas's sociocultural model of communication ...................................37

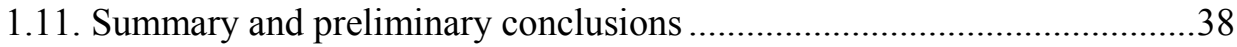

\section{CHAPTER TWO}

\section{J.L. Austin's main tenets of speech act theory: Selected developments and criticism}

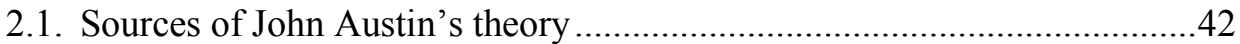

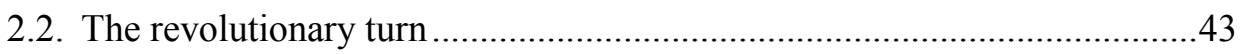

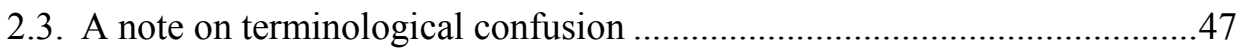

2.4. Performative utterances and speech acts .................................................49

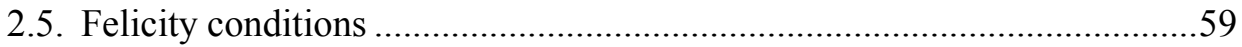

2.6. Speech acts, locution, illocution and perlocution ......................................63

2.6.1. Gesticulary, ingesticula(to)ry, and pergesticulary acts ........................67

2.6.2. Alternative accounts of the internal structure of the speech act ............69

2.7. Acts, deeds, uptake, and tests for performativity.......................................87

2.7.1. Problems with uptake and the distinction between illocutionary and

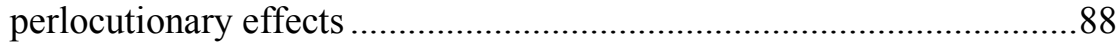

2.7.2. Exclusion of 'non-serious' and 'parasitic' uses ......................................92

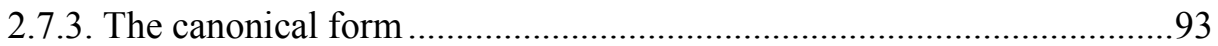

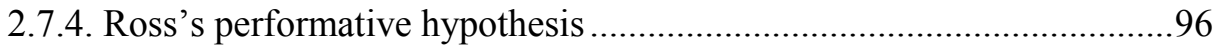

2.8. Searle's speech acts and the construction of social reality .........................99

2.9. Speech act theory - whose discipline? ……….......................................105

2.10. Summary and preliminary conclusions .................................................110

CHAPTER THREE

Speech acts, speech act verbs and metalinguistic classifications................113

3.1. Introduction 
3.2. Speech acts and speech act verbs - between the emic and etic approaches to classificatory criteria

3.3. Austin's taxonomy.....

3.4. Selected classifications of speech acts and speech act verbs beyond Austin .

3.4.1. Searle's modification of Austin's taxonomy

3.4.2. Classifications of speech acts and speech act verbs beyond Austin's and Searle's models.

3.5. Indirect acts and classificatory criteria 158

3.6. Speech act categories in an intercultural perspective 160

3.7. The act of promising $-\mathrm{a}$ 'zooming' perspective 165

3.8. Speech acts and their classifications in a diachronic perspective .181

3.9. Preliminary conclusions

\section{CHAPTER FOUR}

Speech acts and the notion of convention.

4.1. Introduction

4.2. The concept of convention in linguistics and philosophy......

4.3. Convention and intention in the context of speech act theory

4.3.1. Austin on convention in speech acts

4.3.2. Strawson, conventionality of linguistic acts and Gricean intervention 205

4.3.3. Searle on convention and intention in speech acts.

4.3.4. Morgan on conventions and speech acts

4.3.5. Selected cognitive approaches including Bach and Harnish (1979) and Levinson (2000).

4.3.6. Millikan's biological model of language and conventions .220

4.3.7. Brandom and linguistic conventions in a normative perspective

4.3.8. (Preliminary) Classification of intentionalists and conventionalists....234

4.3.9. Convention, semantic minimalism, contextualism, and short-circuited meanings.

4.3.10. Convention and iterability - Derrida and his legacy. .246

4.4. Preliminary conclusions .248 
iv

CHAPTER FIVE

From speech acts to speech actions (and back)....................................25

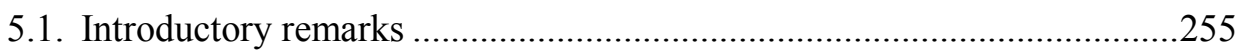

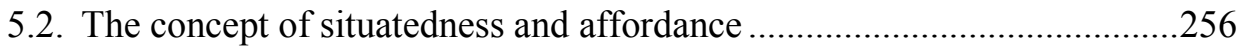

5.3. Speech acts, pragmemes and linguistic communication........................260

5.4. Pragmemes and the ethnomethodological approach............................267

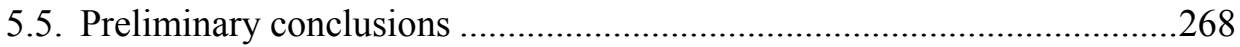

Concluding Remarks:

Speech act theory: retrospects and prospects .....................................22

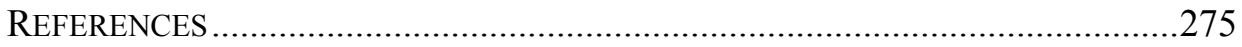

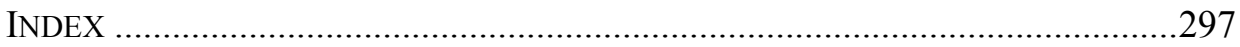




\section{Preface}

I have decided to devote this monographic study to problems of speech act theory in the tradition of J. L. Austin, whose lectures posthumously edited as How to Do Things with Words have continued to exert significant influence in linguistics and philosophy of language.

My interest in speech act theory has continued from the time of my studies at University of Lodz and Trinity College Dublin University in the 1990s and later I used the framework while writing my $\mathrm{PhD}$ dissertation focused on English legal texts. However, back at the time I took speech act theory for granted and did not question its theoretical salience. As my research continued, I gradually grew to appreciate the fact that speech act theory as presented in linguistics handbooks, despite being recognised as the central area of pragmatics, does not in fact exist as none of its main tenets, as suggested by Austin, have been universally maintained. In reality, linguists have to deal with a great variety of different theoretical models which, despite being rich in insightful ideas, are ever so often not compatible with either Austin's theory, or with numerous other conceptions in the field. In addition, speech act-theoretic discussions are infected with terminological confusion, which can often pass unnoticed, but add to the general confusion.

Following my reflections and worries gathered over the years, in the present volume I decided to discuss the main tenets of Austinian speech act theory against the background of its reception, selected later developments, and cognate proposals made at different times and places. In my discussion I focus on a few aspects important for a theoretical account of how things are done with words. Firstly, attention is called to pre-Austinian reflections on linguistic action which bear similarity to Austin's "revolutionary turn", exposing the fact that linguistic utterances can be of actional nature. Secondly, Austin's main tenets proposed for his theory of speech acts are presented with a brief indication of immediate, or most significant modifications suggested by other researchers. A separate chapter deals with the problem of taxonomy of speech acts and speech act verbs, due to its complexity. Another problem approached individually in a chapter is that of conventionality of illocutionary acts. In the last part of the study, I would like to show that the renewed approach to speech actions, which is often seen as 
an alternative to speech act theory, in reality marks a return to Austin's original agenda to elucidate the total speech act in the total situation.

Although my general "non-existence" suggestion may sound pessimistic and dismissive, I want to argue otherwise. My true aim is to indicate the positive side of Austin's proposal and features which have supported his continuing impact in the field of research on linguistic performance.

It is worthwhile to consider the many paths that speech act theory has taken so far, and its many faces. Travestying Stanley Fish, we could say that not only was Austin like a god, who can give and take away, but also researchers who have decided to elaborate his theory would selectively take up his ideas and individually determine their value and shape. Even Austin's initial distinction between performative and constative utterances, abandoned in the course of his lectures, has continued to be an issue in present-day theorising.

From underneath this variety and diversity, there emerges a picture of a theory which has not lost its research potential and whose significance goes beyond just historical interest. The discovery of the fact that things can be done with words, i.e. that words can change reality is only apparently trivial. It offers significant potential for research directions. Both in the micro scale and in a wider perspective such research can give insight into the nature of the social world, and its underlying systematicity. It is among the aims of the book to show that this potential can readily be found in Austin's original thought, despite that his lectures were the first word, not the last.

There are many people to whom I feel deeply indebted professionally and who have encouraged my research, offering stimulating discussion, friendliness, and cooperation over the years. There are more people working in the field of speech act theory and in the interface of semantics and pragmatics than I can acknowledge here as sources of inspiration. First of all, I would like to express my very special gratitude to Professor Barbara Lewandowska-Tomaszczyk, of the University of Łódź, for encouraging me to stay with linguistics, which made all other encounters possible. I would also like to acknowledge the assistance of Professor John I. Saeed, my supervisor from Trinity College, Dublin University. Over the years I have benefited enormously from discussions and encouragement of researchers whom I had the privilege to meet at various linguistics events and those who visited the Meaning, Context and Cognition conferences in Łódź. Adopting a chronological order I would like to express my gratitude to speech act theorists Jef Verschueren, Roman Kalisz, late Robert M. Harnish, Jacob Mey, Marina Sbisà, and Maciej Witek. I would like to cordially thank relevance theorists Robyn Carston and Deirdre Wilson. I also feel indebted to Kepa Korta and his team at the University of the Basque Country. 
I would like to thank my colleagues at the University of Łódź, Poland, and especially Ewa Waniek-Klimczak, for providing me with stimulating and friendly environment at the Department of English Language and Applied Linguistics. Finally, I would also like to thank the reviewers of the book.

I owe very special thanks to my family for their love, patience and constant support: (in order of appearance in my life) Wisia, Zdzisław, Jacek and Martynka. 



\section{INTRODUCTION}

One of the most fascinating aspects of language is its creative potential, its immanent ability to produce an immediate impression, which allows interlocutors to "do things with words", for instance, to promise, to deny, to enact, and in general to change the extralinguistic world they live in. The idea of doing things with words positions linguistic utterances as actions and links them to a wide concept of performativity. Performativity itself is often discussed in relation to rituals and anthropology, and in particular to the actional power of language which can influence and change the reality, in various contexts which range from using the 'magical' healing power of language, to both hate speech and legislation on hate speech, but also include everyday verbal deeds. Performativity, seen as a complex multifunctional power is an inherent part of people's lives, first in practice and then, sometimes, in theoretical investigations. There is rich evidence, from the time of Aristotle at least, that theorists and "ordinary" people have struggled with the concept and that the most tangible and transparent forms in which performativity is present are those that involve linguistic forms.

In linguistics, and in particular in the Anglo-American world, performativity is directly associated with the twentieth-century Oxford philosopher John L. Austin and his investigations in ordinary language known as speech act theory. His book, How to Do Things with Words (1962/1975), has functioned as a landmark in linguistics and philosophy of language, while Austin's concepts of the performative and the speech act have provoked numerous developments not only in linguistics and philosophy, but also in the social sciences in general, culture and ritual studies, gender and identity studies, political studies, and philosophy of law. The concepts have been applied in fields as diverse as clinical linguistics, courtroom practice and law, the theory of art, and information science. The theory is taken for granted in many contexts, e.g. in linguistics handbooks and in practical applications, while the presence of speech act theoretic issues and the context of their uses are marked by polyphonic heterogenity.

In this book, it is claimed that despite the ubiquity of references to Austin, speech act theory does not function as a consistent clearly-defined model for analysis of linguistic utterances with possibly wider implications for performative actions. None of the tenets of speech act theory introduced in 
Austin's lectures, possibly with the exception of the very concept of the actional character of linguistic utterances, has been substantially reaffirmed and retained in further elaborations. Researchers who developed Austin's ideas have been constructing models which are often mutually incompatible, not always true to Austin even in their use of his metalanguage, and much varied in their research perspective. As a result, Austin's original thought seems to have been lost in many of the developments, which is less visible as Austin's own claims were usually tentative in character and, due to his untimely death, he had to leave the original model still in the making. Today, indeed, it may be claimed that, despite the incredibly immense impact over the years, the theory as such does not exist.

Although this book does not purport to be a complete account of speech act phenomena, its purpose is to show Austin's original ideas vis-à-vis later developments in speech act theoretic research as well as in the context of earlier reflection on the actional power of language. It is claimed that even now Austin's ideas are still thought-provoking and that the model of speech act theory which can be seen in his approach is quite modern against the background of the newest proposals in the field of twenty-first century linguistics. It is evident that Austin's original ideas are often richer than later elaborations of his concepts and that his work is worth rereading in the context of the linguistics of the twenty-first century.

Chapter one presents selected pre-speech act theoretic ideas focused on linguistic action, chapter two discusses Austin's original proposals with comments on selected concepts with reference to some of their modifications in the work of later theorists. Chapter three is devoted to problems related to speech act taxonomies with comments on their possible and actual applications. Chapter four discusses the use of the concept of convention in Austin and in other speech act theoretic models. Finally, chapter five presents new proposals for what may be recognised as a theory of speech action or actions and their relation to Austin's original account. The final section sketches possible future perspectives for speech act theory (or theories).

The material to which I am referring, especially beyond Austin's model of speech act theory, is necessarily selective and its aim is to provide illustration for the points in the discussion. Due to immense diversity and richness found in the current speech act-theoretic research, the book does not purport to provide a thorough and balanced description of the field, but attempts to indicate relevance, and, where applicable, also evolution of Austin's ideas. 


\section{CHAPTER ONE}

\section{The Concept of LAnguage as Action IN RETROSPECT}

This chapter discusses relevant aspects of pre-speech act-theoretic reflections on language perceived as action. The overall motivation for the chapter can be explicated through Gilbert Ryle's words, already popularised by Siobhan Chapman (2008: 2):

\footnotetext{
The wise rambler occasionally, though not incessantly, looks back over his shoulder in order to link up the place he has got to with the country through which he has recently passed. It is equally wise for thinkers occasionally, though not incessantly, to try to fix in retrospect the courses that they have followed and the positions from which they have moved.

(Ryle 1956: 1)
}

To what extent such reflections and retrospections have or had been influential in the context of speech act theory is debatable, but the speech-as-actionreflection manifestations definitely belong in the linguistic-philosophical heritage which must have exerted general influence. Thus, the chapter also sketches the environment at the dawn of the theory of speech acts as introduced by John Langshaw Austin with the aim to show the natural perspective on speaking as doing and the motivation which prompted the emergence of the Austinian model in the middle of the twentieth century.

\subsection{Introduction}

The speech act may well be regarded as a category common in linguistics parlance. As Anna Wierzbicka put it back in 1987, 
homo sapiens is essentially, homo loquens, a speaking being [...] a "homo significans [who] lives on expression and communication of meaning"

(Wierzbicka 1987: 1-2)

"Doing things with words" is thus common experience and it should not be surprising that this pervasive experience has found expression in theoretical reflection over a long time. And yet reflection on the specifically performative nature of language, the ability to change the world through linguistic expressions, taken as a starting point for philosophical investigation has been compared to Decartes' proposal of his ontological argument (cf. Verschueren 1977: 2) due to both its significance and the scarcity of related theoretical records in times prior to Austin.

Technically, action has naturally been associated with bodily movement (cf. Davidson's (1963, 2001a) concept of action) and as such speech in the trivial sense is a type of action, a unit of conduct caused by reasons in the form of beliefs, desires and pro-attitudes. It is also understood that what is recognised as action must be intentional under some description although there are numerous diverse opinions with regard to this aspect. For instance, for Hornsby (but not for Davidson), action is independent of its explanation, while linguistic performance as discussed by Austin is always intentional, which could lead to the conclusion that only intentional speech actions are of interest in linguistics.

Naturally, this notion, a kind of presupposed distinction between an action and (just) happening is itself problematic as movements may indeed lead to both intentional and unintentional action and may involve "intelligent agency" and a "planning theory of intention" (e.g. Bratman 1994'). In addition "to intend" is not identical with "to do something intentionally". In a still different perspective, non-action can also be analysed in terms of "action", as in the cases of negligence or omissions.

In a much different "grammatical" point of view, "illocutionary acts" can be defined as descriptive of the function of an utterance of sentence (cf. Quirk et al. 1985/1992: 804f.) which appears to be a statement.

In general, it is common (and common sense) knowledge that communication is intentional and as such naturally lends itself to analysis in terms of speech acts, especially with focus on convention ${ }^{2}$ and socially (pre)defined types of linguistic behaviour. Over time, interest in functional units of language resulted in the accumulation of numerous analyses of linguistic performance, both based on literature and everyday use of language, culled from different times and contexts.

\footnotetext{
${ }^{1}$ Bratman's (1994) analysis is focused on Moore's theory and posited against Fodor.

${ }^{2}$ The problem of the convention-intention axis, or juxtaposition, is of special importance for the theory of speech acts, whose whole history may appear as a struggle between two main orientations immediately related to this distinction. The issue is discussed in further chapters of this book.
} 
Traces of interest in the performative aspect of linguistic utterances can be found in many historical records, from antiquity to the present, in many divergent fields of human activity, such as religion, highly conventional social institutions, or philosophy proper. Many of these examples pay special attention to linguistic action beyond the trivial sense, i.e. to action whose successful performance requires only a relevant linguistic form and a proper social setting.

\subsection{Religious, magic, ritual, and institutional performative utterances of the past and in ethnolinguistics}

There are numerous institutional and philosophical anticipations of speech act performance. The power of language to influence, alter and create reality can be seen all through human history, most easily in institutional and ritual settings. Formulaic language endowed with magical or semi-magical power can be found in most, if not all, cultures. It is present in magical spells whose aim was to bring about a desired state of affairs, related to e.g. health, wealth and prosperity. There are significant similarities in rituals performed in some very distant cultures and the power of language is often emphasised in such rituals, especially in religious contexts. The performative quality is present in utterances such as "Praise be to the Lord!", in wishes, e.g. "May you live a long and happy life" and blessings. Among the most explicit examples, there is holy scripture, e.g. the supra-general utterance of "Let there be ..." of the Bible and the performative "In the beginning was the Word". Cognate examples are found in the Torah, the Quran, where the word of God is not seen as solely descriptive, but as endowed with the power to create the world in all its variety. Religious texts share this feature with many mythologies which associate creation with naming.

Consequently, accounts of instances of performative linguistic force fill books on myths, rituals, and ceremonies, both imaginary and real. One such example can be found in Egyptian papyrus scrolls of c. 1300 BC, where, inter alia, clearly creative power is present in the "Books of the Dead". The contents of the book include "descriptions" of wordly honorable deeds, people's life achievements, which, whether exaggerated or idealised, are to bring peace in the afterlife. The belief in the performative force of such expressions, especially that,

\footnotetext{
${ }^{3}$ The notion "Books of the Dead" has been known since the nineteenth century and was popularised by grave robbers of Egypt (cf. e.g. Hagen \& Hagen 2005 for a description of the Papyrus of Ani, c. 1300 BC). These books in the form of papyrus scrolls, placed in the tomb with a mummy, had been preceded with inscriptions on the walls and initially only available to the mighty. Along with a certain degree of democratisation, the books were also presented to more affluent officials, e.g. scribes (like Ani). It is reported by anthropologists that Egyptians of the past were ready to sacrifice a lot just to secure their "record" in the book, which was not only a promise of a better afterlife "future", but also both expensive and a sign of higher social status.
} 
as we learn, most of the descriptions would fall far from relevant mundane reality, emphasises the long-standing faith in the power of the word, the sayingmakes-it-so strategy.

Another, and a distant example, is the Celtic rhetoric tradition with its boastful warriors' speeches and the bardic world ${ }^{4}$, cf. Cuhulein's speeches as rendered in literature. In the post-Celic tradition, significantly, ("dark") speech in the legal context was presented as saturated with a particularly performative value (cf. Stacey $2007^{5}$ ).

The Bible suggests (however metaphorically) the word as the beginning of all worldly matter. Without retreating in time, the force associated with naming can also be found in today's Africa, while the concentration on 'naming' with the function of brining to life bears kinship relation to ideas of linguistic relativism and modern applications of the theory of speech acts, as exemplified by numerous studies related to the realm of law (e.g. hate speech, cf. McGowan 2003, 2009, Butler 1995; gender studies, e.g. Hornsby 2000, Butler 1990, 1993, work on (the construction of) identity, e.g. Butler 1997, Langton 1993). The parallels between linguistic and non-linguistic performance were commented on in Austin (e.g. 1962/1975: 69) and there is ample literature on e.g. gestures (Feyereisen \& de Lannoy 1991; Fein \& Kasher 1996) that parallel performative utterances.

Linguistic performance is also exemplified in magic spells in folk culture ${ }^{6}$, where the linguistic expression is seen as being endowed in a magical power to influence and shape reality. There are explicit parallels drawn between the work of Austin and anthropological findings, notably such as Bronisław Malinowski's fieldwork on Trobrianders and their culture with emphasis on language as "a mode of action". Bakewell (1998), for instance, links the Polish anthropologist's account of Trobrianders' magical performance (Malinowski 1965), originally from the 1930s, with Austin's (1962/1975) lectures to extend both approaches towards "image acts" (Bakewell 1998: 22ff.), acts performed via images which are not merely descriptive, but images that act. In the model, "veritable" images are understood as "humanmade images $[\ldots]$ from body gestures to "great works of art' and everything in between" (Bakewell 1998: 22). Blakewell further extends her considerations of the necessary link between language and image investigating phenomena such as the popularity of Frida Kahlo and intercontinental extension of her myth or images and narratives associated with

\footnotetext{
${ }^{4}$ The issue can be related to the philosophy of history in general as the bardic tradition, much like chronicle-related reality of the past seems to communicate that history and reality is what has been named and recorded rather than what really happened, happens, or is happening.

${ }^{5}$ In an engaging way Stacey (2007) reconstructs the bonds between legal speech and power and discusses the power of the word with special emphasis on medieval jurists - the unique, first professional legal group in medieval Europe of the eighth and the ninth century.

${ }^{6}$ For data on Polish folklore spells discussed in terms of "disguised directives" related to "an obligated will-endowed being" in a cognitive-pragmatic model see Chudzik 2002.
} 
the concept of madre in Mexican culture. It is implicit in the account that the verbal action should always be seen as at least parallel to the visual, which naturally embodies expressive-actional power ${ }^{7}$.

Malinowski's work is relevant to present-day speech act work in social contexts, which places emphasis on the interplay of linguistic propositional meaning with social meaning conventionalised within certain cultures. Such ethnographic social interactive perspective accepts utterances as instances of "social action", along with gestures and other modes of behaviour. Brown and Yule (1983: 226) cite Labov (1970), who also supports the view that there are rules of interpretation which (conventionally) relate "what is said" to "what is done" and claims that, generally, recognition of both coherence and incoherence in discourse does not stem from the recognition of a sound relation between linguistic utterances, but from recognition of coherent actions behind the words spoken.

These in turn bear resemblance to institutionalised and highly conventional forms used in games, such as bridge. Despite generic differences in types of motivation behind them, ritualised types of behaviour share with games the element of accepted faith in that the world is to match the word, an anticipation of the theoretical notion of the direction of fit.

\subsection{Aristotle and the later philosophical-linguistic perspective}

The present section starts with a mention of the Aristotelian approach to the analysis of language and proceeds to mention other important thinkers who devoted their attention to the actional character of language in various ways and in various perspectives. It covers a very broad span from antiquity to the twentieth century and in terms of timelines crosses over into other sections. However, it gathers cognate approaches which significantly differ from approaches discussed in the other sections of this chapter.

\subsubsection{Aristotle and antiquity}

Theoretical reflection on linguistic action and functions of language can easily be traced back to ancient Greece and times of the Roman empire and is typically associated with the analysis of grammatical categories although, for instance, the instrumental capacity of language was commented on by Plato. Nerlich and Clarke (1994: 443ff), while discussing a (possible) history of linguistic

\footnotetext{
${ }^{7}$ For purposes of her extended speech act approach in ethnographic contexts, Bakewell (1998: 27) refers the concepts of "the pictorial turn" introduced by Mitchell (1994) to mark "a postlinguistic, postsemiotic rediscovery of a picture as a complex interplay between visuality, apparatus, institutions, discourse, bodies, and figurality" (Mitchell 1994: 16).
} 
pragmatics, among the four suggested sources of pragmatic research, pay particular attention to the analysis of mood by Aristotle, Laertius, and Protagoras. These ancient thinkers did not restrict their research to forms of mood, e.g. "indicative, "interrogative", "imperative", but repeatedly make use of notions such as "entreaty", "question", "answer", "command", which in turn were related to the art of rhetoric and had led towards the field which today is recognised as persuasive discourse ${ }^{8}$.

One of the first records in which the existence of non-truth verifiable sentences is acknowledged can be found in Aristotle's writings. Although focused on apophantic logos rather than purely linguistic issues, Aristotle suggests that language resembles mental representation because as "there are in the mind thoughts which do not involve truth or falsity, and also those which must be either true or false, so it is in speech" (Aristotle 350 BC: Section 1, Part 1). In De Interpretatione, however, he simultaneously excludes such sentences which go beyond assertion from analysis, as can be seen in this extract:

Every sentence has meaning, not as being the natural means by which a physical faculty is realized, but, as we have said, by convention. Yet every sentence is not a proposition; only such are propositions as have in them either truth or falsity. Thus a prayer is a sentence, but is neither true nor false.

Let us therefore dismiss all other types of sentence but the proposition, for this last concerns our present inquiry, whereas the investigation of the others belongs rather to the study of rhetoric or of poetry. (Aristotle (350 BC) Section 1; Part 4)

In another translation, the fragment reads:

Every sentence is significant [...], but not every sentence is a statement-making sentence, but only those in which there is truth or falsity. There is not truth or falsity in all sentences: a prayer is a sentence but is neither true nor false. The present investigation deals with the statement-making sentence; the others we can dismiss, since consideration of them belongs rather to the study of rhetoric or poetry.

(17 a 1-5, Edghill translation, version2; cited in Smith 1990: 29)

In both English versions, although they differ significantly, it can be seen that Aristotle clearly perceives the difference between truth-verifiable assertions and utterances which are not relevant for truth and falsity-oriented analyses. Thus, although Aristotle invited an analytical approach to language and dismissed non-

\footnotetext{
${ }^{8}$ Cf. Smith 1984.
} 
assertive sentences as less interesting, he at the same time saved space for them in the ontology of language.

Seuren (2009: 133) reports on yet another philosopher relevant to speech act theoretic research, an even earlier thinker. Appolonius Dyscolus, who lived in the second century AD, is a philosopher who may also be credited with the first mention of what can be recognized as performative verbs understood as an implicit part of the semantic structure in sentences. After Householder (1981: 219) Seuren (2009: 133, fn. 1) quotes Appolonius's words:

[...] it is clear that I call you a thief signifies "I assert by means of the speech which I am uttering that you have done the act of stealing."

However, there is no evidence that Appolonius recognised the performative force as a salient linguistic notion, or even that he believed in the significance of performative verbs themselves.

Appolonius passed relatively unnoticed and Aristotle's comments on nontruth verifiable forms only served as a negative recognition. Aristotle's logic of syllogism, through medieval logic, was further developed and, in the nineteenth century, formed foundations for theories by Augustus De Morgan, George Bode and Gottlob Frege. In the twentieth century, thanks to research by Bertrand Russell and Alfred North Whitehead, it eventually gave the foundations for predicate logic. However, modern theories followed Aristotle's logic of syllogism, which was a logic of truth and not a logic of action, and offered no machinery to represent elements such as goals and intentions. Non-truth verifiable sentences were later kept aside the mainstream of philosophicallinguistic investigation with infrequent instances of attention paid to them until the twentieth century, as evidenced in the further sections of the present chapter.

\subsubsection{The Kantian perspective}

Although not directly speech act-theoretic in today's sense, Immanuel Kant's perspective on language and his ontology is relevant to pragmatics and was evidently innovative at his time. His well-known ideas on the inaccessibility of the "thing-in-itself", or a priori judgments, are known and appreciated, but his work directly related to today's field of pragmatics or discourse semantics has never been sufficiently recognised, and has been largely neglected in the literature of the subject, one exception being a short text in defence of Kant's impact by Alec McHoul (1996). 
McHoul (1996: 587) points to Kant's later lectures published as Anthropology from a Pragmatic Point of View ${ }^{9}$ (Kant 1978/1798), where typically pragmatic issues are discussed. In particular, McHoul mentions Kant's comments on the use of pluralis majestatis and its connection to the "egoistic" perspective and condescension; in other words, his comments on the relation between language and power, where linguistic form marks the latter. Kant's interest in the use of the first person is directly relevant for speech act theory and also brings to mind the concept of enunciation as used in the twentieth century by, for instance, Emilé Benveniste (cf. section 1.8.).

Speech act theoretic traces in Kant are also present in his comments on the meaning of facial expressions and (natural) gestures, where his investigation seems to be focused on search for universal communicative acts. He also explicitly comments on apologising and congratulating and other conversationrelated verbs. McHoul further points to Kant's work on conversational sequencing and "speakers' maxims" relating them to Grice (although, unfortunately, McHoul (1996: 590) misses the fact that Grice in fact did admittedly model his theory of conversation and the maxims on Kantian categories) ${ }^{10}$.

Mulligan (1987) also points to general ignorance on the part of speech act theorists of the relevant philosophical tradition and Kant's work in particular. In his argument, he quotes Searle's statement uttered in an interview:

One of the reasons why the subject of speech acts is so much fun, is that $[\ldots]$ the great philosophers had no theory of speech acts. You can't go and find Kant's view on apologising or congratulating, as far as I know.

(Searle 1984: 25, quoted after Mulligan 1987: 29; emphasis added;)

In fact both Austin (even though he does refer to Kant with regard to moral issues) and Reinach (cf. section 1.6), as well as probably Benveniste, were each convinced that their "discovery" of the performative language use, speech conceived of as action, was in focus for the first time.

Kant deserves attention from pragmaticians for even more reasons. First of all, Kant was the first philosopher to systematically attempt to explicate limits on our perception and cognition. These limits also define the nature of language as we may know it, i.e. inform for instance our expectations as to the precision we are able to achieve. In this perspective, language, being a reflection of reality, is accessible and mediated through two a priori pure intuitions, or forms of

\footnotetext{
${ }^{9}$ Mind the "modernity" of Kant's interests vis-à-vis today's “emancipatory" pragmatics advertised as a "new" field of study.

${ }^{10}$ Cf. Kant's categories of thought: Quantity, Quality, Relation, and Modality, vis-à-vis Gricean's conversational maxims grouped under the four labels: Quality, Quantity, Relation (Relevance), Manner.
} 
cognition: time and space. It follows that language cannot avoid being structured according to these forms. Another significant aspect is that Kant's pure reason allows for, and, in fact, necessitates axiology.

In the context of speech acts, these claims bear relevance and suggest a broader perspective and a kind of unity in perception of "real" things (however inaccessible) and imaginary entities, which, in turn, is in tune with the newer work in pragmatics, e.g. Seuren's (2009) "ecological" view on cognition and linguistics.

\subsubsection{Reid and the concept of 'social operations'}

Despite numerous comments on non-assertive utterances over the years since Aristotle, it is an eighteenth-century Scottish philosopher and a founder of the "common school" philosophy, Thomas Reid, that is credited as being the first philosopher to explicitly raise the issue and contradict Aristotle's theoretical position. Reid argued in favour of extending linguistic analysis of sentences beyond judgments. He criticized the limited research agenda, i.e. an agenda to analyse only one species of sentences - the proposition. Instead, he argued,

To enumerate and analyse the other species must, I think, be the foundation of a just theory of language.

(Reid 1894: 72; quoted after Smith 1990)

Reid referred to different functional utterances, e.g. promises, warnings, etc., as "social operations" or "social acts". Such acts he juxtaposed with "solitary acts" such as judgings, intendings, and desiring. Solitary acts are acts which do not have to be "externally" performed, or in any way expressed, to take place as they do not require understanding on the part of a second party. In contrast, Reid's social acts must be expressed; expression is essential to them, while solitary acts may sometimes just accidentally be expressed. As Smith (1990) points out, Reid emphasized that social acts require a sense of directness in that for instance, for Reid, a command is not just a desire phrased in language, and a promise is more than just an optional expression of intention, will, or consent. According to Reid, in order to be a valid promise an utterance must have a directness towards some other person. Specifically, for a promise to succeed, it must be understood by both parties.

Thus, Reid anticipates both modern philosophical concept of intention and modern models of social science which presuppose social interaction. Smith (1990) claims that Reid's Cartesian dualist ontology must have prevented him from constructing a better account of the social act mechanics, i.e. the relation between an outward sign and the inner intention or will. However, Reid's work 
remained almost unknown and did not exert any significant influence on later theorizing which could be classified as speech act-oriented.

In the beginning of the twentieth century, however, many of Reid's ideas found reflection in evidently independent work by Adolf Reinach (cf. Section 1.6), who discussed social acts in the legal perspective; in turn, his methodology focused on detailed analysis of semantic differences between different uses of words is mirrored in J.L. Austin's linguistic phenomenology.

\subsubsection{Frege's concept of 'force'}

There are two important speech act theoretic notions which can be traced back to Frege. The first one is the concept of the illocutionary force, domesticated in the field of speech act-theoretic research by John Searle, the other is the concept of (and analysis of) assertion (cf. later theorising by Dummett 1981, McGuinness's 1984 edition of Frege, Beaney's 1997 edited collection, and essays edited by Klemke in 1968). Although Frege's concentration was not on "doing while speaking", his relevance for speech act theory lies in his interest in assertion and 'force', which he discussed with regard to the grammatical mood of sentences. In particular, Frege's notion of "force" (Kraft), in opposition to "sense" (Sinn), may be taken as directly corresponding to the speech act-theoretic concepts of force and effect, i.e. a kind of result that the utterance has or may have on the audience within a specific social group.

Frege's concept of "thought" is often translated as "content" and is evidently convergent with the contemporary notion of a proposition. An utterance thus presents things in a certain perspective, where the perspective defined the sense of the utterance. Frege emphasises the fact that although sentences of different mood, e.g. interrogative as opposed to indicative type, may contain the same "thought", there is a meaningful difference in between them in that, for instance, indicative sentences also convey assertion. Following this thought, Frege classifies sentences as assertoric and non-assertoric. Despite the fact that his interest in them pertains mainly to syntax, the discussion bears relevance with regard to speech act theory as propositions cannot be successfully uttered without an accompanying attitude whose sense is similar to that of a speech act ${ }^{11}$. The latter thought was not directly commented on by Frege, but is implicit in his theory.

Frege's classification is further interesting from the point of view of directness and indirectness of speech acts. For instance, for Frege, imperative

\footnotetext{
${ }^{11}$ For instance, Seuren (2009) comments on this aspect of propositions (inter alia as criticism of generative grammar) while discussing Sheffer's and Lewis's analyses (cf. Seuren 2009: 134-136). Lewis is reportedly the first philosopher to introduce a clear distinction between the proposition and its various uses in sentences belonging to different moods, which he further credited to another Harvard philosopher, H.M. Sheffer (as information conveyed in the latter's lectures).
} 
sentences are non-assertoric, while general questions are assertoric. As a result, his "force" may be different for sentences with the same or similar function, e.g. it is different for requests expressed in uttering a question and for requests expressed using indicative sentences with embedded questions, as, for instance, in the following examples:

(1) a. Can you tell me the way to the station?

b. I wonder if you could tell me the way to the station.

For Frege (cf. 1892/1994), assertive force secures a special kind of reference, i.e. evaluation in terms of truth and falsity. The assertive force present in serious utterances about the real world are truth-evaluable descriptions, while utterances which picture imaginary things and are simply non-descriptive of reality have sense, but do not have any reference. Technically, reference can only be made to real existing things, and not to imaginary situations, fiction, or desired states of affairs. In addition, Frege comments on a distinction between the complete sense of an indexical utterance and the partial sense which the uttered sentence itself carries, pointing to the fact that such a partial sense must be completed by information provided by the context in which the utterance is produced. The sense reportedly must first be completed and only then the force may be "added" to the completed sense (Recanati 2007: 126). As suggested by Recanati (2007: 125), who sees Frege's ideas with regard to sense and force as compatible with his model of Moderate Relativism, for Frege truth is a special case of reference.

Frege's firm emphasis on the distinction between sense and force is evidently the strongest link between his original thought and contemporary speech act theory. It may suggest a universal value of a rather arbitrary relation between the form and function of an utterance, a relation which goes beyond semantic linguistic meaning ${ }^{12}$ and may be socially defined.

Frege's thoughts with regard to the force of linguistic expressions and the nature of assertion, however underspecified, have also influenced newly developed theories which aim to encompass the syntactic form of sentences. In contemporary linguistics, Robert M. Harnish (e.g. 1994, 2006) started to develop a theory of speech acts with a focus on grammatical mood of sentences ${ }^{13}$, a theory planned to be a result of conjoining Fregean theory of mood with Austinian speech act theory (cf. Harnish 2001, 1994); selected theorists used Frege's concept of Sinn to parse speech acts (Shwayder 1994) or chose to follow Frege's reflection on assertion and use assertion as a central category and an

\footnotetext{
12 "Semantic" and "linguistic" in the sense of dictionary meaning of relevant locutions.

${ }^{13}$ With regard to speech act theory, it would also be relevant to (re)consider Frege's reflection on compositionality of linguistic expressions.
} 
element in linguistic meaning, a source of discursive commitments and entitlements (e.g. Brandom ${ }^{14}$ 1994, 2000).

\subsection{Wittgenstein and the concept of a language game}

Ludwig Wittgenstein is an unquestionable precursor of theorists who analyse the actional nature of language and emphasise that using language is engaging in socially constrained behaviour. The enigmatic way in which Wittgenstein phrased his ideas, the inherent ambiguity of his writing, makes it nearly impossible to refer to his heritage in a way which does not induce contention. However, his research, under whichever interpretation, provided grounds for analysis of natural language and confirmed natural language as a legitimate source of data for philosophy of language and linguistics. There are passages in Wittgenstein which invite speech act-theoretic perspective, even though, eventually, his work can hardly be classified as directly belonging in the field despite some direct parallels drawn between the two thinkers ${ }^{15}$. However, significantly, there are parallels not just between Austin, but also other implicitly speech act-theoretic thinkers, such as Benveniste. Both Wittgenstein (1960) and Benveniste (cf. section 1.8) commented on the actional (and non-actional) uses of "I".

\subsubsection{The concept of 'meaning as use': Wittgenstein, his contemporaries and further elaborations}

One of Wittgenstein's most frequently quoted lines reads:

For a large class of cases - though not for all - in which we employ the word "meaning" it can be defined thus: the meaning of a word is its use in the language.

(Wittgenstein 1953/1958: section 43, p. 20)

\footnotetext{
${ }^{14}$ In his impressive proposal of a new account of language, an account focused on social reality, Brandom finds inspiration for the suggested inferentialism in philosophers such as Frege, Kant and Wittgenstein. Brandom's conception of assertion includes a claim that every successful assertion involves independent justifications of its own content.

${ }^{15}$ For instance, Furberg (1963), in his study entitled Locutionary and Illocutionary Acts: A Main Theme in J. L. Austin's Philosophy, suggests that the main difference between Austin and Wittgenstein is that Austin was not focused on the possible therapeutic dimension of philosophy. In turn, Chrzanowska-Kluczewska (2004: 26) suggests that "Wittgenstein's theory of languagegames has become a direct predecessor of the Speech Act Theory in modern linguistics".
} 
Among the followers of the concept of meaning as use there are many theorists. In his renowned article concentrated on speech acts, "Meaning and Use", Alston (1963: 107) quotes a number of philosophers who subscribed to the view,

... to know what an expression means is to know how it may and may not be employed...

(Gilbert Ryle, "The Theory of Meaning" in British Philosophy in the Mid-Century, p. 255; qtd in Alston 1963: 107)

Elucidating the meaning of a word is explaining how the word is used.

(Patrick Nowell-Smith, Ethics, p. 67; qtd in Alston 1963: 107)

The meaning of a word is simply the rules which govern its use, and to ask for its meaning is to ask for the rules.

(J. L. Evans, "On Meaning and Verification", Mind, LXII, p. 9; qtd in

Alston 1963: 107)

To give the meaning of an expression $[\ldots]$ is to give general directions for its use to refer to or mention particular objects or persons; to give the meaning of a sentence is to give general directions for its use in making true or false assertions.

(P. F. Strawson, “On Referring”, Mind, LIX, p. 327; qtd in Alston

1963: 107)

...to know the meaning of a sentence is to know how to use it, to know in what circumstances its use is correct or incorrect. [...] A sentence is meaningful if it has a use; we know its meaning if we know its use.

(G. J. Warnock, "Verification and the Use of Language", Revue Internationale de Philosophie, V, p. 318; qtd in Alston 1963: 107)

\begin{abstract}
Alston's argument is that despite the ubiquity of the term "use" in theorising about language, and despite the general acceptance of the opinion that meaning is related to use, there is little, if any, consensus, and in fact little understanding of what it "should" mean. In a sensible perspective, Alston (1963: 110) argues, meaning must be a function of use because the same linguistic forms may mean different things in different language communities and may change over time. What can be seen as a speech act-theoretic mode of application of the Wittgensteinian way of thinking about meaning as use is expressed in the following statement:
\end{abstract}

I think it will be discovered that the smallest linguistic actions which are isolable in the concrete are all normally performed with the use of sentences. (Of course, we have to take into account the fact that any 
linguistic element can function, for the nonce, as a sentence-surrogate, as in one-word answers to questions, e.g., 'John' in answer to 'Who was it that called ?')

(Alston 1963: 112-3)

It follows that for Alston (here), the "use" encompasses both the literal meaning and (primarily in fact) the (illocutionary) function of an utterance. In this sense, the "use" is close to Austin's concept of force in that it exhibits the function of the expression uttered and unites both the (semantic) meaning of words, specifically sentences, and the contextual elements of their utterance. Alston's definition of "sentence use" is "the linguistic act for the performance of which "s" [=sentence] is uttered" (Alston 1963: 113). This has interesting implications for the theory of meaning and understanding of synonymy, which is also discussed by Alston in "Meaning and Use" (1963). It follows that the sentences which are "uttered for the performance of the same linguistic act" (113) are synonymous in that they can be mutually defined one by the other. Such examples, which focus on the function of linguistic expressions are instances of what in modern linguistics is often called pragmatic synonymy as evidently most examples could resist synonymy in the semantic sense, i.e. interchangeability in (all or most) contexts. Thus, Alston exposes linking threads between Wittgenstein, later theorists and contemporary speech act theory.

Wittgenstein also attracts attention to the fact that many exclamations are actional in nature as shown in the following citation:

Think of exclamations alone, with their completely different functions: Water!, Away!, Ow!, Help!, Fire!, No! Are you inclined still to call these words "names of objects"?

(Wittgenstein 1953/1958: section 27, p. 129)

This functional perspective was further an invitation to include "fragments" in speech act theory (e.g. Harnish 2010, 2009b).

Thus, Wittgenstein and research both performed and reported by Alston are illustrative examples of the many approaches in which communication is seen and analysed as a game-like rule-governed type of behaviour (cf. e.g. Alston 1964, Searle 1969).

The "use" theory in its modern models grew to be quite complex and thorough; for example, Brandom's (1994) model $^{16}$, centered on assertion as a basic social act, heavily draws on normativity, attempting to explain meaning in terms of commitments and entitlements which arise when an utterance is produced.

\footnotetext{
${ }^{16}$ Lycan (2008: 83-84) claims that Brandom (1994) is able to amend the use theory so that it may overcome its initial problems, such as, for instance, explaining how processing of novel utterances is possible. Cf. discussion of Brandom's ideas in chapter four.
} 


\subsubsection{Wittgenstein and the concept of a language game and 'family resemblance'}

Although there is no evidence of any direct influence that Wittgenstein should exert on Austin, his ideas expressed in the later period, after Tractatus, are convergent with speech act theory through their emphasis on the actional character of natural language and through the trust which he put in the illuminating potential of ordinary language. "Later" Wittgenstein, expressed in Philosophical Investigations and notes, considered language as a collection of structured "language games". Entire language, and particular languages on their own, consists of forms of life and language games, which are constrained by the world people live in. Language games can be perceived as functional units, or scenarios, which are performed in pursuit of social goals ${ }^{17}$.

Wittgenstein claimed that there is no "essence" of a language game which could be readily explicated. Language games are rule governed, however, the rules are of a very different nature and there may be no single feature which is common for a certain category. This pluralism is seen as a universal feature of language. In paragraph 65 of Philosophical Investigations we can read:

PI 65: Here we come up against the great question that lies behind all these considerations.-For someone might object against me: "You take the easy way out! You talk about all sorts of language games, but have nowhere said what the essence of a language-game, and hence of language, is: what is common to all these activities, and what makes them into language or parts of language. So you let yourself off the very part of the investigation that once gave you yourself most headache, the part about the general form of propositions and of language."

And this is true.- Instead of producing something common to all that we call language, I am saying that these phenomena have no one thing in common which makes us use the same word for all,- - but that they are related to one another in many different ways. And it is because of this relationship, or these relationships, that we call them all "language". [...]

(Wittgenstein 1953/1958: 31)

In $\S 66$, Wittgenstein compares language to games to claim that a collection of activities which people recognise as games may not be unified by one common feature. Finally, in $\S 67$, he introduces the label of "family resemblance"

\footnotetext{
${ }^{17}$ In fact, Wittgenstein's concept of the language game was, at least initially, all-inclusive, not only confined to social life. For instance, he suggested that mathematics is constructed through language games. The meaning of a mathematical formula was to lie in its proof.
} 
to account for the relationship between different games, and, consequently, different language games.

Significantly, among situations which invite performance of language games Wittgenstein in $\S 23$ mentions "giving orders and obeying them", "reporting an event" (Wittgenstein 1953/1958: 11) and "asking, thanking, cursing, greeting, praying" (p. 12). Harris (1988: 97) quotes Wittgenstein's passages from lectures published as Remarks on the Foundations of Mathematics, in which the concept of the institutionalised language game and language perceived as primarily a communication system is explicit:

A game, a language, a rule is an institution. [...] In order to describe the phenomenon of language, one must describe a practice, not something that happens once, no matter of what kind.

(Wittgenstein 1978: 334-335)

In a way, Wittgenstein's language games resemble Bakhtin's (1975/1986) "speech genres", even Goffman's (1974) frames understood as "realms of being" and even selected "contemporary" "genres" investigated through corpus-based study of associations and "bundles" (cf. Biber 1988) or speech (cf. Allwood $1980,1995,2001)$. They are mega-events, which motivate many particular acts. Wittgenstein seems to anticipate later problems of speech act theorists trying to classify and account for speech acts both on the formal and semiotic level, when departing from earlier views he says:

It is interesting to compare the multiplicity of the tools in language and of the ways they are used, the multiplicity of kinds of word and sentence, with what logicians have said about the structure of language (Including the author of the Tractatus Logico-Philosophicus.)

(Wittgenstein 1953/1958: 12)

Although Austin did not explicitly refer to Wittgenstein, and it seems he would go into Moore's footsteps, Wittgenstein appears as the most visible figure among philosophers interested in ordinary language and language in use. Cavell (2002c) explicitly links later Wittgenstein and Austin to show the convergence in their thinking on normativity in language and de Souza Filho (1984) presents both approaches as philosophically convergent. In this light, Austin's speech act theory is sometimes presented as "a final illustration of the Use Theory of Meaning” (Stainton 1996: 156) initiated by Wittgenstein. 


\subsection{Husserl and the phenomenologist perspective}

Among the pre-conditions of speech act theory, Smith (1990) explicitly mentions the emergence of the awareness of the difference between "judgment" and "concept", also referred to as "idea" or "presentation". This distinction is seen as crucial for a conception of judgment as an act in itself, an act which has its own propositional content, rather than a mere association of different concepts.

Judgments and concepts thus became differentiated logically, but they also came to be perceived as distinct psychologically, the quality seen as a prerequisite for speech act theoretic research, which requires immediate perception of the separateness and interdependence of a relevant semantic content and its concomitant pragmatic force. As Smith (1990) suggests, this development made it possible that the pragmatic force became a legitimate object of scientific linguistic study as it showed that propositional contents could be managed in different ways to produce utterances with different functions; for instance the same proposition could be used in utterance tokens of a request and an order.

The new approach is associated with the work of Bolzano, Brentano, Frege (as discussed above), and Husserl, whose selected ideas relevant for speech act theoretic perspective are commented on below.

\subsubsection{Brentano's physical and psychological phenomena}

Contemporary speech act theory, especially in its neo- and post-Gricean models, draws on concepts introduced in philosophy in the nineteenth century. Notably, Franz Brentano's division of acts into the physical and psychological forms a beginning of modern theories of action (cf. Smith 1990). The concept that all psychological acts have contents and are directed (i.e. intentional) towards objects is in turn the beginning of modern cognitive linguistics and in particular intentionalist-type speech act theory, which understands intention in terms of "directness" towards an object, an entity in the world.

Brentano's heritage is also important because of the classification of mental phenomena which he produced. By distinguishing between presentations, judgments, and phenomena of love and hate, he introduced a cognitive classification of acts, which was later to find further development in speech act theoretic models.

He explicitly asserted that speaking, although often brought in opposition with acting, is itself a form of acting (Smith 1990) which induces psychic phenomena. 


\subsubsection{Edmund Husserl and mental activities}

Edmund Husserl's thought, especially as presented in Logical Investigations (cf. e.g. Husserl 2001), evidently inspired considerations of the functions of language. His conception of "objectifying acts", which he had developed on the basis of Brentano's intentional, "object-giving" or, as he would put it, "presentation" acts, served as a criterion for differentiating between types of linguistic action within a holistic theory of language. Thanks to this development, Husserl was able to indicate the distinction between representational acts and non-representational acts, with the latter group including acts such as commanding, requesting, asking questions.

Husserl and his contemporaries anticipated even more of present day linguistics. Smith (1988) gathers quotations from Bolzano and Husserl, as well as comments from Daubert, which serve to show that non-representational uses of language, such as wishes and questions, were dealt with in a manner similar to the later analyses of the deep structure, or the underlying form hypotheses, where, for example, a question is seen as a surface form of a more elaborate affirmative structure, e.g. "I ask whether..." or "My question now is ..." (cf. also Smith 1984). A side effect of this approach, in which questions and commands are "masked assertions", is that all expressions of this type can be considered truth-evaluative, which also anticipated modern models of speech act theory, e.g. Bach (1975), where performatives are perceived "as statements too" 18 .

Smith cites a discussion by Daubert and a schema for the Bolzano-Husserl system, which is represented below:

\begin{tabular}{|l|l|l|l|}
\hline $\begin{array}{l}\text { Form of } \\
\text { expression: }\end{array}$ & Name & $\begin{array}{l}\text { Assertive } \\
\text { sentence }\end{array}$ & Wish-, question-sentence \\
\hline $\begin{array}{l}\text { Expressed } \\
\text { acts: }\end{array}$ & $\begin{array}{l}\text { Presentation } \\
\text { (Objectifying) }\end{array}$ & $\begin{array}{l}\text { Judgement } \\
\text { (non-Objectifying) }\end{array}$ \\
\hline $\begin{array}{l}\text { That of which } \\
\text { we are } \\
\text { conscious in } \\
\text { the act: }\end{array}$ & $\begin{array}{l}\text { Object } \\
\text { State of affairs }\end{array}$ & $\begin{array}{l}\text { Object or state of affairs } \\
\text { wished-for or questioned- } \\
\text { about }\end{array}$ \\
\hline
\end{tabular}

Table 1: Schema for speech actions according to Bolzano and Husserl adapted from Smith 1988: 131

This schema is slightly modified to represent an amended version of the theory put forward by Husserl (cf. Table 2 below), a model which allows that wishes and questions are also objectifying acts. Their being objectifying is a precondition which allows that in performing them, people may have

\footnotetext{
${ }^{18}$ Cf article titles: "Performatives are statements too" (Bach 1975), "How Performatives Work" (Searle 1989) and "How Performatives Really Work" (Bach \& Harnish 1992).
} 
"consciousness-of-something", which is solely a property of objectifying acts in the previous model. In the new model, in cases of wishes, questions, and commands, the very perception, intuitive perception, of the experience functions as an objectifying act.

\begin{tabular}{|l|l|l|l|}
\hline Forms of expression: & Names & $\begin{array}{l}\text { Assertive } \\
\text { sentences }\end{array}$ & $\begin{array}{l}\text { Wish-, question-, } \\
\text { command-sentences }\end{array}$ \\
\hline $\begin{array}{l}\text { Meaning-giving acts, always } \\
\text { objectifying: }\end{array}$ & Presentings & Judgings & $\begin{array}{l}\text { Consciousness or inner } \\
\text { perception of the non- } \\
\text { objectifying acts of } \\
\text { questioning, wishing }\end{array}$ \\
\hline $\begin{array}{l}\text { That of which we are } \\
\text { conscious in the objectifying } \\
\text { act: the objectivity }\end{array}$ & Objects & $\begin{array}{l}\text { States of } \\
\text { affairs }\end{array}$ & $\begin{array}{l}\text { Wishes, commands, } \\
\text { questions, etc., i.e. the } \\
\text { experiences themselves }\end{array}$ \\
\hline
\end{tabular}

Table 2: Husserl's taxonomy of speech actions adapted from Smith 1988: 131.

Husserl promoted interest in human mental activities, "acts", and showed how, through human experience, they are objectified and turned into "objects" of knowledge. With regard to studies on communication and speech acts, it is often emphasised that for Husserl language is still mainly "representative" and cannot be 'essentially' communicative due to Husserl's belief that it is also salient in silent speech or the "solitary life of the soul", where the communicative function is irrelevant as there is no "other" party. Despite this orientation, Husserl's reflection on language proved seminal for speech act-theoretic research and cognitive linguistics. It recognised non-representational uses of language as valuable linguistics and philosophical data and, thanks to its phenomenologist mental-cognitive orientation, and emphasis on the fact that mental acts are intentional, i.e. directed towards an object, enhanced work on intentionality.

Smith (1990) reports on Alexander Pfänder, a Munich phenomenologist, who, inspired by Husserl, in his German work on logic of 1921 discussed "thought formations" (German: Gedankengebilde), such as questions, assertions, reports, warnings, prohibitions, laws, and commands, which were shown to be able to share with judgements "propositional contents" as discussed in logic. In this approach, there is a clear division between the propositional aspect and the functional aspect, where the latter may be related to the speech act theoretic concept of force.

An explicit link between Husserl's approach to philosophy and Austin's analysis of language can be seen in Austin's emphasis that his work should best be labelled as "linguistic phenomenology", which he indicated as a better and a "less misleading name" than "ordinary language" (cf. Austin 1970: 182). The notion of linguistic phenomenology puts stress on the fact that it is not "just" language that is of interest in Austin's modern research, but the experience of and the insight into complex reality which analysis of language can offer. 


\subsubsection{Anton Marty}

Anton Marty, a phenomenologist, followed Brentano (in a way different from that of Husserl) to produce an account of directive utterances. His work deserves much more attention and space than can be granted here, but it is worth mentioning that he explicitly claimed that intentional speaking may be a form of action, whose aim is to influence and modify the hearer's psychic states. Among the acts mentioned, there are complaints, reprimands, commands, requests, threats and many others. In Marty's view, sentences expressing, for instance, questions, command and wishes do not "represent" but "intimate" acts of the speaker and exert some influence on the hearer. Marty's tripartite model, based on Brentano's classification, and enumerating names, statements and emotives (or utterances "calling forth an interest" (Smith 1990)), bears striking resemblance to Karl Bühler's organon model (cf. section 1.7.2) and once more testifies to the universality of intuitions related to speech act theoretic experience.

In particular, Marty, together with Brentano and Husserl, laid a foundation for the development of speech act theory putting forward a distinction between judgement and concept, and enriching theoretical investigations with insights concerning psychological phenomena.

\subsection{Reinach's 'sociale Akte' in language and law and the beginning of speech act theory in Germany}

Adolf Reinach deserves special recognition as a precursor of speech act theory. As early as 1913, Adolf Reinach, a philosopher from Munich, in a monograph entitled The A Priori Foundations of the Civil Law (Reinach 1983 [1913]), presented an account of acts such as promising, questioning, requesting, and commanding with detailed comments on their taxonomy and variation, with particular attention paid to the legal context of enactment and accepting a promise. A phenomenologist, Reinach had been inspired by, inter alia, Husserl and Bühler (cf. Smith 1990), while his work also significantly anticipates many of Searle's later proposals. Despite numerous publications on Reinach (e.g. a collection edited by Mulligan 1987), his work has not been noticeably discussed among speech act theorists, nor among philosophers of language who concentrate on the phenomenology-oriented aspects of his thought ${ }^{19}$, an exception being articles by Barry Smith on speech act theory and its evolution (Smith 1988, 1990).

\footnotetext{
${ }^{19}$ In Polish Austin's phenomenology was discussed earlier by Jerzy Szymura (1982) in Język, mowa i prawda w perspektywie fenomenologii lingwistycznej J.L. Austina [Language, speech and truth in the perspective of J.L. Austin's linguistic phenomenology], however, without reference to Reinach's work.
} 
Incidentally, Reinach, who, just like Austin, was a phenomenologist and a philosopher of law, also put emphasis on acts in the legal context and like Austin, later Searle, and also Austin's professor and friend, H. A. Prichard, focused on the notion of promise. Years before Searle, he used the concept of "fit" (cf. Mulligan 1987: 39) and theorised on the nature of "content" and "meaning", which resembles later discussions of the locution-illocution relation. His writings include comments on the use of the "distinctive function" of the adverb "hereby", which "refers to an event which is happening along with the performance of the act, that is, to the "accepting," which [...] designates itself" (Reinach 1983 [1913]: 30).

Elaborating on Husserl, Reinach puts forward his own theory of language-a theory of "soziale Akte". Social acts in his theoretical model are acts of the mind performed in the act of speaking; their utterance (dubbed as Äusserung) is special in that the act is not simply an outward expression of some inner experience, nor a report on an emotional state. Social acts are further contrasted with statements (Konstatierungen) reporting on experiences and presented as distinct from internal experiences, "solitary" assertions. In this way social acts can be seen as a special kind of action, inherently social in nature.

Reinach's social acts are sub-categorised into "psychological" acts or "experiences" and not entirely psychological acts, which encompass the former type. Mulligan (1987: 38ff) points out that Reinach proposes a more fine-grained analysis of social acts by distinguishing between what today is called "illocutionary force" (i.e. function) and Husserlian "quality", i.e. accompanying subjacent mental acts and states, which, we might say, motivate them. Reinach suggested "determinate types" of experience presupposed in particular social acts that could be represented as pairings illustrated in the following table:

\begin{tabular}{|l|l|}
\hline Social Act & Experience \\
\hline informing & conviction \\
asking a question & uncertainty \\
requesting & wish \\
commanding & will \\
promising & will \\
enactment & will \\
\hline
\end{tabular}

Table 3: "Determinate types" of experience according to Reinach (1913) quoted after Mulligan (1987: 38)

In these pairs, "conviction" and "uncertainty" exemplify states, while "wish" and "will" are episodes inherent in social acts in which they belong. Thus, Reinach's mental acts seem to provide a subtle way to account for people's intentions, as he draws the line between different modes of mental states, and especially between mental action and linguistic action, the latter being subject to volition (cf. Mulligan's (1987: 38, fn.10) example - "I can terrify Mary by 
promising to F, but I cannot do anything by judging that p"). Theorising on the nature of both "social acts" and types of "experience", Reinach once more anticipates Searle both in his approach to illocutionary acts and intentional states, which are landmarks for Searle's two research interests: speech act theory and philosophy of mind. In Searle's account (e.g. 1983), any intentional state involves a type of state and propositional content (just like illocutionary acts involve illocutionary force and propositional content). The similarity between these two independent accounts, separated by decades in the twentieth century, are striking although evidently both Reinach and Searle in construing their theories (admittedly) follow Husserl and (in Searle's case apparently even more) Heidegger.

Reinach's illocutionary force is described as a "moment" (e.g. of questioning or promising), which is hierarchically dependent on its hyperonymous "social act", which in turn "is a determinate of the determinable spontaneous act" (Mulligan 1987: 38). Thus, Reinach comments also include reflection on the episodic character of a speech act.

It is noteworthy that for Reinach some social acts are, and some are not, truth-evaluative; in other words some acts "fit" states of affairs (e.g. judging, asserting), and others do not (e.g. questions, enactments).

Adolf Reinach's work was influential only within the Munich circle. His contribution to speech act theory could have been significant, but it had not been referred to for many years and, as a result, in the Anglo-American tradition, it only serves as evidence that speech act theoretic reflection may come as natural and largely universal in analysis of discourse and, especially, institutional legal settings. Smith (1990) indicates that there is yet another important dimension to Reinach's work, which suggests that speech acts are not just linguistic phenomena suitable solely for linguistic and linguistic philosophical, or logical analysis. Reinach approaches his "sociale Akte" as an ontological phenomenon, by which he expands the perspective and presents speech act theoretic issues as informing a general theory of being. In this theoretical model, species of speech acts exist parallel to biological (e.g. lion or tiger) and logical (e.g. inferring or judging) species.

\subsection{Research into functions of language in the linguistics tradition}

Elements of research which pays attention to the function of language can be found in all important models of language. The present section looks at some analogies between the Austinian concepts and his speech act theory and other models which used various, often convergent terminologies and concepts. Aristotle's tri-partite rhetorical model of communication, which links speaker with ethos, message with logos, and audience with pathos, must have been influential, but it is focused on rhetorical practice rather than a theoretical 
description of language. However, through both its emphasis on a functional use of language and a structural lay-out, it can be felt behind linear models of communication of the twentieth and the twenty-first centuries.

\subsubsection{New voices of the twentieth-century Europe: Ferdinand de Saussure and John R. Firth}

\section{Ferdinand de Saussure}

Ferdinand de Saussure's research (e.g. 1966 [1916]; 1983 [1916], cf. Harris 1988), although central and prolific in modern linguistics, is not directly relevant for speech acts. However, one of deSaussure's dichotomies is of special interest to speech act theory, viz. the juxtaposition between competence and performance, and the related distinction between langue (language) and parole with the additional category of langage (human speech).

It may appear that speech act theory, which focuses on language in use, is most readily associated with performance and thus parole, which is even marked in the partial terminological convergence between "performance" and "peformative expressions" or "performative utterances". However, speech act theory in most of its models has the ambition to give an account of the universal nature of language and its expressions and, as such, distances itself from research on "performance" in deSaussureian terms or may indeed present the dichotomy as irrelevant. Out of speech act theorists, John Searle (1969: 17ff.) explicitly voiced his theoretical orientation towards langue and his interest and belief in universal characteristics of speech acts. Resting on the principle of expressibility, according to which "whatever can be meant can be said", Searle argued that by this very focus on the universality of speech acts, it is langue that is the centre of his research, not parole.

Methodologically, deSaussure, although hardly a speech act theorist, is convergent with Austin in his emphasis on "identities and differences", being the basis for the mechanisms of language. Austin's meticulous method of drawing distinctions between particular uses of verbs and phrases, along with his linguistic phenomenology and search for units of meaning, shows a similar interest and a similar methodological commitment. In a way, these approaches are complementary thanks to Austin's emphasis on speech acts as holistic functional units, which constitutes the core of his heritage.

\section{John R. Firth}

John Rupert Firth (1890-1960), a representative of the London School, although with no direct link to speech act theory, is relevant due to the fact that he 
approached language as an inherently social product. His definition of semantics as a "situational and experimental study" (cf. Seuren 1998: 170) seems to mirror Malinowski's ideas expressed at the time, but also to anticipate future interest in meaning in context of use. For instance, commenting on how the utterance "Say when!" could be used, Firth suggests:

SAY WHEN! [...] What do the words 'mean'? They mean what they do. When used at their best they are both affecting and effective. A Martian visitor would best understand this 'meaning' by watching what happened before, during, and after the words were spoken, by noticing the part played by the words in what was going on. (Firth 1964:

He thus asserts that saying is a form of action with language itself being a product of world powers. In this integrationist perspective, it is understood that the British Empire created English, just as the Roman Empire created Latin, while, in turn, "the word is creation". Language is naturally seen as an instrument. Firth's concentration on the man as an actor in the world can be seen in the following words:

Let us begin by regarding man as inseparable from the world in which he lives. He is just part of it. He is not here primarily to think about it but to act suitably, which must be taken to include the ability to refrain from acting when the situation requires it. This applies to man's most other important social action, the disturbance of the air and other people's ears by means of people's ears by means of bodily utterance.

(Firth 1964: 19)

In a more ethnic approach, during the Third Congress of Linguists in 1933, Firth reportedly (de Beaugrande 1991: 172) alluded to legends and holy books portraying language as the invention of a god. He also indicated that "science should not impose systems on languages", but "look for systems in speech activity" and "state the facts".

Even though Firth's research on actional language was limited in scope and concentrated on phonetic analyses, the ideas which he expressed about "the context of situation" and language as a form of human living, as well as "babelization" and "debabelization", serve to show a growing awareness of the importance of analyses of the actional character of language. 


\subsubsection{Karl Bühler's and Roman Jakobson's models of the functions of language}

Among the people whose work on communication and language functions is particularly relevant with regard to speech act theory, either by implicit acceptance of some of its tenants or by their anticipation, are Karl Bühler (cf. 2001) and Roman Jakobson (cf. 1960), who produced the most influential prespeech act theoretic classifications of the functions of language after Aristotle's grammar-oriented taxonomy (cf. discussion above). Significantly, the very labels "speech act" and "speech act theory" were coined by Bühler.

Although Bühler's focus was on the "sign", the model which he presented in the book Sprachtheorie, published in 1934, belongs to the theories which investigate the actional nature of language. He discussed work by Husserl and Marty with attention paid to the representation function and defended the view that there are sentences which have no representation function, explicitly claiming:

Why should there not be sentences which have no representationfunction? If one has already accepted that there are words of which this holds, then one will hold it possible for sentences, too.

(Bühler's “Rezension von Marty” 1909: 973; quoted after Smith

1990: 45)

There are four axioms in the theory which are relevant in the context of the model of communication, language phenomena perceived as signs, four basic aspects of language (as explained below), and the general linguistic systems which produce words and sentences.

Bühler concentrated on four aspects, defined along two criteria, viz. the level of subjectivity and formalisation, which produced four types of phenomena. A speech act (subjective, more formalised), which came in between speech action (subjective, less formalised) and speech effect (non-subjective, less formalised) ${ }^{20}$. He produced a three-partite model of linguistic functions (cf. Figure 1 below), which includes: 1) representation (Darstellung), 2) intimation or expression (Kindgabe), and 3) appeal or arousal (Auslösung). This Plato-inspired organon, i.e. a "tool" model of language, linguistic signs and communication grants nonrepresentational sentences an independent status in the theory of language.

In the model, Bühler included what he called "Objects and States of Affairs", i.e. the elements of context important for the interpretation of the message. His categories of language functions also partially anticipate speech act types recognised in Austinian models. The main functions in the model include: 1) expression, which focuses on the Sender of the message, 2) representation,

\footnotetext{
${ }^{20}$ The fourth category being language system—non-subjective and (more) formalised.
} 
which is associated with the world, and 3) appeal, which focuses on the audience, the receiver of the message.

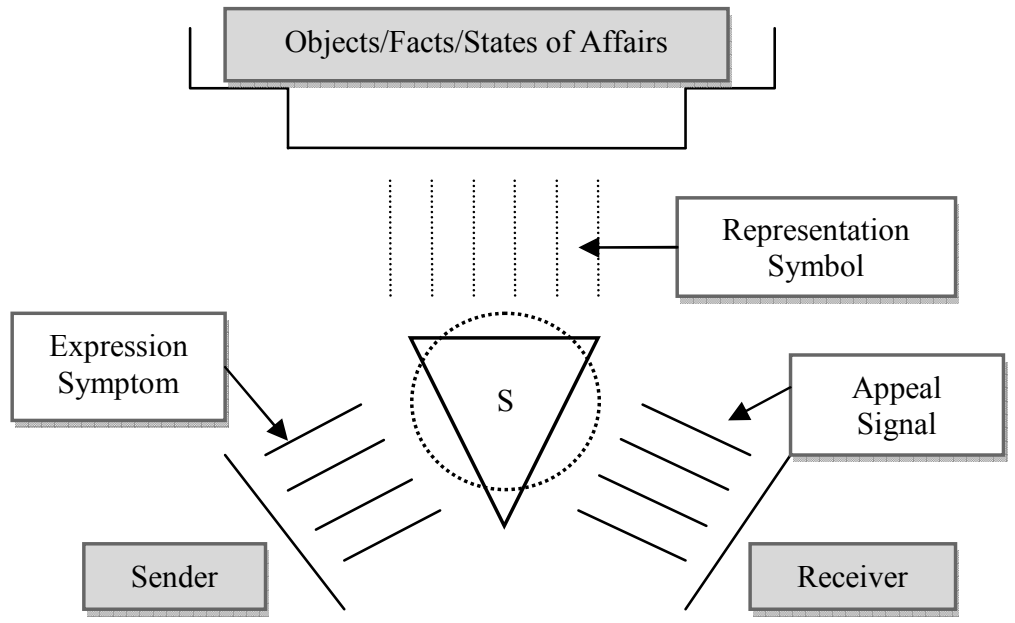

Figure 1: Representation of Bühler's organon model of linguistic functions (based on Bühler 2001: 35)

Functions of language were further discussed by Roman Jakobson in his much quoted essay "Linguistics and poetics". Jakobson $\left(1960^{21}\right)$ did not emphasise the notion of "language as action", nor did he concentrate on criticism of the truth-theoretic semantics, but his discussion of language functions vis-àvis the model of communication explicitly evokes the idea of performance. Developing Karl Bühler's work, Jakobson (cf. 1960: 350ff.) proposed his own schema of language functions associated with the model of communication composed of six essential elements, or constitutive factors in a speech act, viz.: 1) context, 2) addresser, 3) addressee, 4) contact, 5) code, and 6) message. Linguistic communicative functions are realized through interplay of these factors and are relative to the prominence particular factors have in a communicative situation. The functions are as follows:
a) referential (e.g. "This book is beautiful")
b) emotive/expressive (e.g. "I like it")
c) conative (e.g. "Do it now!")
d) phatic (e.g. "How do you do")
e) metalinguistic/metalingual (e.g. "“Dog' is a three letter word")
f) poetic/aesthetic

\footnotetext{
${ }^{21}$ The understanding and discussion of Jakobson's functions of language presented here follows "Linguistics and poetics" as published in Jakobson (1960) edited by Sebeok.
} 
The diagram below presents a schematic representation of the relation between functions and factors in communication in their constant interplay.

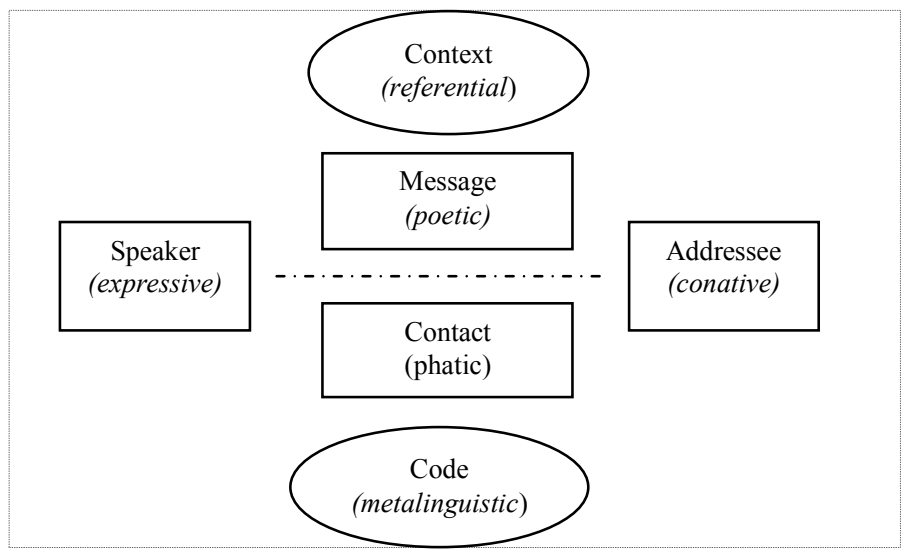

Figure 2: Jakobson's model of communication and communicative functions

Some of Jakobson's functions bear kinship resemblance to Austin's categories. Among the six functions enumerated by Jakobson, it is the conative function, a development of Bühler's "appeal" focused on the addressee, that bears special relevance to Austin's notion of the speech act. The conative function is primarily associated with commands and involves exercising some influence on the addressee. Among the others, the referential function, developed on the basis of Bühler's "representation", corresponds to Assertives, the emotive (Bühler's "expressive") to Expressives, and the phatic may be (selectively) related to institutional uses of Exercitives, which may further suggest universality of at least selected notions used by these theorists, despite evident differences in their research focus.

Not only Jakobson's particular functions correspond to speech act types, the whole model is also saturated with actional value. In particular, what Jakobson called a poetic function, the most prevalent function in communication and directly related to the speaker's creativity, may be in approximation related to the notion of illocution and illocutionary force. Jakobson suggests that the poetic function exceeds beyond the content of the message; it could then be said that it corresponds to the overall function of the message and, as such, by extension, it can tentatively be associated with the message force. Indeed, in many cases the poetic is the function for its own sake.

In addition, Jakobson's model presupposes that language functions are not realized exclusively, i.e. even though one function may be prevalent in a particular situation, this does not mean that the others are not "active". In this respect Jakobson's model is similar to more recent inferential accounts of communication, e.g. that of Grice, cognitive linguists and relevance theorists, 
but also consistent with the original Austinian view, which was more "semiotic" than e.g. later Searle's versions of the theory. Jakobson's model is also closer to speech event theorising such as that presented by Hymes (e.g. 1967).

The question arises whether the Austinian approach to language instantiates an advancement after Jakobson or may be considered a competitive or possibly a complementary account. Significantly, Austin's classification of speech acts into the five main categories was eventually found by the author's own admission, not mutually exclusive. Like Jakobson's functions, Austin's categories form a network which could admittedly cross-cut in a message. An important difference between the two approaches is focus; while Jakobson is most interested in the poetic, aesthetic aspects of language (and as such the symbolic quality), Austin is primarily concerned with the conventional and institutional, especially laworiented uses. It appears that Jakobson's framework lends itself better to analysis of literary language, while the models built in the Austinian tradition are more functional in analysis of institutional discourse ${ }^{22}$. It is also evident that Jakobson's model provides more space for utterances which are not sentences, and not even equivalents of sentences. Elements such as fillers, backchannels, and incomplete or imperfect sentences can be accounted for in the Jakobsonian framework, but find hardly any space in speech act theory in the tradition of Austin. The same can be said about phatic communication which constitutes a substantial part of natural verbal interaction.

\subsection{Benveniste and the concept of 'enunciation'}

Émile Benveniste deserves a special position in any speech act theoretic discussion because his work includes reflections which are cognate to Austin's although developed on the basis of other languages and phrased mainly in French. From what is known, despite striking similarities in their theoretical reflections, both researchers worked thoroughly independently. It is reported (cf. Dosse 1997: 45) that Benveniste did comment on the work by Austin, but only in 1962, while his theorising about speech and utterances, which can be directly relativised to Austin's, dates back at least one decade.

Émile Benveniste (1902-1976), a French linguist of Jewish background, worked within a general functionalist framework. Although Benveniste was mainly involved in structuralist research, he emphasised the functionality in language and the prevalence of the functional over the theoretical. He was specially interested in the subjective linguistic expressions, i.e. expressions in

\footnotetext{
${ }^{22}$ However, as Jakobson's (1960: 377) much quoted final remark from the Indiana conference paper claims " $[\ldots]$ the poetic incompetence of some bigoted linguists has been mistaken for an inadequacy of the linguistic science itself. [... A] linguist deaf to the poetic function of language and a literary scholar indifferent to linguistic problems and unconversant with linguistic methods are equally flagrant anachronisms".
} 
the first-person indicative active voice, the "I", "here", and "now" and analysed extensively, interculturally and interlinguistically (cf. e.g. Benveniste 1971: 195ff.) the relationship between the grammatical person used and the semantics of the verb within utterances. In one of his most influential articles, "Subjectivity in language", originally published in 1958, Benveniste claimed:

It is in and through language that man constitutes himself as a subject, because language alone establishes the concept of "ego" in reality. In its reality which is that of the being.

(Benveniste 1971: 224)

This capacity of the speaker to posit himself as a subject Benveniste recognised as "subjectivity", a feeling not only of "being himself", but a consciousness of one's being "the psychic unity that transcends the totality of the actual experiences it assembles". In other words, "subjectivity" secures "the permanence of consciousness". Subjectivity makes dialogue possible because through reciprocal construction of person through the use of $I$, it also allows for a contrast between interlocutors and, in any case, the very construction of person is possible thanks to there being other entities and the very possibility of contrast.

Focus on the construction of person and the use of pronouns led Benveniste to reflection on particular verbs. For example, while discussing possible modulation of meaning which accompanies a change of the grammatical subject and person in an utterance, he notes that the use of the first person may in the case of selected verbs induce significant differences. Benveniste starts with the statement:

In a general way, when I use the present of a verb with three persons [...], the difference in person does not lead to any change of meaning in the conjugated verb form. I eat, you eat, and he eats have in common and as a constant that the verb form presents a description of an action, attributed respectively and in an identical fashion to "I", "you", and "he". [...]

Now a number of verbs do not have this permanence of meaning in the changing of persons, such as those verbs with which we denote dispositions or mental operations. [...] In saying I feel (that the weather is going to change), I describe an impression which I feel. But what happens if, instead of I feel I say I believe (that the weather is going to change)? The formal symmetry between I feel and I believe is complete. Is it so for the meaning? Can I consider I believe to be a description of myself of the same sort as I feel? Am I describing myself believing when I say I believe (that...)? Surely not. The operation of thought is not at all the object of the utterance; I believe (that...) is equivalent to a mitigated assertion. By saying I believe (that...), I convert into a subjective utterance the fact asserted 
impersonally, namely, the weather is going to change, which is the true proposition.

(Benveniste 1971: 228, emphasis added)

The shared (with regard to Austin) reflection $^{23}$ on the actional nature of language, as illustrated in the fragment above is made even more explicit in Benveniste's further discussion, when he comments on "subjectivity" and verbs of speaking.

[Verbs of speaking] are verbs that by their meaning denote an individual act of social import: swear, promise, guarantee, certify, with locutional variants like pledge to..., commit (oneself) to .... In the social conditions in which a language is exercised, the acts denoted by these verbs are regarded as binding. Now here the difference between the "subjective" utterance and the "nonsubjective" is fully apparent as soon as we notice the nature of the opposition between the "persons" of the verb. We must bear in mind that the "third person" is the form of the verbal (or pronominal) paradigm that does not refer to a person because it refers to an object located outside direct address. But it exists and is characterized only by its opposition to the person $I$ of the speaker who, in uttering it, situates it as "non-person". Here is its status. The form he ... takes its value from the fact that it is necessarily part of a discourse uttered by "I".

Now I swear is a form of peculiar value in that it places the reality of the oath upon the one who says $I$. This utterance is a performance [un accomplissement]; " "to swear'" consists exactly of the utterance I swear, by which Ego is bound. The utterance $I$ swear is the very act which pledges me, not the description of the act that I am performing. In saying I promise, I guarantee, I am actually making a promise or a guarantee. The consequences (social, judicial, etc.) of my swearing, of my promise, flow from the instance of discourse containing I swear, I promise. The utterance is identified with the act itself. But this condition is not given in the meaning of the verb, it is the "subjectivity" of discourse which makes it possible. The difference

\footnotetext{
${ }^{23}$ Cf. a fragment from Austin's fifth lecture: "The 'I' who is doing the action does thus come essentially into the picture. An advantage of the original first person singular present indicative active form - or likewise of the second and third and impersonal passive forms with signature appended - is that this implicit feature of the speech-situation is made explicit. Moreover, the verbs which seem, on grounds of vocabulary, to be specially performative verbs serve the special purpose of making explicit (which is not the same as stating or describing) what precise action it is that is being performed by the issuing of the utterance: other words which seem to have a special performative function (and indeed have it), such as 'guilty', 'off-side', \&c., do so because, in so far as and when they are linked in 'origin' with these special explicit performative verbs like 'promise', 'pronounce', ‘find', \&c.” (Austin 1962/1975: 61)
} 
will be seen when I swear is replaced with he swears. While I swear is a pledge, he swears is simply a description [...].

(Benveniste 1971: 229; emphasis in bold added)

The fragment above shows that already back in 1958, when the article was first published in Journale de psychologie, Benveniste had a clear model of performative utterances, a model directly corresponding to the one independently put forward in Austin's lectures and the initial Austinian distinction between performatives and constatives. The point Benveniste is making here is parallel to that of Austin, although derived from a different orientation, i.e. a more thorough analysis of the grammatical form of linguistic expressions. Indeed, Benveniste's way of approaching the concept of performativity may be found more "linguistic" than Austin's eclectic philosophy of language. Benveniste's analyses are meticulous, systematic, and rich in descriptions of linguistic data.

It is worth noting that in many ways Benveniste is a largely uncredited precursor of linguistic pragmatics ${ }^{24}$; apart from the "speech act" concept of enunciation, his work on pronouns and "subjectification", 25 , the problem of how language users manifest their presence in discourse, is worth attention and has not lost its relevance over time. Incidentally, Benveniste's concept of "subjectivity" also pre-echoes the idea of Gricean-type intentionality.

Benveniste, following his mentor and teacher Meillet, is also important for speech act theory through his interest in how langue is instantiated as parole. His general approach to language puts emphasis on "enunciation", i.e. actuality of linguistic performance. Whether due to Meillet's sociological influence, or other factors, Benveniste evidently practiced speech act theory and analysis of linguistic performativity.

\subsection{Slavic languages and research in speech actions}

Erwin Koschmieder, a Polish linguist ${ }^{26}$ and author of a 240-page volume on Polish verbs and the concept of aspect, Nauka o aspektach czasownika polskiego $w$ zarysie, published in $1934^{27}$, is one of the predecessors of speech act theory in

\footnotetext{
${ }^{24}$ An exception is Nerlich and Clarke 1994, 1996; there are also brief notes in encyclopaedic and general publications (e.g. Chapman \& Routledge 2005).

${ }^{25}$ There is a coincidental convergence of the term 'subjectification' as it is used by Benvieniste and in today's cognitive linguistics; it should be noted that the term is used in different ways in both approaches.

${ }^{26}$ Koschmieder, who left Poland after World War II and extensively published in German is sometimes, even in Poland, considered a foreign linguist (cf. Heinz 1978: 335).

${ }^{27}$ Nerlich and Clarke (1996; cf. also Keck \& Stubbs 1984) comment on Koschmieder's work, however, they do not refer to his book published in Polish in 1935 and concentrate on later work,
} 
the Slavic world. Laying down his account of the interrelations between aspect, tense and time in Polish verbs, Koschmieder defined a category of "coincidence" 28 , associated with what he called "improper imperfectiveness in the coincidence mood" (Pol. "niewłaściwa niedokonaność w trybie koincydencyjnym") (Koschmieder 1934: 108).

Koschmieder's comments are significantly convergent with later explicit speech act theorising. He accepts the distinction between descriptive and actional use of the present tense, pointing to the fact that selected uses of the present tense cannot be accepted as replies to the question "Co tam robisz?" (Eng. "What are you doing?") exactly because they are actional, and not descriptive, in nature. Koschmieder's illustrations include a ticket controller requesting tickets for inspection,

(2) Proszę bilety do kontroli. ask ( $1^{\text {st }}$ sing, present tense, imperf.) tickets for inspection "Tickets for inspections, please."

or

(3) Poproszę bilety do kontroli.

ask ( $1^{\text {st }}$ sing, future tense, imperf.) tickets for inspection

"Tickets for inspections, please."

and a witness in a court of justice declaring

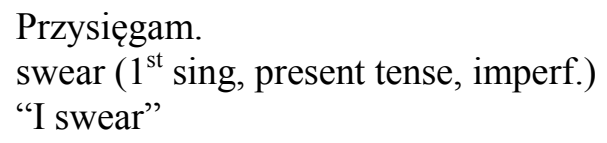

In such cases, Koschmieder asserts, the use of the present tense imperfective verbs (Pol. prosze, poprosze, przysiegam) is an instance of an action and not just a description. In Koschmieder's words:

Takie proszę, poproszę, przysięgam i t. p. nie oznacza, że jestem zajęty prośbą, ale jest właśnie tą prośbą — nie mówi o tym fakcie, ale samo przez się jest tym faktem, podczas gdy: „piszę list do brata” — mówi tylko o danym fakcie, nie będąc nim.

This kind of I request, I ask, I swear, etc. does not mean that I am engaged in asking, but it is the very act of asking-it is not a

published mainly in German. In this chapter, Koschmieder's book (1934) published in Polish is taken as the main point of reference.

${ }^{28}$ The German equivalent of the term used in later works published in German was Koinzidenzfall. 
description of the act, but it is the act in itself, while: "I am writing a letter to my brother" will only report on the act, but it is not the act itself.

Koschmieder explains that uses of imperfective forms are related to "past-tofuture directional relativity" (Pol. "względność kierunkowa z przeszłości w przyszłość") with the speaker (rather than e.g. time) being the central static point, a kind of deictic centre. He further asserts that the "coincidence" type is free from this directional relativity because it is momentary and is typically restricted for the first person form use as a person's utterance, whenever actional in nature, cannot in normal circumstances be taken as an act performed by someone else. In other words, in such contexts, an action can only be performed by the speaker as it is identical (and "coincides") with the utterance. In discussing the difference, Koschmieder illustrates the point by saying that the third person utterance "Mr. $\mathrm{X}$ asks that the certificate be issued" cannot be the act itself, but only a report on the act, while the first-person counterpart of the utterance may be the act in itself. The first person coincidental use is further explicitly linked with verba dicendi "in the broad sense", i.e. verbs which can be used with reference to speech action.

In claiming that the first person utterances may have the unique actional character Koschmieder seems to be close to Benveniste's ideas with regard to the concept of "enunciation".

With regard to research based on other Slavic languages, e.g. work on Slovenian by Šcrabec and Mencej, Koschmieder (1934: 111) points to the fact that in Polish, linguistic action can be performed with the use of the (apparently) future form, e.g. future perfective forms of verbs and parallel present imperfective forms ${ }^{29}$. He also points to the fact that less direct forms (e.g. future

\footnotetext{
${ }^{29}$ It is noteworthy that Polish verbs can never be simultaneously morphologically marked as present and perfective. Naturally, the problem of aspect and Polish verbs is both complex and complicated and may be more successfully approached in terms of Aktionsart, as a substantial part of information about verbal meaning in terms of e.g. duration, continuity or iterativity, termination of the relative action is lexicalised, rather than grammaticalised. Nearly all Polish verbs have two forms, imperfective and perfective, but the perfective ones can often be used as a basis for derivation of the imperfective. There is also a complex system of prefixes which are used to form more complex verbs and which often carry information related to aspect and time relevant for particular verbs.

For instance, the verb obiecać (Eng. promise or to have promised) can be described as perfective and has its imperfective counterpart of the form obiecywać (Eng. promise). Only the latter verb can be used in explicit performatives. However, the future form of the former, obiecam, can be used performatively in indirect acts, e.g. "Zrobię to, tyle ci obiecam" (Eng. "I will do that, I can promise you (that much)"). or "Zrobię to, tyle ci mogę obiecać" (Eng. "I will do that. I may promise you that much") in certain circumstances. Additionally, the verb may have derivative forms which can be both perfective and non-perfective, e.g. (naobiecywać, Eng. promise or "overpromise"). Selected Polish verbs have very rich semantic families of verbs derived just by prefixing, where prefixes add specific information about the event invited by the verb, or modify
} 
perfective forms) may achieve modal interpretation, they often specialise to convey conative uses, but the uses of many of them can also be related to politeness. Thus, Koschmieder's approach is quite modern.

A related, but independent, emphasis on expressions in the first person singular have been referred to by Žagar and Grgič (2011) with regard to Slovenian philosophy of language in the nineteenth century (which had also been commented on by Koschmieder, e.g. 1934: 110-112). Žagar reports on reflections focused on the Slovenian tense and aspect and its correspondence to a (potentially) performative value. Among grammarians who commented on this issue he enumerates Stanislav Škrabec, Luka Pintar, and Viktor Bezek. These theorists evidently struggled with the correspondence between form and force, trying to find a logical and a linguistic "grammatical" account of the phenomenon. They commented on what today is seen as a paradox of the present, which similarly to the philosophical understanding of death, is gone the moment it appears. It is reported that in 1892 Škrabec claimed that discourse, even of the shortest type, is always of a "lasting" nature. On another occasion he also commented on the use of a perfective Slovenian form in performatives as a foreign barbarism. However naïve such an a trust in the possibility of finding a grammatically explicit performative formfor universal use across contexts may seem (Škrabec also referred to "Praesens effectivum" (cf. Verschueren 1999: 207)), this type of research clearly shows that performativity was a real issue in the nineteenth-century Slovenia. In particular, Pintar's philosophical divagations seem to correspond to both Austin's and Benveniste's later reflections, cf.:

Can something that is excluded from the present still be called unlimited? Exclusion from the present is a sufficient limitation. However, if something is in fact unlimited, which is said to be the case with the perfective or aorist present, then it should be possible to use it not only in the past and future, but also in the present.

(Pintar 1910: 500, quoted after Žagar \& Grgič 2011: 51)

the original meaning, e.g. the imperfective pisać (Eng. to write) has a counterpart napisać (Eng. to write, to have written), but within its family there are lexemes such as dopisać (Eng. to add in writing, write more), przepisać (Eng. to copy), odpisać (to copy, to answer in writing), zapisać (to write over, cover in writing), podpisać (to sign, to write below), and many others. Most of these prefixed derivatives are formally perfective, but they may form secondary imperfective forms which preserve their more complex meaning, e.g. przepisać - przepisywać (Eng. to copy, to have copied - to copy, to be copying). In short, it is dangerous to compare the English aspect, whether perfective or continuous with forms of Polish verbs, because lexical information plays a greater role in the Polish verbal system. To conclude, the most prototypical performative uses in the Polish language are formed in the present tense with the verb in imperfective, however, there is no perfective counterpart in the present tense for this form. Thus, although the form used in Polish shows correspondence to English forms, it is significant that the choice in Polish is limited. What is interesting is that, although Polish has a morphologically marked future tense, modal forms can be used parallel to the future forms, which again corresponds to the manner in which modal forms is English are used for indirect speech acts. 
It is evident that the Slovinian forefathers of speech act theoretic research were centered on the correctness of form for particular use and their approach was primarily prescriptive, in which they stay apart from, for instance, Koschmieder. Although they did not use speech act theoretic metalanguage, they evidently searched for linguistic purity and a clear match between the predefined form, an explicit vehicle for action, and the relevant performative function. For instance, they expressed dissatisfaction with reported apparently illogical uses of the perfective to carry present actions. In this respect, their research agenda may seem naïve, but, nonetheless, it testifies to the gravity of the "performative" experience, along with the distinction between (mere) representation and action.

In conclusion, although communication between Slovinian research of the nineteenth century and Western philosophy of language was very limited, convergent, often avant la lettre, ideas had appeared in distant places, distant both culturally and geographically. Even later research by Erwin Koschmieder, at first centered on the Polish language, had not been influential in terms of the "coincidence" mood and there seems to be no evidence that it was positively carried on by further theorists.

\subsection{Habermas's sociocultural model of communication}

Jürgen Habermas's (1984 [1981], 1987 [1985], 1998) socio-cultural conception of communication as a rational activity is another model which relates to the concept of linguistic action and speech acts. This connection, although loose in many aspects, is marked by terminological convergence, which evidently arose thanks to Bühler's model. Among the types of communicative phenomena, Habermas discusses a "constative speech act", i.e. assertion, typically associated with conversation, as well as expressive (for dramaturgical actions), and regulative speech acts (for non-conformative actions), which all involve validity claims. Habermas's expressive act conveys the speaker's communicative intention, conveys the speaker's "subjectivity" and attitudes. Two additional groups comprise "communicatives", whose function is to "organize" speech, and "operatives", pointing to the application of generative rules (e.g. inferring, classifying). He also mentions "the illocutionary binding (or bonding) effects of speech acts" (Habermas 1984: 327) and the wide spectrum of illocutionary forces.

Habermas differs from Austin in how he uses the concept of social life in his theory of linguistic action and, especially, by his reference to actual sociohistorical contexts. The speech acts which he is interested in are usually of a more strategic, often political, character; they refer to situations in which people pursue their "illocutionary" aims. As such, they are best seen against a broad social environment and individual agendas which are often hidden rather than explicated to the general public. Such acts are rarely in the form of sentences 
which can be analysed a priori, with regard to their general potential. More often, they are sets of instances of (linguistic) behaviour, situated in the social world and coordinated with a view to achieving a certain goal. This does not mean that language users are unable to recognise the match between form and function. Habermas's model presupposes pragmatic universals thanks to which speakers and hearers can construe the ideal speech situation. Although rooted in critical theory, Habermas may be seen as a thinker who looks for and arranges meshing for bridging diverse traditions of thoughts with Austin's (and Searle's) speech act theory. For instance, he integrates ideas proposed by philosophers such as Derrida, Rawls, Gadamer, and even Brandom. He also points to elements in Austin's agenda which may save the rational view of language.

In this way, Habermas's thoughts can be seen as both parallel to Austin's and motivated, and influenced, by the Austinian model.

\subsection{Summary and preliminary conclusions}

The aim of the present chapter was to provide a selective survey of an array of reflections on the actional nature of language independent of Austin and his immediate followers. It gathered ideas which emerged prior to Austin and those of his contemporaries. Historically, the survey shows that from the earliest times there have been records of utterances which were understood in terms of creation of reality, which ranged from institutional, religious, and ritual uses to supposedly-operative utterances of everyday life.

Many tenets of speech act theory had been commented on avant la lettre. For instance, the constative/performative distinction, present in Austin's early version of speech act theory, can also be found in Kant, Koschmieder's "coincidence" mood, and in Benveniste; it is pre-echoed in the phenomenologist way of thinking and appears to be implicit in Aristotle in his critique (i.e. a negative recognition) of non-assertion. The social dimension of performatives, so firmly emphasised by Austin, is quite explicitly accounted for in Adolf Reinach's analysis of legal language. In turn, Bühler's model can be directly related to Austin's ambition to account for "the total speech act in the total speech situation" (Austin 1962/1975: 147).

The views mentioned in this chapter illustrate that over the years many philosophers and linguists not only paid attention to the fact that language can be, and often is, used with a function other than that of a description of the world, but also treated such uses with attention.

Thus, the views that language can be a type of action, beyond the trivial understanding of the notion, has been a recurrent topic in Western and general linguistics. For instance, both for deSaussure and Wittgenstein, language, a rulegoverned form of behaviour, is primarily a form of communication accounted for in the functional perspective. 
In a methodological perspective, Smith (e.g. 1990) points to the fact that the distinction between the concept of judgment and that of proposition is itself a prerequisite for speech act theory. Allowing some simplification, as evidenced in documented research into the nature of language, this shift could not have occurred in Western linguistics until theoretical advancements in logic and psychology appeared at in the late nineteenth and early twentieth centuries, i.e. not until there appeared contributions of thinkers such as Frege, Bolzano, Brentano, Marty, or Husserl, whose work allowed for a systematic differentiation between form, content, and function.

Among the ten preconditions for speech act theory put forward by Smith (1984), there are: existence of a "proper" linguistics theory, which embraces psychological and social factors; the recognition of the fact that language is first of all a tool for communication; the recognition of the actional character of language, together with the concomitant cognitive and mental elements in linguistic acts; relevant presuppositions of speech acts (e.g. a belief for an assertion, and a desire for a wish); understanding of speech acts in terms of intimation or expression; as well as "appeal".

A theoretical account of speech actions also requires a distinction between form and content, as well as the distinction between an action and its consequences. All the above-mentioned conditions were either explicitly or implicitly addressed by researchers in the pre-speech act theoretic era, and together formed the basis for speech act theory in its fuller formulation.

The model of speech act theory sketched by Austin embraces previous related research through its generality and an envisaged project of studying "the total speech act" in its total context. In Austin's words:

Once we realize that what we have to study is not the sentence but the issuing of an utterance in a speech situation, there can hardly be any longer a possibility of not seeing that stating is performing an act.

(Austin 1962/1975: 138)

Austin's enigmatic and notoriously underdetermined way of narrating his ideas also makes it possible to subscribe to various orientations and allows for a selective use and subjective saturation of his ideas. The next chapter aims to shed light on which notions may be regarded as Austin's original concepts with more certainty. It will also present selected modifications, which have been suggested in relation to Austin's model, both overtly declared and implicit ones. 



\section{CHAPTER TWO}

\section{J.L. Austin's Main Tenets Of SPEech ACT THEORY: SELECTED DEVELOPMENTS AND CRITICISM}

Once Austin gets started [...], he regularly imitates God by first giving and then taking away —Stanley Fish (1989: 62)

This chapter provides a brief overview of John Langshaw Austin's original account of speech act theory and summarises main modifications introduced by John Searle. It aims to elucidate areas which are perceived as contentious or misleading. It is also an aim of this chapter to provide information which is often referred to in the further sections of the book when distortions or modifications of Austin's model of speech act theory are discussed.

Referring to the performative, Searle (2002a: 535) says that " $[\mathrm{t}]$ he notion of a performative is one that philosophers and linguists are so comfortable with that one gets the impression that somebody must have a satisfactory theory", which is not the case. Indeed, similar remarks can be made about many other speech act theoretic notions. Although there are many references to, e.g. the illocutionary act, locution and perlocution, as well as "conventional acts" or felicity conditions, or "speech act classifications", the concepts referred to are often used in presupposed ways without clear definition, while Austin's view are often "vitiated by misunderstanding" (Berlin 1973: v; cf. also Sbisà 2007). Relevant discussions abound in metalinguistic and terminological confusions. Selected sections of this chapter expose the most relevant problems related to concepts and terminology which derives from Austin's legacy. 


\subsection{Sources of John Austin's theory}

The received picture of John L. Austin includes clichéd epithets such as the ones cited by Gustaffson (2011: 1ff.): "the doyen of Ordinary Language Philosophy", "a master of observing minutiae of linguistic use", and "the founder of speech act theory". However, although it is John Austin that is credited with the introduction of the theory of speech acts and despite the ubiquity of references to his work, his original thought has often been distorted in subsequent research, and (re)interpreted in various, sometimes mutually incompatible, ways. The account of Austin's theory presented here has been based on his publications and comments of his critics and disciples.

Austin was known as a charismatic speaker and not a prolific writer, which poses problems for a definition of how details of his theorising should be understood. He only published seven articles during his lifetime ${ }^{30}$ before his death ended his tenure as White's Professor of Moral Philosophy in 1960. One more piece of his work which can most directly be used by today's researchers is the text of his B.B.C. lecture entitled "Performative Utterances". Partly due to the tentative and inherently vague character of his writing (or lectures turned into texts by editors) most of the speech act-theoretic notions remain contentious. The version of speech act theory that we know had been developed through a series of lectures which Austin gave at Oxford between 1952 and 1954, and the William James Lectures delivered at Harvard in 1955, which were posthumously published in 1962 as the book How to Do Things with Words (Austin 1962), and revised by J.O. Urmson together with Marina Sbisà for the 1975 revised edition. The book serves as the main reference, but it is noteworthy that it was based on Austin's lecture notes, which had never been prepared for publication by the author. Austin's other texts were also gathered, edited and published after his death (cf. Philosophical Papers 1961/1970, Sense \& Sensibilia 1964). Austin himself remarked that his ideas concerning linguistic action had been formed in 1939 (Austin 1962/1975: vi) and further elaborated in his Oxford lectures entitled "Words and Deeds" between 1952 and 1954 before receiving a (more) final shape in Harvard, in 1955, in the series of lectures entitled "How to Do Things with Words", whose title, as reported by Pitcher (1973: 22), was chosen for its "pragmatic ring", to honour the man after whom the lectures were named-William James.

Austin's legacy is most readily seen in the concepts associated with speech acts and the metalanguage employed to talk about them. Although the theory itself has evidently got independence and, in many ways, has been alienated ${ }^{31}$

\footnotetext{
${ }^{30}$ Berlin (1973: 16) comments on "true intellectual happiness" and lack of any pressure to publish in the Oxford-Cambridge-Vienna "magic circle" at the time.

${ }^{31}$ This alienation can be illustrated with the fact that even speech act theoretic researchers sometimes conduct their work without any direct reference to Austin and his word, e.g. Drabik (2004) in her work entirely devoted to the speech act of complimenting does not make any
} 
from Austin's original thought, most of the terminology used today in speech act-theoretic research finds origin in his reflection on the nature of language in action with current discussions relative to ideas put forward in his work. For example, in research quite distant from speech act theory, terminology such as "illocutionary" or "felicitous" are used without hesitation.

The motivation behind this short introduction is mirrored in the quote from Nerlich and Clarke, expressed with regard to the whole of pragmatics,

In the case of pragmatics, some of the past got lost or forgotten in the excitement of the present. As a result something of the discipline itself was lost, in the same way that individuals can lose their identity by losing their memory.

(Nerlich \& Clarke 1994: 440).

The words cited are especially relevant with regard to Austin, who, according to Cavell (2002b: 112) was a philosopher "devoted to unmasking". In Cavell's opinion, Austin "has done more than any philosopher in the Anglo-American tradition (excepting Wittgenstein) to make clear that there is a coherent tradition to be dealt with" (Cavell 2002b: 114) ${ }^{32}$.

The next sections present a short record of a selection of the supposed rudiments of Austin's original work, which can often be misshaped or distorted, with the aim of setting a basis for further discussion of these issues.

\subsection{The revolutionary turn}

At the time when Austin was delivering his "speech act lectures" at Oxford, and later Harvard, his theory of speech acts was primarily seen as a reaction against the verificationist movement and logical positivism, within which it was assumed that all language, at least all language worth theoretical attention, could and should be analysed with regard to the truth and falsity of its sentences. Against this mainstream, Austin maintained that there are linguistic utterances which may be "factually defective", i.e. non-descriptive and neither true, not

reference to Austin. On the other hand, others picture him as an active developer of the theory even at times when he had already been gone, i.e. after 1960, cf. Williams 2005, Hutton 2009, who unmetaphorically comment on Austin's changing the theory with 1962 or 1975 editions of How to Do Things with Words, e.g. "[a]s is well known among linguists and philosophers of law, in 1962 Austin introduced his classical speech act theory. His ideas were later developed by Searle (1969), and Austin revised his original work in 1975" (Williams 2005: 53) or "when J. L. Austin published his How to Do Things with Words (1962), it was hailed as an intellectual breakthrough. Austin pointed out that language involved acts ('speech acts') which in part constitute - rather than simply reflect - social reality" (Hutton 2009: 57). It is evident that speech act theory and Austin as its father are taken for granted with often limited interest in the original work.

${ }^{32}$ These words are also cited in Glendinning (2011: 32), where Austin's work as a philosopher is discussed in more detail. 
false, but simply successful or not successful. He introduced new metalinguistic ways of referring to the concept of successfulness, using the Latinate happinessoriented words: felicitous and infelicitous. Expressions judged as felicitous (or not) rather than true or false include non-descriptive uses of language, e.g. commands, requests, questions, promises. Instead of being truth verifiable, they are instrumental in making things happen, which renders language a tool for changing the world.

Austin postulated that:

truth and falsity are (except by an artificial abstraction which is always possible and legitimate for certain purposes) not names for relations, qualities, or what not, but for a dimension of assessment-how the words stand in respect of satisfactoriness to the facts, events, situations, \&c., to which they refer.

[...] By the same token, the familiar contrast of 'normative or evaluative' as opposed to the factual is in need, like so many dichotomies, of elimination. (Austin 1962/1975: 148)

In other words, Austin rejected the verificationist approach to concentrate on "the total speech act in the total speech situation" (Austin 1962/1975: 147), but his rejection was targeted at the belief that the analysis focused on truth and falsity is the only dimension worth considering, and that it is a thorough dimension in that, for instance, the felicity-oriented approach would have to stand in opposition to it. In fact, contrary to common belief, Austin held that the truth/falsity dimension is just one aspect of utterances and, in many cases, not the most prominent one. While discussing performative utterances, Austin points out that there is "an obvious slide towards truth or falsity in the case of, for example, verdictives, such as estimating, finding, and pronouncing" (Austin 1962/1975: 140). Thus, one may estimate, for example, rightly or wrongly that it is half past two, but finding (e.g. "that he is guilty") or pronouncing (e.g. "that the batsman is out) will be assessed as correct or incorrect.

Austin's method of analysis which he applied to reach the revolutionary turn was meticulous and linguistic in nature. He believed that any reliable and scientifically sound philosophical analysis should start with a careful investigation of how words are used, which, eventually, should reveal the true nature of communication and social life. He did not trust theories illustrated with selective, language use samples limited in number and saw the future of philosophy in catalogue-like descriptions of linguistic functions (cf. Chapman 2008: 88; Austin 1962/1975: lecture xii et passim), with due attention paid to lexical "trailing clouds of etymology" (Austin 1970: 201). Due to this emphasis, Austin's approach is sometimes described as a Leibnizian type of linguistic analysis with its faith in the fruitfulness of analysing natural language and vocabulary in its richness. As has already been noted, Austin recognised his field 
of study as linguistic phenomenology (Austin 1970: 182; section 1.5.2 on Husserl).

In Austin's own words,

In view of the prevalence of the slogan 'ordinary language', and of such names as 'linguistic' or 'analytic' philosophy or 'the analysis of language', one thing needs specially emphasizing to counter misunderstandings. When we examine what we should say when, what word; we should use in what situations, we are looking again not merely at words (or 'meanings', whatever they may be) but also at the realities we use the words to talk about: we are using a sharpened awareness of words to sharpen our perception of, though not as the final arbiter of, the phenomena. For this reason I think it might be better to use, for this way of doing philosophy, some less misleading name than those given above - for instance, 'linguistic phenomenology', only that is rather a mouthful.

(Austin 1970: 182; “A plea for excuses") ${ }^{33}$

It is also worth noting that Austin's focus on natural language was not "blind". In "The plea for excuses", in which he advocates the relevance of natural language for philosophical investigations, he says:

Certainly ordinary language has no claim to be the last word, if there is such a thing. It embodies, indeed, something better than the metaphysics of the Stone Age, namely, as was said, the inherited experience and acumen of many generations of men. But then, that acumen has been concentrated primarily upon the practical business of life. [...] Certainly [...] ordinary language is not the last word: in principle it can everywhere be supplemented and improved upon and superseded. Only remember, it is the first word. (Austin 1970: 185)

Austin's general philosophical orientation was not unique at the time. He was not the sole progenitor of ordinary language philosophy, to mention just G. E. Moore, Gilbert Ryle, and (later) Wittgenstein, who all wrote influentially about ordinary language (cf. Chapman 2008: 68ff. for an overview). Together with Gilbert Ryle $^{34}$, Austin belonged to the circle of Oxford philosophers whose ideas grew to be in conflict with views on language shared by logical positivists, philosophers of the Vienna Circle and Oxford figures such as A. J. Ayer, who firmly maintained that only truth-verifiable sentences are worth scientific attention. In opposition to logical positivism, Gilbert Ryle advocated relevance

\footnotetext{
${ }^{33}$ In this context cf. Husserl's concept of "the things themselves" (2001)

${ }^{34}$ For a discussion of differences between Ryle's and Austin's philosophy see e.g. Cavell 2002c.
} 
of natural language as data for philosophical analysis and the publishing of his book, The Concept of Mind, in 1949, may be perceived as a formal beginning of the period of "ordinary language philosophy" in Oxford.

Introducing the theory of speech acts Austin announced a revolution in philosophy which was also to be a revolution in how to approach language data. This revolution was at the time, i.e. in the middle of the twentieth century, mainly a reaction to the philosophy of logical positivism. Austin decided to fight what he dubbed the "descriptive fallacy", i.e. the view, an illusion, that language is primarily used to "describe ${ }^{35}$ reality and as such truth-conditional ${ }^{36}$.

Moreover, Austin was in general rather cautious with regard to the notion of truth and and it seems quite motivated that eventually he housed all descriptive, or constative, utterances within the class of speech acts. In the essay entitled "Truth", he points to the fact that "true" and "false" are just two terms among many adjectives "concerned $[\ldots]$ with the relations between the words $[\ldots]$ and the world" (Austin 1970 [1961]: 129). He further explains,

We say, for example, that a certain statement is exaggerated or vague or bald, a description somewhat rough or misleading or not very good, an account rather general or too concise. In cases like these it is pointless to insist on deciding in simple terms whether the statement is 'true or false'. Is it true or false that Belfast is north of London? That the galaxy is the shape of a fried egg? That Beethoven was a drunkard? That Wellington won the battle of Waterloo? There are various degrees and dimensions of success in making statements: the statements fit the facts always more or less loosely, in different ways on different occasions for different intents and purposes.

(Austin 1970 [1961: 129-130])

The fragment shows Austin's appreciation of minute differences in the semantics of words, sentences and utterances, which is indicative of his philosophical position. Related to that seems his scepticism as to the possibility of constructing a thorough theory of linguistic action. His agenda appeared to be more modest. He noticed a lacuna of ignorance with regard to non-descriptive, non-truth-liable linguistic expressions, which (universally) constitute a majority

\footnotetext{
${ }^{35}$ Although it is worth noting that Austin was not quite satisfied with the adjective "descriptive" as used here, recognising it as "special" (Austin 1962/1975: 3) and recognising that not all truthconditional statements are descriptions, which was eventually the motivation for adopting the term "Constative".

${ }^{36}$ Note that, as indicated by Nerlich and Clarke (1996), similar reflection can be found earlier in e.g. Bréal. While discussing subjective linguistic forms, Bréal refers to a similar "descriptive" or "logicistic" fallacy in linguistic analysis: "Speech was not made for purposes of description, of narration, of disinterested considerations. To express a desire, to intimate an order, to denote a taking possession of persons or of things - these were the first uses of Language". (1924 [1897]: 243; 238 quoted after Nerlich \& Clarke 1996: 261)
} 
of cases of language use, and decided to look at them in more detail. Significantly, Austin's first lecture opens with the words:

What I shall have to say here is neither difficult no contentious; the only merit I should like to claim for it is that of being true, at least in parts.

(Austin 1962/1975: 1)

He continued:

The phenomenon to be discussed is very widespread and obvious, and it cannot fail to have been noticed, at least here and there, by others. Yet I have not found attention paid to it especially.

(Austin 1962/1975: 1)

In today's perspective, even if Austin's revolution against verificationist linguistics is not as performative as he might have expected it to be, it stirred the linguistics debates at the time when it emerged and has continued to motivate insightful research into the nature of linguistic meaning and linguistic action ever since. It is significant that Austin did not fight the truth-conditional analysis altogether, but was the first to explicitly reject verificationism as an inadequate and misleading basis for linguistic research.

\subsection{A note on terminological confusion}

One aspect of speech act theory which particularly deserves attention is the terminological confusion which originated with Austin and has been accumulating along with the emergence of new models and approaches based on Austin's thoughts.

The two elements which call for special attention are the understanding of the nature of the speech act, its relation to the phenomenon of "performativity", and the understanding of the concept of convention, especially while taken in opposition to intention.

For instance, even in serious research and in literature on the subject, there are references to "performative speech acts" (e.g. Charnock 2009) 37 , or even "virtual performative speech acts" (e.g. Ross 2003), with attribution to Austin's ideas. The references seem to suggest that there may be at least two types, viz. performative and non-performative speech acts. This confusion can even be seen in selected titles, such as "Performative speech acts, ethnography and fiction"

\footnotetext{
${ }^{37}$ In a lighter approach, Porter (1993) also discusses "counter-performative speech acts" and, especially, "perlocutionarily counter-performative speech acts", which he directly relates to selfdefeating speech acts as discussed by Vanderveken and Searle (Vanderveken 1980, Searle \& Vanderveken 1985).
} 
(English 2007) or "Performative speech acts in linguistic theory [...]" (de Beaugrande 1998).

Naturally, "performative speech acts" are most commonly associated with ritual and social-institutional uses of predefined linguistic formulae, but it is significant that the label is often used with reference to speech acts and not just speech which accompanies "performance" as it is understood in culture and theatre studies ${ }^{39}$. Suggestions that there are "performative speech acts" reveal more than the fact that common language lacks precision, they also show how deeply the constative/performative distinction is contained in intuitions of language. It seems implicit in such labelling that although in a very broad sense all language use is performative in nature, it can be "more performative" on some occasions or produce phenomena such as "illocutionary silencing" and "perlocutionary free speech" (cf. Bird 2002). Illocutionary force itself is not rarely recognised as a common feature of communication and not just language; it is supposed to be of a scalar character and, as a result, actions such as hunger strikes, self-immolation, or cutting off one's finger, can be discussed as "extreme communicative acts" (cf. Wee 2004) with "boosted" illocutionary force.

In a different context, the category of "whimperative" (related to the concept of the "performative") was suggested to refer to the common conversational convention of casting a directive in question or declarative. The name itself, as Sadock (1970: 237, fn.1) explained, was created when "Grimm's law was allowed to apply to the first morpheme for decorum's sake", producing a form with the wh-prefix typical of indirect requests (e.g. "Why don't you read that?"). Another terminological proposal based on speech act-theoretic metalanguage and directly related to the performative hypothesis is that of "performadox" (cf. Sadock 1985, Böer \& Lycan 1980).

It is also worth noting that in the lectures which were turned into How to Do Things with Words, Austin himself referred to performatives in various ways, viz. as just "performatives" or "performative utterances" and even "performative sentences" as if anticipating the notion of illocutionary potential that sentences may have.

\footnotetext{
${ }^{38}$ Incidentally, in this paper, whose full title reads "Performative speech acts in linguistic theory: The rationality of Noam Chomsky", de Beaugrande (1988) accuses Chomsky of exercising rhetoric which produces "performative dualisms" and "performative idealisations", replacing "real language" with a private allegedly "ideal language", and taking a route "from illocution and perlocution to persecution" (1988: 793ff.).

${ }^{39}$ In a more distant perspective, in philosophy, "performative" is also often used to mean "expressing beliefs by means other that arguments" (e.g. Reiner 2009: 278, fn. 41). Reiner (2009), for instance, while discussing reconstructing "webs of beliefs" in historical texts on the example of Plato's dialogues, suggests that all texts include an element of performance in the sense that various "performative devices", such as sarcasm or distancing, are utilized in them and can serve as a basis for (re)building past opinions. In this approach "performative" may sometimes mean "indirect" as in the cases of authors who "conceal" literal meaning for fear of persecution.
} 


\subsection{Performative utterances and speech acts}

Having accepted that language is primarily used in a successful or nonsuccessful way, rather than as "true" or "false", at the beginning of developing speech act theory and in an attempt to differentiate instances of language when language is primarily used "to do something" from those related to "just saying something" (cf. Austin 1962/1975: 7), Austin suggested two broad categories of utterances: performatives ${ }^{40}$ and constatives. By doing this he partly followed Aristotle's distinction into apophantic and non-apophantic logos. In short, performatives were understood as those which are neither true, nor false, but by virtue of their actional nature could be felicitous or not, i.e. successful or not successful, productive or not. Constatives, on the other hand, at least in the first theoretical approach, are truth-verifiable utterances. Although Austin acknowledges a number of truth-evaluable implications connected with any performative utterance (cf. Austin 1962/1975: 45ff), he also emphasises that the nature of such implications for constatives and for performatives is very different. The utterance "I am running" is true by virtue of the person's running at the time, while the utterance "I apologise" is successful thanks to "the happiness of the utterance" itself $\mathrm{fl}^{41}$.

However, Austin later realised that a clear distinction between the two types of utterances cannot be maintained. Even utterances which constate something e.g. "There is a rat under your chair" - are richer in their message which may go beyond description and involve some action, such as a warning, a directive, etc. He also noted that utterances such as "I apologise" can be analysed as felicitous or not, but also as true of what they refer to, i.e. they can be simultaneously felicitous and true as descriptions of the act being performed. Other utterances, which may appear more descriptive, can, in turn, possess a performative value, for instance, as Austin (1962/1975: 141) suggests, "we should distinguish the 'statement' that the bull is about to charge from the warning itself".

Thus, the constative/performative dichotomy is suggested in the first lecture and having been discussed in the course of further lectures is eventually abandoned with Austin's statement: "It is time to make a fresh start on the problem" (Austin 1962/1975: 91).

\footnotetext{
${ }^{40}$ Commenting on his choice of labels, Austin remarked, "Formerly I used 'performatory': but 'performative' is to be preferred as shorter, less ugly, more tractable, and more traditional in formation" (Austin 1962/1975, p.6, fn3). There is also an indication that "many performatives are contractual ('I bet') or declaratory ('I declare war') utterances" (7), yet the scope of the latter terms is more limited.

${ }^{41}$ Austin does mention here the grammatical difference of the continuous aspect (page 47), but also indicates that even in languages without this grammatical distinction there is systematicity with regard to the concept.
} 
At the beginning of lecture XI, "Statements, Performatives, and Illocutionary Force", Austin writes,

[It] seems to point to the conclusion that whenever I 'say' anything (except perhaps a mere exclamation like 'damn' or 'ouch') I shall be performing both locutionary and illocutionary acts, and these two kinds of acts seem to be the very things which we tried to use, under the names of 'doing' and 'saying', as a means of distinguishing

performatives from constatives. If we are in general always doing both things, how can our distinction survive?

(Austin 1962/1975: 132)

Even earlier he also concludes:

$[\mathrm{U}]$ nhappiness $[\ldots]$ seems to characterize both kinds of utterance, not merely the performative; and [...] the requirement of conforming or bearing some relation to the facts, different in different cases, seems to characterize performatives.

(Austin 1962/1975: 91)

Austin's agenda can be seen in its more explicit form as below:

We must consider the total situation in which the utterance is issuedthe total speech act - if we are to see the parallel between statements and performative utterances, and how each can go wrong. So the total speech-act in the total speech situation is emerging from logic piecemeal as important in special cases; and thus we are assimilating the supposed constative utterance to the performative.

(Austin 1962/1975: 52, closing words in Lecture IV)

Eventually (145 ff.) he concludes that

(a) With the constative utterance, we abstract from the illocutionary (let alone the perlocutionary) aspects of the speech act, and we concentrate on the locutionary: moreover, we use an over-simplified notion of correspondence with the fact-over-simplified because essentially it brings in the illocutionary aspect. This is the ideal of what would be right to say in all circumstances, for any purpose, to any audience, \&c. perhaps it is sometimes realized.

(b) With the performative utterance, we attend as much as possible to the illocutionary force of the utterance, and abstract from the dimension of correspondence with facts. (Austin 1962/1975: 145-146) 
Austin further allows that the two "abstractions" may be just two ends of a continuum, or elements related in historical development ${ }^{42}$ and that

[t]he doctrine of the performative/constative distinction stands to the doctrine of locutionary and illocutionary acts in the total speech-act as the special theory to the general theory.

(Austin 1962/1975: 148)

The received view presents the original theory of speech acts as, at least up to a certain degree, self-defeating in that Austin was unable to maintain the constative/performative distinction, an alleged theoretical flaw which has induced a substantial body of criticism over the years ${ }^{43}$. This perspective has important implications for the theory of linguistic action and the view on the nature of language, when it is holistically seen as performative, but it also suggests that Austin's original idea was mistaken.

The "self-defeating" view of the development of Austinian ideas is present in literature related to speech acts, whether in theoretical, research papers and books (e.g. Bach \& Harnish 1979) or handbooks on pragmatics, semantics and general linguistics (e.g. Levinson 1983: 231ff; Saeed 2009: 237; Huang 2007: 95ff; Chapman 2011: 61ff). A similar opinion is also expressed by Austin's contemporary, G. J. Warnock (1989), Austin's friend and colleague at work, who emphasised that Austin was unclear about the central distinction of the performative as opposed to constative utterances, which was eventually his motivation for abandoning the distinction and starting a new analysis. This standard narrative is accepted both by supporters and opponents of the distinction and the theory as such.

\subsubsection{Comments on the relationship between the concept of the performative, constative and the speech act}

\subsection{1.a. Sbisà and the 'proof by contradiction' claim}

In the lectures, Austin does explicitly state that there is "no one absolute criterion" (67) which should enable us to differentiate between the performative and the constative and not even a list of such (possible) criteria. Lately, however, Marina Sbisà (2007), a co-editor of the 1975 revised version of How to Do

\footnotetext{
${ }^{42}$ Although he also struggles with the distinction indicating that, for example, the expression "I hold that..." can be performative when said by a judge and constative when said by a layman (Austin 1962/1975: 88).

${ }^{43}$ Cf. also a fragment of Max Black's 1963 review of How to Do Things with Words cited in Sbisá (2007: 462): "The late John Austin's William James Lectures might well have borne the subtitle 'In Pursuit of a Vanishing Distinction'”
} 
Things with Words, claimed that in fact the whole discussion of the performative-constative distinction offered by Austin should be approached not as a sign of a direct development of his ideas, but as a pre-designed proof by contradiction. In short, Sbisà argues that it was Austin's original agenda while preparing the lectures which were later to become How to Do Things with Words to present constatives as a special case of performatives.

According to Sbisà, the Austinian program reveals itself as a deliberate reductio ad absurdum of the performative/constative dichotomy, which can be schematized in the following way:

Hypothesis $(\boldsymbol{P})$ : "Some utterances are performative"

Thesis $(\boldsymbol{A})$ : "All of our utterances perform actions of the same kind as those performed by performative utterances"

A proof by contradiction:

Suppose that $\boldsymbol{A}$ does not hold (not $\boldsymbol{A}$ ): since some utterances are performative $(\boldsymbol{P})$, it should be possible to distinguish them sharply from constative utterances (if $\boldsymbol{P}$ and $\boldsymbol{n o t} \boldsymbol{A}$, then $\boldsymbol{P} / \boldsymbol{C}$ );

But the performative/constative distinction is flawed, and therefore not $\boldsymbol{A}$ does not hold;

So the supposition that $\boldsymbol{A}$ does not hold is false, and therefore, $\boldsymbol{A}$ holds.

(cf. Sbisà 2007: 463)

The proof quoted above rests upon internal arguments, e.g. that assertions have felicity conditions and, as such, are also performative in nature and that any utterance can be reformulated as an explicit performative ${ }^{44}$.

It seems that Sbisà's view can be backed with more data from How to Do Things with Words. All through the lectures, there are numerous comments on the (universally) actional nature of language, whether with reference to law (e.g. Austin 1962/1975: 19) or philosophy of language and analysis of linguistic behaviour in ethics (Austin 1962/1075: 19-21), or statements referring to nonexistent entities, with the classical example of 'The present King of France is bald' (cf. Austin 1962/1975: 20). Finally, there is the explicit statement of inclusion of "the supposed constative" (52) to the performative (cf. citation in section 1.3.4.) further supported with a discussion in Lecture V (53ff).

Under this new interpretation, as contentious as it may seem, the theory of speech acts from its very beginning can be seen as a holistic theory of linguistic communication; in fact, by extension, of all human communication with illocutionary force being an omnipresent dimension of natural language.

One more point which goes beyond the constative/performative distinction, and one of the basic problems for any theory of linguistic action, is the inevitable difficulty in accounting for the relation between particular words and either the

\footnotetext{
${ }^{44}$ See Sbisá (2007) and Austin (1962/1975: Lecture VI: 67-82; 134-139) for illustrations and problems of these claims.
} 
subsequent action or completion of such an action. Inter alia, this difficulty may hamper assessment of felicity. For instance, examples given by Austin in Lecture IV are paired with accomplishments of related actions, as in:
a. 'I give' and surrender possession,
b. 'I do' (take this woman \&c.) and consummation,
c. 'I sell' and completion of sale,

These examples illustrate the recognised "dubity", as e.g. in between "promising" and executing the promise. This kind of dubity is inherent in many speech actions where the degree in which "real" action and a statement which is used as its vehicle are blended may be of various intensity or saturation.

\subsection{1.b. Performatives, statements and speech acts}

Even immediately during the time following Austin's presentation, not all critics agreed that the performative/constative distinction should be abandoned altogether. For instance, in his essay "Some types of performative utterances", Austin's friend and academic colleague Warnock (1973) claims that when Austin initially says that saying is "doing" things, what he genuinely means is that only "sometimes" it is the case (cf. Warnock 1973: 69). Although Warnock accepts that all utterances may be approached as speech acts, he argues that the notion of the performative should be kept and, additionally, that the category of the performative includes two sub-types, explicit performative utterances and operative performatives, which acquire their force thanks to social conventions ${ }^{45}$.

Searle expresses a related view when he says that while all utterances are instances of "performance", only a small class are "performative" in the technical, speech act theoretic sense. Marking his position, Searle (2002a: 536) explicitly claims: "On my usage, the only performatives are what Austin called 'explicit performatives'. Thus, though every utterance is indeed a performance, only a very restricted class are performatives".

Searle's performatives are also necessarily explicit performatives, i.e. utterances (or rather sentences) in a canonical form. The point can be illustrated with the following forms:

(6) Leave the room

(7) I order you to leave the room.

According to Searle, only (7) is a performative, while (6) may constitute "a performance of making of an order" (Searle 2002a: 537), but is not technically a

\footnotetext{
${ }^{45}$ Warnock's arguments against the view that all speech acts are operative by convention are discussed in chapter four.
} 
"performative". Additionally, not all sentences sharing the grammatical characteristics of (7) can be performative, as can be seen in Searle's examples:

(8) I promise to come on Wednesday.

(9) I promise too many things to too many people.

Only (8) can be performative in the right context, while (9) is always just descriptive.

Warnock's and Searle's discussions of the performative is a good illustration of terminological confusions affiliated with speech act theory. In Austin's original account, an utterance is recognised as a performative thanks to its operative value; in Warnock's interpretation, both primary and explicit forms are performatives, but the explicit form does not "operate" by convention. In turn, Searle's original approach (e.g. 1969) recognises only explicit utterances as candidates for performatives.

There has been a lengthy debate among Searle (1989) and Bach and Harnish (cf. Bach 1975, Bach \& Harnish 1992) under the titular label "performatives are statements too". As Bach (1975: 230) rhetorically asks:

Why cannot one both perform an act and in the same breath state that one is performing it? Why should the use of certain verbs in a performative utterance be any less of a statement than the use of the same verbs in non-performative utterances, just because this use is also something other than a statement?

A more explicit claim can be found in Bach and Harnish's later formulation:

[A] performative sentence when used performatively is used literally, directly to make a statement and indirectly to perform the further speech act of the type (an order, say) named by the performative verb ('order').

(Bach \& Harnish 1992: 98)

As early as 1975, Bach further suggested that approaching performatives as statements would contribute to their definition as performatives. He pointed out that such utterances are first comprehended as statements ${ }^{46}$ and it is only later that their performative value is discovered. The process is shown in the procedure below, a reasoning which is, by the author's own admission, purposefully "artificially elaborate" and "needlessly explicit" (Bach 1975: 235):

\footnotetext{
${ }^{46}$ Naturally, this is a hypothesis which has not been sufficiently documented. As experimental pragmatic research shows, familiar speech acts, even if not direct, not explicit and not literal, may not take any longer in processing. Still, Bach's hypothesis may prove plausible in many contexts.
} 
$[\ldots]$ in the case of performative utterances [...] normally the audience reasons, and is intended to reason, as follows:

(1) He is saying 'I order you to leave'.

(2) He is stating that he is ordering me to leave.

(3) If his statement is true, then he must be ordering me to leave.

(4) If he is ordering me to leave, it must be his utterance that constitutes the order (what else could it be?).

(5) Presumably, he is speaking the truth.

(6) Therefore, in saying 'I order you to leave,' he is ordering me to leave.

(Bach 1975: 234)

Bach suggests that explicit performatives have two distinct forces, for instance, the sentence such as (10), when uttered performatively, has the primary force of an order, and the secondary one of a statement.

I order you to leave.

The explicit form of such utterances, Bach suggests, provides explicit information on the type of act being performed. For instance, the use of the adverb "hereby" can be read as an equivalent to "In uttering this sentence, I order you to leave". Similar explication can be found in phrases which may be added to primary utterances, such as:

(11) Leave; and that's an order.

(12) I will come; and that's a promise.

Bach maintains that all such utterances simultaneously have their performative force, but also describe the act being performed, i.e. in fact they have the feature which in Austin's theory was to be unique for explicit performatives because the performative verbs used in them are "making explicit (which is not the same as stating or describing) what precise action it is that is being performed by the issuing of the utterance" (Austin 1962/1975: 61). Explicit utterances may also involve truth and falsity and, thanks to making use of performative verbs, tell both about the action and acting without any other self-referential comments as those included in examples (11) and (12) above ${ }^{47}$.

Bach uses this argument to defy Schiffer's (1972) strong claim that performatives are constative in their logical form or conventional force and, essentially, that they are used with "the slightly less than their full conventional force" (cf. Schiffer 1972: 104-110; Bach 1975: 231-232). It is also indicated that in fact performatives make explicit their force, for instance, that of being an order in the case of the example above, but they also state something, while their

\footnotetext{
${ }^{47}$ Cf. Katz's (1977) claim that only constatives (to some extent identified with primary utterances)
} are assertive and have truth-conditions and can indeed be valued as true or false. 
"conventional force" is not reduced in these utterances in comparison to others. Criticising Schiffer (1972) for his view that explicit performatives are "constative" in their conventional force, Bach yet acknowledges that Schiffer's argument is clearer than that of Austin.

Bach and Harnish (1992, cf. 97-99), when defying Searle's criticism of their claim that explicit performatives are simultaneously statements, point to the fact that explicit performatives do not have to constitute a special theoretical class whose function needs a special kind of explanation. According to Bach and Harnish, as all explicit performatives can also be performed in non-explicit ways, their form is not so much an operative factor in their being performative; rather, it functions as an indicator of what act is being performed. An explicit promise differs from a promise made in a less direct form not in its very nature, but in the description of the act which it simultaneously carries. Evidently, in this perspective, there is no need for a special theory of explicit performatives. Searle (1989: 554) also admits that "there is no special semantic property of performativity", but seems to believe that a special theory explaining functioning of explicit performatives is both possible and needed.

In Holdcroft's (1974) opinion, what Austin might have had in mind, when he introduced his theory and used the terms "performative utterance" and "statement" is any of the following:

$\begin{array}{ll}\begin{array}{l}\text { 'performative utterance } \\ \text { 'performative utterance }\end{array}, & \text { 'a sentence which is a performative' } \\ = & \text { 'act of uttering a sentence which is a } \\ & \text { performative to perform an act (e.g. to } \\ & \text { give an order, or make a promise)' } \\ = & \text { 'sentence which can be used to make a } \\ & \text { statemento' } \\ \text { 'statement } & \text { 'that which can be true or false and } \\ & \text { asserted or denied' } \\ \text { 'statement } & \text { 'act of asserting a statemento' }\end{array}$

(Holdcroft 1974: 2)

Struggling with Austin's exposition, and focusing on the potential that certain sentences have to be performative when uttered, Holdcroft acknowledges the fact that if primary utterances, such as "I shall be there", are to be analysed as parallel to explicit ones, e.g. "I promise to be there", then the term " "performative' turns out not to be the name of a feature possessed by some, but not all, sentence types, but of one possessed by all" (Holdcroft 1974: 16). In conclusion, performativity turns out to be a feature of "being useable to perform an illocutionary acts" (16). Holdcroft points out that by accepting this position, however tenable for most examples, we seem to blur a very important distinction between explicit and primary acts. It is suggested that the distinction should be 
maintained to single out sentences which contain "a device which makes explicit what act is being attempted by a serious and literal utterance of itself" (17) and only such sentences should be technically recognised as "performative".

Conflicting views on the nature of the (possible) co-existence of both the constative and performative (other than that of a statement) force in explicit performatives, as well as performatives in general, still exist. It may seem that related debates are limited to the problem of explicit utterances phrased in the canonical form, but in fact the problem touches on the very basic tenet in speech act theory, viz. whether performatives, or in a broader perspective, speech acts, can be described as a consistent group of utterances with a sufficient account of their force.

As early as 1975, Bach (e.g. 1975: 234-235) also envisaged that a general theory of speech acts should be construed and that only within the theory such problems of performative utterances could be accountable. Such a theory, according to Bach, should specify the necessary and sufficient conditions for the successful performance of particular speech acts; within the theory, conditions for statements should elucidate the problem of explicit performatives. However, despite numerous optimistic expectations as to the emergence of such a theoretical model, no specific holistic theory of the kind has been proposed.

The performative/constative distinction is thus one of the elusive features of speech act theory. When Fish (1989: 62) says that Austin is like a god in that he gives and takes away, he is evidently referring to a quality in Austin's writing, which is both important and difficult; the quality which is psychologically sound but difficult to account for in a systematic way. Austin's lectures reveal his belief that linguistic performativity is a real phenomenon, both difficult to grasp and associated with great intuitive certainty. Linguistic performatives share this quality with many other types of action. However, Austin's performative quality is seen as special; an utterance is not recognised as performative just because it produces consequences in the extralinguistic world. It constitutes a speech act because the action is communicative in nature.

Loxley (2007: 2) attempts to explain this quality in the following way:

There is something both immediately convincing and yet still striking about Austin's basic position. Austin points up the way in which our utterances can be performative: words do something in the world, something that is not just a matter of generating consequences, like persuading or amusing or alarming an audience. The promises, assertions, bets, threats and thanks that we offer one another are not this kind of action; but nor are they the linguistic description of nonlinguistic actions going on elsewhere: they are actions in themselves, actions of a distinctively linguistic kind. They are 'performed', like other actions, or take place, like other worldly events, and thus make a 
difference in the world; it could be said that they produce a different world, even if only for a single speaker and a single addressee.

Implicitly, Loxley shows here a distinction between (intended) illocutionary goals or even perlocutionary effects and illocutionary conventions, which are discussed in chapter four. Speakers may, for example, amuse their audience without intending to do so, which will be a case of producing an effect which does not "belong" in the core of a performative utterance, but is at least partially external to it. In contrast, promises and bets are linguistic actions inherently performative in nature.

The distinction between the performative quality of an utterance and its "assertive" reading can also be approached as a case of pragmatic ambiguity (cf., e.g. Recanati 1987). Instead of arguing whether certain utterances are statements or performatives, their nature may be presented as relative to speakers' intuitions. This approach seems to remain in agreement with Austin's explicitly rendered intuition that a promise, even in its most explicit form (e.g. I hereby promise ...) is simply not an assertion, but an operative utterance. Naturally, this approach is associated with Gricean and post-Gricean linguistics, which explains meaning with reference to speakers' intentions in utterance production, or, in its later version, exemplified in Recanati's theory, as recognition of speakers' communicative (rather than inner, personal) intentions. To surpass the difficulty of explaining how utterances formed in the same grammatical mood can be associated with different illocutionary forces, Recanati (1987) suggested that the indicative mood should be approached as "force-neutral", i.e. compatible with any direct illocutionary force. This, it was argued, can remove the problem that the indicative mood is used for both describing the world, i.e. in typically assertive utterances, and for changing it, i.e. in typically performative, e.g. commissive or declarative, utterances. In this perspective, accepting that the indicative mood is ambiguous in that it allows different interpretations with regard to its force would lead to different species of such acts being multiplied beyond necessity, which would eventually call for Occam's razor.

In summary, although Austin eventually presents both constatives and performatives as species of speech acts, and in fact includes constatives in the class of performatives (cf. Austin 1962/1975: 91 et passim), the phenomenon of performativity is revealed as a dimension of language which seems deeper than it might look on the surface, and the distinction between language which (just) describes and language which is conduct and includes acts which produce changes in the world agrees with people's intuitions and is psychologically sound. In the end, although the notion does not receive a clear definition, it is retained as methodologically important.

In an explicitly formal semantic approach offered by Katz (1977) the distinction is also asserted, and in fact revived, to aid linguistics methodology. Suggesting that abandoning the constative/performative division Austin was 
confused with regard to semantic and pragmatic performativity, Katz uses the constative/performative distinction as instrumental in indicating the contrast between semantics and pragmatics as two distinct fields. It is suggested that different kind of "performativeness" exists in either field. For instance, semantic performativeness can be found in sentences which are in Austin's canonical form and also in imperative and interrogative moods. Katz's model, however contentious itself ${ }^{48}$, revives Austin's "old" distinction placing much trust in his original notions.

\subsection{Felicity conditions}

There is ample evidence that Austin was well aware of the fact that there is more to linguistic communication and to "doing" in or by speaking than just words. He emphasised the need for the appropriateness of context and noted that in many cases of speech acts the same or a similar act may be performed by a nonlinguistic action or a combination of the linguistic and the non-linguistic, e.g. betting can be done using a slot machine and in most institutionalised settings words can provide just idiomaticised "complementation" to the rules laid down within the institution.

Frequently, Austin refers to "convention" as an element necessary for a successful performance of an act. Some of the acts that he mentions heavily rely on social conventions, as e.g. the act of marrying, whose details are pre-defined in a particular culture. Austin also mentions an example of a possible, but necessarily unsuccessful, potential attempt to divorce one's spouse by saying "I divorce you" in English culture, which stays in contrast to some Eastern communities. The variety of Austin's examples seem to blur the theoretical picture of felicity. For some acts to be successful, convention in the sense of an existing social institution is necessary (e.g. marriage, divorce, appointment), other acts seem to rely more heavily on the speaker's (also social) "local" authority (e.g. declaring war, appointing ministers), while still others are more private and focus on inner feelings and intentions (e.g. "private" promises). In other words, sometimes the procedure and standardised expressions are more important than people's feelings and intentions; on other occasions, intentions may be of primary importance and speakers may be granted much freedom as to the words and phrasing that they use. It is not surprising then that Austin's thought has been further developed within two main theoretical streams, one

\footnotetext{
${ }^{48}$ Katz (1977) explicitly attempts to integrate ideas which come from generative grammar and speech act theory, which went two separate ways due to Austin's premature death-reportedly (Katz 1977: xii), Austin had planned discussions of Chomsky's Syntactic Structures in Oxford. However, the model presented by Katz is not free from its own problems (e.g. the above mentioned classification of sentences as semantically performative or not, or the definition of semantics vis-à-vis pragmatics.
} 
focused on the conventional aspect of a performative use of language in the sense of social institutions with pre-defined patterns of linguistic performance, the other concentrated on intentional states ${ }^{49}$. This divide has relevance for many theoretical and methodological issues, including the definition of pragmatics ${ }^{50}$. Austin is commonly recognized as a member of the "conventional" school, however, even his original account of felicity conditions, or "the appropriate circumstances", essential for a successful accomplishment of a speech act, shows that he attempted to encompass all aspects of utterances, as can be seen in his schematic doctrine of the infelicities quoted here:

(A.I) There must exist an accepted conventional procedure having a certain conventional effect, that procedure to include the uttering of certain words by certain persons in certain circumstances, and further,

(A.2) the particular persons and circumstances in a given case must be appropriate for the invocation of the particular procedure invoked.

(B.I) The procedure must be executed by all participants both correctly and

(B.2) completely.

$(\Gamma$. I) Where, as often, the procedure is designed for persons having certain thoughts and feelings, or for the inauguration of certain consequential conduct on the part of any participant, then a person participating in and so invoking the procedure must in fact have those thoughts and feelings, and the participants must intend so to conduct themselves, and further

( $Г .2)$ must actually so conduct themselves subsequently.

(Austin 1962/1975: 14-15)

Austin's conditions are grouped into two main categories, one more "social" and the other more "psychological" in focus, thus, by extension, "more conventional" and "more intentional" to follow well established labels. Under his interpretation, any violation or "sin" against the conditions of the A and B type results in infelicity in that the act in question cannot be seen as "performed"; the name used for such violations is misfires. On the other hand, violation of the conditions listed under $\Gamma$, e.g. an insincere promise, results in an act which is "achieved", but at the same time is an instance of abuse, hence the technical label abuses for this group. A more fine-grained classification of types of

\footnotetext{
${ }^{49}$ A more detailed discussion of these issues can be found in chapter three on speech acts taxonomies and in chapter four on the notion of convention in the theory of speech acts.

${ }^{50}$ Pragmatics following in Austin's footsteps has sociological orientation, while intention-based pragmatics research invites a cognitive psychological orientation.
} 
infelicities can be seen in the following diagram (the question marks indicate areas for which the labels were not yet given):

\section{Infelicities}

A B

Misfires

Act purported but void

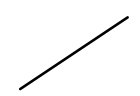

A

Misinvocations

Act disallowed

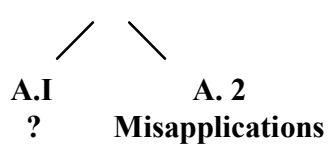

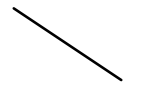

B

Misexecutions Act vitiated

B. I B.2

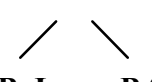

Flaws Hitches

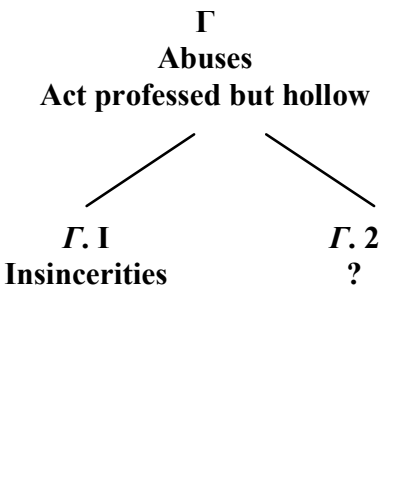

Figure 3: Types of infelicities. Adapted from Austin 1962/1975: 18.

In this schematisation of felicity conditions Austin implicitly envisages future developments of speech act theory and the above-mentioned split into the conventional and the psychological, cognitive, intentional, often recognised as post-Gricean orientation. He explicated the A and B type infelicities as acts "purported", "disallowed", "empty", "void or without effect", where the form is devoid of "expected" meaning. The A group comprises "misinvocations", further divided into misapplications and a "no-name" group, for which Austin apparently lacked a more favourable Latinate name. The B group"misexecutions" - comprises "flaws" and "hitches". On the other hand, the $\Gamma$ type infelicities produce acts describable as "professed", "hollow", "not implemented" or "consummated", which include "insincerities" and another "no-name" section" 52 . In particular, group $\Gamma$ involves problems with feelings, thoughts, and intentions, as if anticipating the future development of a speech act theoretical move towards the Gricean model of communication. Austin emphasises here that the distinctions employed are so "loose" that it may be

\footnotetext{
${ }^{51}$ Significantly, Austin emphasises the fact that in any (linguistic) action, even those that are infelicitious, "lots of things will have been done" (Austin 1962/1975: lecture II, p. 17). However, it seems that there is always one (superior) act recognised in context as being attempted and eventually either felicitious or not. This assumption, although implicit in Austin, invites the conclusion that speech acts are in fact primary units of meaning in communication.

${ }^{52}$ As noted by J. O. Urmson (Austin 1962/1975: 18, fn. I) Austin experimented with names for some of the categories and also used e.g. A.I, Non-plays; A.2, Misplays; B, Miscarriages; B.I, Misexecutions; B.2, Non-executions; $\Gamma$, Disrespects; $Г$. I, Dissimulations; $Г .2$, Non-fulfillments, Disloyalties, Infractions, Indisciplines, Breaches.
} 
difficult to distinguish, for instance, intentional insincerity from mere mistake in judgement, which may result in making the act in question either "void" or "excusable" (cf. Austin 1962/1975: 41-43). He also recognises that "both promising and asserting are procedures intended for use by persons having certain thoughts" (Austin 1962/1975: 50). Under this interpretation someone who gave an insincere promise may be taken as having promised because of the overt appearance of the act, even though there is a fault in the act itself. This reflection is mirrored in a much later model, put forward by Korta and Perry (2007, 2011), who call this aspect of utterances "forensic" because often speakers are held responsible for meanings which might not have been intended by them. In contrast to the previous categories, failure to conform to a convention, as when one lacks authority to declare a war, would result in the act being void.

In Austin's model, a (purported) marriage may "misfire" in the context of bigamy, i.e. of the existence of a previous marriage commitment even though the form of the ceremony was correct; the performance may be abused when, for instance, participants of the act lack adequate intentions.

The classification of (in)felicity is to illustrate the most salient types, but the types do not constitute clear-cut and mutually exclusive categories; by Austin's own admission they may "shade into one another" and "overlap" (Austin 1962/1975: 23).

Austin emphasised the fact that infelicity is a widespread phenomenon. His exposition of the problem implicitly invites a conclusion that, sensing infelicity, language users may detect the performative force. He did, however, point to the fact that in ethics, for example, acts are "exposed to infelicity" more directly than to considerations of purely physical movements. Sbisà (2002), who is strongly committed to reconstructing Austin's original and intended model of speech act theory, also emphasises that the felicity of a speech act is obtained by default unless indicated otherwise, and that speech acts are context categories.

In a cognitive-linguistic framework, speech acts are sometimes analysed as radial categories (e.g. Kalisz 1993) to the effect that felicity conditions are seen as prototypical conditions associated with a certain act type.

An interesting proposal came from Culler (1981), who suggested that Austin's system can be understood as parallel to de Saussure's system of interrelated signs. In Culler's view, we can account for the system of speech acts by accounting for meaning of utterances and their illocutionary forces. This finds a parallel in deSaussurean analysis of sentences with regard to the general linguistic system, only repeated at a different level of signification. Because an illocutionary force can be explained by defining felicity conditions of an act, Culler believes that the performative value is directly relevant to possible infelicities, that an act exists thanks to its possibility of going wrong. Consequently, every act carries its illocutionary force relative to internally contained conventions and conditions. 


\section{Felicity conditions and unintentional acts}

One of the points of criticism voiced with regard to Austin's account of felicity conditions is that only intentional acts are considered (cf. e.g. Navarro-Reyes 2013). A rich area for analysis opens if the possibility of unintended acts, whether felicitous or not, is accepted. Naturally, the most contentious issue in this perspective is how to apply the conditions related to the speaker's intentions and whether such an application is at all relevant. It seems that for Austin, all speech acts are consciously performed, at least all acts that can be recognised as speech acts are intentional acts with a caveat that perlocution may import effects and consequences which are hard, or impossible, to envisage. However, in reality, there are acts which the audience would most probably classify as having an illocutionary force even though they emerge independently of the speaker's intentions. For instance, I may inform someone unintentionally, make my audience believe that I ordered something, or accept a commitment which I did not realise was going to appear. The question arises whether the speaker is responsible for such acts, whether the above-mentioned "forensic" dimension, as suggested by Korta and Perry $(2007,2011)^{53}$, should apply, i.e. if my words may mean something that I did not intend, and if in such a situation they still constitute a valid speech act as attributed to the speaker by an addressee.

An easy way out of the problem would be to conclude that all unintended acts are perlocutionary in nature, and, as such, largely independent from the speaker. However, taking this position would violate language users' intuitions about the nature of such acts as their (alleged) efficacy seems to arise from conventions governing language use. An additional problem is that language, being a dynamic and varied system, may involve different expectations in different groups of its users. As a result, phenomena related to felicity conditions may be perceived differently by different speakers of the seemingly common language system, the fact richly documented in inter- or cross-cultural communication studies (cf. also chapter four). Irrespective of the conclusion, the area provides ground for further investigation and attention in speech act studies and indicates yet another field of underdeterminacy in the theory.

\subsection{Speech acts, locution, illocution and perlocution}

Another tenet of speech act theory, along with the constative/performative distinction and felicity conditions, is exemplified by the distinction between locution, illocution and perlocution. As Austin explains,

\footnotetext{
${ }^{53} \mathrm{Cf}$. section 2.6.2.d for a more extensive exposition of the problem.
} 
The doctrine of the performative/constative distinction stands to the doctrine of locutionary and illocutionary acts in the total speech act as the special theory to the general theory. And the need for the general theory arises simply because the traditional 'statement' is an abstraction, an ideal, and so is its traditional truth or falsity.

(Austin 1962/1975: 147)

Having abandoned the performative/constative distinction, Austin suggests that a speech act can be analysed as a simultaneous performance of three internal acts: locution, illocution and perlocution. The assumption lying at the core of speech act theory, which can be also traced back to Frege, is that any utterance has two basic aspects: it involves sense and force. In order to account for the actional nature of language, Austin found it relevant to differentiate between three simultaneous aspects, corresponding roughly to an utterance form, function, and effect/result. Locution is defined as composed of three elements, viz.:

1. Phonetic act (uttering certain noises), i.e. a phone;

2. Phatic act (uttering certain words in a certain construction, noises of certain type), i.e. a pheme;

3. Rhetic act (performance of a pheme with a more or less definite sense and a more or less definite reference, where sense plus reference are equivalent to "meaning"), i.e. a rheme.

For instance, "He said, "The cat is on the mat"" is a report on a phatic act, while "He said that the cat is on the mat" reports a rhetic act.

The description, given in Austin's notoriously underdetermined phrasing, sometimes deemed "extremely fuzzy" (Harrison 1979: 169), indicates that the overall locution should (roughly) be understood as literal, semantic, and a maximally decontextualised vehicle of meaning. In Austin's words, it amounts to "saying something", which in turn is:

the utterance of certain noises, the utterance of certain words in a certain construction, and the utterance of them with a certain 'meaning' in the favourite philosophical sense of that word, i.e. with a certain sense and with a certain reference.

(Austin 1962/1975: 94).

In contrast, illocution corresponds to the function (or force) of an utterance. Austin also explicitly admits that one locution may be used to perform many different illocutions (possibly at a time), whose force come from (again a notoriously underspecified) convention (Austin 1962/1975: 108) ${ }^{54}$.

The basic difference between illocution and perlocution is that the illocutionary act is performed in uttering words, while the perlocutionary by the

\footnotetext{
${ }^{54}$ For a critical discussion of the notion of convention and the role of uptake in Austin and the theory of speech acts, see e.g. Sbisá 2001, 2002, 2007 and 2009 and Harnish 2009a.
} 
utterance $^{55}$. It suggests that there should be a conventional bond between the expression and its illocution, which is stronger than the bond between the locution and the corresponding perlocution.

The definition of perlocution is a broad one and focuses on the results that the act produces. In Austin's words, it is defined as follows:

Saying something will often, or even normally, produce certain consequential effects upon the feelings, thoughts, or actions of the audience, or of the speaker, or of other persons: and it may be done with the design, intention, or purpose of producing them [...] We shall call the performance of an act of this kind the performance of a 'perlocutionary' act.

(Austin 1962/1975: 101)

In short, Austin identifies locution, illocution, and perlocution as three simultaneous acts done "of saying", "in saying", and "by saying", respectively. He illustrates the three aspects of the speech act with the following examples (1962/1975: 101-102):

Act (A) or Locution

He said to me 'Shoot her!' meaning by 'shoot' shoot and referring by 'her' to her Act (B) or Illocution

He urged (or advised, ordered, \&c.) me to shoot her. Act (C.a) or Perlocution He persuaded me to shoot her.

Act (C.b)

He got me to (or made me, \&c.) shoot her.

(E. 2)

Act (A) or Locution

He said to me 'You can't do that'.

Act (B) or Illocution

He protested against my doing it.

Act (C.a) or Perlocution

He pulled me up, checked me.

Act (C.b)

He stopped me, brought me to my senses, \&c.

He annoyed me.

\footnotetext{
${ }^{55}$ See also discussion of intricacies and exceptions in applying the "in saying" and "by saying" formulae for paraphrasing locutionary, illocutionary and perlocutionary acts in Austin 1962/1975: Lecture X, 121ff).
} 
The examples given by Austin are not perfectly convincing; for instance, the "urging" and "persuading" seem to be very closely related. In this light, it has been suggested that in fact (at least many instances of) Austin's illocutionary, or even locutionary acts are of a perlocutionary nature (e.g. Davis 1979) because they are naturally oriented towards their effect or an envisaged goal of the whole act. In present speech act-theoretic research, there are explicit claims of the supremacy of the perlocutionary frame, where both illocution and locution are internal to the perlocution (cf. e.g. Post 2001 for a cognitive and axiological account), there are also voices pointing to the supremacy of a general illocutionary perspective (e.g. Hornsby 1994; cf. also section 2.6.2.e). Due to possible confusion, which has also accumulated in post-Austinian speech act theory, perlocution has sometimes been labelled "the Achilles' heel of speech act theory" (Marcu 2000), while the theory itself was depicted as being at an "perlocutionary impass" (cf. Gu 1993).

Perlocution embraces all sorts of "consequences" (Austin 1962/1975: 207) including changes in the audience's feelings, thoughts and attitudes, and the resulting actions. A part of such "consequences" will depend on the locutionary content of an utterance, others will be related to illocution, and many of them in general will be specific to the hearer/audience, whose sensitivity to different factors will depends on particular personal and situational contexts. As Austin asserts, "clearly any, or almost any, perlocutionary act is liable to be brought off, in sufficiently special circumstances, by the issuing, with or without calculation, of any utterance whatsoever" (Austin 1962/1975: 109).

There is a possible causal link between illocutionary effects and perlocutionary effects in that, for instance:

You may, for example, deter me [...] from doing something by informing me, perhaps guilelessly yet opportunely, what the consequences of doing it would in fact be $[\ldots$,$] you may convince me$ $[\ldots]$ that she is an adulteress by asking her whether it was not her handkerchief which was in X's bedroom: or by stating that it was hers.

(Austin 1962/1975: 110)

Austin used examples such as the ones quoted above to justify drawing a line between illocutionary and perlocutionary acts.

It is noteworthy that Austin realised that some acts which may "feel" action can never be explicated in a canonical form. In lecture nine, he suggested that there may be an act with a function, which only have a locution and perlocution, but for which there is no illocutionary formula:

Some perlocutionary acts always have sequels rather than objects, namely those where there is no illocutionary formula: thus I may surprise you or upset you or humiliate you by a locution, though there 
is no illocutionary formula 'I surprise you by ...', 'I upset you by ...', 'I humiliate you by ...'

(Austin 1962/1975: 117)

At this stage Austin suggests that characteristically perlocutionary effects may be achieved also by non-linguistic means, while illocutionary ones are language-dependent. Later, it seems, Austin concludes that conventionality is the most characteristic feature of illocutionary acts, a feature which allows for their differentiation (even illocutions which are non-verbal in form) from perlocutionary acts (pp. 118ff., $120 \mathrm{ff} . \&$ passim).

Although notoriously underspecified and a subject of prolonging debate and criticism (e.g. Forguson 1973, Furberg $1963^{56}$, Strawson 1973, Searle 1968, 1969, Black 1963, de Souza Filho 1984, Davis 1979, Recanati 1987, Korta and Perry 2007, 2011), Austin's tripartite division of a speech act into locution, illocution and perlocution has been widely accepted in linguistics and served as a guideline for demarcating a border between semantics and pragmatics. Evidently, both the function and the effect of an utterance are explicitly pragmatic in nature, but for locating the borders of pragmatics, the divide between locution and illocution is especially important.

This tri-partite division, as well as the fact that illocutionary force is closely associated with intentionality, bear relevance for acts of speech which are not in their canonical form. Speech acts may be indirect or direct. They are indirect when their force is not seen on the surface, as in the case of uttering "Open the door!" as opposed to "Could you open the door?". Additionally, they may be explicit or implicit, when meaning is spelled out fully or incompletely, and they may as well be literal or not. Indirectness and nonliterality normally involve conversational implicature and complicate the picture of the internal architecture of an act.

Of the three aspects of the speech act, illocutionary acts have attracted the most attention over the years. This is not surprising because it is within the illocutionary aspect where the core of a speech act may be found; it is illocutionary acts that are identified as "meaning determining acts" which constitute "the primary subject matter of speech act theory" (Tsohatzidis 1994: 1).

\subsubsection{Gesticulary, ingesticula(to)ry, and pergesticulary acts}

Austin's model of the tri-partite architecture of a speech act turned out to be prolific and there have been attempts to extend it so that it could cover broader

\footnotetext{
56 Interestingly, Furberg (1963) identifies Austin's distinction between locutionary and illocutionary acts with Hare's (e.g. 1970; 1971) distinction between phrastics and neustics, although the parallel seems to be rather contentious (for instance identical phrastics, it seems, may correspond to different locutions/forms).
} 
aspects of communication which go beyond language proper. For instance, in an attempt to explore the relationship between words and gestures in comics, the terms "gesticula(to)ry", "ingesticulatory" and "pergesticulary" were coined to refer to three aspects of a gesture. This has been subjected to research and illustrated with the use of frequent gestures from Asterix comic books. Ten gestures were used in the first part of the study together with their accompanied utterances in the comics, in order to examine the gesture-utterance connection.

The research contributes to the view that language is not an autonomous system in the sense that meaning encoded in words constitutes only a small fraction of information normally conveyed in linguistic communication, especially in conversation. Gestures are of special importance in this context and have been subjected to research for a long time (e.g. Feyereisen \& de Lannoy 1991, Morris et al. 1979), but it was Fein and Kasher (1996) that proposed using the speech act theoretic methodology in research on comic strips. Interestingly, having coined new terminology for the analysis of gestures and gesticulatorylinguistic chunks in a corpus of Asterix comics strips, the linguists recognised their research area as 'comics pragmatics'. ${ }^{57}$ Commenting on the Austinian tripartite distinction, Fein and Kasher acknowledge its more universal nature which transcends solely linguistic behaviour. In their words,

Austin's tripartite distinction does not pertain only to speech acts, but
to many other intentional acts as well. We assume, then, that there are
three things that we do with gestures: gesticulary, ingesticulary and
pergesticulary acts. A gesticulary act is the act of generating the
movements and combining them into a gesture. An ingesticulary act is
what we do in gesticulating. We use gestures in order to greet, order,
threat, express certain emotions and so on. Finally, a pergesticulary act
is what we do by the gesture we perform. By gesturing we can
influence feelings, thoughts or behavior: we can persuade, provoke or
confuse.
(Fein and Kasher 1996: 794)

Thus, the three acts correspond closely to the Austinian locutionary (producing linguistic form), illocutionary (metalinguistic function realised in saying something), and, finally, perlocutionary act or effect, achieved by saying something.

There are a few interesting implications of such an exercise. Firstly, the researchers were interested in the potential correspondence between gestures and illocutionary acts. It follows that if that correspondence is recognised, proved and justified, it should be a good indication that illocutionary acts are universal, at least within limits of a particular culture. It would also be an indication that gestures constitute a system in many aspects similar to natural language, which

\footnotetext{
${ }^{57}$ In opposition to 'medieval art pragmatics' as exemplified by Kasher and Barasch (quoted in Fein and Kasher 1996: 794) and following e.g. Kendon 1995.
} 
can further be linked to judging a non-linguistic performance as speech, which has, for instance, been practiced in the United States in legal contexts ${ }^{58}$.

The research reported by Fein and Kasher dates back to 1996, but related research into the meaning of gestures, though without reference to the theory of speech acts, has been conducted in cognitive linguistics and has also been related to sign language. Inter alia, it has been shown in a diachronic perspective that gestures evolve in a similar manner to words $\mathrm{s}^{59}$.

The research, however, has its (evident) limitations. Furthermore, the gestures in comics may be seen as 'meta-gestural' in that they are not real-life gestures, only a (possibly caricatural) representation of natural ones. However, in turn, they may as such be perceived as generalised "types", akin to speech act categories.

Interestingly, speech act perspective on gestures may be traced back in time, dating to Immanuel Kant (cf. McHoul 1996), who attempted a systematic account of intentional and unintentional facial expressions and their meanings, which, despite his pragmatic (or rather pragmatism-oriented) motivation, was indeed speech act-theoretic in nature (cf. Kant 1978).

\subsubsection{Alternative accounts of the internal structure of the speech act}

Austin's tri-partite model of the speech act has been extended to cover signs beyond language as could be seen in the above proposal of the "gesti"constituents, but it also has received criticism and motivated proposals of further modifications. Some of the criticism has been based on the mistaken assumption that it should be possible to separate the three internal acts in an ideal way, which has never been Austin's proposal, who defined them as mere abstractions within one unitary act (cf. Austin 1962/1975: 146).

\footnotetext{
${ }^{58} \mathrm{Cf}$. judgments related to speech treated as conduct and conduct recognised as "speech" in cases involving discrimination or hate speech, e.g.: Texas v. Johnson. 491 U.S. 397 (1989) where the burning of the flag was recognized as protected speech expressing protest towards American policy, cf. also R.A.V. v. Cu'v of St. Paul. 112 S. Ct. 2538 (1992). Wearing a black arm-band to school as a protest sign against the Vietnam war was recognized as an instance of protected speech in Tinker v. Des Moines School District, 393 U.S. 503 (1969), but burning the army draft was deemed "speech mixed with conduct" (United States v. O'Brien 68. 392 U.S. 367 (1968)). Cf also a discussion of such issues in Witczak-Plisiecka 2013.

${ }^{59}$ Related research was commented on by Sherman Wilcox during the High Desert Linguistics Society (HDLS-8) conference in Albuquerque,New Mexico, in November 2008. The reported research, which concentrated on the evolution of a hand gesture (with one arm raised, the index finger directed upwards) seems to confirm Fein's and Kasher's proposal that in most cases in art pragmatics the relation between gesture and force is an arbitrary one, i.e. it is conventional and the meaning is closely related to the gesture itself without a strong relationship with the propositional content simultaneously expressed. This particular gesture was classified as 'Discovery' in Fein and Kasher (1996), but it is also closely related to the well-known 'Stop/Wait' gesture.
} 
Proposals of further modifications of the model explicating the internal structure of the speech act and the status of its component parts or aspects relate to other important notions which emerged in linguistics and philosophy of language; in particular they can often be related to the Gricean notion of "what is said" as opposed to "what is meant" or implicated, and further discussions focused on the distinction between the two. According to Grice, "what is said" in uttering a sentence $S$ means ' $p$ ' "in virtue of the particular meanings of the elements of $S$, their order, and their syntactic character" (Grice 1989: 87); in contrast, "what is implicated" does not need to be rooted in the form of the utterance and constitutes meaning beyond the words.

On the side, it must also be noted that Grice's theory of conversational implicature and natural meaning, much as it is both influential and throughprovoking, is itself vulnerable to certain methodological problems. Levinson (2000), for instance, refers to "Grice's circle"; the phenomenon is also referred to as "pragmatic intrusion". Although "what is said" theoretically forms basis for a construction of "what is implicated", it is not possible to determine what "was said" without engaging in pragmatics inferential processes. As a result, although "what is implicated" has as its content information read "beyond" "what is said", "what is said" is not available without at least some reference to "what was meant" or implicated ${ }^{60}$.

Returning to Austin, theorising on the internal architecture of the speech act is of direct relevance for a definition of pragmatics because much of this theorising is focused on finding a divide between "stable" meaning, which may be associated with dictionary-based meanings of words that are independent of the context of use, and "pragmatic" meaning in context. The elusive divide can be sought between locution and illocution, i.e. between form and function, but it may also reside within illocution itself as markers of illocutionary force can exhibit a more semantic or a more pragmatic nature.

For instance, it has been suggested (Recanati 1987) that the notion of the locutionary act could be reserved for acts "semantically indicating" a particular illocutionary act, i.e. semantically explicit acts, with the provision that there are also illocutionary acts which are not semantically indicated as it is, for instance, the case when speakers convey irony or sarcasm. Under this interpretation, which seems to depart from Austin's account, there may be illocutionary acts

\footnotetext{
${ }^{60}$ Some of the problems posed by Grice's theory may be eradicated when a less linear view of meaning construction is allowed. One such proposal comes from Korta and Perry (2011), who link Austin's speech act theory and Grice's theory of conversational implicature, pointing that inference leading to a discovery of the speaker's plan in performing an utterance can be of complex nature, when the hearer uses all available signs simultaneously to work out the meaning of the utterance. This proposal seems to be validated by research in relevance theory and experimental pragmatics, where results from processing time measurements indicate that processing of non-literal and non-direct utterances does not take longer than processing of explicit and direct ones in contexts which the exhibited type of indirectness and inexplicitness is of relatively high frequency.
} 
semantically indicated but not actually performed, just as there are illocutionary acts performed but not semantically indicated. In Recanati's account, at least in the 1987 model, Austin's locutionary act is shown to become (rather than be for instance identical or coincidental with) an illocutionary act in explicit utterances where speakers mean exactly what they (semantically) say.

Other comments indicated that the potential of speech act theory is best seen in concentrating on social consequences of acts of communication (cf. Allwood 1977) with less attention paid to individual sentences and their (potential) uses. This line of thinking about speech act theory, foregrounding the perlocutionary aspect, emphasises the importance of elements such as speakers' intentions and emotional states, together with the role that psychological cognitive elements play in (re)constructing utterance meaning on the part of the hearer.

Later approaches to the tri-partite distinction include suggestions that communicative intention, by its very nature, is "perlocutionary" (cf. Barker 2004: 64) as it focuses on the effects of actual or envisaged speech action.

The following sections summarise selected proposals with regard to a description of the internal structure of the speech act.

\subsection{2.a. Searle's (1969) modifications of the internal structure of the speech act}

The category of locution is rejected in Searle's (1969) early elaboration of the theory of speech acts. Searle bases his criticism of the category on the fact that locutionary acts could not be sufficiently differentiated from illocutionary acts of saying. Searle claims that no sentence can be completely force neutral; as a result, there is always an illocutionary dimension in the case of every sentence (or utterance). This motivation does not seem entirely convincing as Austin did not claim that it should be ever possible to have an abstracted locutionary act in a pure form; instead, he suggested that the locutionary act is a useful approximation. Nonetheless, Searle's suggestion is clearly an attempt to put forward a more precise description of the nature of the speech act from the one he derived from Austin.

Among constituents of speech acts, Searle mentions "performing utterance acts", i.e. uttering words, "performing propositional acts", i.e. referring and predicating, "performing illocutionary acts", e.g. stating, commanding, and, finally, performing perlocutionary acts, i.e. producing consequences or effects (Searle 1969: 24-25). There is a lot of convergence between Searle's constituents and the internal acts suggested by Austin; for instance it looks as if Searle renamed a construct built from Austin's phonetic and phatic acts as "utterance", and turned the rhetic act, originally housed within locution, into the "propositional" one. In this way, elements of the original locution are redistributed and, for instance, in the case of the Austinian phatic act, partially 
merged into the new categories. Searle's amended conception of the speech act includes thus the following components:
Utterance acts: $\quad$ Austin's phonetic and phatic acts that entail uttering words (morphemes, sentences)
Propositional acts:
Illocutionary acts:
referring and predicating
stating, questioning, promising, commanding, etc.

Perlocutionary acts: the consequences or effects of an utterance on the actions, thoughts, or beliefs, and behaviour of hearers.

(cf. Searle 1969: 24-25)

Searle's separation of the "utterance act" together with the "propositional act" from the illocutionary act and the perlocutionary act produces a shift in attention paid to particular elements in the speech act, but it also produces similar confusion and theoretical difficulties as the Austinian distinction into locution, illocution, and perlocution. For example, Searle's success conditions mix lexical knowledge with world knowledge, linguistic considerations with context intervention.

Searle's proposal foregrounds the propositional content and the illocutionary point, which is seen in the proposed general formula for speech acts: $F(p)$, where $F$ corresponds to illocutionary force and $p$ corresponds to propositional content ${ }^{61}$. As a result, despite the fact that illocutionary and perlocutionary acts are maintained in the model, it appears to be dyadic rather than tri-partite.

Searle's amendment is also an interesting example of how metalinguistic terminological commitments are relative to assumptions. In putting forward his model, Searle emphasises the inadequacy of the original proposal which included the locutionary act. His main point of criticism, as mentioned above, is that all sentences have illocutionary force potential, which means that the locutionary act cannot be a separate entity. Searle believes that the notion of locution makes sense only for cases in which a sentence could be force-neutral, but sentences are not neutral; what can be neutral is their propositional contents. Thus, propositional content which may serve as a vehicle for different illocutionary forces needs to be separated from the illocutionary act. Another

\footnotetext{
${ }^{61}$ The theoretical soundness of such a clear distinction between force and propositional content can be further justified by cases of relative surface "invisibility" of the illocutionary force as can be seen in analyses of, e.g. buiscuits conditionals, such as "There are buiscuits on the sideboard if you want them" or "There are buiscuits on the sideboard of no one has eaten them. (cf. Austin's (1970) paper "Ifs and cans" and, e.g. Siegel (2006)). In such sentences, the if-clause seems to apply to the illocutionary act performed in uttering the main clause and not to its propositional content.
} 
point of criticism voiced by Searle is that meaning and force are inseparable. Another point of criticism Searle expressed is that meaning and force are inseparable. Searle believes that his conception of the speech act is more unitary and more integrated than the one put forward by Austin. However, Searle's criticism rests on a heavy-handed interpretation of Austin as in fact Austin promoted a view in which a unitary speech act contained three simultaneous aspects of the locution, illocution and perlocution and not separate acts (cf. preceding section). Subsequently, although Searle's model may be seen as more practical and as more convincing, the motivation behind it is not firmly grounded in facts found in Austin's original account.

\subsection{2.b. Alston's illocutionary act potential and speech acts}

Another influential modification of Austin's ideas is that proposed by Alston (1994, 2000). Alston's central position in accounting for speech acts is that sentence meaning must be identified with illocutionary act potential (IAP) so Alston puts forward "the illocutionary-act-potential (IAP) thesis", phrased in the following way: "A sentence's having a given meaning consists in its having a certain illocutionary act potential" (Alston 1994: 29) ${ }^{62}$.

Consequently, the illocutionary aspect of the speech act is foregrounded and endowed with special significance. It forms the lenses through which to perceive meaning. Alston emphasises that his proposal does not reject the received views on sentence meaning, thus, it may be concluded that he decides to match the concept of illocution, and especially illocutionary act potential, with aspects of meaning discussed with no intervention from speech act theory.

Alston's model, just like Searle's, is focused on sentences in the sense of "types" rather than "tokens", and on "language" rather than "speech" (or langue, not parole), which allows for a formulation of a generalised theory. This, however, also limits the research questions and results in a much generalised view, in which "private" or nonce, speaker's meaning is suppressed or at least backgrounded. It also marks a departure from the naturalistic botanizing approach applied by Austin.

Searle's account is followed with modification by Alston (2000), who replaces Austin's locutionary act with the "sentential act", which corresponds to Austin's phatic act. Additionally, Alston claims that "typical linguistic communication involves both illocutionary acts and perlocutionary intentions" (2000: 169) in which he largely rejects Austin's tri-partite architecture of the speech act, but saves the central position of illocution and the intuitive feeling that a description of a communicative act often naturally involves notions which pertain to the effects of such acts.

${ }^{62}$ Cf. Holdcroft (1978) for critical comments on Alston's approach. 
In this context it is noteworthy that Alston explicitly addresses the notion of illocution and the illocutionary act, remarking that the concept is often "seriously underexplained for a technical term" (Alston 1994: 31). The useful approximation offered is that illocution corresponds well to "our familiar indirect discourse form", in which the "content", or the "message" conveyed by a speaker, is reported and made explicit, as distinct from what sentence was uttered.

Alston suggests an interesting perspective on other speech-act-theoretic approaches. For instance, in retrospect, he dubs Locke's, Stevenson's and Grice's work "perlocutionary-act-potential theories" because they all concentrate on hearer meaning and how meaning is communicated so that it could reach the hearer and produce impact on the hearer's psyche. The examples of how these theories work are (adapted from Alston 1994: 340):

a) $\mathrm{U}$ got $\mathrm{A}$ (addressee) to believe (know) that it was raining outside.

b) U got A to give him a ride home.

c) U frightened A.

d) U led A to be more favourably disposed toward the candidate.

e) U irritated A.

As can be seen, the "meaning" of utterances reported on is profiled towards the effect that they have on the speaker, which makes them "perlocutionary". Although producing an effect, or a desire to produce an effect, is a natural feature of communication, Alston argues that perlocutionary-act-potential theories are mistaken because any illocutionary effect must arise from the illocutionary act. Alston's model is thus linear. Perlocution can exist thanks to illocution, which precedes it in time. In his words, "a sentence has a distinctive perlocutionary act only by virtue of having a distinctive perlocutionary act potential" (Alston 1994: 35).

Alston illustrates this point with an utterance of the sentence "The guests have all left". It is argued that the meaning of the utterance is communicated in such a way that hearers, whether actual or potential, knowing both the rules of the language and conventions for using additional contextual information, will naturally take the speaker to be "asserting of some contextually determined guests that they have left the scene of the utterance at the time of the utterance" (Alston 1994: 35). Additionally, unless there are context-bound reasons for the hearer to doubt what he or she can hear, the hearer will normally believe the utterance, by which the utterance will have carried out its perlocutionary intention. Alston's emphasis is on the point that the achievement of perlocutionary aims is dependent on the utterance's illocutionary potential, which can be related to reason. Unless it is assumed that interlocutors use some private code, the number of (conventional) meanings which an utterance of a sentence can carry is limited. For instance, it is not at all likely that the utterance 
"The guests have all left" should ever carry meanings such as "Please, move over" or vice versa.

To discharge accusations that the illocutionary act potential is just sentence meaning, Alston puts forward a theory of illocutionary acts which should account for their nature as distinct from (just) sentence meaning. It is acknowledged that normally one sentence may be used to perform a number of distinct speech acts and that one type of speech act can normally be performed with the use of a number of distinct sentences. There is an apparent clash between accounts which concentrate on types and those focused on tokens. In Alston's approach this difficulty of reconciling the abstract and the particular is resolved through the introduction of a match not between sentences and illocutionary acts, but between sentences and their "matching" illocutionary act potential, i.e. the potential of the sentence to be used to perform a particular "matching" illocutionary act type or types. To avoid a "perlocutionary" account of a speaker's intention as a basis of explanation for speech acts, Alston puts forward a different notion, a notion of "Speaker's taking responsibility" in performing a speech act. Instead of claiming that the speaker's plan in, for example, performing an assertion is making his audience believe what is asserted (which may often not be the case), Alston suggests the speaker just "takes responsibility" for his assertion and creates a new normative situation.

Alston's is an attempt to provide a speech act theoretic account of meaning and communication which is consistent, systematic, and does not disintegrate when too much context is allowed in. It is a theory of sentences and their standard usability, being at the same time an interesting proposal of a combination of the code-oriented perspective with the intention-based element as inspired by Austin and Grice. Nonetheless, the model does not offer novel insights into the mechanisms behind illocutionary acts.

\subsection{2.c. Speech acts composition and 'what is said'}

The division into locution, illocution and perlocution can be relativised to the Gricean (1975) concepts of "what is said" and "what is meant" or "what is implicated". Although Grice can hardly be regarded as a speech act theorist, his ideas have had a significant impact on the development of speech act theory, especially on the speech act-theoretic account of indirect utterances. Allowing some simplification, locution is often directly associated with "what is said", i.e. the semantic content of the utterance which may travel across different contexts of use. In turn, functions of language may be approached as "what is meant". However, Grice's notions are underdetermined in a way similar to Austin's tripartite division.

Grice's concept of "what is said" is most probably the closest equivalent for Austin's locutionary act that one could find. In linguistics and philosophy of 
language "what is said" is directly associated with the semantic notions of referring and predicating. For instance, Korta and Perry (2011: 114-5) root the conception in Kaplan's earlier distinction between the character and content of a sentence, stressing that in this approach "what is said" must be seen as a semantic notion. In numerous publications, Bach (e.g. 2001, 2005) defends "a purely semantic notion of what is said" (2001: 15) against various objections.

The correlation may be reinforced by the fact that "what is said" forms basis for inference with regard to "what is implicated". In the ideal picture then, the semantic "what is said" allows for a further (linear) interpretation of what the speaker meant in performing the utterance. What the speaker means is in most cases not simply derived from what is said, but is inferred on the basis of the very fact that something is said and also from the way in which it is said. In this sense, "what is said", being the most accessible sign which undergoes interpretation, is similar to the locutionary act, which also corresponds to the words spoken "with a certain sense and with a certain reference" (Austin 1962/1975: 94).

However, Austin's notion of the locutionary act seems to be more advanced in certain aspects. First of all, Austin emphasises the fact that a speech act happens with the simultaneous performance of its three components (or aspects), viz. the locutionary, the illocutionary, and the perlocutionary act (even though the perlocutionary act seems to extend beyond the time and place of the utterance). Thus, Austin provides a picture in which he is able to extract the phonetic, the referential and the propositional from the speech act and keep it under one label, but he does not claim any linearity in moving from the locutionary "upwards". Making sense of the speech act involves first of all both the locutionary and the illocutionary aspects which are both presented as simultaneous and conventional. Grice, in turn, suggests that meaning beyond (literal) words arises above the "what is said" element.

Bach (2001) suggests that Grice's use of the verb "say", where "what is said" always involves "meaning something", may induce confusion and that

Grice should have invoked Austin's distinction between locutionary and illocutionary acts. Austin, it may be recalled, defined the locutionary act (specifically the "rhetic" act) as using certain "vocables with a certain more-or-less definite sense and reference" (1962: 95). That sounds a lot like Grice's notion of saying, except that for Grice saying something entails meaning it: the verb 'say', as Grice uses it, does not mark a level distinct from that marked by such illocutionary verbs as 'state' and 'tell', but rather functions as a generic illocutionary verb that describes any constative act whose content is made explicit.

(Bach 2001: 41, fn.2) 
This opinion implicitly praises Austin's adoption of a new metalanguage, which he explicitly devised to avoid possible misunderstandings and misinterpretation.

Grice himself scarcely explicitly refers to speech acts, although, while commenting on the distinction between "what is said" and "what is conventionally meant" in the context of a speech act (Grice 1989: 121ff), he gives interesting comments which can be related to the concept of locution. In this discussion Grice seems to use the concept of "what is said" in an opposite to his later theory way, i.e., at least at that stage, "what is said" may be equated with "real" meaning, i.e. either literal (intended) message or implicature, while the concept of "what is conventionally meant" seems to correspond here to the literal, semantic, dictionary sense of a given expression (which further illustrates the metalinguistic difficulty involved).

Grice also recognises that producing an utterance people may simultaneously perform more than one act, for instance, uttering (14):

$$
\begin{aligned}
& \text { My brother-in-law lives on a peak in Darien; his great aunt, on the } \\
& \text { other hand, was a nurse in World War I. } \\
& \text { (Grice 1989: 361) }
\end{aligned}
$$

the speaker may perform "a ground-floor statements" about the brother-in-law and the aunt, but these statements may be accompanied by a higher-order speech act of commenting on the lower one (here: expressing criticism) ${ }^{63}$.

In a closer perspective, the Gricean distinction between "what is said" and "what is meant" does not correspond to the Austinian notions of locution and illocution (possibly enriched with perlocution) as neatly as it might appear. For Grice, the meaning of an utterance, i.e. what is implicated and meant, arises not so much from the form, i.e. "what is said" (which seems to correspond to Austin's locutionary acts performed "in saying"), but is brought about "by the saying of what is said" and "putting it that way" (cf. Grice 1989: 39), which is not directly associated with Austin's locution alone ${ }^{64}$. In the example (14), directly related to what Grice recognized as conventional or "formal" implicature, the speaker engages in (at least) two speech acts at a time, which are interconnected in that one "comments" on the other. The "ground-floor" act is an explicit assertion, and, as a result, can be truth-evaluable, but the other higherorder speech act more heavily relies on context, in that the speaker can hardly be held responsible for its meaning; at this level, the criticism (or contrast) expressed is not a "forensic" issue and can be denied.

A survey of processes involved at the level of "what is said" or "locution" serves to show that making sense of utterances always involves pragmatic

\footnotetext{
${ }^{63} \mathrm{Cf}$. also a post-Gricean relevance theory-based discussion of multiple speech acts and multiple logical forms in Carston (2002: 125-134)

${ }^{64} \mathrm{Cf}$. also Kissine (2009) for an inferential account of speech acts and the discussion of levels of meaning and the notion of illocution vis-à-vis "what is said".
} 
inference. Even apparently explicit utterances, such as Austin's examples quoted earlier and the following,

\section{I name this ship the Queen Elisabeth}

require pragmatic processing. For example, an interpretation of (15) and the expressions "Shoot her" and "You can't do that", quoted in (13), not only require processes of assigning reference to deictic expressions, but also create a need for disambiguation of seemingly explicit forms as it is evident that forms such as (16), which appears explicit, may receive conflicting interpretations in different contexts.

\section{Coffee would keep me awake}

Whether (16) is to be taken as a "yes" or "no" in response to an offer of a cup of coffee does not depend on the "semantic" meaning of its component parts or even whether it can be understood as a sentence, but has roots in an extralinguistic context of the utterance, which will determine "what is said". Other much quoted examples which show context sensitivity of meaning and the non-independence of truth-theoretic semantics include:

(17) It is raining

(18) He is too old.

Even within maximally (minimalist) semantic approaches, the assignment of the truth value to the sentences above requires not only assigning a reference, but also using extralinguistic knowledge (e.g. information on the place of reference for (17), and a type of activity for (18)).

Literature from the areas of pragmatics, semantics, and philosophy of language provides many examples and ample evidence for the fact that "semantic" content always underdetermines speaker meaning (cf. e.g. Bach 2001, Carston 2002, 2008). A variety of labels is used to refer to the phenomenon in its many aspects and the way in which meaning of an utterance is saturated, e.g. "semantic enrichment", particularised and generalised implicature, "non-literal" readings, e.g. related to humour, irony and sarcasm, "polite" indirectness, "default" meaning, etc.; it is evident then that theorising on the divide between "what is said" and "what is meant" informs theorising on the nature of the speech acts. However, it is also clear that "what is said" is not a perfect equivalent for the locutionary act. As noted above, Austin's distinction is often seen as more practical. For instance, Bach suggests that the Austinian distinction between "locutionary" and "illocutionary", i.e. between saying something and doing something, is nowadays commonly neglected most probably due to the fact that the verb "say" is often used interchangeably with "state" or "assert". 
However, stating and asserting, taken metalinguistically, constitute illocutionary acts which go beyond mere "locutionary" saying. Following this line of thinking, Bach (2005) argues that both "the locutionary notion of saying" and the "strictly semantic notion of what is said" are needed in order to account for four different situations, the cases in which the speaker:

- says something but does not mean (=does not mean to communicate) anything at all (e.g. as in acting, translating);

- does not say what he intends to say (e.g. misuse of words, a slip of the tongue);

- means what he says and something else as well (e.g. indirect speech acts, implicature);

- (intentionally) says one thing and means something else instead (nonliteral utterances, e.g. irony, sarcasm) (cf. Bach 2005: 25).

In Bach's model, subsequently, there is not just a correspondence between the locutionary act and what is said, but, when "what is said" (by the speaker and according to the speaker, rather than "what is said" taken from the hearer's perspective) is secured as a semantic notion, the locutionary act is needed in order to be able to explain cases such as those listed above. Even though utterance meaning is always underdetermined, in Bach's (e.g. 1994a, 1994b, 1997) view, pragmatics influences not what is said, but the speaker's choices in saying something and the hearer's identification of the speaker's meaning on the basis of what is said.

\subsection{2.d. Korta and Perry's 'what is locuted' and 'what is said'}

With a focus on referring and in an attempt to refine Austin's tri-partite internal division of the speech act, as well as to solve problems invited by the concept, Korta and Perry $(2007,2011)$ suggest that locution should be approached as a practical notion, which, however, needs further amendment and subcategorisation into "what is locuted" and "what is said". In the most straightforward form, the locutionary act is seen as a combination of referring to a person or a thing and predicating something about that person or thing. It has an epistemic-pragmatic role which the speaker desires to exploit. In this account, locution corresponds to dictionary, semantic, explicit meaning, while the notion of "what is said" (as in the initial Gricean model mentioned above) is associated with, roughly, hearer meaning. "What is said" is used here in a manner in which it is applied in reported speech in the form "She said that ...", where the thatclause carries interpretation of the original utterance. This reflects the fact that "saying" is naturally associated with the illocutionary act, i.e. the function performed in producing an utterance. In this sense the notion of "saying" appears to be similar to that of assertion, with possibly weaker connotations (Korta and Perry 2011: 115), although in speech acts things can often be locuted 
(mentioned), but not asserted in the technical sense, as in, for instance, antecedents and consequents of conditionals.

Korta and Perry argue that locution can be, and in fact often is, identified with "what is said" or the propositional content in the sense Searle (e.g. 1969) uses the notion, but only in cases of successful communication. The cases of non-successful (or "less successful") communication in which the difference between "what is locuted" and "what is said" is visible, include e.g. undetected (but speaker intended) irony, instances of embedded propositions, and an unexpected interpretation on the part of the audience with a subsequent clash between speaker meaning and hearer meaning.

Furthermore, Korta and Perry's "what is said" has some flexibility in that what the hearer takes as having been said can be sensitive to what the speaker is trying to convey, or to what the hearer thinks the speaker is trying to convey. This feature is not characteristic of the locutionary act in its original formulation, but Korta and Perry bridge the gap with Austin. Their central point of interest is "reference" and "referring" and Austin's original definition of the locutionary act includes the notions of "sense" and "reference" (Austin 1962/1975: 94-95).

Interestingly, Austin (96-97) also reports cases when (potentially) "the sense or reference is not being taken as clear" (Austin 1962/1975: 97), which may result in the information given in quotation marks, e.g. "He said I was to go to the "minister', but he did not say which minister" or "I said that he was behaving badly and he replied that 'the higher you get the fewer"' (97). However, all cases discussed by Austin are cases of vagueness or ambiguity and not of there being an evident clash between speaker and hearer meaning.

Korta and Perry's model recognises that utterances may have double lives. They are "defined" by the speaker as there are normally intentions, the speaker's plan, behind every linguistic performance, but they also receive a definition from the hearer, the audience whose participants will construct their own interpretations of what they can hear (or read) and sometimes such an interpretation (or re-interpretation) can hardly be denied by the speaker ${ }^{65}$, whether just in between the speaker and the hearer or in front of a wider audience. The hearer's meaning may often embrace unintended, but foreseeable consequences of some carelessness on the part of the speaker.

Korta and Perry's "what is said" is in fact close to illocution as it partly accounts for the function of the utterance. Furthermore, it is closely related to assertion. It is labelled as "a forensic concept" because speakers can be taken responsible for "what was said" (rather than intended); there is a forensic element, Korta and Perry say, "that affects the way we use the concepts of "what

\footnotetext{
${ }^{65}$ This point finds a reflection in the legal sphere. For instance judgements of hate speech, slander, verbal abuse, or even blasphemy are based on conventional interpretations of utterances and speakers will often be held responsible for their utterances whose conventional force is taken for granted irrespective of those speakers' most inner intentions (cf. chapter five and, e.g., WitczakPlisiecka 2013 and the references within).
} 
is said' and 'what is referred to' [...] - forensic in the sense of having to do with adjudication of responsibility and blame for the result of the act" (Korta and Perry 2011: 49). "What is said" can thus transcend, or escape, (intended) "referential" meaning. For example,

Aristotle enjoyed philosophy.

can be "locuted" about Aristotle, the Greek philosopher, while "said" of (i.e. interpreted as referring to) some other "Aristotle", for instance Aristotle Onassis in certain contexts (cf. Korta and Perry 2007: 176 ff). In a similar manner in (the somewhat outdated example (20),

(20) If Hillary is elected, Bill will enjoy his return to the White House.

neither of the propositions 'Hillary being elected' and 'Bill enjoying his return to the White House' is "said" or "asserted"; they are merely "locuted", one may say "mentioned". In (21),

John is turning red.

the speaker's intended meaing may be "literal", i.e. the speaker wants to suggest that John's face is turning red in colour, but the audience's interpretation may also be that John is becoming a communist, for which judgement the speaker may be believed "responsible".

In all the examples cited there is a clash between "what is locuted" and "what is said" in the sense of communicated content, and sometimes "what is locuted", i.e. the supposedly stable element of speaker meaning, may be understood in a way that the speaker neither envisages, nor intends due to flexibility involved in the concept of "saying" 66 .

With the aid of Perry's (2001) reflexive-referential theory (RRT), Korta and Perry (2007) defend the notion of the "locutionary act" with the provision that it should be broken down into more fine-grained concepts. The definition of the locutionary act is as follows:

The locutionary act involves referring to an object (or objects) and predicating something of it (or them). (Korta and Perry 2011: 50)

\footnotetext{
${ }^{66}$ A related perspective on meaning, although without the locutionary/illocutionary focus, is voiced by Cappelen and Lepore (2005) in their Insensitive Semantics and when, among the corollaries of their "positive views on semantics", in the précis of the book (Cappelen \& Lepore 2006: 427) they mention the "Denial of First Person Authority over what's said", pointing to the fact that speakers simply do not have access to all that they say with a single utterance and that they do not need to know much (or anything) about the contexts in which their utterances are interpreted, while such contexts function as determinants of what they say.
} 
Locution is to be sub-categorised into the "intended" reflexive locutionary content (not dependent on the listener) and the actual locutionary content, the latter corresponding to its reception in a particular context of use.

A side effect of the model is attention drawn to a kind of "uptake", a notion considered by Austin and corresponding to a recognition (here: whether "correct" or "false") of the speaker's communicative intention on the part of the audience ${ }^{67}$, which, however, was originally introduced as a proof for an illocutionary act. As Korta and Perry (2007: 175) claim about natural communication:

our ordinary concept of what is said is to some extent responsive to uptake on the part of the audience [...] What is said seems to have both illocutionary and perlocutionary aspects

In confrontation, the speaker may hold that he "said" something he intended, but was misinterpreted, while the hearer may believe that the speaker "said" what she takes the speaker to have said. Meaning is debatable and negotiable.

It is evident that Korta and Perry's concept of "what is said" is by no means only "semantic". Due to its "forensic" dimension, it involves perlocutionary effects, i.e. "results" of the speech act in which it belongs; it refers directly to pragmatic aspects of highly contextualised meaning. In the model, locution is a kind of (possibly semantic) template for meaning construction in context. In this way, "what is said" involves context-based inferences, and processes often dubbed in linguistics as "semantic enrichment", implicature, default meaning, etc., i.e. notions notoriously troublesome for the distinction between "what is said" and "what is meant". A direct consequence of allowing these processes into the concept of locution is that the concept cannot be identified as purely semantic. In this model, the semantics/pragmatics divide, if such a divide is to be envisaged, is more likely to be hidden deeper within locution, unlike Austin's model in which it can most readily be placed between locution and illocution. Here it might be placed not even between "what is locuted" and "what is said", but rather in between the intended reflexive locutionary content (possibly inside the speaker's mind) and the actual locutionary content, which seems to be open to largely unrestricted enrichments and unpredictable interpretations and belongs with the audience.

\footnotetext{
${ }^{67}$ The problem of uptake and its status in the theory of speech acts is also relevant for defining the scope of pragmatics and the semantics-pragmatics distinction. In the (more) convention-based theories, an uptake is usually seen as a necessary element for there being an illocutionary act at all. In theories focused on intention, uptake, if important, can be found in considerations on the "intended" nature of the act, i.e. what the speaker intends to perform or her envisaged effects on the hearer and the world (cf. also Sbisà 2009).
} 
Locutionary acts and locutionary contents are thus different species. For instance, an act of referring is presented as a conscious execution of a speaker's plan in which she competently produces (English) sentences and refers to certain items in the world. In referring to an individual, a speaker's performance involves:

(1) producing singular terms in English, by speaking, writing, typing, signing, or other means;

(2) doing so with appropriate intentions that resolve:

(a) which words, of those consistent with the sounds uttered (or letters typed ...), are being used

(b) which meanings of those permitted by the conventions of English for the words and phrases being used are being employed

(c) nambiguities ${ }^{68}$; that is, issues about reference of names which various persons, things, or places share

(d) the primary reference of demonstratives and other deictic words and issues relevant to the reference of indexicals

(e) anaphoric relations.

In addition, the speaker will have:

(3) (possibly quite minimal) beliefs about the facts that resolve the semantic values of indexicals, and which objects play the various roles exploited by demonstratives, which objects are the origins of exploited networks, and which objects fit the description used;

(4) The intention of producing an utterance that will have certain referential truth-conditions, in accord with these beliefs, in virtue of having utterance-bound truth-conditions;

(5) (possibly quite minimal) further intentions to accomplish other results by producing his utterance: conveying inmplicatures, performing illocutionary and perlocutionary acts, and the like;

(6) (possibly quite minimal) intentions to accomplish other results by doing all of this; getting salt for the steak; influencing votes; starting a war; etc.

(Korta and Perry 2011: 116-117)

As can be seen from this list, the locutionary content is determined by the speaker's intentions and the facts important for reference assignment. The utterance-bound contents of the locutionary act has to correspond to the internal contribution. There may be a difference between the intended locutionary contents and the actual locutionary content because the former is defined by the

\footnotetext{
68 "Nambiguity" refers to instances of ambiguity with regard to names whose form can be shared by a large population, even though they are usually used to refer to just one person or thing, (cf. Korta and Perry 2011: 74-75)
} 
referential content relative to the beliefs mentioned in (3) above, while the latter will be defined in relation to the facts of the world.

In an example which Korta and Perry adapt from Kaplan (Korta and Perry 2011: 47-49), a professor predicates "The greatest philosopher of the twentieth century" carelessly pointing to the wall on which there are two portraits, one of Carnap and the other of Dick Cheney, the politician. The professor intends to refer to Carnap, but due to ineptness of his gesture, some alumni take him to refer to Cheney. In this context, Korta and Perry (2011: 49) suggest,

If saying is all about communication, it seems that one says what one conveys to semantically competent and attentive listeners who pay attention to the meanings of one's words and gestures.

A similar point may be illustrated with cases involving irony (e.g. uttering "He is a fine friend" with the intention to mean the opposite). Where the speaker means her utterance to convey irony, even in cases when irony is not detected by the hearer, it would be improper to claim that the speaker should be responsible for "saying" what the incompetent audience is taking her to have said. In such cases, it may be concluded that the speaker "locuted", but not "said" what the utterance literally meant.

Consequently, in theory it has to be maintained that meaning is identified primarily with speaker meaning, while the "forensic" "what is said" which departs from meaning intended by the speaker has to be handled with reference to perlocutionary effects. Misinterpretation on the part of the audience resulting from the speaker's inept performance is produced by the speaker, but not envisaged by her and is not represented in the speaker's intentions. The issue of responsibility with regard to the "untoward consequences" is seen in terms of responsibility for unintended (but sometimes foreseeable) action.

It is noteworthy that the notion of "what is said" is sometimes used in linguistics with the meaning which Korta and Perry give to "what is locuted", i.e. as corresponding to "general", "literal" meaning, which is believed to universally hold (as much as such "universal" meaning is possible at all). In this other perspective Korta and Perry's concept of "what is locuted" could be rendered as "what is communicated", implied, etc. ${ }^{69}$

Further contrasts related to "what is locuted" and "what is said" include, for instance, the distinction between "what is said" and "what is asserted", which concentrates on the potential or actual difference between literal meaning of the

\footnotetext{
${ }^{69}$ Similar examples of non-literal meaning with elements of conscious deception (silent disclaimers) on the part of the speaker are discussed with reference to "what is said" (equivalent to "locuted" as used in Korta and Perry) and "what is communicated" (equivalent to Korta and Perry's "what is said") in Horn 2006.
} 
expression uttered (here: "what is said") and the assertion (a kind of truthful commitment) which is associated with it ${ }^{70}$.

Although typically speech act accounts make use of the label "Assertion", "Assertoric", or "Assertive", , as a cover term for a (more descriptive) speech act type, the category of assertion is also of a special kind in that it permeates all discourse and in that sense can often be presented as at least an aspect of other, i.e. classified in groups parallel to Assertions, (illocutionary) acts ${ }^{72}$, in many cases in a manner similar to that of the concept of "what is locuted".

The proposal to amend the concept of the locutionary act is illuminating in that it calls attention to aspects of communication which are often neglected. It is also a proposal whose aim is to introduce more order into theoretical accounts of utterances. By inviting the hearer's perspective and pointing to contexts in which there may arise a gap between the speaker's and the hearer's meaning, it calls for more precision and exposes areas in the traditional speech act account which are in need of refinement.

\subsection{2.e. Illocution and perlocution in feminist theory, gender studies, and free and hate speech studies}

The need to refine the concepts of illocution and perlocution, with less stress on locution, is seen in the field of gender studies, feminist theory and hate speech. In these research areas, which develop within a broad philosophical background, the speech and conduct dichotomy is specially emphasised. For instance, in the United States of America, the Free Speech Clause issues have been directly associated with speech act theory, both in a positive and in a negative (e.g. Haiman 1993) sense. In numerous legal cases the task has been to decide whether speech should be interpreter as conduct or whether conduct, in its force, should be regarded as equivalent to speech. In other words, the decision involved distinguishing between representation and (performative) action. In cases related to hate speech, representation of personal feelings and convictions, a free expression of a viewpoint within "the marketplace of ideas" is protected by the law, however, speech recognised as an injurious aggressive act, i.e. "fighting words" is illegal and prosecuted. The body of legal decisions shows that seemingly equivalent instances, for instance, of burning of the cross may receive different interpretations and be recognized as protected speech or

\footnotetext{
${ }^{70}$ In this context see Searle $(1969 ; 141$ f.) for a discussion of the assertion fallacy, which exposes (and criticises) the widespread view that the content of an assertion can be derived from the semantic value of the words which compose the utterance in question.

${ }^{71}$ Cf. e.g. Stalnaker 1978, Searle's (1979a) collection.

${ }^{72} \mathrm{Cf}$. discussion in chapter three on speech act classifications.
} 
harmful conduct, depending on the circumstances ${ }^{73}$. In selected cases there have been explicit references to speech act theory and the performative dimension of language, whose significance, as well as the very existence, have been taken for granted.

A performative perspective on language has further acquired a strong link with Critical Legal Studies (CLS), Critical Race Theory (CRT) and feminist theory, all of which have experienced a strong impact from the notion of deconstruction and Jacques Derrida's ideas of critical dismantling. In all these fields, state power, and in particular law and legal reasoning are perceived in terms of active force fields in the construction of the social sphere. In these active fields, it is understood, people are able to construct, maintain, and then justify lasting social relations, including illegitimate relations of inequality legitimised by a coercive state. In the Western Anglo-American tradition, radical feminist voices have argued that the language of the law continuously "enacts" patriarchal values and male domination in the present world. Many theoreticians and activists directly refer to Austin's speech act theory, or to Searle, while discussing issues such as pornography as a from of "enactment", being at once a concrete practice and an ideological statement" (MacKinnon 1991: 802, cf. also MacKinnon 1989), a construction of gender identity through linguistic performance, or the power and mechanisms of hate speech (Butler 1990, 1993, 1995, 1997).

Speech act theory, and the architecture of a speech act is sometimes amended with new concepts being added, or through a modification of its original model. For example, Butler recognises that speech has a rhetorical and political potential to harm individuals and explores notions of interpolation. Building on Derrida, and focusing on the injurious effects of hate speech, pornography, as well as self-identification of gays in the U.S. Army, she proposes a novel theory which asserts the potentially active role of the addressee in reshaping the (unjust) social sphere.

In the context of locution, illocution and perlocution it is interesting that while for MacKinnon pornography and hate speech are forms of social action and primarily involve perlocutionary effects, Butler emphasises that hate speech and pornography can in fact be "illocutionary". Under such interpretation, hate speech is a speech act; it has its illocutionary force, being an act of injury, and consequent perlocutionary effects. Unique in Butler's approach is the emphasised possibility of "reversal", an idea that every instance of hate speech creates an opportunity to reverse its harmful meaning by citing "into reverse meaning". This potential 'reversibility', the changeable power of language, is called "discursive performativity" and conceived of not as a series of speech acts,

\footnotetext{
${ }^{73}$ The gravity of the issue can be seen in that even at the level of the Supreme Court, judgments on such cases have sometimes been as divergent as five to four (cf. Texas v. Johnson. 491 U.S. 397 (1989) where the burning of the flag was recognized as protected speech expressing protest towards American policy; cf. also R.A.V. v. Cu'v of St. Paul. 112 S. Ct. 2538 (1992) and fn. 58).
} 
but instead "a ritual chain of resignifications whose origin and end remain unfixed and unfixable" (Butler 1997: 14). Consequently, a speech act being referred to is not "a momentary happening, but a certain nexus of temporal horizons, the condensation of an iterability that exceeds the moment it occasions" (Butler 1997: 14).

Critical Race Theory and feminist theory use speech act-theoretic ideas in a way which foregrounds perlocutionary effects, i.e. effects which are not, at least not typically, conventional in the Austinian sense. The relation between the action, especially the verbal action in question, and its effects is not conventional on the lexical level; its force resides in a broader context of the utterance, in less readily traceable threads between social contexts, situated perceptions, power relations, and associations which the utterance can evoke. Acts discussed in these terms seem to be closer to the pragmatic concept of pragmemes (cf. Mey 2001; cf. also chapter five), i.e. highly situated speech acts, which are defined by the social environment and show deep context sensitivity.

The way in which the concepts of illocution and perlocution are used in the field of critical race theory, feminist theory and free speech or hate speech shows that the notions are underdetermined and easily yield to different interpretatons; it also shows that the notions are found methodologically attractive. Researchers such as Butler, Langton (1993), and MacKinnon directly refer to Austin as their source of theoretical inspiration. Significantly, they rely on Austin's theory rather than on Searle's, finding it more adequate for their purposes.

\subsection{Acts, deeds, uptake, and tests for performativity}

There have been many attempts to grasp the intuitive notion of performativity in a systematic way and to account for it. Among Austin's relevant notions there are, for instance, the concept of uptake, the concept of the canonical form, and a number of markers which are presented as potential vehicles for the actional value of utterances. Although theoretical descriptions of these notions are endowed with much intuitive certainty, their accounts lack theoretical precision as most of the theorising turns in their conclusions to speakers' feelings and intuitions rather than systematic grammatical or lexical information.

It lies at the core of speech act theory that language can be perceived as a type of action although understanding linguistic action and its relation to action in general remains a contentious issue. There are disputes among cognitive scientists whether processing of linguistic action differs from processing of nonlinguistic action with, for instance, an indication that non-linguistic action is understood thanks to its consequences, while it is exactly the very understanding of linguistic action which is able to produce its effects.

A distinction can be marked between the notion of an act and that of an action, where an act is a token, a specific occurrence, and an action refers to the 
type of acts. Actions are also understood as executions (movements) and accomplishments (results).

\subsubsection{Problems with uptake and the distinction between illocutionary and perlocutionary effects}

One of the received candidates for making an act "valid" is what Austin calls "uptake". Indeed, in many later approaches (e.g. Strawson 1964, Searle 1969), uptake is seen as a necessary and sometimes sufficient condition for an act to take place. Uptake is defined as the hearer's understanding of the utterance in the sense of understanding both its semantic "meaning" and force. For instance, Searle (1969: 47) talks about "the hearer understanding the utterance of the speaker" and identifies it as the "illocutionary effect", while Bach and Harnish $(1979,1992)$ speak of the hearer identifying the speaker's attitude expressed in the utterance, and Hornsby (2006: 901) suggests that the response in the sense of the audience's recognition of the very intention that generates that response is what Austin must have had in mind'.

In lecture IX, while referring to the concept, Austin says:

Unless a certain effect is achieved, the illocutionary act will not have been happily, successfully performed. This is to be distinguished from saying that the illocutionary act is the achieving of a certain effect. I cannot be said to have warned an audience unless it hears what I say and takes what $I$ say in a certain sense. An effect must be achieved on the audience if the illocutionary act is to be carried out. How should we best put it here? And how can we limit it ? Generally the effect amounts to bringing about the understanding of the meaning and of the force of the locution. So the performance of an illocutionary act involves the securing of uptake.

(Austin 1962/1975: 116-117; emphasis in bold added)

He also says:

The illocutionary act 'takes effect' in certain ways, as distinguished from producing consequences in the sense of bringing about states of affairs in the 'normal' way, i.e. changes in the natural course of events.

(Austin 1962/1975: 116)

Uptake has also been defined as an "understanding" of illocutionary force, in other words, of "working out" the speaker's intention behind the utterance. This meaning is present in Strawson (1964), Searle (1969), and forms a basis of more inferential approaches, such as that of Bach and Harnish (1979); it has also 
found its way to pragmatics reference books (e.g. Huang 2009) as part of the definition of an illocutionary act. In the received view of today's speech act theory, uptake is associated with "reading" the complexities of the speaker's intentions usually understood in terms of Gricean theory and speaker meaning. As Strawson suggests:

[...] to secure uptake is to secure understanding of (meaning and) illocutionary force; and securing understanding of illocutionary force is said by Austin to be an essential element in bringing off the illocutionary act.

(Strawson 1964: 448)

In his earlier version of speech act theory, Searle (1969) also discusses "illocutionary effects" in explicitly Gricean terms ${ }^{74}$ :

Human communication has some extraordinary properties, not shared by most other kinds of human behaviour. One of the most extraordinary is this: If I am trying to tell someone something, then (assuming certain conditions are satisfied) as soon as he recognizes that I am trying to tell him something and exactly what it is I am trying to tell him, I have succeeded in telling it to him. [...] In the case of illocutionary acts we succeed in doing what we are trying to do by getting our audience to recognise what we are trying to do. But the effect on the hearer is not a belief or response, it consists simply in the hearer understanding the utterance of the speaker. It is this effect that I have been calling the illocutionary effect. The way the reflexive intention works then, as a preliminary formulation, is: the speaker $S$ intends to produce an illocutionary effect $I E$ in the hearer $H$ by means of getting $H$ to recognize $S$ 's intention to produce $I E$. (Searle 1969: 47)

Thus, following Searle's understanding fo uptake, we may define two different types of infelicity, one related to the "illocutionary effect", and the other related to the "perlocutionary effect". For all acts, "understanding" of the illocutionary force on the part of the hearer, i.e. uptake, will count as a success of the act on the illocutionary level. In turn, successful accomplishment of the purported act, e.g. compliance beyond mere "understanding" in the case of a directive, will count as felicity with regard to the perlocutionary effect.

The "uptake-as-understanding" view has been challenged by Marina Sbisà (2007, 2009), who argues for a more sophisticated deeper reading of Austin's words. Sbisà suggests that Strawson's and Searle's reformulation of Austinian ideas resulted in the later "impoverishment of the heuristic potential of the notion of illocutionary act in the analysis of verbal interaction" (2009: 37).

\footnotetext{
${ }^{74}$ Simultaneously Searle also voices his doubts over Grice's particular ideas.
} 
According to Sbisà, well before Searle, Strawson communicated a few assumptions in his 1964 seminal article, which defined later development of speech act theory, a development in which some of Austin's original ideas got distorted. She argues that uptake is a special quality in that it goes beyond "understanding". Indeed, as can be read in the citation above, Austin claims that " $[t]$ he illocutionary act 'takes effect' in certain ways, as distinguished from producing consequences in the sense of bringing about states of affairs in the "normal' way, i.e. changes in the natural course of events" (Austin 1962/1975: 117). If Sbisà's approach is to be followed, we should look for special "nonnormal" (not regular and common) ways in which the act changes reality, ways distinct from perlocutionary effects. Illocutionary uptake-related ways in which an act "takes effect" may be seen as changes in the normative situation of the speaker and the audience, in the social world in which the act is situated. Taking Austin's rather vague example, following the ceremony of the naming of a ship, some patterns of behaviour will be irrelevant and inappropriate, while "a new reality" has been established. Because Austin emphasises the fact that illocutionary acts (along with locutionary acts) are conventional, Sbisà links the ways in which acts "take effect" with conventions (conventional effects motivated by a conventional procedure) and claims that uptake is related to the "conventional character ${ }^{75}$ of the core effect of illocutionary acts" (Sbisà 2007: 464). Consequently, while for many speech act theorists (e.g. Strawson 1964, Searle 1969) uptake (taken as understanding of the speaker's intention in locuting something) is received as evidence of the intention-based nature of illocutionary acts, Sbisà $(2007,2009)$ uses the concept to remind us of their conventional character and argues that uptake is necessary and stems from the fact that illocutionary acts rely on conventional effects. This view, she argues, follows from what Austin said about their nature (cf. the citation above).

The discussion of uptake pertains to problems of intention vis-à-vis convention as operative forces in the production of illocutionary acts, which are discussed in more detail in chapter four. The concept of uptake is further pertinent to how illocutionary effects are distinguished from perlocutionary effects and consequences, which should aid our understanding of how (speech) acts work. For instance, Strawson points out that the difference (or one of the differences) between showing off and warning is that "your recognition of my intention to put you on your guard may well contribute to putting you on your guard, whereas your recognition of my intention to impress you is not likely to contribute to my impressing you (or not in the way I intended)" (Strawson 1964: 453), which illustrates the problem with selected acts, usually sociallystigmatised acts, such as boasting, insinuating, etc., which can never be found, or successfully performed, in an explicit form.

\footnotetext{
${ }^{75}$ For a discussion of the concept of convention in Austin's theory and also Sbisà's position on this, see chapter four.
} 
There is also a clear difficulty in judging speakers' intentions in producing particular utterances. As Strawson (1964: 452-453) indicated, in saying to an audience what he or she says, the speaker may intend to produce "the primary response $r$ by means of audience recognition of the intention to produce that response" (452), but simultaneously may also produce (and intend to produce) "further effects by means of the production of the primary response $r$ " (452). It seems that in such a situation, the "further effects" element should also be included in the illocution space and not seen as perlocutionary. This problem that can be identified as a problem of the scope of speech acts has been neither thoroughly discussed nor solved in an adequate way until now, although there is a vast body of related literature which includes, inter alia, discussions of the problems of linguistic manipulation and persuasive discourse. The issue is also at least partially reflected in alternative approaches to linguistic action, such as those discussed in chapter five.

In the traditional (Austinian) view, it is just said that illocutionary acts "take effect" in a conventional way. Austin points to the fact that in most contexts, uttering words secures uptake and, thanks to relevant conventions, makes the locutionary and illocutionary acts possible. In Austin's words (Austin 1962/1975: 121): "a judge should be able to decide what, by hearing what was said, what locutionary and illocutionary acts were performed, but not what perlocutionary acts were achieved". However, in many contexts it is felt that there is more to the meaning of the words uttered than just locution and illocution and that in general participants in a discourse situation have insight into not only what was achieved in a a posteriori perspective, but also into what effect was intended, often beyond the illocutionary point. An utterance may "split" into a number of functions, some of them intended, some (possibly) unintended, and others consciously kept secret. Are all such acts to be considered illocutionary or perlocutionary? Is an act which is intended, but covert, an illocutionary or perlocutionary act? And is uptake an issue in this perspective? In addition, at least some perlocutionary aspects of speech acts are brought about "by" certain utterances, but they can be accounted for in terms of corresponding conventions. Politeness theory provides ample data on socially unpopular acts, which may be intended by the speaker, but never appear in explicit form, and are rarely overt. Other acts, such as surprising someone, or deceiving someone, need to be covert to succeed at all. The status of such acts, and the corresponding notion of uptake in the context of their performance, remain contentious issues in speech act theory. 


\subsubsection{Exclusion of 'non-serious' and 'parasitic' uses}

It is worth noting that Austin excludes from his analysis all so-called "parasitic" uses of language or "etiolations", i.e. utterances used in 'non-ordinary' circumstances, e.g. while acting, reciting a text, "spoken in soliloquy" (Austin 1962/1975: 22), in what could possibly be seen as non-primary context. As Austin decides, "[o]ur performative utterances, felicitous or not, are to be understood as issued in ordinary circumstances" (Austin 1962/1975: 22).

Austin's exclusion of the "parasitic" uses of language is interesting vis-à-vis further definitions of the performative as opposed to the non-performative use of language, especially the influential model given by Bach and Harnish (1979). While Austin excludes "etiolations" as non genuinely communicative utterances, Bach and Harnish, applying seemingly related criteria, exclude all "institutional" acts, i.e. Austin's most prototypical examples, such as acts of christening, or numerous "legal" uses ${ }^{76}$, as non-communicative (or rather non-conversational) and "conventional" uses of language, whose success depends on the recognition of a relevant convention and not directly on inferring communicative intentions.

Austin's original position is itself debatable, and, for instance, Sbisà (2007), who read his lecture notes, argues that Austin's conception of etiolation is closer to "mitigation" than, e.g. "pretending", "doing as if", etc. In addition, it has been suggested that "appeal to what is 'serious' or 'normal' does not go beyond an appeal to intuition" (Davidson 1979 [2001b]: 111), i.e. that interlocutors possess only an approximate grasp of the very notion of serious (and non-serious) utterances ${ }^{77}$.

In a different perspective, the distinction between non-serious uses and serious uses may be problematic when related to iterativity of linguistic forms and a varied density of intertextual elements present in non-literary contexts where creativity can easily be blended with repetitiveness and import of indirect meaning.

The relation between indirect and direct acts can also be problematic in this light as many indirect utterances may be seen as "non-serious" in that they do not "mean" what they (really) "mean". This point can be taken further to include all elaborate speech events where the overarching goal is superordinate with regard to "local" uses. This can be exemplified by negotiations and mitigations (cf. e.g. Fraser 2001; Mey 2011, Bell 1997), which come on a scale from private and domestic to international and dyplomatic. In such settings, it seems a simplification to treat individual utterances as either "serious" or "non-serious" in the Austinian sense as they are instrumental in a different way. It seems that

\footnotetext{
${ }^{76}$ Bach and Harnish's conception of speech acts is discussed in more detail in further parts of this book.

${ }^{77}$ Here Davidson point that it is impossible to establish firm relations between moods and assertions. See also a critical response to Davidson's view on fictional discourse in Hare 1989.
} 
these kinds of difficulties led researchers such as Mey (e.g. 2001) to extend the received view of Austin's theory into a theory of pragmatic acts ${ }^{78}$.

With regard to philosophy and literary studies, Austin's exclusion of literary and other "non-serious" utterances from speech act theory provoked strong reactions, which include an elaborate set of comments from Derrida (1977/1982; 1988), later turned into a decade or more of discussion between Derrida and Searle. After Derrida, there have come many other voices to comment on the possibility and limitations of speech act theoretic analysis of literary work (e.g. Johnson's (1980) deconstruction-based comments on Mallarmé's poetry and performative language ${ }^{79}$; Felman 2003) ${ }^{80}$. In fact, even Searle (1975b), in an essay on the logical status of fictional discourse, claimed that analysis of literary texts which "contain largely pretended illocutionary acts" (Searle 1975: 332) may prove important for understanding human social communication and creativity, but also that serious, non-fictional speech acts may be conveyed by fictional texts, even though such acts are not explicated in the text. This route of thinking about speech acts have not been seriously pursued in theory, but can be found, inter alia, in the notion of the pragmatic act as discussed by Mey (2001, 2011), for instance with reference to diplomatic discourse.

\subsubsection{The canonical form}

Next to "seriousness", Austin considers other criteria important for a definition of the performative utterances and, later, in a more holistic approach, illocutionary force. One of the main initial assumptions is that there may exist criteria of grammar of vocabulary which should inform speech act theory.

The first candidate for such criteria was the potential possibility of expressing every single performative utterance in an explicit form. Although from the very beginging of the lectures, Austin points out that there is a great variety of forms in which performative utterances may appear, he also asserts that their characteristic feature should be their ability to be phrased in an explicit form, also known as a canonical form. As Austin suggests:

\footnotetext{
${ }^{78}$ Cf. chapter five.

${ }^{79}$ Inter alia, Johnson (1980: esp. 52ff) emphasises the correspondence between the use of performative verbs in Austin (1962) and the language of poetry, defending relevance of analysis on the one hand the language of poetry as "performative" and, on th eotehr hand, the performative nature of (reciting) poetry in general, endorsing the locutionary-illocutionary-perlocutiobnary perspective and the explicit/non-explicit dimension. She defends the view that any performative utterance fictionalises its utterer by redirecting attention to convention. Thus, both staged performance (in the sense of producing a performative utterance) and a serious verdict given by the judge are "fictional" and "serious", but a staged utterance loses its force in the world due to the recognised duality, i.e. that the utterer is not the "doer" of the action.

${ }^{80}$ The distinction between literary and non-literary language has itself often been questioned and presented as non-productive and unhelpful, cf. Tambling 1988.
} 
we should feel tempted to say [...] that any utterance which is in fact a performative should be reducible, or expandible, or analysable into a form with a verb in the first person singular present indicative active (grammatical).

(Austin 1962/1975: 61-2)

It follows that, for instance, "Out" is equivalent to "I declare, pronounce, give, or call you out" with the provision that it is used in a performative way and not, for example, when a person is "called out by someone not the umpire or recorded as 'out' by the scorer" (Austin 1962/1975: 62). In turn, "Guilty" is equivalent to "I find, pronounce, deem you to be guilty." In a much similar manner, "You are warned that the bull is dangerous" is equivalent to "I, John Jones, warn you that the bull is dangerous". An equivalent message may be conveyed when this "John Jones" writes "This bull is dangerous" on a piece of paper and adds his signature, e.g. "(Signed) John Jones".

In the tentatively "testing" explicit form, utterances are phrased in the first person, present tense, indicative active and the adverb "hereby" is either present or it may be inserted in the sentence; the utterance is characterised by a selfreflexive character as in this example:

(22) I hereby declare the meeting open.

Performative utterances are to be apparently and superficially assertive, instances of actions in disguise, "masqueraders" as Austin (1962/1975: 4) qualified them.

It is evident, however, that being "masqueraders" they "grammatically" pretend to be what they are not and, as such, are not readily recognisable as illocutionary because they "look" assertive. The grammatical form in which even the most explicit performatives are phrased does not guarantee their recognition as utterances possessing special quality; their illocutionary force is more elusive than expected. Simple descriptions, not being instances of action in a sense that is important for Austin, may share the lexico-grammatical form with illocutionary acts. Consider Searle's (2002a: 537) examples again:

a. I promise to come on Wednesday.

b. I promise too many things to too many people.

Only (23a) can instantiate a performative in the sense discussed here, while (23b) is only descriptive. The point can be even more dramatically illustrated with the following examples adapted from Seuren (1998: 442) which include the adverb hereby:

I hereby cut this knot. 
Example (25) may sound contentious, but example (24) does not seem unacceptable if, after Seuren (1998: 442), we imagine it is a sentence uttered by Alexander on raising his axe in order to cut the Gordian Knot. Thus, even successful insertion of the adverb "hereby" in a sentence in the canonical form does not guarantee that the sentence functions as a vehicle for performativity. In (24), hereby is not token-reflexive; it does not refer to the verbal action, but to the physical action of raising the axe.

Problems with accounting for token-reflexive utterances, which embrace explicit performatives, have further implications. For instance, Seuren (1998: 442) quotes an interesting fact that all classical model-theoretic semantics in the tradition of Russell and Tarski literally ban mixing object language and metalanguage and forbids token-reflexivity. It may implicitly suggest there being very little potential in finding a sound description of natural language where form interacts with social and cultural qualities.

Thus, there is no grammatical-linguistic guarantee to be able to identify performatives not only for utterances in primary form, but even in contexts when they are to be explicit. Their special quality is a function of the social rather than the linguistic sphere. Inability to find reliable grammatical markers for the performative dimension of language leads Austin to the following remarks:

This reduces us to an impasse over any single simple criterion of grammar or vocabulary.

(Austin 1962/1975: 59)

Now we failed to find a grammatical criterion for performatives, but we thought that perhaps we could insist that every performative could be in principle put into the form of an explicit performative, and then we could make a list of performative verbs. Since then we have found, however, that it is often not easy to be sure that, even when it is apparently in explicit form, an utterance is performative or that it is not; and typically anyway, we still have utterances beginning 'I state that. .' which seem to satisfy the requirements of being performative, yet which surely are the making of statements, and surely are essentially true or false.

(Austin 1962/1975: 91)

The problems do not disappear if research is narrowed to speech acts solely, i.e. Austin's later model in which all utterances are defined as performative with three internal aspects which are known as locution, illocution and perlocution. In this approach, sentence meaning may be (roughly) identified with what Austin defined as a phatic act (cf. section 2.6.); an utterance meaning may be seen as located in locution, while it is the illocution that corresponds to the functional, i.e. "performative", value. Naturally, identifying utterance meaning with either 
locution or illocution is problematic and a way into metalinguistic confusion. The problems reported in sections (2.6. and sub-sections within) related to Austin's tri-partite division of the speech act indicate relevant issues, which are also widely represented in the dispute between semantic minimalists (e.g. Cappelen \& Lepore 2005) and contextualists (e.g. Recanati 1987, 2004; relevance theorists, e.g. Carston 2002), the dispute focused on the role of context in knowledge, language processing and meaning. Both semantic minimalists and contextualists report "mereology" and "galaxies" of speech acts although they differ in their understanding of literal meaning (and, in fact, with regard to its very existence). Nonetheless, in relevant literature including the minimalist and contextualist debates, it has been sufficiently shown that it is not possible to secure an explicit account of speech acts or to find their most explicit (or primitive) form(s).

Another problem which remains unresolved is the distinction between performatives and speech acts. It may be assumed that performatives are prototypical speech acts, whose instances are classified as Exercitives in Austin's and as Declarations in Searle's (1979b [1975]) model. However, there is no explicit opinion on the relation that would come from Austin himself or any elaborate account produced by his followers.

The canonical form problem is related to the performative/constative distinction and the debate concerning the nature of explicit performatives, which has been discussed in an earlier part of the volume. It may be argued that the canonical form is not important for speech act account with its only merit, and uniqueness, being the encoded (in the performative verb) information about the act being performed (cf. discussion on the nature of explicit performatives in Searle (1989), Bach (1975), Bach and Harnish (1992) and Section 2.4.1.b..

\subsubsection{Ross's performative hypothesis}

Theorising on the performative dimension of language and explicit canonical utterances resulted in Ross's (1970) hypothesis, which claims that there is a deep underlying structure for every utterance which explicates its performative quality. In an independent way, it shares Katz's (1972: 155) opinion that illocutionary force is a concept that should belong in grammar and also answers Austin's need to find a grammatical criterion for the performative phenomenon.

Performative hypothesis formulated by Ross (1970) in his paper "On declarative sentences" advocated the view that all declarative sentences have a performative-type formula in their deep structure, i.e. the underlying structure, a kind of matrix filled with a performative verb which subsumes a surface varying form, e.g. an utterance of the form: 
has an underlying structure which can be represented as: I (hereby) promise you that I will come.

and the matrix for all utterances has the form:

$$
\text { I (hereby) } \varphi \text { you that } \mathrm{X}
$$

where $\varphi$ represents a performative verb and " $\mathrm{X}$ " is a complement clause.

In this model, Austin's performative verbs are given great theoretical significance and serve as basic categories of natural speech actions. There was a view that the hypothesis should also provide a theoretical account of indirect speech acts.

However, the performative hypothesis has been severely criticised along different lines (cf. Anderson 1971, Fraser 1974a) ${ }^{81}$. Among points of criticism, there is a problem of possible circularity as evidently any utterance may further be supplemented with an initial supposedly final "performative" introduction so the recursive prefixing could go ad infinitum (e.g. "I state that I state that I state that ..." $)^{82}$. Searle, in turn, suggested that the meaning of explicit performatives (the performative prefix) determines at least one possible illocutionary force of an utterance.

Additionally, a difficulty in analysing conversational discourse is amplified by the fact that not only different sentences, or stretches of sentences, may be used to perform the same function, but also one utterance may simultaneously perform more than one function, e.g. the functions may be merged in one as in Brown and Yule's (1983: 233) example:

Hey, Michelle, you've passed the exam.

Taken as an utterance that a husband addresses to his wife, it may be interpreted simultaneously as "asserting", "congratulating", or "apologising" (for the husband's doubts), etc.

\footnotetext{
${ }^{81}$ Cf. an early extensive critique of this view with contrastive examples in Anderson 1971, who disagrees with the hypothesis on the grounds that it can be both contradicted by numerous examples and more successfully "explained" in terms of semantic structure, instead of syntax.

${ }^{82}$ Cf. also the so-called 'Cohen's problem' (Cohen 1964, 1973) concerning truth-conditions of performative sentences and the status and nature of the (allegedly) performative prefix. Among other objections, Cohen suggests that there are acts which cannot be accounted for using Austin's model. For instance, if we consider a situation in which a shareholder utters "I protest" at a shareholders' meeting, it turns out that the speaker performs, but does not name the act being performed. In other words, the utterance cannot be successfully accounted for in terms of a locutionary act (including a rhetic act) and the illocutionary act as it has a force, but seems to lack Austin's "meaning" (it has reference but lacks sense) (cf. Cohen 1973: 129).
} 
Furthermore, there are performative utterances which are never openly phrased in an explicit form, especially acts which are inherently antisocial in nature, such as threats, insults, and lies. Whether such acts are recognized as illocutionary or perlocutionary, they pose problems for the performative hypothesis in its original form.

However, Ross's hypothesis, although methodologically untenable and rooted in transformational grammar, is an interesting implicit attempt to include the performative, i.e. a social dimension in a linguistic grammatical theory. In Austin's perspective, all utterances need to be seen as vehicles of social commitments and Ross's is one of the first attempts to embrace this quality in grammar.

It has to be accepted that Austin's account is a work-in-progress model; he promotes the view of language as a type of action, and even where he thinks considerations of certain issues may have been largely irrelevant (cf. the example of baptizing penguins at the end of lecture II), he wants to be (just in case) "ready, as jurists are" (Austin 1962/1975: 24), with the right terminology and taxonomy for any instance of linguistic action. However, the model has a rather tentative character, evidently even more so due to Austin's aversion to hasty commitments. The model remains enigmatic at parts with a firm indication that the author's ambition is to provide a thorough description of a unitary speech act, i.e. "the total speech act" (Austin 1962/1975: 52).

Austin's ambitions may appear too great and, consequently, he was largely unsuccessful in achieving his aims. There are many critical voices with regard to his ideas and treatment of "the total speech act" in its "total situation" (e.g. Harnish 2009a), but, at the same time, reading Austin's original work reveals not only that in today's thinking about speech act theory there are many points falsely attributed to him, but also that he was genuinely original in his pioneering ${ }^{83}$ approach to speech acts.

Eventually, it seems there is no definition as to how speech acts may be defined apart from the vague suggestions that illocutionary acts (together with their locutionary counterparts) must be conventional. By Austin's own admission, there is no grammatical form which could make an utterance undeniably performative in a special and not just trivial sense. In a trivial perspective, all speech acts are performative by definition, but their special illocutionary "meaning", the force which make them what they are in the context of being uttered successfully, has no unique form. The force may be rooted in varied elements of the context of use, as there are utterances which are good candidates for performatives, but for example, are phrased in the second or third person, or, e.g.:

You are hereby authorized to pay ....

\footnotetext{
${ }^{83}$ pioneering and original despite there having been parallel and prior models which shared some characteristics of speech act theory (cf. previous sections of this chapter)
} 
Passengers are warned to cross the track by the bridge only.

or in the "impersonal passive" (cf. Lecture five, pp. 57ff.):

Notice is hereby given that trespassers will be prosecuted.

Austin points to the fact that acts may derive their force from lexical items such as "guilty" or "offside". In addition, there are acts which are felt to be illocutionary, but never happen to be phrased in an explicit form, for instance,

$$
\text { I hereby fire you }
$$

is hardly acceptable as an utterance.

All through his lectures, Austin commented on the provisional nature of his theory (on his "floundering", cf. p. 61) and at the beginning of lecture two says:

We must learn to run before we can walk. If we never made mistakes how should we correct them?

(Austin 1962/1975: 12)

As Austin also admits at the end of the lectures:

In these lectures $[\ldots]$ I have been $[\ldots]$ producing a programme, that is, saying what ought to be done rather than doing something

(Austin 1962/1975: 164)

Eventually, the recognition of the performative dimension of language rests on the hearer's expertise in reading situated meanings of utterances, on their ability to recognise socially sanctioned meaning, often quite independent from dictionary, semantic meaning of the words spoken and the compositional sense of the sentence (or expression) uttered. In conclusion, Austin's exposition of the problems related to the canonical form of performative utterances or speech acts may be better seen not as a sound theoretical model, but as a discussion whose main merit lies in its provocative potential, in stirring theoretical thinking on speech actions, both more and less explicit.

\subsection{Searle's speech acts and the construction of social reality}

Searle is often seen as a person who systematised Austin's model, often indeed "the" person most immediately associated with speech act theory. While Austin is often presented as the "father" of speech act theory, Searle is suggested to be its "founder". It is of special significance, however, that in the theory which has been developed for over fifty years now, Searle has elevated speech acts to the 
position in which they form a precondition for all social and cultural phenomena through the emergence of normativity in language. Speech acts, especially declarative speech acts, according to Searle, make the social world as we know it. Over the years, in numerous publications, Searle exposed speech acts in various realms and with different "zooming", but the linking thread behind all his models is a theory of institutional facts as structured in terms of declaratives.

As early as in 1965 Searle claimed that a speech act, which he also calls an illocutionary act, is a minimal unit of linguistic communication, as evidenced in the quotation below:

It is not, as has generally been supposed, the symbol or word or sentence, or even the token of the symbol or word or sentence, which is the unit of linguistic communication, but rather it is the production of the token in the performance of the speech act that constitutes the basic unit of linguistic communication. To put this point more precisely, the production of the sentence token under certain conditions is the illocutionary act, and the illocutionary act is the minimal unit of linguistic communication.

(Searle 1965 [1996: 130])

He later devoloped the perspective to claim that:

Speaking a language is engaging in a (highly complex) rule-governed form of behaviour. To learn and master a language is (inter alia) to learn and to have mastered these rules. (Searle 1969: 12, cf. also 16ff)

To perform illocutionary acts is thus to "engage in a rule-governed form of behaviour", a form of behaviour in which language rules can be related to norms applied in playing chess or baseball, to norms which govern participation in coctail parties and, more contentiously, conventions which make marriage or religion possible. Searle's agenda from the 1960 s is the following:

The procedure which I shall follow is to state a set of necessary and sufficient conditions for the performance of particular kinds of speech acts and then extract from those conditions sets of semantic rules for the use of the linguistic devices which mark the utterances as speech acts of those kinds.

(Searle 1969: 22)

Thus, initially, Searle was mainly interested in the "linguistic devices", illocutionary force indicating devices (IFIDs), which mark and define speech acts as belonging to certain types. Among IFIDs, i.e. elements which function as vehicles of illocutionary force in English, there are items such as: word order, stress, intonation contour, puctuation, the mood of the verb, and performative verbs (cf. Searle 1965; Searle and Vanderveken 1985: 1). Commenting on IFIDs 
with regard to promising, Searle suggests that there is an important difference between forms such as "I promise to come" and "I promise that I will come", arguing that in the former sentence the IFID and the proposition are grouped, while in the latter they are clearly divided (Searle 1969: 30ff.).

Searle also acknowledges the fact that on some occassions non-linguistic context may provide enough information with regard to the nature of the speech act so that using a (grammar-oriented) function-indicating device is optional and not at all necessary. However, his concentration at this stage is on sentences which can be used in order to perform speech acts:

[F]or every possible speech act there is a possible sentence or set of sentences the literal utterance of which in a particular context would constitute a performance of that speech act.

(Searle 1969: 19)

Searle saw the study of speech acts and the study of sentences as complementary, in fact "one study from two different points of view" (Searle 1969: 18), arguing that the study of sentences and their meaning necessarily involves speech acts (as "every meaningful sentence in virtue of its meaning can be used to perform speech acts") and the study of speech acts involves the study of sentences as it is only through the uttering of sentences that speakers may perform speech acts.

While concentrating on individual sentences, Searle yet makes an important point (e.g. 1969: 16ff.), saying that speaking a language always presupposes an interlocutor, a role of the hearer, the addressee, which makes communication sensible and effective. Only little attention was devoted to the problem, but at least it was asserted.

In the early model of speech act theory, Searle (e.g. 1969, 1979a) modifies some of Austin's notions. As noted above, he rejects the notion of the locutionary act and proposes a new internal composition of the speech act explicated in terms of "utterance acts", "propositional acts", "illocutionary acts", and "perlocutionary acts" (Searle 1969: 24-26). Searle's early investigations are focused on illocutionary acts which are explicated in terms of a combination of propositional content and illocutionary force, which can be summarised in the formula $F(p)$, where $F$ indicates illocutionary force, and $p$ stands for propositional content.

One of Searle's innovations is his distinction between constitutive and regulative rules, which are operative for speech acts. Constitutive rules are essential for the act because they not only regulate the act in question, but also constitute it in the sense that the act has no independent existence (of such rules). Regulative rules, in turn, do not "create" acts, but regulate pre-existing acts. This can be illustrated with games, e.g. playing chess. The rules which specify acceptable moves in chess do not only regulate the conduct of the players, but "constitute" the game, which would not exist without them. Other rules, such as 
rules of etiquette, merely regulate social behaviour, but are not necessary for its existence. Constitutive rules are best expressed in the formula " $\mathrm{X}$ counts as $\mathrm{Y}$ in (context) C", for instance, making an $\mathrm{X}$ on a ballot paper counts as voting (Searle 1969: 24). Regulative rules have a macro formula of the form: "Do X", or alternatively, "If Y do X". The two types of rules have implications for the system of necessary and sufficient conditions, which secure the successfulness of the speech act. Constitutive rules define an act amd make it happen, thus, their violation makes the act void or not the case, while any violation of regulative rules can only affect performance by making it less successful.

Searle further modifies Austin's account of felicity conditions and suggests that for illocutionary acts to be successful they need to meet necessary and sufficient conditions relevant for particular acts. There are four main types of conditions for every speech act:

a) the propositional content condition

b) the preparatory condition

c) the sincerity condition

d) the essential condition.

As may be expected from the labels, the propositional content condition refers to what kind of content is allowed for a particular speech act type, the preparatory condition addresses the contextual elements of the world needed for the performance of the act, the sincerity condition refers to the speaker's intentional state and her attitudes, and, finally, the essential condition refers to the core of the act (what the act in question is all about).

There is a lot of correspondence between Searle's types of conditions and Austin's types of infelicity, for instance, preparatory conditions are equivalent to Austin's misinvocations and sincerity conditions to Austin's abuses. However, Searle's system seems more transparent and systematic. One of its main merits is that it can be used to systematically explain indirectness (Searle 1975a). A modified speech act taxonomy put forward by Searle has also gained popularity and has been used as a standard since its formulation in the 1970s. It comprises of five major categories and is characterised by a clarity of exposition and neatly defined twelve classificatory criteria with reference to the direction of fit between the world and words spoken. Searle's account of constitutive and regulative rules, as well as conditions for a successful performance of speech acts found the most elaborate illustration in his analysis of the act of promising (cf. Searle 1969: 63ff. and Section 3.7).

Searle's pivotal element in speech act theory seems to be intentionality. In comparison to Austin, Searle puts more emphasis on the fact that linguistic communication derives from people's intentions. He also emphasises the novelty of the speech act theoretic approach in treating proposition as an element in a speech act, not simply identified with the assertion-related aspect. For Searle, all speech acts are derivative of mental intentionality, which later translates into linguistic intentionality. They are all governed by rules imposed through 
instances of the speech act of Declaration and later become alienated within human institutions.

Searle's intentionality is philosophical and possesses the feature of "aboutness" or "directness" in the world. With reference to intentionality, Searle explains that all illocutonary acts are by definition "intentional", while perlocutionary acts can be both intentional or non-intentional because illocutionary acts are units of meaning in communication.

He also claims that it is speakers' linguistic competence that allows them to use linguistic elements in a way which is both "regular and systematic" (cf. Searle 1969: 13) and suggests a principle of expressibility, which says that whatever can be meant can be said (although not necessarily understood by others) (Searle 1969: 19ff). For Searle, speech acts are always rule-governed (conventional on the level of natural languages) and speech act types are language universals (conventional in a more abstract sense) ) $^{84}$, with the notion of convention strictly bound to realizations of rules.

A strand of Searle's work that seems particularly important is his joint research with Vanderveken explicitly aimed at elucidating speech act theoretic issues by answering the following questions, cited from the preface to Foundations of Illocutionary Logic:

\begin{abstract}
What is an illocutionary force? Can the set of all illocutionary forces be defined recursively from a few primitives, and if so, how? What are the conditions of success of elementary illocutionary acts which consist of an illocutionary force with a propositional content, such as statements, orders, promises, requests? How can the conditions of success of the complex illocutionary acts such as conditional speech acts and acts of illocutionary denegation be defined from the conditions of success of their constituent parts? What is the relation between illocutionary force and the meaning of sentences? What is the logical form of performative sentences?
\end{abstract}

(Searle and Vanderveken 1985: ix)

This joint research resulted in a proposal of illocutionary logic (Searle and Vanderveken 1985; Vanderveken 1990, 1991a, 1991b, 1994, 1995, 2002a), which was to provide a logical account of all basic speech act types and particular illocutionary verbs (cf. chapter three). Inter alia, the account includes considerations of two distinct types of negation relevant for speech acts, i.e. the above-mentioned "denegation" and negation of the propositonal content. Denegation is applied on a meta-level; for instance, it may communicate that the speaker is not promising or not making an assertion ("I do not promise that $p$ "), which "denegates" the potential illocutionary act of promising, while negating

\footnotetext{
${ }^{84} \mathrm{Cf}$. section on convention and intention in speech act theory in chapter 3 .
} 
the propositional content would result in a promise "not to $p$ " ("I promise that not $p ")$.

In more recent publications, Searle $(1995,2010)$ puts forward a holistic model in which speech acts form a basis for a construction of social reality in the broadest possible sense. Building on his earlier contributions in the philosophy of language, the philosophy of society, as well as the philosophy of mind (especially 1969, 1983, 1995, 2001, 2007), and modifying selected elements, Searle maintains his earlier claim that speech acts create all social institutions, from the institution of money and cocktail parties to marriage and religion, and concentrates on the nature of social reality, which he discovers to be speech-act theoretic and performative. The new research agenda is the following:

"What is the nature of social reality?" How can it be the case that there is an objective reality of money, property, marriage, government, cocktail parties, and football games in the world consisting entirely in physical particles in fields of force?

(Searle 2002b: 13, for a discussion cf. Searle 1995)

In general speech acts, and especially Declarations, are granted a very special power in the construction of the social world. Reporting on the three main claims of Making the Social World (2010), Searle says:

First, all of human institutional reality, and in that sense nearly all of human civilization, is created in its initial existence and maintained in its continued existence by a single, logico-linguistic operation. Second, we can state exactly what that operation is. It is a Status Function Declaration. [... T]hird, the enormous diversity and complexity of human civilization is explained by the fact that that operation is not restricted in subject matter and can be applied over and over in a recursive fashion, is often applied to the outcomes of earlier applications and with various and interlocking subject matters, to create all of complex structures of actual human societies.

(Searle 2010: xxxiv, cf. also $201 \&$ passim)

In other words, according to Searle, all people live in the world of brute and institutional facts. Using declarative speech acts, it is suggested, people can perform institutional acts, create (social) institutions (and institutional facts) by imposing on them status functions which then continue their existence independently of subsequent individual wants, intentions, and desires. Deontic powers, both "positive" and "negative" (e.g. obligations) create further desireindependent reasons for action-in that sense such deontic powers constitute a "glue" that holds human civilization together. In the model depicted in Making the Social World (2010), in an even broader picture that in earlier accounts, 
language is a powerful tool used not only to create institutional reality in the sense of universities, corporations and banks; it is used for the articulation of both legitimate and illegitimate power, a prerequisite for all culture and determinative of phenomena so distant as rational action in general, free will, human rights, entertainment and family.

In summary, Searle's most important modifications of Austin's speech act theory include his rejection of the concept of locution and the locution/illocution distinction, a greater focus on intentional states and the philosophical concept of intentionality in the sense of mental "directedness", a modified and more systematic taxonomy of illocutionary acts with twelve classificatory criteria, which differentiate between different speech acts and explain mechanisms of indirectness. Developed for over fifty years now, the theory has gathered a substantial body of literature and gained recognition as a stable working model. It is questionable, however, whether Searle's model is an advancement and an evolutionary descendant from Austin. Naturally, the theory is rooted in Austin's work, but Searle's research agenda is much different. With Searle, speech acts have been elevated to the level of a pre-condition of social reality and the social world, but this holistic picture is far removed from Austin's "botanising" methods and his plan to discover the various conventions behind linguistic practice. Language is granted the position of the most important social institution which makes all other institutions possible by first "representing" them as factual. Searle's discourse suggests that the words "create", and not just "confirm" institutional reality. Searle's proposals are thus best seen not just as a systematisation and development of Austin's speech act theory, but as an alternative way of approaching linguistic action.

\subsection{Speech act theory - whose discipline?}

Divergence (and convergence) of ideas expressed in Austin's and Searle's models of speech act theory, as well as the great variety of ways in which theorising on speech acts has been continued after Austin, may suggest that speech act theory can be better seen in terms of a general approach to speech actions and not a unitary theory proper. However, the popularity of Austin's proposals, together with the fact that his "theory" (despite being a "theory in the making") provided grounds for the development of pragmatics ${ }^{85}$, resulted in that "speech act theory" itself is taken for granted.

\footnotetext{
${ }^{85}$ It is only natural that speech act theory is seen as central in the field of pragmatics, which, following Morris (1938) can be best defined as the study of the contextual "relation of signs to their interpreters" (Morris 1938: 6), one of the three main dimensions of semiosis (or as the study is called today-semiotics), a general theory of signs, the other two being syntactics (p.7), understood as the study of the structural and formal relation of signs to one another in abstraction from the relation of signs to objects or their interpreters, and semantics, being the study of "the
} 
In a historical perspective, speech act theory reveals how diverse interests can be associated with speech act issues. It also reveals a variety of research areas in which such interests originated and in which the theory has been applied and elaborated.

Naturally, first theoretical reflections on speech acts can be found in philosophy, whether by a negative recognition and exclusion of non-assertives, such as that exercised by Aristotle, or through interest in ordinary language and its functions as, inter alia, exemplified by Kant. Philosophical roots of speech act theorising should not be surprising as linguistics did not emerge as a discipline until the nineteenth (or even the twentieth) century. However, even later the division of labour associated with speech act analysis and its application has invited diversity and an interdisciplinary approach.

Austin was a philosopher rather than a linguist, and Searle $(1969: 4,41)$ explicitly asserts that he does not consider himself to be a linguist even though his main interest is in the most prominent human institution, viz. language. Most contemporary researchers, from gender studies to critical race theory, e.g. Mae Langton (e.g. 1993; Hornsby and Langton 1998), Katherine MacKinnon (e.g. 1993), Judith Butler (e.g. 1990, 1993, 1995, 1997), Jennifer Hornsby (1993, $1995,2000,2006$ ), whose research is focused on performativity, are not directly associated with linguistics. Cognitive philosophers, such as Ruth Millikan, also focus on language in their search for data in a broad philosophical, social and anthropological orientation. Speech act theory is further richly represented in research pursued by lawyers, philosophers and semioticians of law (e.g. Hart 1961). In fact, speech act-theoretic research has found a number of applications in the legal practice, e.g. via the presence of linguists as expert witnesses or recognition of speech acts for practical purposes in courts of justice (cf. e.g. Shuy 1994, 2001). It may sometimes appear that there is more interest in speech acts outside linguistics proper than within the field.

Austin, in turn, saw a potential in careful analysis of particular utterances and minute differences present between closely related forms, which were to give insight into their semantic nature and, consequently, account for reality. As such, his research subscribes to "linguistic philosophy", which, in the Wittgensteinian manner, sees language as a trap, but also a tool for solving (or dissolving) philosophical problems (cf. Rorty 1967: 3). As Austin claims in "A plea for excuses":

First, words are our tools, and, as a minimum, we should use clean tools: we should know what we mean and what we do not, and we must forearm ourselves against the traps that language sets us. Secondly, words are not (except in their own little corner) facts or things: we need therefore to prise them off the world, to hold them

relations of signs to the objects to which the signs are applicable" (p.6), objects which they may, or do indeed, denote, i.e. designata. 
apart from and against it, so that we can realize their inadequacies and arbitrariness, and can re-look at the world without blinkers. Thirdly, and more hopefully, our common stock of words embodies all the distinctions men have found worth drawing, and the connexions they have found worth making, in the lifetimes of many generations: these surely are likely to be more sound, since they have stood up to the long test of the survival of the fittest, and more subtle, at least in all ordinary and reasonably practical matters, than any that you or I are likely to think up in our arm-chairs of an afternoon-the most favoured alternative method.

(Austin 1970: 181-2)

Further on in the lecture, there is an even more explicit though metaphorical vision of future dispersion and specialization of philosophical research; in the final section of "Ifs and cans", in a prophet-like style, Austin says:

In the history of human inquiry, philosophy has the place of the initial central sun, seminal and tumultuous: from time to time it throws off some portion of itself to take station as a science, a planet, cool and well regulated, progressing steadily towards a distant final state. This happened long ago at the birth of mathematics, and again at the birth of physics ... Is it not possible that the next century may see the birth, through the joint labours of philosophers, grammarians, and numerous other students of language, of a true and comprehensive science of language? Then we shall have rid ourselves of one more part of philosophy (there will still be plenty left) in the only way we ever can get rid of philosophy, by kicking it upstairs.

(Austin 1970: 232)

It is evident that speech act theory in its variety is indeed an interdisciplinary field and many distant research programmes may and do claim it as their own. Even within modern philosophy itself, its interdisciplinary character is shown in that it is recognised as relevant in fields defined as distinct ones, e.g. that of philosophy of language, philosophy of linguistics, and linguistics philosophy. In theory, philosophy of language is described as a "catch-all phrase" (Vendler 1967: 5), but also a label for "the midwife of the scientific study of language, and language use" (Soames 2010: 1). The "language use" mentioned here covers both private use in one's thoughts and public use for communication. Since the middle of the twentieth century, the field has grown and undergone differentiation whose different orientations are to be integrated by consistent theoretical commitments, whether these are applied in (pure) linguistics, or its adjacent fields of e.g. cognitive studies, language acquisition studies (e.g. Reeder 1980; Gass \& Neu 1995, Holtgraves 2007), psychology, sociology, literary 
theory, clinical pragmatics (e.g. Kissine et al. 2012, Meilijson \& Kasher $2004^{86}$, Prutting \& Kirchner $1987^{87}$ ), artificial intelligence (e.g. Allen \& Perrault 1980) ${ }^{88}$, economy, performance studies and art (e.g. Bauman 1977, Finnegan 1992), biblical studies (e.g. Briggs 2004), or just ritual contexts, such as cross-cultural musical healing customs (e.g. Laderman \& Roseman 1996). Philosophy of linguistics, sometimes classified as "a division of science" (cf. Davies 2006: 23 and Davies 2003: 90), should in turn illuminate the historical development of the former, and finally, linguistic philosophy, which seems to agree with the Wittgensteinian tradition, is an attempt at finding solutions to philosophical problems through analysis of the language in which they are expressed, the language whose use at the same time maintains these problems and leaves researchers "entangled" in a vain search for reliable metalanguage.

While the philosophy of language is "concerned with the underlying nature of the phenomena that linguists study" Mackenzie (1977: ix), linguistics proper is seen as the empirical study of natural language and "linguistic philosophy is an approach to the philosophy of language" (Mackenzie 1977: ix). It is also often taken for granted that the philosophy of language is a subject, while linguistic philosophy is a method.

In Searle's view (1969: 3-4), linguistic philosophy is "the attempt to solve particular philosophical problems by attending to the ordinary use of particular words or other elements in a particular language" (3). In turn, the philosophy of language is "the attempt to give philosophically illuminating descriptions of certain general features of language such as reference, truth, meaning, and necessity" (4) and does not concentrate on particular individual languages. In other words, "linguistic philosophy" is "a name of the method" (Searle 1969:4) and "the philosophy of language" is "the name of the subject".

Considering a proper domain for the location of speech act theory, there is some tension even within linguistic studies, a tension usually related to the division of labour between semantics and pragmatics (cf. e.g. Witczak-Plisiecka 2009a and references within) (with the provision that in a way it provided the basis for the development of pragmatics). A view has been proposed that speech act theory had been indeed "relegated" (Seuren 1998: 441ff.) for some time from semantics to pragmatics because semantics was not able to cope with the

\footnotetext{
${ }^{86}$ For example, Melijson and Kasher (2004) use the category of "Speech Acts", along with four other categories: "Topic", "Turn-Taking", "Verbal", and "Nonverbal" as five main parameter clusters for assessing linguistic performance in chronic schizophrenia and contrast such patients' pragmatic abilities with those present in other disorders, e.g. mixed-depression disorder or hemispheric brain damage.

${ }^{87}$ Prutting and Kirchner (1987) analyse language impairments in the framework close to conversational analysis (CA) focusing on complex sets of speech acts, such as: 1) directive/compliance, 2) query/response, 3) request/response, and 4) comment/acknowledgement. ${ }^{88}$ See e.g. Ramsay (2000) for a sceptical opinion with regard to using speech act theory in studies related to artificial intelligence (AI) due to inability to match speech acts and surface forms of utterances.
} 
problem of how to accommodate speech act theory within a model-theoretic logical framework. However, it was taken back as eventually analysis of sentences devoid of a speech act-theoretic approach seemed to impoverish relevant studies, especially when semantics includes discourse (cf. Seuren's (1985) conception of “discourse semantics") Thus, although Austin's theory acts against the Aristotelian logical bivalence and introduces a new perspective in the environment of the twentieth-century model of semantic studies, it can hardly be deemed as "non-semantic".

Discussions of speech acts have also been related to the so-called "exporting" and "importing" models of language (cf. Thibault and van Leeuwen 1996), the former ones are said to "export" speech acts out of grammar and semantics, while the latter show tendency to "import" what commonly is recognised as pragmatic into grammar and, consequently, invite discussions of speech acts in terms of lexico-grammatical criteria, which may lead to the "renewing" the connections between "grammar, society and speech act"

Criticism of speech act theory can be found in different areas where the existence of the theory is asserted, but its relevance questioned. For instance, relevance theorists criticise its explanatory power (Sperber \& Wilson 1986/1995: 243-254), even though they often use speech act-theoretic notions in an assertive way ${ }^{90}$, and Brown and Yule (1983: 233) claim that "[a]s it is presently formulated, Speech Act theory does not offer the discourse analyst a way of determining how a particular set of linguistic elements, uttered in a particular conversational context, comes to receive a particular interpreted meaning".

It is also noteworthy in this context that Searle (1969) explicitly states that the theory of speech acts is a theory of linguistic competence and not performance, i.e. in deSaussurean terms; for Searle, it is langue that is the object of research of the theory of speech act, not parole. Searle's claim shows his belief that the theory of speech acts is "possible" as a (most probably) universal theory of linguistic action; it also shows that pragmatics, insofar as Searle can be seen as a pragmatician, can be "formal"

\footnotetext{
${ }^{89} \mathrm{Cf}$. the title: "Grammar, society, and the speech act: Renewing the connection" (Thibault and Leeuwen's 1996: 561).

${ }^{90}$ Cf. e.g. Sperber and Wilson's statement with regard underdeterminacy of linguistic expressions: "There may be implicatures to identify, illocutionary indeterminacies to resolve, metaphors and ironies to interpret" (Sperber \& Wilson 2012: 261; emphasis added) or their comments on "illocutionary adverbials" (e.g. Wilson \& Sperber 2012b:163).

${ }^{91}$ This point should not, however, be seen as contentious, cf. e.g. definition of pragmatics given in Kadmon (mentioned above) in her book entitled Formal Pragmatics: "roughly, semantics only covers 'literal meaning'. Pragmatics has to do with language use, and with 'going beyond the literal meaning'. There is a separate distinction between 'what's in the grammar' (linguistic knowledge) and 'what's outside grammar' (principles that may affect language use, but are not specific to language). [...] Note that there is no a priori reason to assume that semantics is in the grammar while pragmatics is not. [...] Let us assume that the grammar contains a semantic component and a pragmatic component. In addition to these, there are certainly factors outside the
} 
A different aspect of the influence of the Austinian thought can be seen in the domestication of his categories in linguistics not only "locally", but also in a wider perspective. For example, Douglas Robinson (2003), in an all-embracing approach, suggests that "performative linguistics" should give rise to research which perceives language in terms of speech acts and performance as opposed to constative linguistics, which "freezes" language and presents its less natural, static image. In this way, Robinson, who concentrates on actual speech and translation, suggests that "performative" means being of the actional (active) nature, being aware of context-dependence and the dynamicity inherent in language. In an almost opposite perspective, McHoul (1997: 1), considering different grounds for pragmatics, cites "speechactism" as one of the sources.

Robinson's assertion of the holistic picture of "performative" linguistics is also mirrored in art studies. While discussing art through the lenses of John L. Austin's, Martland (1970: 169-170) refers to the practice as "an activity which makes a difference in the way things are" and further claims that such an (artistic) activity is "an 'indulging' activity which does, which coalesces with its own fulfillment. It is an activity which brings about redirections and rearrangements of the world which we experience." The understanding of performativity in this bird-eye perspective on creative research practice is convergent with the use of Austinian concepts as practicedin gender studies, feminist theory, critical race theory, etc. (cf. section 2.6.2e).

Having reviewed various approaches to the problem, the dispute with regard to the theoretical and methodological location of speech act theory does not seem sound, especially in the context of inevitable and constant entanglement of linguistics and philosophy as there are a sufficient number of philosophical issues in linguistics and linguistic issues in philosophy (cf. e.g. Higginbotham 2002). The claims coming from various, more or less, specialised fields, testify that speech act theory may find various applications and can provide varied methodological tools which, in turn, can be used in analyses distant in space and theoretical commitments. It may be best seen as an integrative factor which not only promotes diversity, but also brings distinct research programs together.

\subsection{Summary and preliminary conclusions}

Introducing the distinction between the constative and the performative allowed Austin to ground his criticism with regard to the "descriptive fallacy", a verificationist simplified picture, which was prevalent at the time in analytic philosophy of language and which positioned language as truth-relative and primarily descriptive in nature. Austin further managed to promote the more

grammar that affect meaning - probably both factors that affect semantics and factors that affect pragmatics" (Kadmon 2001:3-4). 
adequate picture according to which many, or even a majority, of natural utterances are not good candidates for verification in terms of truth and falsity. In particular Austin emphasised that many (in fact most of) natural language utterances are "factually defective" (i.e. non-descriptive). Pursuing this idea, he proposed a theory "in the making", which was never completed, but seminal in the linguistic programme over the following years, where his suggestions have been subject to constant (re)interpretation. By attracting attention to performative utterances, Austin not only paved the path for a systematic analysis of non-descriptions, but also gave numerous suggestions as to how such analysis could be carried out. It is also noteworthy that his "revolutionary turn" was basically methodology-driven.

Another aspect promoted by Austin's research was that his investigation into felicity conditions emphasised links which language naturally has with the social sciences. It also foregrounded different aspects in which form and function interact. Methodologically, despite all underdetermination involved, speech act theory provided a firm basis for theoretical emancipation of a new research field of pragmatics.

Most of Austin's metalinguistic proposals have remained to function as constant sources of theoretical debates in pragmatics and philosophy of language. The most contentious issues in Austin's model of speech act theory, which are often misunderstood and subject to criticism include the above-mentioned constative/performative distinction together with the idea that the lectures published as How to Do Things with Words had been prepared in (a largely unsuccessful) pursuit of the performative ${ }^{92}$, the significance and understanding of convention (and intention) in linguistic performance, as well as the nature and significance of uptake, the status of his classification of speech acts or verbs. It is clear from the above list that these contentious issues are core issues for speech act theory and its implications for a general, possibly universal theory of language.

Considering how many of Austin's original proposals and tenets of speech act theory have been challenged or rejected, the theory itself may appear nonexistent. However, although identified problems have rarely been clarified, the Austinian model in its vague form continues to function at different levels of linguistics analysis.

There have been many responses to Austin's ideas related to the performative dimension of language. Whether critical (e.g. Quine 1965/1969; Derrida $1977 / 1982$ ) or favourable, they serve to show that the model may be contentious,

\footnotetext{
${ }^{92}$ Cf. four "bones" of contention suggested in Sbisá (2007): 1) the idea that How to Do Things with Words was written "in pursuit of" performatives; 2) the characterization of illocutionary acts as producing the uptake of the meaning and force of the utterance; 3) the characterization of perlocutionary as dependent on extra-linguistic goals, i.e. performing a perlocutionary act amounts to using language to produce consequences; 4) the alleged undue exclusion of "non-normal" cases (non-serious speech acts).
} 
but it remains thought-provoking and touches an intuitively salient aspect of language which escapes immediate clarification and description. In the subsequent sections, selected aspects of Austin's theory and its developments are discussed with the aim to indicate their stability over the years and their potential for future research. 


\section{ChAPTER THREe}

\section{SPEECH ACTS, SPEECH ACT VERBS AND Metalinguistic Classifications}

"There is nothing more basic to thought and language
than our sense of similarity; our sorting of things into
kinds"
Quine (1969b: 116)

\subsection{Introduction}

Speech act theory rests on the assumption that speech acts are identifiable units in linguistic communication. As has been mentioned in the previous chapter, in many models, including Austin's original account (1962/1975), but also explicitly in, for instance, Searle and Vanderveken's model (Searle and Vanderveken 1985; Vanderveken 1990, 1991a/b, 1994, 2002a), speech acts are granted the status of fundamental and minimal functional units of language. In addition, in an ideal picture, an utterance should be matched with just one function $^{93}$. It follows that a thorough taxonomy of such acts could represent the (possibly universal) world of speech actions. It is not surprising then that, whether in a more universal or a more "local" perspective, over time, the speech act-theoretic studies have motivated many different classifications of speech acts, conceived of as functional units. Such classifications are related to the notion of the performative verb as introduced by Austin, a notion that by Austin's own admission is very difficult to maintain and to account for. Frequently, the notions of a performative verb, a speech act verb, or an illocutionary verb, have been identified with metalinguistic labels used in taxonomies of speech actions,

\footnotetext{
${ }^{93}$ See Cappelen and Lepore (2005) for criticism of what they dub "Speech Act Monism".
} 
or even speech events ${ }^{94}$. As a result, there is an array of taxonomies with abstract speech act metalinguistic labels, and many classifications which list performative verbs which could function both as names for types and tokens.

The discussion in the present chapter aims to review the most influential taxonomies produced in the field, together with the most frequent criteria used for classifying verbs or acts, in order to illustrate selected problems which such taxonomies expose and with which the theory has had to struggle.

\subsection{Speech acts and speech act verbs - between the emic and etic approaches to classificatory criteria}

One of the contentious issues that arose from Austin's model of speech act theory is the distinction between classifications of speech acts and speech act verbs. In particular, the original model is often criticised for being advertised as a classification of speech acts, whereas in fact what it offers is a rather imperfect classification of speech act verbs.

It is naturally taken for granted that all languages have verbs which can relate to speech acts, whether these are to be understood narrowly, as explicit performatives (i.e. performative verbs), or wider, as any identifiable type of speech action or linguistic behaviour. Such verbs, especially those falling within the former approach (cf. also section 2.7.3), are often referred to as "speech act verbs" or "performative verbs" as most of them can be used in literally and explicitly used utterances where they simultaneously name and "perform" the act in question, as in (34):

I hereby undertake to paint the room blue.

In the example above, the commissive act of undertaking is being made explicit by the verb. To reiterate, typical explicit performative utterances, according to Austin, should have the following characteristics: the performative verb used in them should be in the first person, indicative, non-progressive aspect, active and present tense; i.e. they should embody Austin's "canonical form" (cf. Austin 1962/1975: 61-2).

It may thus be tempting to identify speech acts with performative verbs, conceived of in this restricted way, in the manner where every explicit speech act should be indicative of a separate category. In fact, in Austin's initial lectures, a similar suggestion is voiced. For example, Austin claims that "the whole apparatus of 'explicit performatives' $[\ldots]$ serves to obviate disagreements as to

\footnotetext{
${ }^{94}$ There is terminological confusion related to acts, actions, and events which are defined in different ways by researchers. For instance, Wierzbicka (1996: 50) contrasts actions with events suggesting that "actions" are about "doing things", while events are more like narrative accounts of what happens, i.e. less focused on agency.
} 
the description of illocutionary acts" (1962/1975: 116, fn I), suggesting that speech acts may be explicated when the performative equivalent for the action is given. Austin indicates that explicit speech acts have their counterparts in "primary" acts, i.e. acts which do not include explicit performative verbs, verbs which would correspond to the illocutionary force of these acts. Thus, (34) may find its counterpart in (35):

I'll paint the room blue.

which, interpreted as a commitment, should produce the same effects as (34). Austin also indicates that primary acts are etymologically prior to explicit ones, which, in a more holistic approach, may suggest that in his opinion speech acts evolve along with social life and mark salient social functions, and that at some time in their evolution they reach the point of explicitness.

However, the proposal to identify acts with verbs cannot be maintained universally for all communication as, on reflection, it is evident that there are acts which are never explicit in this way. There are many socially unpopular acts, such as threatening, boasting, or offending, performing which, the actor is not supposed to literally communicate what he or she is doing because this could result in a social stigma or could invalidate the act. This fact has been well documented over the years in, e.g. research on politeness ${ }^{95}$. It has also been claimed that performative verbs cannot be used performatively in compliments (cf. Ross 1970: 252) for reasons related to politeness and (at least apparent) modesty. Most of utterances produced in the fields mentioned above would lose their illocutionary force and even their performative potential with any attempt to reformulate them as explicit acts with overt intent. For example, one may successfully threaten the audience by saying:

$$
\text { I will find you and you'll regret it. }
$$

but is not likely to produce a similar effect by uttering:

(37) I hereby threaten you that I will find you and you'll regret it.

or (with less certainty):

I hereby threaten you that I will take legal action against you.

\footnotetext{
${ }^{95}$ Cf. also Verschueren (1977: 8-10) on speech action verbs which are never used in explicit performative utterances with the adverb "hereby" or in related performative structures such as: "You are hereby threatened/boasted...", "I'd like to threaten/boast...", or "Let me threaten/boast...", etc. It is yet indicated that such "descriptive" verbs can be used, for instance, in "response-controlling but-prefaces" (8), e.g. "I do not want to boast/threaten you, but....".
} 
To provide an illustrative example, using (39) or would entirely ruin the purported act of lying:

$$
\text { I hereby lie to you that I will do what I promised }{ }^{96} \text {. }
$$

Indeed, in many such 'anti-social' utterances explicitness would appear comic or ridiculous. There is some variety among 'never-explicit' acts and among the verbs which serve as labels for them. Thus, some verbs are good candidates for labels of speech actions and are commonly included in the group of "linguistic action verbs", but cannot be successfully used as performative verbs in explicit speech acts, e.g. threaten, frighten, boast. Selected others, for instance promise, undertake, order, can do both: can be successfully used in explicit performative utterances and can successfully function as metalinguistic labels.

Another problem is posed by the fact that some verbs even when used explicitly seem to 'waver' (cf. Austin 1962/1975: 147-163; Seuren 2009: 137) between the performative and the descriptive. Their reading is inherently vague and the difficulty in defining their function goes beyond the performative/descriptive use as discussed in Austin's early lectures, cf. the examples below:
a. I blame him for having ruined my chances.
b. I admit that what I said was tactless.
c. I argue that corruption must not be tolerated.
d. I predict that there will be snow tomorrow.

Such and related difficulties led to labelling the verbs which can clearly be used in explicit speech acts as "performative verbs", while the other group is usually referred to as "speech act verbs", although the latter term can be ambiguous in between the two meanings. In order to guard against such ambiguity, a superficially contradictory notion of "non-performative speech act verbs" was also proposed (cf. e.g. Verschueren 1977). Other labels used as equivalent for "speech act verbs" include "illocutionary verbs", "linguistic action verbs", "verbs of saying", "verba dicendi", with a slightly more restricted group of "verbs of reporting", and "verbs of communication". The group most general in scope includes verbs such as mutter (descriptive of manner) or broadcast (descriptive of the medium involved), which, in the narrower

\footnotetext{
${ }^{96}$ It may be claimed, for instance in a relevance-theoretic perspective, that lying cannot be a speech act at all as the fact that the speaker is lying is neither explicitly, nor implicitly communicated. However, even if (39) is rejected, the point can be made clear with related unsuccessful utterances, such as "I hereby say sarcastically that you are a genious", where explicating sarcasm (which is necessarily communicatively implicit) will also ruin the act.-I owe this suggestion to Agnieszka Piskorska.
} 
approach, would have to stay outside the group of more saliently actional "performative verbs" (e.g. promise, deny, order).

In summary, most frequently, the category of "speech act verbs" includes both "performative verbs" (which can be used in canonical performative utterances) and "non-performative speech act verbs" ("just" speech act verbs), as represented in the diagram below.

\begin{tabular}{|c|c|}
\hline \multicolumn{2}{|c|}{ Speech act verbs (SAVs) } \\
\hline performative verbs & non-performative verbs \\
\hline
\end{tabular}

Table 4: Speech act verbs - basic division

In order to further subcategorise speech act verbs with regard to their internal properties, other categories have been suggested. For instance, speech act verbs may be defined as content-descriptive, neutral, and phonically descriptive with a further sub-categorisation of the content-descriptive group into locutionary content-descriptive verbs, illocutionary content-descriptive verbs, and perlocutionary content-descriptive verbs (e.g. Huang 2012) (cf. Table 5 below).

\begin{tabular}{|c|c|c|c|}
\hline \multicolumn{3}{|c|}{ Speech act verbs (SAVs) } \\
\hline $\begin{array}{c}\text { Content-descriptive SAVs } \\
\text { content- } \\
\text { descriptive } \\
\text { SAVs }\end{array}$ & $\begin{array}{c}\text { Illocutionary } \\
\text { content- } \\
\text { descriptive SAVs }\end{array}$ & $\begin{array}{c}\text { Perlocutionary } \\
\text { content-descriptive } \\
\text { SAVs }\end{array}$ & $\begin{array}{c}\text { Phonically } \\
\text { descriptive } \\
\text { SAVs }\end{array}$ \\
\hline
\end{tabular}

Table 5: Speech act verbs - selected categories used in taxonomies

As can be seen, Austinian notions and his metalinguistic categories have been adopted and adapted in varied and sometimes divergent ways, which prompted later miscellaneous approaches.

In a more discourse-focused research, Schiffrin (1980: 202ff.) points out that languages have in their vocabularies meta-linguistic verbs, i.e. "verbs for things in the language, including things people do with language", where the world of verbal communication is understood in terms of categories (which, in turn, is one of the indicators of metalanguage). In her words:

One group of meta-linguistic verbs names acts of speech: verbs of saying, such as say, tell, ask, and assert. Other verbs indicate that something will be done to a piece of talk: clarify and define, for example. And still others name speech events, for example, argue and joke.

(Schiffrin 1980: 202) 
She also identifies "discourse units" (p. 205) which are externally bound and reveal an internal structure of particular "discourses". For instance, metalinguistic expressions such as "I'll put it this way:..." or "That's how I see it", sometimes also being referred to as "discourse brackets" (Schiffrin 1980: 206), similar to Gricean "hedges", can be recognised as speech act-theoretic in nature through their ability to guide "functional" interpretation"

Grice himself, although he could hardly be considered a speech act theorist, while commenting on conditionals, suggests that it is possible to specify the conditions for performing speech acts which should reveal a class of "central" speech acts, i.e. fundamental, basic speech actions (Grice 1989 [1968]: 121 ff.), possibly of a universal nature. Grice's examples of the markers for "noncentral" acts include "moreover" and "however" also indicates that there are "higher order" and "lower order" speech acts which may sometimes coincide, for instance while a speaker is commenting on a lower order speech act using lexemes such as "so" or "therefore". In such utterances, these lexemes turn language 'on itself', i.e. they function as metalinguistic comments on a kind of micro-scale acts.

In a different perspective, Recanati (2007) also points to a similar metalinguistic aspect of certain (in his nomenclature) "illocutionary acts". For instance, he suggests that phrases such as "I suppose" are parts of complex illocutionary acts (Recanati 2007: 126-7, fn.). Supposing, or assuming, is then seen as a specification of an imaginary (or not) situation against which further information (the contents of the "supposing", etc.) will be evaluated".

Beyond particular verbs, longer stretches of words have attracted attention as markers or vehicles for the illocutionary force in utterances. For instance, Ginet (1979) analyses not only verbs, but longer units, which are called "performative verb phrases", such as "bet you a quarter that it will rain tomorrow", "congratulate you on your promotion", "sentence you to 30 days in jail", "promise to be there", "deny that I ever said that", "see your five and raise you ten", whose performative quality is seen in that when they are represented by " $\varphi$ ", uttering "I $\varphi$ ", or "I hereby $\varphi$ " under the right circumstances counts as " $\varphi$ ing", i.e. the performance of the act " $\varphi$ ". In other words, if a person intentionally

${ }^{97}$ Cf. also Mittwoch (1977) "How to Refer to One's Own Word: Speech-Act Modifying Adverbials and the Performative Analysis".

${ }^{98}$ The list can be extended, as suggested by Bach (1997: 38), by adding items such as: after all, anyway, at any rate, besides, be that as it may, by the way, first of all, finally, frankly, furthermore, if you want my opinion, in conclusion, indeed, in other words, now that you mention it, on the other hand, otherwise, speaking for myself, strictly speaking, to begin with, to oversimplify, to put it mildly..

${ }^{99}$ Recanati contrasts such cases with a more general template within which illocutionary force of an utterance is handled "through the specification of the situation against which the utterance is meant to be evaluated" (Recanati 2007: 126). For instance, an assertion is evaluated by checking the facts of the actual world, a command is evaluated against a situation the addressee is asked to actualise, etc. 
$\varphi s$, it follows that that person does something, which counts as " $\varphi$-ing" and in doing which he or she means something "in Grice's non-natural sense of "means"' (Ginet 1979: 245). Ginet contrasts performative verb phrases with nonperformative ones, e.g. "pay you a flowery compliment", "amuse you with a quip", "describe the scene", "tell you what time it is". The introduction of this contrast, although focused on propositional content, shows that, beyond the level of verbs, he attempts to find the cognate distinction to that between the constatives and performatives as initially researched by Austin.

There are classifications which concentrate on the circumstances of the speech situation in which the act in question is uttered (cf. section 3.4.2.f on "resource situation types"), such as the number of addressees. For instance, Thomas (2005) discusses "group performatives", Hancher's (1979) classification concentrates on "cooperative speech acts", and Clark and Carlson (1982) analyse distributive or collective interpretation of "collective speech acts", which are produced by one speaker, but addressed to more than one addressee/hearer. Collective speech acts with multiple agents, multiple addressees, or multiple both agents and addressees (e.g. "This committee rejects the union's allegations of unfairness") are also critically discussed by Meijers (2007) with a focus on Searle's concept of collective intentionality. As Meijers claims,

speech act theory has been a blind spot for those speech acts that are performed by collective agents. The paradigm case has been an individual speaker addressing an individual hearer. [... S]peech acts performed by collective speakers are sui generis acts. They cannot be reduced to individual speech acts.

(Meijers 2007: 109)

One of the consequences of the uniqueness of collective speech acts is that taxonomies, such as Searle's, and many others based on Austin's ideas, are inadequate in that they reduce collective speech acts to individual acts. Consequently, there appears to be an urgent need to improve such models. A similar problem received considerable attention in an analysis of speech acts embedded in legislative texts and contexts ${ }^{100}$.

There is thus a significant variety of approaches to the phenomenon of the speech act and the speech act verb, to the effect that in many cases the most

\footnotetext{
${ }^{100}$ Cf. e.g. Kurzon (1986), Witczak-Plisiecka (2001) and references within for a discussion of speech acts with collective performers or/and audiences in legal contexts. In a general conversational perspective, more elaborate structures for the concept of "the audience dimension" has been suggested, cf. e.g Clark's (1987: 13) representation which follows Erwin Goffman's ideas (cf. also Clark 1992: 205-297):
}

\begin{tabular}{|c|c|c|c|c|}
\hline \multicolumn{3}{|c|}{ Hearers } \\
\hline Self & \multicolumn{3}{|c|}{ Others } \\
\hline & \multicolumn{3}{|c|}{ Participants } & \multicolumn{2}{|c|}{ Overhearers } \\
\hline & Addressee & Side Participant & Bystander & Eavesdropper \\
\hline
\end{tabular}


essential issues are understood differently among researchers pursuing deceptively and only apparently similar agendas. The differences pertain to the nature of the very categories in question as well as to their theoretical and methodological status.

Another important issue in speech acts and speech act verbs distinction is the function of the performative verb in explicit speech acts. Following Austin's lectures, it may be concluded that explicit speech acts are statements in disguise. They were called "masqueraders" by Austin himself (1962/1975: 4), i.e. performative utterances in disguise of descriptivity. However, in intuitive judgment, for many users of language such utterances are both; they are perceived as actions which simultaneously name the (often extralinguistic) act being performed. The issue itself motivated a lengthy philosophical debate (e.g. Bach 1975, Bach and Harnish 1992, Searle 1989) as to the nature of speech acts in general with the focus question on whether all speech acts should be necessarily seen as statements/assertions, which in many cases may coincide with a more salient function, e.g. that of a promise, denial, etc ${ }^{101}$. Whether or not it is accepted that analyses of speech act verbs and their illocutionary potential is essential for the recognition of speech act type, it still seems that such analyses can inform our understanding of how language in general and how particular languages function.

There are thus numerous reasons for studying speech act verbs (SAVs) and attempting to produce their classifications; for instance:

- following Austin's original method of linguistic "botanizing", through an analysis of speech act verbs, it should be possible to catalogue all speech acts and account for their mereology; such an analysis should also shed light on minute distinctions between different functions which correlate with different utterances;

- Austin's "botanizing" method of analysis applied to SAs (speech acts) and SAVs exposes correspondences between linguistic and natural phenomena, where SAs and SAVs are reflective of natural and "biological" complexity found in the world;

- Austin's agenda when applied in intercultural and multicultural contexts should help produce an account of speech acts relevant for a certain culture or a community, and to account for the potential of some verbs to be used performatively; it should also provide a reliable foundation for an analysis of intercultural differences;

- comparative research into speech acts and speech act verbs should also reveal aspects of natural language, for instance by indicating which speech acts appear first in natural pragmatic development along with the process of first language acquisition;

${ }^{101}$ Cf. Chapter two. 
- reliable classifications of speech acts can facilitate professional practice in various spheres of social life, as even today's not-entirely-perfect taxonomies are occasionally used, inter alia, in legal contexts, in clinical pragmatics contexts, and in foreign language teaching contexts.

It is evident that addressing the issues listed above involves varied perspectives on speech acts and must result in different classificatory objectives and methods. The most straightforward question is: "How many acts and how many verbs are there?" accompanied with the issue of hierarchy and importance ascribed to particular acts and/or verbs.

In the most general approach, there are conflicting opinions on how many speech acts and speech act types there are and how many of them are theoretically important, or significant enough to suggest a categorial label.

Austin's (1962/1975) method seems to converge with Wittgenstein's approach in its rather maximalistic botanizing perspective, although the number of main types suggested for speech acts is confined. In contrast, Searle (1979b [1975]: 29) explicitly contradicts this maximalistic view claiming that "[t]here are not, as Wittgenstein [...] and many others have claimed, an infinite and indefinite number of language games or uses of language". He advocates the view that there are five main types, one of which - Declaratives - is most salient and a precondition for social life in general (cf. section 2.8 and section 3.4.1).

The bottom-up research focused on verbs, instead of the five categories can be exemplified by Verschueren's study (1977: 4-5) where 173 English speech act verbs are listed with detailed descriptions of their use(s) and by Ballmer and Brennenstuhl's (1981) contrastive classification.

The varied objectives behind the taxonomies of speech acts and of speech act verbs often substantially depart from Austin's phenomenological approach, even in the case of researchers who concentrate on verbs. Such objectives depend, inter alia, on the type of a particular author's approach to speech acts, specific interests, and the envisaged level of precision. Many theorists set their agenda on classifying speech act verbs in order to reveal salient functional categories, following the path indicated by Austin and his methodological hopes related to analysis of ordinary language. This implicitly biological approach treats speech acts as natural species which can be "collected" and ordered.

Various later agendas include attempts aimed at providing a taxonomy of speech acts understood explicitly as natural kinds of independent existence and involve research programmes based on the belief that it is possible to discover natural categories of speech acts which language users possess as their internalised knowledge. Other investigations focus on social engineering in contexts where speakers possess, or lack, the power which is translated into the force of their utterances (e.g. political linguistics, gender studies, hate language studies, speech acts in the context of socially disadvantaged groups). 
Research which focuses on language acquisition and children's linguistic development (e.g. Bates et al. 1975; Bates 1976) is oriented towards discovering the most natural order in mastering different speech acts and producing a catalogue of such acts. This perspective is connected with clinical linguistics where speech act informs medical professionals with regard to therapy in speech impediment (cf. Cummings 2009). In turn, classifications oriented towards grammar look into convergences between the grammatical mood, syntactic structures and the semantics of speech act verbs (e.g. Atkins et al. 1988). Semantic similarity is often matched with similar syntactic behaviour. Furthermore, for different semantic fields different features play salient roles as components of meaning. It has been suggested that "attitude", for instance, is crucial for differentiation between verba tacendi related to linguistic silence, while concepts such as "truth", "quality \& quantity", or "gradability", are salient in analysis of verba mentendi related to lying (cf. Verschueren 1985, 1987a).

Speech act theorists have produced dozens of taxonomies of speech acts over the years, but the majority of post-Austinian classifications can be divided with regard to two main criteria deployed in their formation. Typically, speech acts are grouped according to their semantic and pragmatic features or according to their syntactic characteristics.

Another way to look at these classifications is to divide them into epic and emic approaches. There is a strong belief behind many taxonomies that a reliable classification must be based on careful analysis of vast amount of data, possibly large corpora of natural utterances and texts, which exhibits an etic approach. This approach can be directly traced back to Austin. On the other hand, theorists such as Searle and his followers seem to believe that philosophical, holistic approach to language phenomena, from the very beginning conceived of as a system, is more important and not less fruitful. In this emic approach, it is not natural language data that constitutes a natural point of departure, but a systemic bird-eye view at language, a view which is supposed to be verified by natural language examples, but finds its origin in general reasoning. Many theorists present a mixed orientation in which epic and emic approaches are not even put next to each other, but blended.

For example, Searle (1965, 1975a, 1979b [1975]) seemed to follow the semantic approach initiated by Austin, but created a more elegant and clearer taxonomy thanks to his application of the direction of fit, to eventually adopt emic criteria. In a much different manner, Vendler (1972) used Austin's original ideas to produce a classification based on syntactic features of English verbs. Although based on the English language, his syntax-oriented classification points to characteristics associated with Aktionsart, which might prove relevant for other languages. McCawley (1977) and Fraser (1974b) also used syntactic properties to classify verbs with focus on their complementation, structures with depended prepositions, etc. 
Naturally, syntax-related taxonomies are typically taxonomies of verbs rather than abstract acts; in contrast, "more pragmatic" classifications group utterances of much varied forms under a functional category. Very often, syntactic criteria relate to the canonical form and attempt to identify verbs which can be used performatively. Some others, however, use a more complex frame. For instance, Verschueren's (1977) approach accepts verbs which reject the canonical form, i.e. first person, present simple, singular, active voice. It is recognised that institutional speech acts, especially where the "speaker" or/and the "addressee" is a collective body, are typically performed with the use of passive voice, e.g.

(41) Passengers are advised to guard their belongings at all times.

(42) We would like to inform you that smoking is not allowed on this flight.

It is further worth noting that grammar-oriented classifications, which concentrate on the structure of sentences, sometimes make use of concepts from speech act theory. For instance, Quirk's extensive grammar book asserts that

Terms such as DECLARATIVE, INTERROGATIVE, IMPERATIVE, and EXCLAMATIVE can be used [...] in referring to grammatical categories [...], to types of clause or types of sentence. The terms STATEMENT, QUESTION, DIRECTIVE, and EXCLAMATION [... are] applied to the logical or semantic status of an utterance - what it means, and what it is used for, $[\ldots]$ as defining categories of sentence.

(Quirk et al. 1985/1992: 78)

It is, however, only in small print that comprehensive grammar books would comment on speech acts and the distinction between an utterance and a sentence, and possible multiple functions of certain sentences ${ }^{102}$. If there are considerations of sentence types and discourse functions, they are typically based on Searle's (1979b [1975]) taxonomy (cf. Quirk et al. 1985/1992: 803-806). In such approaches speech acts are normally understood as utterances of sentences, i.e. "acts of verbal behaviour (spoken or written)" (804). Naturally, illocutionary acts are then associated with particular semantic classes of sentences, for instance, the act of inquiry with questions, but it is also acknowledged that especially statements may correspond to many different functions as indirect speech acts are very frequent. Classifications of that kind expose one of the continuing problems related to speech act theory, i.e. the problematic relation between the illocutionary force of a particular utterance and its form, a notoriously underdefined relation between abstract sentences and their contextualised uses, e.g. corresponding utterances, the difference between

${ }^{102}$ Cf. the small print "Note" in Quirk et al. (1985/1992: 78) and the section on illocutionary acts (section 11.3; p. 804). 
"semantic" meaning and force. This quality, as indicated above, was emphasised by Austin's calling performative utterances "masqueraders," (1962/1975: 4) statements in disguise of descriptions, in other words, actions pretending to be statements. Naturally, all classifications focused on mood whether explicitly, or only implicitly, must abandon, or significantly limit this perspective.

\section{Speech act verbs and delocutivity}

Another issue relevant in the context of verbs of linguistic action is delocutivity, a notion introduced by Benveniste. Originally, delocution was related to French formulaic expressions which gave rise to verbs, which, in English, may be illustrated by examples such as "to okey" (based on "O.K."), or "to encore" (as based on the French "Encore!"). There is an evident relation between such verbs and linguistic action, although particular examples may be of varied kind. In general, (as suggested in Anscombre et al. 1987) delocutivity relies on a pragmatic rather than semantic competence. A delocutive verb has thus been redefined as a verb which has been "morphologically derived from a formula and includes in its meaning a reference to the illocutionary act performed in a specific use of the formula" (Anscombre et al. 1987: 46 ${ }^{103}$ ). With regard to English, it has been claimed that delocutive verbs can often be used both in performative utterances and as successful labels for speech act types. For instance, a person may be reported to have "encored", even if the exact phrase that he or she used was "One more time!", or "Again!" without explicitly saying "Encore!" (Anscombre et al. 1987: 47).

With the use of the concepts of "program", "action", and "norm", with delocutivity in mind, another model for classification of verbs related to speech action has been suggested. The basic assumption is that linguistic action consists in performing a linguistic program, which, in turn is immersed in a wider communicative program, part of a general universe of discourse. In this light, a promise is a linguistic action, a speech act, and the notion of, e.g. "command" (conceived of as a type) is a communicative program (cf. Anscombre et al. 1987: 54). It follows that speech acts may be performed through a linguistic action, or a non-linguistic action (e.g. a gesture) to the effect that all linguistic actions are speech acts, but only some speech acts are performed through a linguistic action. This perspective invites a different classification of types of verbs related to linguistic action, which is represented in Table 6.

${ }^{103}$ See Anscomre et al. (1987) for an array of examples culled from different languages. 


\begin{tabular}{|c|c|c|c|c|}
\hline \multicolumn{5}{|c|}{ ACTION VERBS } \\
\hline \multicolumn{4}{|c|}{ VERBS RELATED TO SPEECH ACTIVITY } & OTHER \\
\hline \multirow{2}{*}{$\begin{array}{l}\text { COMMUNICATIVELY } \\
\text { NORMED VERBS }\end{array}$} & \multicolumn{3}{|c|}{ QUASI-SAVs } & \\
\hline & $\begin{array}{l}\text { SEMI- } \\
\text { SAVs }\end{array}$ & \multicolumn{2}{|c|}{ SAVs PROPER } & \\
\hline \multirow[b]{2}{*}{$\begin{array}{l}\text { to sell } \\
\text { to } \sin \end{array}$} & \multirow[b]{2}{*}{$\begin{array}{l}\text { to marry } \\
\text { to play } \\
\text { chess }\end{array}$} & $\begin{array}{l}\text { SAVs (with non- } \\
\text { verbal substitutes) }\end{array}$ & LAVs & \\
\hline & & $\begin{array}{l}\text { to agree } \\
\text { to cry uncle } \\
\text { to surrender }\end{array}$ & $\begin{array}{l}\text { to } \\
\text { speak } \\
\text { to } \\
\text { boast }\end{array}$ & $\begin{array}{l}\text { to die } \\
\text { to sleep }\end{array}$ \\
\hline
\end{tabular}

Table 6: Basic distinctions between different kinds of verbs describing a speech activity (adapted from Anscombre et al. 1987: 58).

The distinctions used in building the classification include, first of all, the recognition that language is a type of action, but verbs can refer to non-linguistic action (section "other verbs"). Communicatively normed verbs explicitly refer to "doing things with words" and quasi-SAVs list verbs which refer to actions with a linguistic element, but of a less defined nature; for instance, in order to play bridge certain linguistic formulae must be uttered, but they do not directly "make" bridge happen and can be of different kind. This classification, focused on delucutivity-related issues and delocutive verbs culled from different languages is yet another illustration of how underdetermined both the notion of the speech act and the concept of speech act verbs linked to linguistic actions are.

In the following sections, selected classifications of speech acts and/or speech act verbs are discussed with focus on the criteria used in their taxonomical analysis and their relation to Austin's programme.

\subsection{Austin's taxonomy}

While commenting on possible criteria for performatives (cf. especially Lecture V \& VI), Austin indicates that there is a systematic asymmetry between a "peculiar and special" use of the first person singular present indicative active form of certain verbs and the use of other persons and tenses of the same verb. For instance, the nature of the use of "I bet" or "I promise" is significantly different from that of "he bets" or "he promises". This kind of asymmetry does not yet arise in the case of non-performative verbs (cf. "I run/I am running" and "He runs/is running") (Austin 1962/1975: 63ff, 67ff). In fact Austin does admit that this criterion is not free from limitations, as e.g. even the (seemingly) 
explicit performative forms can be identical with expressions, inter alia, of habitual action, and performance may be accompanied with words which seem to be (and sometimes are) descriptive (e.g. "I am protesting" accompanied with an adequate movement, e.g. chaining oneself to park railings). There are many other factors which can make it difficult to pinpoint the operative element in a performative utterance (cf. Austin 1962/1975: 64ff) and delay, or prevent, its proper understanding, i.e. recognition of its operative character. In the light of such difficulties Austin decides to concentrate on the use of verbs. One of Austin's initial assumptions was that it should be possible to compile a list of all performative verbs and that for all performative utterances (typically of the form "I $x$ that", "I $x$ to", and "I $x$ ") it should be possible to produce a paraphrase in the "preferred" explicit form (68ff).

Austin suggests a number of tests for performativity, e.g. posing questions concerning the (potentially) volitional character of the content of the utterance ("Could he do it deliberately?"), truth and falsity tests ("Could it be literally false that ...?"), none of which however are sufficient for establishing whether an utterance is performative or not.

To reiterate, as briefly indicated in chapter two, Austin's approach to speech acts and their taxonomy was both phenomenological and "botanizing". He believed that an analysis of utterances as they were used in ordinary language should reveal the underlying structure of the (social) world and would also allow for a transparent taxonomy of acts performed in the social sphere. With regard to speech act labels, in the essay "How to Talk", Austin comments:

Names for speech-acts are more numerous, more specialized, more ambiguous and more significant than is ordinarily allowed for: none of them can be safely used in philosophy in a general way (for example, 'statement' or 'description') without more investigation than they have, I think, yet received. [...] we have been concerned with only a few speech-acts of a single family, but naturally there are other whole families besides.

(Austin 1970: 150; "How to Talk")

Austin further comments on the taxonomic metalanguage and how attempts at classifying speech acts may elucidate people's understanding of speech acts in the "total situation":

To some extent we probably do, even in ordinary language, make use of models of the speech-situation in using the terms that we do for speech-acts. At any rate, the construction of such models can help towards clarifying the varieties of speech-act which are possible. Any such model, even the simplest, seems bound to be fairly complicated too complicated for the standard subject-predicate or class-membership model. Moreover, we seem bound to use a whole series of different 
models, because the difference between one named speech-act and another often resides principally in a difference between the speechsituations envisaged for their respective performances.

(Austin 1970: 150-151, "How to Talk"; original emphasis)

Although, as can be seen above, Austin first approaches speech acts in a categorical way without much emphasis on particular verbs, he later moves on to concentrate on verbs, which is a result of his phenomenological perspective on the world of speech actions. In the classification introduced in his lectures the broad functional labels serve to introduce lists of verbs corresponding to their distinct uses.

Austin (1962/1975: 151) suggests five broad classes of (not just performative), but speech act verbs, labelling them (by his own admission) with "more-or-less rebarbative names" as listed below:

- Verdictives (e.g. aquit, convict, find, hold, rule, estimate, locate, rank, grade, assess, describe, diagnose, analyse)

- Exercitives (e.g. appoint, degrade, dismiss, excommunicate, name, command, sentence, nominate, vote for, enact)

- Commissives (e.g. promise, convenant, contract, intend, plan, envisage, swear, bet, consent, adopt, espouse, oppose)

- Behabitives (e.g. apologize, thank, compliment, criticise, welcome, bless, toast, dare, defy, challenge)

- Expositives (e.g. affirm, deny, ask, testify, accept, recognize, interpret, deduce, mean, call, regard as).

As can be seen from the examples, the groups correspond roughly to 'giving' or 'as if giving a verdict', exercising institutional power, promising and undertaking, showing social attitudes, and, finally, to discourse moves.

Austin summarises the taxonomy as follows,

...we may say that the verdictive is an exercise of judgement, the exercitive is an assertion of influence or exercising of power, the commissive is an assuming of obligation or declaring an intention, the behabitive is the adopting of an attitude, and the expositive is the clarifying of reasons, arguments, and communications.

(Austin 1962/1975: 163)

Austin's classification, as the rest of his speech act theory, was left in the making. In the state as it is accessible, one category often blends into another and the classes vary with regard to their definitional criteria. Specifically, suggesting his taxonomies, Austin indicated that what would not survive the transition, unless perhaps as a marginal limiting case, was the notion of the 
purity of performatives. This was hardly surprising, by the author's own admission, as the distinction would give trouble from the start having been based upon a belief in the dichotomy of performatives and constatives, which, as could be seen later, had to be abandoned "in favour of more general families of related and overlapping speech-acts", which were exactly what Austin attempted to classify (cf. Austin 1962/1975: 150).

Such families - amounting to a list of verbs of "the order of the third power of 10" (Austin 1962/1975: 150), "a good margin" between 1000 and 9999, Austin decided to arrange into the classes which, once more by his own admission, were not equally successful. For instance, in a playful tone, Austin called Behabitives "a shocker list". He also emphasised that the last two groups were particularly contentious and susceptible to overlaps, and, in a self-critical manner allowed that maybe "some fresh classification altogether is needed" (Austin 1962/1975: 152) ${ }^{104}$.

In general, Austin's criteria in defining the groups are many and varied although the most salient aspects were retained in the form of two Austinian "fetishes" (151), viz. the truth/false, and the value/fact distinction. Verdictives seem to hang around the concept of judgement, as Austin put it "the delivering of a finding, official or unofficial" (153) and formally (i.e. in their form) are close to the concept of truth-evaluability. They involve naming reality, both the changes that have taken place (cf. an umpire's calling "Out" during a match or a game) and the "pictures" which are to be sustained (cf. a judge's verdict on a case). Exercitives are particularly "social" by their emphasis on authority and power. Commissives, on the other hand, are much varied and range from "private" commitments to official declarations. Behabitives are "social" in a different way from Exercitives; they are "concerned with reacting to behaviour" (Austin 1962/1975: 83) and with behaviour towards others, designed to exhibit attitudes and feelings. They are embedded in the social world with its expectations concerning (linguistic) conduct and everyday interaction. The last group, Expositives, seems to gather items which are metalinguistic in nature in that the verbs included in the category report on a type of linguistic action.

Austin's openness in pointing difficulties in his own model is, as usual, striking, but his discussion reveals also a deep trust in the salience of the categories in question, which both share meaningful aspects with the other classes and are distinct thanks to a certain significant feature. The discussion further suggests that the classes can be representative of possibly universal aspects of language. As mentioned above, Austin believed in lexical botanising, in that a meticulous analysis of the semantic differences between distinct uses of

\footnotetext{
${ }^{104}$ Austin emphasises the tentative character of his theorising all through the book, allowing that in his taxonomy there are numerous instances of cross-classification and says: "[some verbs] seem both to be included in the other classes and at the same time to be unique in a way that I have not succeeded in making clear even to myself. It could well be said that all aspects are present in all my classes" (Austin 1962/1975: 152).
} 
the same verb, or cognate uses of different verbs, may indeed reveal important facts about the real world, the structure of reality which is hidden behind various linguistic utterances. This was an aspect which made him recognise his research area as "linguistic phenomenology" (Austin 1970: 182). Even though it may seem at first sight that Austin's classification in many aspects was more of a failure, later systematic research into speech act types seems to validate many of Austin's intuitive comments. In addition, some of his categories, for instance Exercitives, have been revived in the contemporary speech act research oriented towards particular social values (e.g. McGowan 2003, 2009) for which numerous other classifications proved insufficient.

Returning to the metalinguistic issues and the theoretical status of speech act categories, it is noteworthy that Austin (1962/1975) explicitly addressed the problem while commenting on the illocution/perlocution distinction:

The verbs that we have classified $[\ldots]$ as names of illocutionary acts seem to be pretty close to explicit performative verbs, for we can say 'I warn you that' and 'I order you to' as explicit performatives; but warning and ordering are illocutionary acts. We can use the performative 'I warn you that' but not 'I convince you that', and can use the performative 'I threaten you with' but not 'I intimidate you by'; convincing and intimidating are perlocutionary acts. (131)

But what then is the relation between performatives and these illocutionary acts? It seems as though when we have an explicit performative we also have an illocutionary act. (132)

The inherent tentativeness of Austin's discourse is also found in the text "Performative utterances", where Austin also emphasises that there is a difference between "making explicit" and "stating" what kind of act someone is performing, where explicitness refers to "showing" the kind of act in question.

Apparently Austin hoped (vainly as concluded by Bach 1975: 229) that the group of performative verbs, which had the potential to be used in present simple declarative sentences in the first person, singular and active from, could be identified thanks to the fact that using them in some other form (e.g. the third person) would produce truth-evaluable sentences, which, however, turned out problematic.

Later, in the final lecture (148ff), Austin in fact explicitly admits that the initial agenda to make a list of all explicit performative verbs must be abandoned in favour of listing illocutionary forces of utterances, i.e. verbs which make explicit the illocutionary force of the utterance (150).

It is worth noting that Austin's original account (78ff) includes a discussion of the verbs of "emotion" or Behabitives, which he sub-classifies into three sets, 
ranging from pure performatives, through mixed, i.e. half-descriptive types, to reporting uses, cf. example (43):

$\begin{array}{lll}\text { I thank } & \text { I am grateful } & \text { I feel grateful } \\ \text { I apologize } & \text { I am sorry } & \text { I repent } \\ \text { I criticize } & \text { I blame } & \text { I am shocked by } \\ \text { I censure } & & \text { I am revolted by } \\ \text { I approve } & \text { I approve of } & \text { I feel approval } \\ \text { I bid you welcome } & \text { I welcome } & \\ \text { I congratulate } & \text { I am glad about } & \end{array}$

(Austin 1962/1975: $79 \& 83$ )

Austin never solves the problem of the distinction between a pure performative and other types of utterances, within the range between semiperformative and non-performative, and only acknowledges the varied forms that performatives may take and indicated underdeterminacy which this fact involves.

In summary, Austin's taxonomy, although severely criticised, turned out to be significantly thought-provoking. The metalanguage suggested in his model survived until the present day and has been developed in many different directions; many of the distinctions marked by Austin have been later elaborated. The inherent complexity and tentativeness of Austin's classification gave rise to many attempts at improving his taxonomy and motivated further research questions. Subsequent research not only produced novel approaches, but also revealed certain merits of the original model, which eventually turned out to be more significant than it might have seemed in the decades immediately following its formulation in the second half of the twentieth century.

The following sections review selected post-Austinian classifications pointing to their most characteristic features.

\subsection{Selected classifications of speech acts and speech act verbs beyond Austin}

This section presents selected classifications of speech acts which range from immediate elaborations or amendments of Austin's taxonomy to models which refer to speech act theory, but use novel methodology. The section also includes critical opinions with regard to speech act classifications voiced by researchers committed to different theories, including relevance theory. The discussion does not claim to be exhaustive, numerous influential classifications (e.g. Fraser 1974b, Sadock 1974, 1994, Hancher 1979, Sbisà 1984, Croft 1994, Vanderveken 
2001) are not discussed in detail due to space constraints and the focus on Austin's legacy.

\subsubsection{Searle's modification of Austin's taxonomy}

\subsection{1.a. Searle's classification and taxonomical criteria}

Searle's is the single most influential classification of speech acts offered so far and has been widely adopted as "the" taxonomy of speech acts and an improvement of Austin's original account (as well evidenced in linguistics handbooks, e.g. Thomas 1995).

Searle sets out by criticising Austin's taxonomy, indicating that "the first thing to notice about these [i.e. Austin's] lists is that they are not classifications of illocutionary acts but of English illocutionary verbs" (Searle 1979b [1975]: 9) ${ }^{105}$ and declining the expectation that "a classification of different verbs is $e O$ ipso a classification of kinds of illocutionary acts" (Searle 1979b [1975]: 9). Having revised Austin's classification, Searle concludes:

In sum, there are (at least) six related difficulties with Austin's taxonomy; in ascending order of importance: there is a persistent confusion between verbs and acts, not all the verbs are illocutionary verbs, there is too much overlap of the categories, too much heterogeneity within the categories, many of the verbs listed in the categories don't satisfy the definition given for the category and, most important, there is no consistent principle of classification.

(Searle 1979b [1975]: 11-12)

In the hope of being able to remedy the situation, Searle decided to base his classification on the criterion of the direction of fit ${ }^{106}$ and suggested a new set of five broad types of speech acts. Among the other criteria used in Searle's classification there are features related to the conditions that have to be met if acts are to be performed successfully. These rule-oriented characteristics include: illocutionary point, expressed psychological state, and propositional content ${ }^{107}$. The central feature of the direction of fit is descriptive of the relation between the world and the words spoken. Speech act types according to Searle (1969, 1979b [1975]) are the following:

\footnotetext{
${ }^{105}$ Cf. also Searle 1969: 69, fn.I on Austin's ad hoc classificatory criteria.

${ }^{106}$ A cognate idea can be found in Reinach, cf. section 1.6.

${ }^{107}$ An illustration of analysis focused on the act of promising has been discussed in more detail in section 3.7 .
} 
- Assertives or Representatives, which commit the speaker to the truthfulness of his words, e.g. asserting, reporting, stating;

- Directives, in which the speaker attempts to make the addressee do something, e.g. ordering, requesting, advising;

- Commissives, in which the speaker takes on a commitment of some kind, e.g. promising, offering, refusing;

- Expressives, in which the speaker expresses her emotional states and attitudes, e.g. apologising, thanking, congratulating.

- Declaratives or Declarations, which bring about immediate changes in the world typically of institutional nature, e.g. declaring a war, giving a verdict in a court of justice, bidding as in bridge, etc.

The table below shows the five categories with their corresponding values of the direction of fit and the expressed psychological state.

\begin{tabular}{|c|c|c|c|}
\hline & \multicolumn{3}{|c|}{ Category } \\
\hline \multirow{6}{*}{$\frac{\mathscr{E}}{\stackrel{\Xi}{\sigma}}$} & $\begin{array}{l}\text { Illocutionary point / } \\
\text { Speech act type }\end{array}$ & $\begin{array}{l}\text { Direction of fit } \\
\quad(\text { symbol })\end{array}$ & Expressed psychological state \\
\hline & Assertives & $\begin{array}{c}\text { words-to-world } \\
(\downarrow)\end{array}$ & Belief \\
\hline & Directives & $\begin{array}{c}\text { world-to-words } \\
(\uparrow)\end{array}$ & Desire \\
\hline & Commissives & $\begin{array}{c}\text { world-to-words } \\
(\uparrow)\end{array}$ & Intention \\
\hline & Expressives & (Ø) & $\begin{array}{c}\text { a variety of states can be } \\
\text { expressed }\end{array}$ \\
\hline & Declarations & $\begin{array}{l}\text { words-to-world } \\
\text { and }(\uparrow) \\
\text { world-to-words }\end{array}$ & --- \\
\hline
\end{tabular}

Table 7: A summary of Searle's criteria in classification of speech acts

Searle's concentration on institutional acts motivated the introduction of the sixth hybrid category of Assertive Declarations or Representative Declarations. Acts belonging in this additional category blend the characteristics of Assertives with certain features of Declarations and are most frequently found in highly institutional settings. According to Searle, this happens because

in certain institutional situations we not only ascertain the facts but we need an authority to lay down a decision as to what the facts are after the fact-finding procedure has been gone through. The argument must eventually come to an end and issue in a decision, and it is for this reason that we have judges and umpires. Both, the judge and the 
umpire, make factual claims: "you are out," "you are guilty." Such claims are clearly accessible in the dimension of word-world fit. [...] But at the same time both have the force of declarations. [...] Institutions characteristically require illocutionary acts to be issued by authorities of various kinds which have the force of declarations. [...] Unlike the other declarations, [representative declarations] share with representatives a sincerity condition. The judge, jury, and umpire can, logically speaking, lie, but the man who declares war or nominates you cannot lie in the performance of his illocutionary acts.

(Searle 1979b [1975]: 19-20)

This type of speech act is especially important for institutional settings and, as a category, has often been used in analyses of speech acts in, for instance, legal contexts (e.g. Danet $1980^{108}$ ). Assertive Declarations are also the only type in Searle's taxonomy which is explicitly of mixed nature. As a result of this quality, such acts are sometimes accounted for in terms of cognitive blends in the tradition of Fauconnier $(1985,1997,1999)$ and Turner (Fauconnier \& Turner 1996 [2001], cf. e.g. 2001, Sweetser 2002, Witczak-Plisiecka 2009b, 2011).

Pointing to the fact that for some acts the most salient aim is to express the speaker's attitude towards his or her utterance, i.e. making an axiological point, it has been suggested that Searle's classification should be amended with a seventh category (Kalisz 1989, 1993, 2001), a category of evaluative acts. Following Krzeszowski's (1997) perspective on language, it is claimed that such acts are axiological in nature and cannot be identified with expressive acts as they have a specific direction of fit; while expressives have no direction of fit, evaluative acts are characterised by the "words-to-world" direction, where the world precedes the words ${ }^{109}$. The new class of evaluative acts would thus be another hybrid category, a blend of assertives and expressives.

It may be argued that the main reason why Searle's taxonomy proves to be so influential and popular must be its methodological clarity and the fact that indirect speech acts can be systematically accounted for by referring to the conditions which have to be satisfied for a successful performance of a speech act $^{110}$. Such clarity is not present in Austin's taxonomy which mixes both different classificatory principles and different types of indirectness.

\footnotetext{
${ }^{108}$ Danet (1980) cites examples where official formulaic language plays a role, as in, e.g. pleas of guilty/non-guilty or giving a verdict in a court of justice, or other utterances "'fateful' regardless of their truth values" (Danet 1980: 460-461) when uttered in institutional settings; Cf. also Trosborg's $(1991,1995)$ approach to classifying legal (speech) acts.

${ }^{109}$ It is further suggested that there is a syntactically marked difference; expressives do not invite "that-clauses", while the construction is prototypical for evaluative acts.

${ }^{110}$ Searle's method of accounting for indirectness is illustrated in section 3.7 devoted to the act of promising.
} 
Returning to Declarations, they are of special interest to Searle in an even broader perspective, inter alia, because they provide means for "making" the social world and all social institutions, and also because they are most representative of what speech act theory is focused on. With a different degree of zooming, Searle (2002a: 541) even claims that "all performatives are declarations", although "[n]ot all declarations are performatives" (550), just because not all declarations are phrased in the canonical form ${ }^{111}$.

Searle's discussion of the difference between proposition and assertion is also worth acknowledging. Searle emphasises that in speech act-theoretic perspective a proposition can be expressed without its being asserted because a proposition can be an element in many distinct speech acts (cf. Searle 1969: 29ff). Thus, when a proposition is expressed it is necessarily a component of a speech act (although a speech act may be performed without expressing a proposition).

In summary, Searle's classification is supposed to be an improvement of Austin's taxonomy and poses claims of universality. It is for instance indicated that Searle's classification of illocutionary acts is more general and less language dependent than Austin's thanks to its concentration on direction of fit (Vanderveken 2002b: 143ff.). It is also explicitly claimed that it should be an element of Universal Grammar of meaning and use.

\subsection{1.b. Searle and Vanderveken's illocutionary logic}

The allegedly universal dimension of Searle's taxonomy is reflected in Searle and Vanderveken's model of illocutionary logic, which was introduced in Foundations of Illocutionary Logic (Searle and Vanderveken 1985) and has been later developed by Vanderveken (1990, 1991a/b, 1994, 2001, 2002a) with the aim to provide a unifying account of truth conditional semantics in the tradition of Frege, Tarski, and Montague, combined with speech act theory.

The problem of a logical account of speech acts reveals and reinforces a number of important questions for speech act theory. First of all, if speech act theory is to be perceived as a part of a theory of action, a problem arises whether action can be adequately represented in logic. The type of logic typically accepted in linguistic analysis is predicate calculus, which was mastered at the beginning of the twentieth century by Bertrand Russell and Alfred Whitehead, and can be traced back through Frege, Boole and De Morgan, down across the Middle Ages to Aristotle's logic based on syllogisms. The model can be successfully applied to represent reasoning, but leaves limited space to account for action-oriented aspects.

While Aristotle is recognised as father of modern logic, the separation between the logic of truth and the (allegedly underdeveloped) logic of action is

${ }^{111}$ As Searle (2002a: 550) shows, "Let there be light!" is not. 
also attributed to him. For example, Ohlsson (2007: 21) claims that this separation resulted from Aristotle's discussing the two types of logic in separate works, theoretical logic (the precursor of predicate calculus) in Prior Analytics and Posterior Analytics, while practical reasoning (directly related to action) in Nichomachean Ethics. This separation, it is suggested, "was so influential that the logic of truth and the logic of action moved along independent trajectories for two millennia" (Ohlsson 2007: 21).

In Foundations of Illocutionary Logic, Searle and Vanderveken (1985) pioneered a logical account of speech acts, thus extending Searle's earlier work and contributing a new dimension to Austin's legacy. Having accepted Searle's claim that speech acts are primary units of meaning and communication in the use and comprehension of language, they lay down a theory of success and satisfaction for illocutionary acts. This theory includes an account of the main principles for speech act success and builds on Austin by breaking down his notion of illocutionary force. Among the components of illocutionary force, Vanderveken (2002b: 144ff.) names illocutionary points, degree of strength, preparatory and sincerity conditions, and propositional content. Under this interpretation, propositional content is located "inside" illocutionary force, which, it might seem, should challenge the theoretical commitment often emphasised by Searle that a speech act is composed of illocutionary force and propositional content. However, it appears that in summarising the main tenets of the theory, Vanderveken just generalises and simplifies the picture, mentioning propositional content as an essential element in any speech act ${ }^{112}$ and treating illocutionary force as the most significant element. As the main objective of illocutionary logic Searle and Vanderveken cite creation of "a recursive theory of success and of satisfaction" (e.g. Vanderveken 2002b: 146).

In short, Searle and Vanderveken's illocutionary logic includes a classification of speech acts in terms of their main forces. It is not to be a taxonomy of verbs, but a taxonomy of universal functions with which people use linguistic expressions engaging in social life and institutional reality. Searle's earlier classification into five main categories is accepted as a system of five primitive universal illocutionary forces, forces at the most general level, each having just one basic illocutionary point. The five categories are:

1) the force of assertion;

2) the force of a commitment to a future action;

3) the force of a directive;

4) the force of a declaration;

5) the force of expressing an attitude.

It is claimed that all other forces are more complex and can be "genetically" relativised to the primitive ones through showing scalar modifications in e.g. "the degree of strength" (increasing or decreasing), the introduction of a novel

\footnotetext{
112 At other places Vanderveken speaks of "components of illocutionary force and propositional content" (e.g. 2002b: 145), evidently meaning force as opposed to propositional content.
} 
"mode of achievement" of the illocutionary point in question, or by expanding the list of preparatory and sincerity conditions.

Successful performance of a speech act in the form of $F(p)$, where $F$ stands for illocutionary force and $p$ for propositional content, consists in achieving the illocutionary point of $F$ on propositional content $p$ with the mode of achievement of $F$ in the context of the utterance. It also must be the case that $p$ satisfies the propositional content conditions of $F$ in the context. The speaker must also presuppose all the preparatory conditions of $F(p)$ and must express the attitudes that enter in the sincerity conditions $F(p)$ with the degree of strength appropriate for $F$. This perspective, where (illocutionary) acts can be "attempted" in a successful and non-successful way, e.g. successfully attempted insincere acts and defective attempts in which speakers do not achieve desired illocutionary points, allows Searle and Vanderveken to re-construe the Austinian notion of felicity by suggesting that what Austin understood to be felicitous illocutionary acts forms a special class of "successful", "not defective", and "satisfied" illocutions.

However, in their explicitly "logical" account, Searle and Vanderveken also suggest that some complex acts are not directly reducible to the five basic illocutionary acts. These are, e.g., illocutionary denegation, conditional illocutionary acts, and conjunctions of illocutions.

Denegations are acts of the form " $\neg A$ ", in which the speaker denies, refuses, and in general makes explicit that the "act" being referred to is not to be performed. Examples of denegations include denegation of an acceptance, i.e. refusal. For this type of act its satisfaction conditions include that there is no performance of the act mentioned, i.e. A is not performed.

Conditional illocutionary acts are summarised in the form " $\mathrm{P} \Rightarrow \mathrm{A}$ " and can be exemplified by an offer, in which the "promise" is dependent on consideration; it can only be successful, i.e. A can be successfully performed, if $\mathrm{P}$ is true.

Conjunctions of illocutions, schematised in the formula "A \& B", gather acts in which two (or more) illocutions are bound together. Illustrative examples include a fire alert, which can be seen as a bond of an assertion and a directive, two simultaneously performed illocutions, whose (joint) success relies on their simultaneous performance.

In an attempt to cover all communicative phenomena, illocutionary logic distinguishes between "strong" and "weak" illocutionary commitments. This distinction is used to elucidate logical compatibility of certain acts and incompatibility of others. For example a speaker who is weakly illocutionarily committed to one act is bound to consistent performance in the use of other, especially immediately following and related acts. In other words, it would be logically incompatible to perform simultaneously an illocutionary act and then an illocutionary denegation of the other (following and related) act; in other word, such acts could not be simultaneously successful. 
In an article on Searle's theory, Vanderveken (2002b: 145 ff.) emphasises that the theory of success and satisfaction of illocutionary acts is in fact more "constructible" and more effective than any theory of truth can be. This is explained with reference to human experience of the world, in which Fregeantype truth-relations are less accessible and approachable than illocutions as in fact they are largely "external" to people's knowledge. In other words, people may not be aware of many aspects that pertain to truth conditions, but thanks to the profoundly intentional nature of communication they know exactly what they attempt to do while producing an utterance. Significantly, according to Searle and Vanderveken, people in general show more expertise on illocutionary forces than on (semantic) properties of the propositional content which they use in their utterances. Vanderveken also claims that in contrast to propositional strict implication, strong illocutionary commitment is "well founded, cognitive, finite, and decidable" (2002b: 146). Thus, in communication, people show weak and strong illocutionary commitments to either elementary or complex illocutionary acts. For Vanderveken, the strength of illocutionary commitment is relative to the number of felicity conditions involved (in other words it is also relative to the level of its generalisation). A promise to come to a certain place at a certain time is thus stronger than a promise to come (e.g. at any or some time). In general, the more conditions an illocutionary commitment involves, the stronger it is.

It is noteworthy that building on both Grice and Searle, Vanderveken suggests a new method for analysis of illocutionary acts, especially non-literal acts. He indicates that of all Gricean maxims, the maxim of quality and the maxim of quantity are especially suited for adoption, and in particular the former can be used as a very general principle of speech act theory. This is because both the maxim of quality and the maxim of quantity concern the logical structure of language and because this logical structure is of universal nature; the maxims operate irrespective of possible differences between languages and cultures. Vanderveken (2002b: 150) grants the two maxims the status of "pragmatic universals of language use". He also suggests that Grice's sub-maxims can be modified to even better suit the needs of speech act theory, for example the submaxim of quality for promises (and generally commissive acts ${ }^{113}$ ) could read as follows:

Let your promise be a successful commitment to doing something! Let it be a promise that you intend and are able to keep and that is good for the hearer! Let it be a promise that you eventually keep!

\footnotetext{
${ }^{113}$ It would be interesting to see how these sub-maxims work for the whole Commissive group as the benevolence exhibited here would certainly have to be denied for some other commissive acts, e.g. threats, where the action "promised" is not (at least on average) in the interest of the other party.
} 
In turn, a sub-maxim of quality for assertions could be rephrased as follows:

Let your assertion represent how things are in the world. Let it be an assertion for which you have reasons, that you believe and which is true!

These sub-maxims are evidently related to conditions of success and satisfaction as they seem to name presupposed elements of contexts such as speaker's attitudes, expectations, desires, and social standards which regulate (linguistic) performance (e.g. you can only successfully promise something that is in the interest of the promisee).

The maxim of quantity translated into illocutionary logic would require that the illocutionary commitment is "as strong as required" to achieve the desired aims (succeed in linguistic performance) in the context. Vanderveken gives an example of a special sub-maxims of quantity for commissives: "Let your commitment to a future action be as strong as required!"

Searle and Vanderveken's logic also suggests logical metalanguage to represent the meaning of all basic types of speech acts, based on Searle's taxonomy. This metalanguage includes so-called illocutionary operators, i.e. notation to represent illocutionary force. Next to standard logical truthconditions, there are also 'rational commitments' which correspond to changes in assertion on the part of the people involved in communication.

Interestingly, Vanderveken (1990, 1991a) also demonstrates how to explain and formally predict the speaker's weak illocutionary commitments by generalizing Kaplan's ramification and his notions of strong and weak entailments and the introduction of a double semantic indexation. Applying the double semantic indexation consists in two steps taken while interpreting sentences: first, a sentence is evaluated with regard to the linguistic meaning, which it should demonstrate in every utterance of a literal illocutionary act; second, the illocutionary act in question is evaluated with regard to its success and satisfaction values. Both levels involve contextual factors, but of a different kind. This framework can further be extended to embrace strong and weak commitments to speech acts within the recursive theory of success.

Focusing on verbs, Vanderveken (1990: 166-219) lists as many as 70 assertives, 32 commissives, 56 directives, 85 declaratives, and 28 expressives. On the basis of his joint research programme with Searle, he also emphasises that "many speech act verbs have several uses and can name different illocutionary forces" (Vanderveken 1990: 168), while some are "systematically ambiguous between several illocutionary points". For instance, to alert is naturally read as conveying either the assertive or the directive force. In Vanderveken and Searle's approach, acts "correspond" to the verbs used in the classification, but the verbs need not be present in the acts. 
Both Searle (e.g. 1992a, 1992b, 1969: 16ff) and Vanderveken indicated that using language means engaging in forms of social behaviour, which presupposes interaction and reciprocity. Building on illocutionary logic applied to individual sentences/utterances, Vanderveken (2001) put forward a proposal of a discourse typology focusing on replies in the context of different types of conversations "with a proper discursive goal", e.g. descriptions, interviews, deliberations, consultations, evaluations, etc. Vanderveken's analysis points to a discursive complexity found in conversations whose "interlocution is creative" (2001: 225) as the speakers need to constantly adjust their plans to achieve their master act goals. However, such inherent dynamicity does not prevent discourse from having a logical (and illocutionary) structure, which can be formally represented.

Searle's and Vanderveken's interest in the logic-oriented dimension of speech acts was followed by other researchers concentrating on formal philosophical issues. For instance, Perrault (cf. 1990) links speech acts with default logic and Jurafsky (2004) presents an overview of applications of speech act theory in studies related to artificial intelligence and computational linguistics.

Searle and Vanderveken's illocutionary logic is an interesting example of how Austin's model can be extended to form a universal theory of language and communication within a logical frame embracing conversational structures (cf. Vanderveken 2001). It blends criticism of the original model with a praise for its tenets and recognition of the potential of Austin's metalinguistic legacy.

\subsubsection{Classifications of speech acts and speech act verbs beyond Austin's and Searle's models}

Classifications based on grammatical criteria naturally tend to be classification of sentences rather than utterances. The simplest examples of such classifications concentrate on sentences type relative to the grammatical mood. There is evidence that grammatical moods of the kind that can be found in the English language have a universal dimension. Comparative studies show that the repertoire of main sentence types is shared by many different languages and many different communities (cf. Sadock 1994, Sadock and Zwicky 1985 and a brief discussion in Sadock $2008^{114}$ ). One of the advantages of mood-based classifications is that they offer clarity in that one sentence cannot simultaneously be a member of two, or more, different classes. The structurebased classes are mutually exclusive and, for instance, an affirmative, declarative sentence cannot be at the same time an interrogative.

\footnotetext{
${ }^{114}$ Sadock (2008) compares the distribution of such phenomena with studies on the distribution of colour terms across cultures done by Berlin and Kay (1969) suggesting that all languages seem to distinguish at least one declarative type, one interrogative type, and one imperative type.
} 
All languages seem to have the basic three sentence types, i.e. the declarative, the interrogative, and the imperative, while some languages further subdivide the moods to grammaticalise further features. Correspondences between the mood types and language functions implicate a universal value. There is also evidence that similar syntactic structures may correlate with semantic similarities, and, especially, that verbs which invite the same or similar structures may often be semantically related (e.g. Atkins et al. 1988; Jackendoff 1990: 109 \& passim).

In English language-based speech act-theoretic research in which basic speech act types correspond to moods of the English language, the categories that are most frequently cited include assertions, commands, questions, and often requests as a separate group (cf. Kasher 1994: 319).

While classifications based solely on mood seem to miss the very basic speech act theoretic element indicated by Austin, viz. that performative utterances, and especially speech acts phrased in the canonical form, are statements in disguise, classifications based on syntactic similarities of verbs seem more promising.

It is presupposed that the knowledge of the basic set of speech acts is part of the core pragmatic knowledge and it has further been suggested that such knowledge is necessary in order to master any natural language, as evidenced by the fact that patients with mental diseases or brain damage often show deficiency in the area of these pragmatic functions (e.g. Meilijson \& Kasher 2004; Prutting $\&$ Kirchner 1987 on paired speech acts).

Commenting on children's acquisition of language, Bates, Camaioni and Volterra (Bates and al. 1975; cf. also Bates 1976) use speech act metalanguage to name three phases in spoken language development prior to the age of 16 months, which they call perlocutionary, illocutionary and locutionary, respectively, to claim that the performative structures being developed in a prelinguistic phase at this time are triggered and expressed by signs such as gestures or eye contact. The authors relate to general forms such as the imperative or the declarative pairing them with interactive social functions (e.g. using a person as a means to get something, or demonstrating or giving in order to attract attention).

In an alternative grammar-oriented approach, Kearns (2006) uses Searle and Vanderveken's framework to suggest a (more) holistic account of speech acts including conditional illocutionary acts. He concentrates on assertions, excluding from his analysis counterfactuals and subjunctive conditionals. Structural patters are also central in analyses of speech acts in historical linguistics (cf. section 3.8). 


\subsection{2.a. Alston and the illocutionary act potential}

In a more theoretical and sophisticated "grammatical" approach, sentence types can be explicitly described in terms of their illocutionary act potential. Alston's (2000) influential account of speech acts follows this line of investigation (cf. section 2.6.2.b).

As evidently verbs are focal to sentences and define the scenarios or frames for events which sentences introduce (cf. e.g. Fillmore 1977a, 1977b, 1977c, Lewandowska-Tomaszczyk 1996), they are also in the centre of "grammatical" approaches. In his 1963 article, Alston used the distinction between the illocutionary and perlocutionary verbs, crediting Austin with the theoretical framework on which his discussion was based, cf. the examples quoted below (after Alston 1963: 115),

\begin{tabular}{|c|c|}
\hline $\begin{array}{l}\text { I. Group one: } \\
\text { illocutionary verbs }\end{array}$ & $\begin{array}{l}\text { II. Group two: } \\
\text { perlocutionary verbs }\end{array}$ \\
\hline report & bring x to learn that ... \\
announce & persuade \\
predict & enceive \\
admit & irritate \\
opine & frighten \\
ask & amuse \\
reprimand & get x to do \\
request & inspire \\
suggest & impress \\
order & distract \\
propose & get x to think about ... \\
express & relieve tension \\
congratulate & embarrass \\
promise & attract attention \\
thank & bore \\
exhort & \\
\hline
\end{tabular}

Table 8: Alston's illocutionary and perlocutionary verbs

Alston suggests that there are important differences between illocutionary and perlocutionary verbs, viz. perlocutionary verbs refer to acts which are clearly characterized by some result.

I could be said to have made a report, request, or admission, asked a question or offered congratulations, no matter what resulted from my utterance. I have still asked a question whether you answer it or not, or 
for that matter, whether or not you pay any attention to me or understand me

(Alston 1963: 116)

Illocutionary acts may, by Alston's own admission, involve a sort of result, which is understanding, but such a result is not helpful in distinguishing within their group, while a perlocutionary act is "defined" by the very result associated with that particular act. What is more, perlocutionary acts, in contrast to illocutionary acts, can be performed unconventionally whereas illocutionary acts are always conventional in some way. For example, people may be "perlocutionarily" manipulated into noticing something that the "manipulator" wants them to notice, which does not have to be linguistically "conventional". It is also indicated that illocutionary acts are "more fundamental in the means-ends hierarchy" ". A related opinion can be found in Searle (1969) who suggests that perlocutionary acts can be "denoted" (Searle 1969: 25) by verbs such as: persuade, convince, enlighten, edify, inspire, scare, alarm, but also expressions of the kind: get someone to do something or get someone to realise something.

In his approach to verbs of speaking and speech acts, Alston (2000) retains five main categories of which the most "institutional" group is named as Exercitives:

Assertives (e.g. assert, allege, report, answer, deny, predict, complain)

Directives (e.g. ask, request, implore, suggest, recommend)

Commissives (e.g. promise, bet, guarantee, invite, offer)

Expressives (e.g. thank, apologize, compliment, express ...)

Exercitives (e.g. adjourn, appoint, pardon, name, fire, approve)

It is evident that Alston's approach is mixed in that both syntacticgrammatical and semantic criteria are used. However, it is also an example of an approach that is explicitly focused on form and the significance of the conventional grammatical structure.

\subsection{2.b. Vendler's 'syntactic' classification}

An interesting approach has been presented by Vendler, who believed that speech is the expression of thought in a code ${ }^{116}$ and after Descartes advocated the idea that there is an essential connection between "real speech" (i.e. Cartesian vera loquela) and the thought (cf. Vendler 1972: 179). He argued that

\footnotetext{
${ }^{115} \mathrm{Cf}$. "I can request you to pass the salt in order to get you to pass the salt, or in order to irritate, distract, or amuse you. But I could hardly amuse you in order to request you to pass the salt, or get you to know that my battery is dead in order to report that my battery is dead" (Alston 1963: 116). ${ }^{116}$ Vendler's general conclusion is that "there is almost universal identity of the objects of speech and thought" (1972: 36)
} 
"say" has two different senses; the "weak" sense corresponds roughly to uttering words, while the other, "full" sense, means that saying "something [...] is to perform an illocutionary act" (Vendler 1972: 53) ${ }^{117}$. Much earlier, commenting on verbs, grammatical tenses, (real) times, and "achievements", Vendler $(1957)^{118}$ pointed out that due to the fact that some states are involuntary and "one cannot know, believe, or love deliberately or carefully" (Vendler 1957: 147), one cannot "be accused of, or held responsible for, having [...] spotted or realized something" (147). It follows that some "states and some achievements cannot be qualified as actions at all" (147), cannot be "done" or "performed". It is significant that Vendler directly attributes this conclusion to J.L. Austin and his Harvard lectures (Vendler 1967: 147, fn. 11). In the preliminary version of his theory, in a somewhat Aktionsart-oriented manner, Vendler suggests that there are (roughly) verbs denoting activity (e.g. running, walking, swimming, pushing or pulling something), and verbs denoting "accomplishments" (e.g. painting a picture, making a chair, reading a novel, playing a game of chess, growing up, recovering from illness). Then there are "achievement" verbs such as recognizing, realizing, losing or finding, being born and dying; finally, there are those which denote clear states, e.g. having, possessing, desiring, liking, knowing, and believing. The last group in this early version also includes, verbs such as ruling and dominating.

Having elaborated on the notions, Vendler (1972) presents a model in which verbs are classified into the following groups:

1) performative verbs

2) psychological verbs

a) mental state (e.g. believe, know) (verbs which "include the present" and involve a span time criterion)

b) mental act with proposition (e.g. decide, discover) (verbs which are propositional like performative verbs and resemble performatives in "speaking" of a moment of "achievement", but never used in the $1^{\text {st }}$ person, singular present)

c) mental act without proposition (e.g. observe) (non-propositional verbs of observation which express present time and are typically used in the present continuous tense).

The classification suggested by Vendler (1972) contains seven main categories characterised by the syntactic patterns which the verbs within a particular category typically select. The new categories are Operatives, which combine the features found in Verdictives and Exercitives, and Interrogatives (e.g. ask, question, enquire), which are usually followed by an "indirect question". The schematic representations for all categories, in which "the

\footnotetext{
${ }^{117}$ The two types can according to Vendler be distinguished via a direct-indirect quotation test; the "weak" sense expression cannot be represented in indirect quotation, but indirect reproduction is "licenced" by an illocutionary act (cf. Vendler 1972: 53ff).

${ }^{118}$ The 1957 text was later included as chapter four in Vendler 1967.
} 
symbolism will speak for itself' (Vendler 1972: 24), are as follows (the sentences cited after each pattern illustrate the structure):

Expositives:

$\mathrm{N}_{\mathrm{i}} \mathrm{V}_{\text {ep }}\left[\mathrm{N} \mathrm{V+]} \quad \rightarrow \quad \mathrm{N}_{\mathrm{i}} \mathrm{V}_{\text {ep }}\right.$ that $\mathrm{N} \mathrm{V}+$

e.g. I confess seeing her. $\quad \rightarrow \quad$ I confess that I have seen her.

Verdictives:

$\mathrm{N}_{\mathrm{i}} \mathrm{V}_{\mathrm{vd}}\left[\mathrm{N}_{\mathrm{j}}\right.$ is $\left.\mathrm{Nk} / \mathrm{A}\right] \rightarrow \quad \mathrm{N}_{\mathrm{i}} \mathrm{V}_{\mathrm{vd}} \mathrm{N}_{\mathrm{j}}$ (as) Nk/A

e.g. It is murder. $\quad \rightarrow \quad$ I call it murder.

Commissives:

$\mathrm{N}_{\mathrm{i}} \mathrm{V}_{\mathrm{cm}}\left[\mathrm{N}_{\mathrm{i}} \bmod (\mathrm{V}+)\right] \quad \rightarrow \quad \mathrm{N}_{\mathrm{i}} \mathrm{V}_{\mathrm{cm}}$ to $\mathrm{V}+$

e.g. I promise (you) that I shall pay on time. $\rightarrow$ I promise (you) to pay in time.

Exercitives :

$\mathrm{N}_{\mathrm{i}} \mathrm{V}_{\text {ee }}\left[\mathrm{N}_{\mathrm{j}} \bmod (\mathrm{V}+)\right] \quad \rightarrow \quad \mathrm{N}_{\mathrm{i}} \mathrm{V}_{\mathrm{ee}} \mathrm{N}_{\mathrm{j}}$ to $\mathrm{V}+$

e.g. I advise you that you (should ) remain silent. $\rightarrow$ I advise you to remain silent. Operatives :

$\mathrm{N}_{\mathrm{i}} \mathrm{V}_{\text {op }}\left[\mathrm{N}_{\mathrm{j}}\right.$ becomes $\left.\mathrm{N}_{\mathrm{k}}\right] \quad \rightarrow \quad \mathrm{N}_{\mathrm{i}} \mathrm{V}_{\text {op }} \mathrm{N}_{\mathrm{j}}$ to be (come) $\mathrm{N}_{\mathrm{k}}$

e.g. I appoint you so that you (shall) be(come) the president. $\rightarrow$ I appoint you to be(come) president.

or:

$\mathrm{N}_{\mathrm{i}} \mathrm{C}\left[\mathrm{N}_{\mathrm{j}}\right.$ becomes W] $\quad \rightarrow \quad \mathrm{N}_{\mathrm{i}} \mathrm{V}_{\text {op }} \mathrm{N}_{\mathrm{j}}$ Behabitives:

$\mathrm{N}_{\mathrm{i}} \mathrm{V}_{\text {bh }}\left[\mathrm{N}_{\mathrm{j}}\right.$ past $\left.(\mathrm{V}+)\right] \quad \rightarrow \quad \mathrm{N}_{\mathrm{i}} \mathrm{V}_{\text {bh }} \mathrm{N}_{\mathrm{j}}$ P nom (past $(\mathrm{V}+)$ )

e.g.I thank you that you helped me. $\rightarrow$ I thank you for having helped me. Interrogatives:

$\mathrm{N}_{\mathrm{i}} \mathrm{V}_{\text {ir }}[\mathrm{N} \mathrm{V+]}$

I question his doing it. $\rightarrow \quad \mathrm{N}_{\mathrm{i}} \mathrm{V}_{\text {ir }}$ wh-nom $(\mathrm{N} \mathrm{V}+)$

$\rightarrow \quad$ I question whether he has succeeded .

(Cf. Vendler 1972: 24-25)

Vendler also provides a classification of the verbs of mental acts and states and shows how grammatical correspondence between complementation patterns of "mental" verbs and "performative" verbs gives insight into kinship relationships which hold across categories, where verbs showing similar syntactic patterns also share semantic features. This systematicity can be found between the categories of "performative" and "mental" verbs and within each group $^{119}$.

Although Vendler's programme involves a "correction" (cf. e.g. Vendler 1972: 5 ; 16) of Austin's theory and his classificatory criteria, the proposed classification can be seen as a corroboration of Austin's hypothesis concerning

\footnotetext{
${ }^{119}$ The reported correspondences indicated by Vendler were identified as "fascinating parallels" by Bach (1975: 235, fn. 4).
} 
speech act typology. While Austin suggested his model on the basis of largely intuitive criteria, Vendler laid down a meticulous description of the grammatical constructions, and especially nominal complementation, of the verbs subjected to analysis. The striking convergence between the two models (despite evident modifications or "corrections") appears to confirm the validity of many aspects of Austin's classification and prompts conclusions as to its universal value ${ }^{120}$.

\subsection{2.c. Katz's 'performative types' and semantics}

Katz (1977) follows Vendler in his interest in syntactic criteria but tries to base a classification of what he calls "performative types" on principles for classifying "types of performative propositions [...] statable in terms of the formal structure of semantic representations" (Katz 1977: 199). It is pointed out that the main difference between Vendler's and Katz's approach is to be that while Vendler concentrates on syntactic structures, Katz bases his classificational principle in semantic structure. The expected advantages of such an approach are that "the limitations of syntactic analysis in dealing with semantic phenomena" (199) may be overcome, and second, that the produced classification should be free from language-specific limitations of the English syntax.

As asserted above (cf. chapter two), Katz introduces a distinction between "semantic performativeness" and "pragmatic performativeness" arguing in favour of Austin's constative/performative distinction and, in his own words, suggesting "how to save Austin from Austin"121.

With regard to a proper classification of speech acts, Katz suggests a classification of "performative types" (Katz 1977: 195-222), explicitly based on the "purity of performatives" and "the dichotomy of performatives and constatives" (Katz 1977: 196) and aimed to show that Austin's abandoning of the performative/constative distinction was not necessary, and in fact a mistake $^{122}$.

\footnotetext{
120 Vendler's background is Chomskyan linguistics-however non-mainstream; he closely cooperated with Zelig Harris on grammatical transformations - and he does believe that linguistic knowledge rests on some universal language acquisition device - explicitly that human beings are endowed with an equipment which "codes the fundamental illocutionary, syntactic, and semantic features of any possible human language" (Vendler 1972: 140) so that eventually knowing a language presupposes knowing that language specific code.

${ }^{121}$ Cf. "How to save Austin from Austin"-Katz's title of the concluding section in chapter five (1977: 177-194).

${ }^{122}$ Cf. Austin's (1962/1995: 149) opinion: "What will not survive the transition [... (from the theory of the performative to the theory of speech acts)], unless perhaps as a marginal case, and hardly surprisingly because it gave trouble from the start, is the notion of the purity of performatives; this was essentially based upon a belief in the dichotomy of performatives and constatives, which we see has to be abandoned in favour of more general families of related and overlapping speech acts, which are just what we have now attempt to classify".
} 
While praising selected aspects of both Austin's and Searle's classifications, Katz claims that there is "no comprehensive doctrine that determines in general the kind of conceptual distinctions that can be used to characterise illocutionary types" (198). Before offering his classification, Katz distinguishes between two types, or two aspects, of propositions: propositional type (force) and propositional content. In order to account for propositional types, both the Illocutionary Success Conditions and the Converted Conditions, must be specified. In summary, starting with syntax and discussing syntactic criteria in much detail (esp. chapter two), Katz eventually claims that syntactic form leads to the meaning of speech acts through semantics. Semantics can inform us about the sentence illocutionary potential, and also pragmatic performativeness can be accessed through semantics as it is on semantic structures that pragmatic rules operate.

In general, Katz suggests that semantically performative sentences are those whose syntactic structures are either imperative or interrogative, or those that are phrased as explicit performatives, i.e. in Austin's canonical form, and for which the time of their utterance coincides with the performance of the act mentioned in the sentence. In Katz's opinion pragmatic performativity could be explained in a parallel manner by applying pragmatic rules to sentence meaning.

Katz does not provide an exhaustive classification, but next to the Assertive and the Requestive type, he suggests seven other propositional types (e.g. two sub-types of Requestives, Advisives, Expressives and also Permissives, Obligatives, Expositives, and Stipulatives) which are also to be analysed in terms of Illocutionary Success Conditions and the (un)Converted Conditions which are discussed with the use of his own notation.

It is implicated that Katz's classifications, possibly after some future completion, should be a thorough taxonomy of all propositional types, i.e. illocutionary acts. By implication, all speech acts, if they are to be included in the classification, would have to possess a proposition type and content, which is an individual proposal and moves against selected other voices in the theory (cf. Austin's (1962/1975: 152) example of an umpire's calling “'Out!").

\subsection{2.d. Selected other approaches}

There is a long list of other classifications of speech acts and speech act verbs offered as alternative vis-à-vis Austin's account, or as an elaboration, or an amendment of his taxonomy, with possibly even more classifications indirectly related through their concentration on Searle's account. This section presents a variety of sometimes very divergent approaches to further illustrate both the richness of responses to the original model and a diversity characteristic of research in the field. 
Not only Katz (1977), but also Holdcroft (e.g. 1974) suggest that the constative/performative distinction should play a role in classifications of speech acts. Holdcroft explicitly claims that only "performatives", in the sense of sentences which contain a device which makes the attempted act explicit, in other words, sentences phrased in the canonical form, should be classified. His claim is that adopting such a position "does not threaten to destroy the contrast between what is performative and what is not" (Holdcroft 1974: 17-18) as this approach, i.e. retaining the distinction between performatives and nonperformatives "in no way affects the fact that numerous sentences do not contain devices which make explicit what act is being attempted by uttering them" (18). Implicitly, explicit performative sentences, with their performative potential, are the only group whose classification seems worthwhile as analysing them may produce a taxonomy which is transparent and well principled.

The tension between more semantic and more pragmatic criteria in classifying speech acts, together with the tension involved in posing the very distinction between semantics and pragmatics have produced interesting modern approaches. For instance, Barker's $(2004,2007)$ model presupposes the kind of ontology in which the world is composed of real objects, properties and relations, and where objects instantiating properties and relations are situation-like "complexes". Following Barker, we are led to believe that such real entities show mereological complexity, but logically they do not have to present a complex compositional structure. Thus, for instance, 'intendings' can be components of speech acts (with no necessity of de re complexity). Accepting that complexes are structured independently of human cognitive activity presupposes that language users can choose categories in which to describe the world; as it is claimed:
Complexes possess mereological complexity, but not logical complexity. Complexes are structured independently of human cognitive activity. That does not mean language users are forced to describe the world using certain categories. Instead, the world itself offers a vast plurality of categories, and language-users can decide amongst those suiting their interests.
(Barker 2004: 70)

This cognitive perspective justifies existing differences in speech act categories which may emerge whenever language users feel that they are needed, implicitly, along with changes in particularities of social life. Intention (intentional states with representational properties), in the philosophical sense, is then seen as a foundation for semantics (Barker 2004: 19-20) in which sentences involve two types of intention, representational intentions and communicative intentions. It is significant that for Barker, the Speech Act Theoretic Approach (STA) presupposes that semantics is a branch of psychology; it is "psychologistic" and even "wedded to psychologism" (Barker 2004: 221). Semantics may also in this 
context be defined as "a kind of formal, abstract pragmatics" (2004: 63). Meaning theory is the description of proto-act types (2004: 79). As a result, following the "cognitive move" towards seeing language as a cognitive phenomenon, a categorisation of speech acts does not have to be explicit or clear-cut as types may emerge without being named and classified. In such a cognitive approach, their features are more readily perceived as salient than necessary, and possibly they may remain in a constant state of flux. Such perspectives allow for dynamicity in speech acts, in which they appear to be close to the original Austinian view and his phenomenological perspective.

Barker's cognitive approach also seems convergent with selected opinions voiced in relevance theory, especially by Sperber and Wilson (1986/1995), even though such opinions are sometimes in a negative note. One of the relevantist claims against speech act theory itself is that although speech act theoretic approach to utterances is "perhaps the most uncontroversial assumption of modern pragmatics" (Sperber \& Wilson 1986/1995: 243), the vast range of data that speech act theorists have been concerned with is of no special interest to the field. In particular, certain speech acts do not need to be recognised, or identified, in order to be successfully performed. In other words, the assignment of a speech act type is not crucial in comprehension and interpretation of utterances, both on the level of explicature and implicature. In consequence, it is claimed, that classification in terms of speech acts plays a minor, if any, role in processing meaning ${ }^{123}$. Speech act types which, according to Sperber and Wilson, need to be ostensively communicated and recognised in order to be successfully performed include, inter alia, promising, ordering, thanking, and bidding, but many other acts, for instance, predicting, denying, claiming, or even warning, do not require any special pragmatic tools to be interpreted and successfully performed; simply, they do not need to be ostensively communicated.

Relevance theory is primarily a theory of how linguistic utterances are processed and understood, it is focused on inferential processes and ostensive communication, which must exert influence on which aspects found in speech act theory are seen as important, salient or essential. This further influences relevance theoretic perspective on speech act classifications. It is interesting in this light that the categories that relevance theory asserts as universal and cognitively real are those directly related to grammatical moods and also to the basic speech act verbs, viz. "saying", "telling" and "asking". These generic speech acts must therefore be recognised as part of the comprehension process and more detailed speech-act description may, but does not have to be inferentially developed.

\footnotetext{
${ }^{123}$ One of the examples quoted to support the thesis is that of tennis, which can be played even when the actual players do not know related theoretical terms (Sperber \& Wilson 1986/1995: 243).
} 
An independent proposal of a taxonomy of illocutionary acts comes from Kukla and Lance (2009), who extend Brandom's (1994, 2000) normative analysis of assertions ${ }^{124}$. Within this approach, speech acts are analysed in terms of entitlements and commitments which they involve; in other words, they are discussed in terms of normative changes that are introduced in the world as a result of producing certain speech acts. In Kukla and Lance's original model, there are two main dimensions, viz. the input dimension and the output dimension. In general, the focus is on the "distinction between input and output - that is, between the normative statuses constitutive of entitlement to a given speech act and the normative changes (in the status of the speaker, or of others in the discursive community) that the act strives to produce" (Kukla \& Lance 2009: 15; original emphasis). All speech acts are said to strive to bring about certain normative changes and, for instance, an assertion involves a strife to impart certain beliefs and grant inference licenses, while orders strive to impute responsibilities for action (Kukla \& Lance 2009: 12). Although what a speech act "strives" to accomplish must not be identified with what is really accomplished in a particular situation, the deontic changes under discussion will naturally relate to interlocutors' rights and obligations. The input and output conditions for both interlocutors may be of two kinds: they are either agentneutral or agent-relative. "Neutral" means that there are no restrictions with regard to who can act, and "relative" means that only selected persons could engage in the activity (i.e. in a successful performance of the linguistic act in question). The authors acknowledge that speech acts may involve multiple layers of normativity and function governing discourse, but they also indicate that the fact does not undermine language users' natural ability to both distinguish between and isolate these (possible) layers.

In summary, if natural and relative dimensions are measured, there may be four different categories of speech act, depending on whether the input for either of the interlocutors, i.e. the speaker and the hearer, is neutral or relative, and, then depending on the parallel output values. The correspondence is represented graphically in Table 9.

\footnotetext{
${ }^{124}$ Both Brandom's $(1994,2000)$ and Kukla and Lance's (2009) approach to conventionality in speech acts is discussed in chapter four (section 4.3.7).
} 


\begin{tabular}{|c|c|c|}
\hline Input $\rightarrow$ & Agent-neutral & Agent-relative \\
\hline Agent-neutral & $\begin{array}{c}1 \\
\text { Neutral input } \\
\text { Neutral output }\end{array}$ & $\begin{array}{c}\mathbf{2} \\
\text { Relative input } \\
\text { Neutral output }\end{array}$ \\
\hline Agent-relative & $\begin{array}{c}\mathbf{3} \\
\text { Neutral input } \\
\text { Relative output }\end{array}$ & $\begin{array}{c}\mathbf{4} \\
\text { Relative input } \\
\text { Relative output }\end{array}$ \\
\hline
\end{tabular}

Table 9: A schema for the values of normative situation in a speech act based on Kukla and Lance (2009: 19)

Kukla and Lance (2009) elaborate the two types, or dimensions, of speech acts in more detail as represented in Table 10.

Imperatives are always placed in box 4 because they are speech acts "that are entitled by specific facts about a speaker's normative position and relationship to the target of the imperative, and they serve to make a demand upon a specific person or persons" (Kukla \& Lance 2009: 19). However, box 4 may also house other speech acts, which are not imperatives. Such acts may, inter alia, include promises, invitations, and reproaches, as in uttering all of them a speaker would make a claim based on his or her particular normative position, and upon another person's being in a certain normative position. In turn, claims about a public truth will be housed in box 1 (e.g. "Cats like to sleep on mats"; "There are no analytic a posteriori truths"). Marriage ceremonies, although focused on particular agents, will also involve a "general" recognition (and be classified as agent-neutral) by changes which they induce in the social normative sphere. 


\begin{tabular}{|c|c|c|}
\hline Input $\rightarrow$ & Agent-neutral & Agent-relative \\
\hline Agent-neutral & $\begin{array}{c}1 \\
\text { Neutral input } \\
\text { Neutral output } \\
\text { Declaratives } \\
\text { Categorical } \\
\text { Imperatives }\end{array}$ & $\begin{array}{c}\mathbf{2} \\
\text { Relative input } \\
\text { Neutral output } \\
\text { Kantian judgments of taste, } \\
\text { baptisms, some recognitives, } \\
\text { i.e. observatives, some } \\
\text { acknowledgments }\end{array}$ \\
\hline Agent-relative & $\begin{array}{c}\mathbf{3} \\
\text { Neutral input } \\
\text { Relative output } \\
\text { Prescriptives }\end{array}$ & $\begin{array}{c}\mathbf{4} \\
\text { Relative input } \\
\text { Relative output } \\
\text { Imperatives } \\
\text { (promises, invitations, } \\
\text { reproaches...) } \\
\text { Ostensions, some } \\
\text { recognitives, i.e. vocatives, } \\
\text { some acknowledgments }\end{array}$ \\
\hline
\end{tabular}

Table 10: A classification of illocutionary acts according to Kukla and Lance (2009: 150)

It is emphasised that it is the function and not a surface grammar form that defines a speech act. Similarly, agent-relativity and agent-neutrality are defined with reference to context. For example, even though an agent-relative output could apply de facto to everyone due to, e.g., the semantic structure involved ("Everyone raise your right hand") or because of facts in the world which define relevant extension ("Those of you under nine feet tall, wear this badge"), the output of the cited orders will be agent-relative as they influence particular persons (Kukla \& Lance 2009: 23). The universality of the target in such cases is not seen as a function of their pragmatic structure. Kukla and Lance further make a distinction between two species of agent-relative normative statuses: on the input end, there may be kind-relative entitlements, and on the output end, there may be kind-relative claims. Kind-relative entitlements and claims result from agents belonging to a certain group, or their being of a certain "kind" (e.g. colonels entitled to give orders to privates, etc.). There may also be agentspecific statuses. For instance, 
When Martha pronounces Bob and Jerry married, her entitlement to do so is agent-relative and kind-relative, but Bob and Jerry's new status as married is agent-relative and agent-specific: the ceremony alters the normative statuses of Bob and Jerry, qua concrete individuals rather than qua fungible instances of a larger category.

(Kukla and Lance 2009: 24)

Similarly, a promise generates an entitlement on the part of the promisee to expect fulfilment of what has been promised; it also generates a commitment on the part of the promisor to fulfill the promise. The obligation on the part of the promisor is always agent-specific. There is a difference between kind-relative statuses and agent-specific statuses in that the former type does not distinguish between actual and possible instances of the kind. The definitions involved may be of de dicto type with no specific, and actual, references. On the other hand, kind-related expressions may be used to define the group of referents (e.g. "Attention citizens of Gotham: I promise to rid your city of masked supervillains!”) (Kukla \& Lance 2009: 24).

Among the many interesting points put forward by Kukla and Lance, there is their discussion of the "mixed" categories and sub-categories criss-crossing the general types, e.g. the group of observatives (box 2) and the group of vocatives (box 4). For instance, acknowledgments constitute a group of speech acts characterised by "individuating", a personal, or personalised, relation that could be described by the label "from me to you" or "in each case mine", or defined as "second-personal" (cf. Kukla and Lance 2009: 135ff and chapter two and three).

The normative classification put forward by Kukla and Lance takes for granted the very existence of speech acts and concentrates on their normative aspects, but seems to work independently of the Austinian tradition in its attempt to produce a taxonomy based on a novel methodology with speech acts organised under new labels.

The classifications mentioned in this section are illustrative of the methodological-theoretical diversity present in the field; they also indicate the dynamicity characteristic of speech act-theoretic research, where there still is a strife to discover and account for new categories and to produce the most adequate taxonomy of speech acts.

\subsection{2.e. Speech act verbs - lexicological and lexicographical approaches}

In linguistics, many researchers followed Austin by concentrating on listing verbs rather than "acts". In consequence, there appeared inventories of speech action verbs whose descriptions were of lexicological, or even lexicographical nature. In a way, such accounts directly follow Austin's explicitly 
phenomenological approach as they are underlined with a belief that an analysis, and a description, of how particular verbs are used must give insight into significant aspects of human interaction. However, lexical approaches can also depart from Austin's philosophical stance and move towards lexicographic practice.

An independent approach is offered by Wierzbicka (1987) who lists English verbs using a new semantic metalanguage, a supposedly "primitive" and universal set of vocabulary, known as "semantic primes", in which speech acts could be explicated through "reductive paraphrase". Reductive paraphrase was introduced as a method in which only 150 lexemes are used (in contrast to, e.g., 2000 as defined at the time for the Longman Dictionary of Contemporary English) in order to provide an explanatory definition of a concept in terms of a few simple sentences ${ }^{125}$. As Wierzbicka (1987: 11) puts it, "instead of comparing an unidentified meaning with various other meanings, one could simply identify it by enumerating all its constituents".

Wierzbicka's metalanguage is based on a minimal set of fifteen "semantic primitives", i.e. elementary conceptual building blocks, which themselves are not defined. The set includes: I, you, so, something, this, want, not want, think (of), say, imagine, know, place, part, world, and become (cf. Wierzbicka 1972, 1980, 1985a, 1985b, 1987, 1996). In the speech act dictionary some other words, which are not primitives themselves, but help to capture crucial semantic similarities, are added, such as: good, value, do, happen, good, bad, feel. It is interesting that in order to exclude possible "vicious circles", only one basic speech act verb, i.e. "say", has been used in the definitions ${ }^{126}$. According to Wierzbicka, the metalanguage includes "cultural scripts" which should make it possible to objectively describe emotions and cultural values and attitudes. Eventually, Wierzbicka's Natural Semantic Metalanguage (NSM) (cf. e.g. Wierzbicka 1999: 34) is to be an "alphabet of human thoughts" and is supposed to be an especially effective tool for a description of speech acts in intercultural contexts.

In numerous publications, Wierzbicka (e.g. 1987: 15ff., 1991, 1999) argues that speech acts exteriorize the speaker's mental states and are reflection of mental acts. In her earlier book, English Speech Act Verbs: A semantic dictionary (Wierzbicka 1987; cf. also 1996: 174-178), she integrates her approach with Austin's and Searle's theories presenting speech acts as bundles of two main components, the dictum and the illocutionary purpose, as illustrated in the example below:

\footnotetext{
125 The number of Wierzbicka'a semantic primes, i.e. atomic expressions in the tradition of Leibniz have fluctuated over time ranging between 13 to over a hundred.

${ }^{126} \mathrm{Cf}$. Description of "promise" in section 3.7.
} 
Illocutionary purpose: "I say this because I want to cause you to know it"

The dictum element is expected to be hierarchically composed depending on the nature of particular verbs. For instance, some verbs are shown to require a more elaborate structure for the "I say" element as illustrated in the entries for inform and suggest below:
a. inform:
"I say: [...]"
b. suggest:
"I say: I think it would be good if [...]"

The dictum and the illocutionary purpose element can be complemented, where necessary, with further information on, e.g., emotional or intentional states, although in natural speech, for the greater majority of utterances, the illocutionary force is unambiguous (Wierzbicka 1991: 199). In her analyses, Wierzbicka often goes beyond the English language and provides a contrastive study with other languages, mainly Polish and Russian.

Another analysis which follows Austin's phenomenological agenda to discover how social life is reflected and codified in language is an explicitly lexicographic analysis offered by Ballmer and Brennenstuhl (1981), who analyse 4800 verbs in their performative contexts in order to classify them according to hierarchically organised semantic fields.

Ballmer and Brennenstuhl's general project is a comparative contrastive study of German and English verbs, for which speech activity verbs are the initial focal area. In this "cognitive-behavioural" analysis, verbs, although used as a starting point, are treated as abstract labels for "human speech activities" (Ballmer and Brennenstuhl 1981: 28). They were culled from dictionaries and thesauruses and later classified in fields and subfields (600 basic groups) or categories labelled after their focal verbs. For instance, the category of "rejecting" includes verbs such as reject, dismiss and decline. All Ballmer and Brennenstuhl's categories, having been analysed along presupposition-oriented criteria, are further classified within 24 models and 8 model groups, which include: emotion, struggle, valuation, institutional, enaction, discourse, text, and theme ${ }^{127}$. This structure gives rise to a three-dimensional picture of the verbs' meaning.

\footnotetext{
${ }^{127}$ Ballmer and Brenensthul (1981: 27) describe the so-called "hat structure" identified for many models which might offer a new perspective on lexical semantics of verbs in general integrating issues discussed with reference to aspect and Aktionsart. Interestingly, the authors' analysis of speech act verbs was designed as a part of a larger lexicographic project for all German vocabulary.
} 
The speech act-theoretic approaches sketched above are directly linked to Austin's research plan, but also mark a considerable departure from his original agenda offering novel, more systematic methodologies. They adopt the general idea that speech can be a kind of action to offer catalogues of verbs with their potential, and most frequent uses. They follow Austin's meticulous descriptions, but more explicitly refer to verbs rather than abstract actions.

\subsection{2.f. Speech acts and 'resource situation type'}

Another approach which struggles to embrace context in its theoretical frame is exemplified by Proost (2009), who, drawing on German speech act-theoretic research, argues for the adoption of the notion of the "general resource situation type" as a starting point in classifying speech act verbs. It is first suggested that speech act verbs are used to refer to situations which are characterised by features such as: specific roles of the speaker, roles of the hearer, a set of speaker's attitudes and presupposed context-related information. They may also often involve a proposition of some kind. It is concluded that such elements of a communicative situation can be used in formulating relevant classifications. Figure 4 below illustrates different types of specifications of each of these elements based on a comparative analysis of sentences containing speech act verbs, in which criteria such as well-formedness are taken into consideration ${ }^{128}$. It is further argued that "different combinations of specifications of the different kinds of speaker attitudes and of the properties of the propositional content constitute special resource situation types, which indicate, and are referred to by distinct types of speech act verbs" (Proost 2009: 913). It is evident that the model attempts to embrace broad communicative acts, in part implicitly importing criteria from standard models of communication and combining them with speech act theoretic notions.

The approach illustrated in Figure 4 gives rise to classifications which are presented in Table 11. Elements of the situations referred to are shown to be components of the meaning of the corresponding speech act verbs. There are six distinct classes, where group (1a) and (1b) are united as sub-types of Representatives and (4a) and (4b) are grouped under the label of Expressives. Although the taxonomy is based on contextual-communicative and syntactic criteria, the description shows striking correspondences to (and agreement with) Searle's (1979b. [1975]) "armchair" classification (cf. section 3.4.1).

\footnotetext{
${ }^{128}$ For instance, a comparison of the well-formed "I order you to leave" with the ill-formed "I order you to have left" is used to indicate that to order lexicalises the specification "future action of $\mathrm{H}$ [H=hearer]" for the properties of the propositional content (Proost 2009: 913).
} 


\section{General resource \\ Situation type}

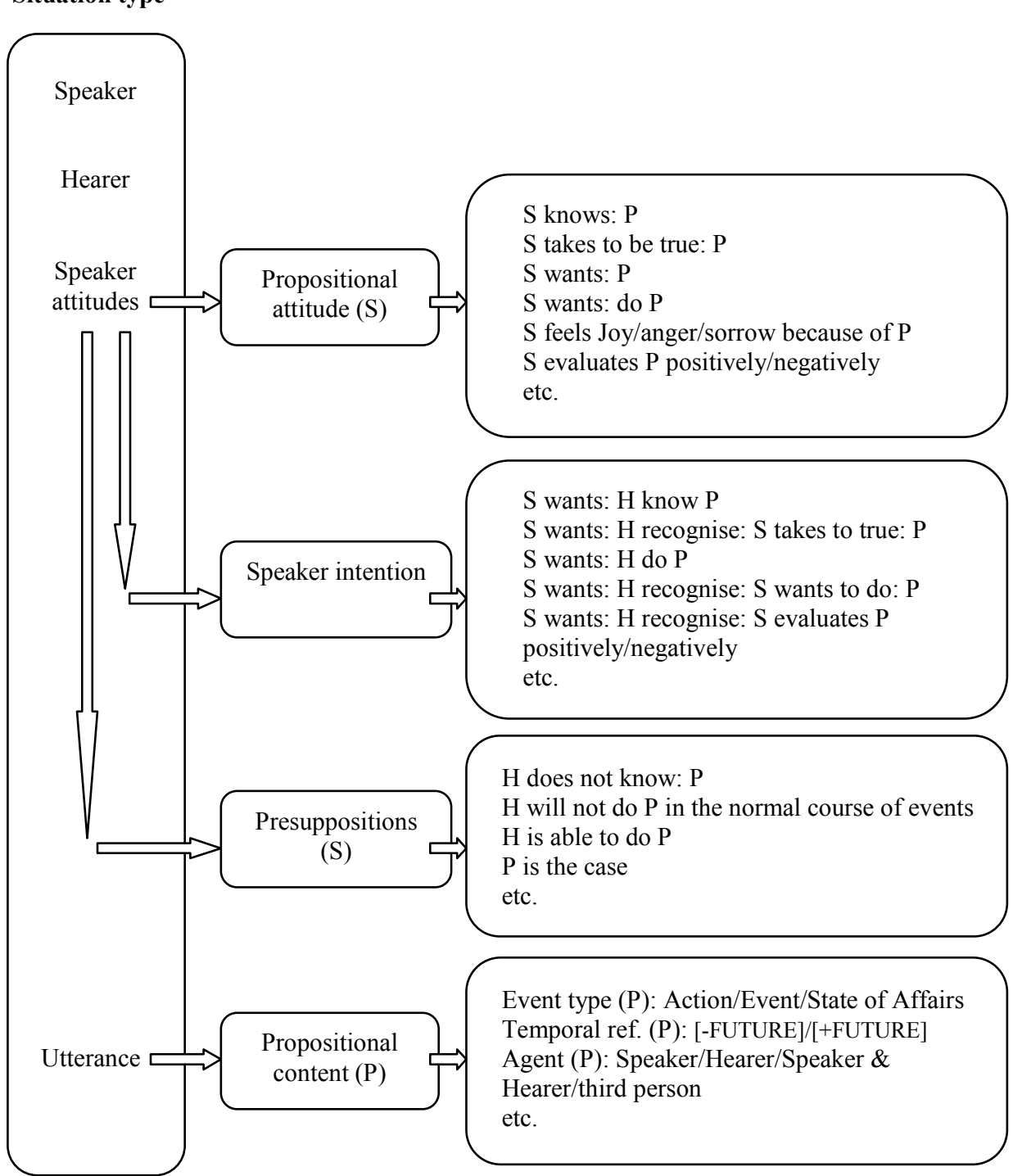

Figure 4: Specification of the elements of the general resource situation type

(Proost 2009: 913) 
(1a) Assertives: claim assert, ...

Propositional attitude (S):

Intention (S):

$\mathrm{S}$ takes to be true: $\mathrm{P}$

Presupposition (S):

$\mathrm{S}$ wants: $\mathrm{H}$ recognise: $\mathrm{S}$ takes to be true: $\mathrm{P}$

Event type (P):

$\mathrm{H}$ does not know: $\mathrm{P}$

Temporal reference $(\mathrm{P})$ :

Action/Event/State of Affairs

[- FUTURE]/[+FUTURE]

(1b) Information verbs: inform, tell, impart,communicate, ...

Propositional attitude (S): $\quad \mathrm{S}$ knows $\mathrm{P}$

Intention (S):

$S$ wants: $\mathrm{H}$ know: $\mathrm{P}$

Presupposition (S):

$\mathrm{H}$ does not know: $\mathrm{P}$

Event type (P):

Action/Event/State of Affairs

Temporal reference $(\mathrm{P})$ :

[- FUTURE]/[+FUTURE]

(2) Directives: ask (sb to do sth), order, request, ...

Propositional attitude (S): $\mathrm{S}$ wants: P

Intention (S):

S wants: $\mathrm{H}$ do: $\mathrm{P}$

Presupposition (S):

$\mathrm{H}$ will not do $\mathrm{P}$ in the normal course of events

Event type (P):

$\mathrm{H}$ is able to do $\mathrm{P}$

Agent (P):

Action

Temporal reference $(\mathrm{P}): \quad[+\mathrm{FUTURE}]$

(3) Commissives: promise, guarantee, pledge, vow ...

Propositional attitude (S): $\quad \mathrm{S}$ wants to do $\mathrm{P}$

Intention (S)

$S$ wants: $H$ recognise: $S$ wants to do $P$

Presupposition (S):

$\mathrm{P}$ is in the interest of $\mathrm{H}$

Event type (P):

Action

Agent (P):

Speaker

Temporal reference $(\mathrm{P})$ :

[+FUTURE]

(4a) Verbs expressing emotions: rejoice, complain, scold ...

Propositional attitude (S): $\quad \mathrm{S}$ feels joy/anger/sorrow because of $\mathrm{P}$

Intention (S):

Presupposition (S):

$\mathrm{S}$ wants: $\mathrm{H}$ recognise: $\mathrm{S}$ feels joy/anger/sorrow because of $\mathrm{P}$

Event type (P):

$\mathrm{P}$ is the case

Temporal reference $(\mathrm{P})$ :

Action/Event/State of Affairs

[-FUTURE]

(4b) Verbs expressing evaluations: praise, criticise ...

Propositional attitude (S): $\quad \mathrm{S}$ evaluates $\mathrm{P}$ positively/negatively

Intention (S):

$\mathrm{S}$ wants: $\mathrm{H}$ recognise: $\mathrm{S}$ evaluates $\mathrm{P}$ positively/negatively

Presupposition (S):

$\mathrm{P}$ is the case

Event type (P):

Action

Agent (P):

Hearer of Third Person

Temporal reference $(\mathrm{P})$ : $\quad$ [-FUTURE]

Table 11: Classes of speech act verbs according to Proost (2009: 914)

Proost's account of speech act verbs is also interesting as it implicitly leads towards speech act-theoretic developments which attempt to maximally embrace contextual factors in their descriptions of what is more readily called "speech actions" than speech acts (cf. chapter five). Taking this direction can be seen 
both as an elaboration of Austin's ideas, a departure from his theory, and as a move back towards his maximalistic original programme in which speech acts should be considered in all richness of context.

\subsection{Indirect acts and classificatory criteria}

Indirect acts require classifications which relate to force rather than the form of utterances as they naturally involve a discrepancy between overt form and communicated function and in this way would naturally escape approaches based on syntactic or formal-semantic criteria as the ones described in the preceding sections.

There are different approaches to the nature of such acts. Searle (1975a, 1979b [1975]) suggested a remarkably consistent way of classifying indirect speech acts by relating indirectness to the direction of fit and their conditions for successful accomplishment. In general, according to Searle, in indirect acts there are two simultaneous illocutionary forces at work, in other words, "a sentence that contains the illocutionary force indicators for one kind of illocutionary acts can be uttered to perform, IN ADDITION, another type of illocutionary acts" (Searle 1975a: 59, original emphasis). Searle distinguishes between cases in which the speaker means what she says, but also "means something more" (e.g. "I want you to do it") and cases in which the speaker means what she says "and also means another illocution" (e.g. Can you reach the salt?") (Searle 1975a: 59, 60). In both cases Searle's utterances have double illocutionary forces. In the context of taxonomy, this fact produces a situation in which a sentence would have to be double classified, according to both its primary and secondary meaning. This aspect of Searle's programme seems counterintuitive as in natural communication participants rarely feel that utterances suggest double, or multiple, interpretations. Such understanding appears to be confined to humorous uses, word play, or, sometimes, manipulative discourse, but is not normally recognised to be part of common communication, at least not as a feature of which interlocutors would be aware.

There is evidence (cf. e.g. Asher and Lascarides 2001) that the meaning of an indirect speech act is calculable, which means that the primary (i.e. indirect) meaning is foregrounded, but it is claimed that indirect acts are not calculable in the manner in which a Gricean implicature can be calculated. Paraphrases of indirect acts can rarely be successful as equivalent speech acts.

Proposals such as Searle's are also problematic because of the varied nature of indirect speech acts and their varied linguistic behaviour. For example, many indirect acts are "directly" interpreted. A "question" such as:

(46)Can you pass me the salt? 
being probably the most frequently cited example, as well as many other "indirect" requests, can be easily modified by "please", which explicates or reinforces the fact that the utterance is used as a request, and whose insertion is not possible in case of "pure", "real" questions. Such examples are often described as "conventionalised", "standardised", or "illocutionary standardised" (e.g. Bach 1995; Bach \& Harnish 1979).

Asher and Lascarides (2001) suggest that conventionalised indirect speech acts "can block their 'paraphrases' from being interpreted as indirect speech acts, even if this interpretation is calculable from Gricean-style principles" (Asher \& Lascarides 2001: 183). They side with Horn and Bayer (1984) recognising "a principle of blocking" or "pre-emption by synonymy" to which speech acts are subject. This would suggest that for many indirect speech acts it is indeed possible to indicate the form-and-meaning structure. However, the degree of conventionality or standardisation can differ much across indirect speech acts (cf. chapter four on conventionality) and as a result an even approximate description is difficult. Evidently, in Asher and Lascarides' approach, speech act types are treated as relations between utterances (2001: 223) and not, e.g. properties of utterances. Selected indirect speech acts are calculable through Gricean inference, others thanks to their conventional form.

Later research in speech act comprehension shows that common indirect speech acts do not take longer to process and that the interpretation of many indirect speech acts just does not include a literal phase. Instead, it is claimed that context allows for prompt understanding of such indirect utterances (e.g. Ervin-Tripp 1976). It could thus be concluded that utterances of this kind are "short-circuited" and involve just one illocutionary force; one of the methodological consequences of this perspective is that such utterances should be classified according to their primary illocutionary force, and not with reference to their surface form. This ethnomethodological approach has produced rich literature, especially focused on politeness issues and intercultural differences.

With regard to the status of speech act categories in the context of indirect acts, Ervin-Tripp (1976: 28) claimed that

Terms like 'promise', 'tell', 'request' which appear as performatives in some linguists' rules $[\ldots]$ are derived from the vocabulary of indirect speech, in which speech events are reported as categories". The verbs used in indirect speech are a source of information about native speakers' categories in the ethnography of speaking. The English verbs used in reporting are not necessarily the best analytic categories for classifying speech events, though they are a plausible first hypothesis. There is no reason to believe English has a good metalanguage for itself, as linguistic terminology testifies. 
In this perspective, although Ervin-Tripp's focus is mainly on Directives, it is evidently suggested that categories emerge spontaneously when language users become theoretical about the speech actions that they (or other people) perform. Once more, the categories that arise in this way are "situated" and relevant for a particular community as they will emerge in a bottom-up manner, as reflection on actions which have already taken place. In this context, it has been pointed out that the social distribution of their carried forms is both systematic and relative to categories such as "familiarity, rank, territorial location, difficulty of task, whether or not a duty is normally expected, whether or not non-compliance is likely," etc. (Ervin-Tripp 1976: 25). It is thus clear that speech acts in such contexts are primarily social in nature and taken to be reflective of the social structure in question. They are dynamic and rooted in interaction rather than abstract linguistic forms.

The claim of universality of speech act categories may either be phrased in a much general manner, where all human beings are seen as similar in their linguistic performance, or must be focused on a particular language community, or rather on a particular ethnic group as there are differences in verbal deeds between communities which belong in different cultures even if on the surface they use the same language. This fact has been richly documented in literature on intercultural communication where using parallel language forms not only does not guarantee successful communication, but may indeed produce fundamental misunderstandings ${ }^{129}$.

In an intercultural perspective Rosaldo (1982) suggests that analysis of conversational acts, such as exemplified in Dore's (e.g. 1979) research, where conversationally realised typifications of linguistic actions provide the basis for speech act classification, may provide a more stable foundation, and be theoretically sound, for categorisation of verbal deeds, which allows for inclusion of cultural and institutional issues ${ }^{130}$.

\subsection{Speech act categories in an intercultural perspective}

One of the most frequent applications of speech act taxonomies, where speech act theory is frequently taken for granted, is the field of intercultural and crosscultural studies. This research area has motivated its own body of literature, where speech act classifications can be approached as an explicit, etic and "behaviourally applicable" research tool (cf. e.g. Reiss 1985). Many of such

\footnotetext{
${ }^{129} \mathrm{Cf}$. considerations of parameters such as high and low context cultures, collectivist and individualist societies, power distance, other cultural dimensions, etc. in the tradition of Hall (1976) and Hofstede (e.g. 1997).

${ }^{130}$ Conversational clusters of speech acts, similar to adjacency pairs analysed in conversational analysis, have also been proved useful in clinical linguistic contexts, cf. e.g. Prutting \& Kirchner 1987.
} 
approaches (including Reiss 1985) concentrate on "observer-defined categories", locutionary forms, without attempting mind-reading of either the speaker's or the hearer's particular intentions and attitudes. In many intercultural studies, researchers list and classify the patterning of speech forms in certain cultures and can often focus on speakers' intended perlocutionary effects, as envisaged by the observers, attempting to illustrate 'how' things are done with words in relevant communities. There is a natural link between this type of analysis and ethnomethodological studies (cf. e.g. Turner's 1974 edited collection; Garfinkel $1967 / 1984$; 1972) as it is at least implicitly accepted that particular data may suggest categories relevant for research in the field, while the observer's task is to identify the categories manifested in how discourse participants use language and how individuals construct and give meaning to the social world (cf. Wierzbicka 1997 for a cross-cultural study ${ }^{131}$, cf. Blum-Kulka et al. 1989; Sharifian 2011) ${ }^{132}$.

The sections below illustrate selected merits offered by applying a speech act taxonomy in ethnographic description, and further indicate implications that etic empirical analyses may have for the theory of speech acts, its possible evolution and verification of its tenets.

\section{Rosaldo's taxonomy of Ilongots' speech acts}

The view that speech acts are directly reflective of the social reality that particular people experience has been endorsed by, inter alia, Rosaldo. Pointing to the language of Ilongots of Phillipines, Rosaldo (1982) emphasises the fact that some languages may encode a different perspective on the world. In her view, users of English typically see their language as a tool to "express" or to "refer". In contrast, Ilongots think of language primarily in terms of action (Rosaldo 1982: 203). As Rosaldo claims,

They see commands as the exemplary act of speech, displaying less concern for the subjective meanings that an utterance conveys than for the social contexts in which utterances are heard. (Rosaldo 1982: 203)

Rosaldo emphasises the striking salience of directives in the lives of Ilongots, which was visible in all communicative contexts. Reportedly, the community did not have institutions such as the church, the court of justice, or the office, and spent their lives in one room houses. What is interesting in the context of speech

\footnotetext{
${ }^{131}$ In particular, Wierzbicka's analysis of "unique" Australian speech act verbs is of interest in this context (1997: 202-217).

${ }^{132}$ Cf. Everett's (2012: 51) comment that “Austin was by no means the only person to recognize the power of language as a tool. This importance has been recognized in most societies and in most subcultures" with an indication that his book was "one of the most influencial treatises in the history of language studies.
} 
act taxonomy is that Rosaldo was one of the first researchers to point to the inadequacy of Searle's (and as it can be supposed Austin's as well) taxonomy in the context of such situated communication. In the midst of Ilongots' directives, Rosaldo noticed that

the hierarchies associated with Ilongot commands are social facts that must themselves be understood within the context of folk views about the nature of their local social world. In particular, it would appear that llongot hierarchies of prerogative and respect must be seen ultimately as matters not of power, deference, or control, but rather of particular persons' needs and skills and of the reciprocities (and inequities) that grow through regular performance of sex/age appropriate chores.

This point needs stressing. Attention to universal "features" such as "power," "dominance," and the like will be misleading if the social relationships so described go unexplored. Inequities exist for Ilongots; they are articulated and negotiated in the social uses of commands. But an understanding of what Ilongot directives mean requires an account not just of rank but of ideas defining social roles and bonds.

(Rosaldo 1982: 207-208)

Rosaldo's example serves to show that superficially cognate form may be correlated with different values. Directives may be socially defined as not a sign of domination, but respect and care. In comparison to English, they may serve different aims and evoke different emotions. It is thus at least questionable whether a taxonomy such as Searle's speech act classification can be useful in building a model of Ilongots' verbal interaction as there is an evident need for reformulation of the functional categories. For Ilongots, apparent Assertives are rarely concerned with fact or truth, Declarations are directed to supernatural powers, and Commissives seem not to have any realisations apart from a formulaic oath of salt. On the other hand, communication is perceived as action. As Rosaldo suggests, promises are overt signs of undertaking commitments in public, they seem to arise from "inside out", from the speaker's inner world, and as such, would promote perception of language in terms of individual inner life, although it is the social sphere that motivates (linguistic) action. On reflection, it is tuydek, i.e. a command, a "fetch-me-that", that is seen as a foundation for all social life. Directives, in this particular context, primarily in the form of imperatives and interrogatives, are perceived as the core of language and of thought, with thoughts, in turn, perceived as "utterances of the heart."

In summary, Rosaldo suggests that looking through the prism of Searle's classification, Ilongots have two basic categories of speech acts, i.e. Directives and Declaratives with other Austinian and Searlian categories hardly visible. She emphasises the fact that this categorisation (there being the two basic groups) is consistent with the way in which the community organises and understands 
social action, and, in particular, relationships in between its members, while the "categories of speech acts that they recognize with distinctive verbal names reflect indigenous concerns with order in their social world" (Rosaldo 1982: 223).

An important question raised by Rosaldo concerns the criteria for classification of acts, both direct and indirect, employed by Ilongots. There appeared a necessity to distinguish "commands" or tuydek, from related acts such as "prohibitions" (tukbur), "orders and warnings" (tengteng), "requests" (bēge), "appeals" ('ungi'ungi), and other unlabeled directives including, e.g., "awakening" (pabēngun) and "hurrying up" (pekamu). It turned out that the people classified their verbal deeds irrespective of their grammatical form, or concepts such as that of "face" or politeness. For instance, indirect requests were not seen as "softer", or more polite than their direct counterparts (cf. "Is there some water here?" versus "give me water" cited in Rosaldo 1982: 223). Instead, what seemed most salient was the type of the cooperative activity which the action involved. The concepts behind classifying acts were local and situated and reflective of the people's concerns in everyday life. These were related to the division of labour between men and women and the younger and the elderly, which was reflected in reference to concepts such as "knowledge" and "move", which were further coded in directives characterised by a particular quality related to "interruption" and "movement". Another set of criteria had to do with concern for coordination of tasks and services in the context when the hierarchy within Ilongots' community was based on parity, and their autonomy was based on cooperative work. As a result, as Rosaldo suggested, directives were distinguished "in terms of hierarchical as against more mutual or reciprocal chains of service and command" (227). Finally, as directives were evidently central in the articulation of the experienced kinship order, they differed depending on the type of action, and in particular, depending on whether the relationship was perceived as "given" and stable, or whether it required reaffirming in "cooperative displays". To reiterate, "indigenous views of human actions and interactions - concerns for movement; for social hierarchy and cooperation; and for the temporal fragility of social bonds" (227) proved necessary to an understanding of conventions recognised in categorisation of speech acts.

Rosaldo's criticism of Austinian and Searlian, and especially Searlian taxonomy concentrated on the fact that "action is something constituted by social beings who, in acting, implicate their understanding of the world in which they live" (227), which, allegedly, was neglected in the model through concentration on the speaker's psychological state and "corresponding inattention to the social sphere" (227). It is emphasised that in the AngloAmerican and European perspective on speech acts the emphasis is put on propositions, while Ilongots would see directives as paradigmatic acts of speech. 
As a result, the view of human sociality is different, and in Rosaldo's opinion problematic, in both (broadly perceived) cultures.

One of the implications of Rosaldo's research is the fact that understanding speech acts involves understanding social relationships, which are not directly accessible through transferring, for instance, Anglo-American concepts of how language works and how things are done with words to culturally foreign communities. Instead, understanding verbal communication in a different cultural context requires an insight into how the other social world shapes interaction and relations between its people, how participants of the other community form and recognise their deeds and bonds. Self-critically, Rosaldo points to the fact that "certain of our culturally shaped ideas about how human beings act have limited our grasp of speech behaviour, leading us to celebrate the individual who acts without attending to contextual constraints on meaning" (228). Saying that, paradoxically, she accuses speech act theory, commonly seen as one of the central fields, or indeed "the" central field, of pragmatics of little concern for contextual factors.

In conclusion of her account, Rosaldo claimes that

Reflections on Ilongot notions concerning acts of speech should serve, then, as a reminder that the understanding of linguistic action always, and necessarily, demands much more than an account of what it is that individuals intend to say: because, as Ilongots themselves are well aware, the "force" of acts of speech depends on things participants expect; and then again, because, as our comparison makes clear, such expectations are themselves the products of particular forms of sociocultural being.

(Rosaldo 1982: 228-229)

Another implication from research such as that of Rosaldo's is that, possibly, speech act taxonomy only makes sense in a particular social context and is not really possible beyond a trivial concentration on Directives, thus, not really practical, in a more universal manner.

It is also worth noting that Rosaldo's general agenda is consistent with Austin's original agenda for his linguistic phenomenological research aimed at uncovering the hidden social structure reflected in the words of speech actions. Consequently, the criticism voiced by Rosaldo with regard to speech act taxonomy, although mostly directed to Searle ${ }^{133}$ and only extended in a number of points to Austin, may well be seen as criticism of what Searle suggested in his more purified and transparent model of speech act classification. Rosaldo's ideas seems closer to Austin's original approach to classifying speech acts and the use

\footnotetext{
${ }^{133}$ In Rosaldo's opinion, Austin's ideas related to speech act theory received "their fullest formulation in the writings of the Berkeley philosopher, John Searle" (Rosaldo 1982: 229; fn. 4), although, in the context of Derrida's conception of speech acts, she also acknowledges that Searle departed from Austin in a significant way (230-231; fn.15).
} 
to which verbs can be put. They both concentrate on discovering the social underlying structure although for Austin it was the English language use that was the object of analysis, and not a foreign language rooted in a foreign culture. Both Austin's and Rosaldo's approach to speech acts may be seen as a path to later theories and models, such as the ones discussed in chapter five, which emphasise speech "actions" rather than "acts" and concentrate on situated meaning.

In summary, Rosaldo's research embodies both a departure from Austin, by deserting his focus on the English language, and as a reinforcement of certain aspects of his work, which, significantly, were ignored or abandoned by others, i.e. his concentration on the social reality behind speech acts. Rosaldo's work is further an indication that speech act taxonomies, such as those proposed by Austin or Searle, cannot be perfectly universal due to their bond with not only the English language, but also the "local" social relations.

\subsection{The act of promising - a 'zooming' perspective}

In linguistics and philosophy of language, the concept of 'promise' and the verb to promise have both received much attention and may serve as an informed illustration of what kind of problems speech act theory has to face and what kind of agendas are pursued in this research field. As Searle suggests, the act of promising "has more than local interest, and many of the lessons to be learned from it are of general application" (Searle 1969: 54). Austin (1962/1975: 9), in turn, describes promises as one "of the more awe-inspiring performatives".

Such views are confirmed by the fact that, for instance, even in rather distant philosophical fields which involve axiology and, possibly, pluralism about values, e.g. in utilitarianism, there are discussions of people's obligations (or possibly a lack of such obligations) to keep promises in contexts which do not concern the problem of causing pain or pleasure. Indeed, promising can "zoom" speech act theoretic problems from the most general ideas of (possibly) universal values and concepts of sincerity, morality, responsibility, and obligation ${ }^{134}$, to situated recognition of certain linguistic forms as commissive. Promising can be seen as only a (sub)category in the speech act taxonomic structure, a "heading" entry in the commissive group, or as an omnipresent element, one of the basic features, and a constitutive feature, of social life, pervasive in all communication. Promising is inherently performative as one cannot genuinely promise without being involved in a social relation and without communicating what, or that, one promises. In this respect promising is different from acts which can be internal

\footnotetext{
${ }^{134}$ For instance Lewis (1969: 148ff. \& 1983 [1975]: 137ff; also cited in Millikan 2005: 16) claims that conventions of language are: "truthfulness" and "trust".
} 
and "non-social", such as "knowing" or "(dis)believing", which can exist prior to an utterance ${ }^{135}$.

The actional nature of promising was commented upon before Austin formulated his speech act theory. Historically, the abstract concept of promising was sometimes presented as a prerequisite for communication and social life in general. For instance, in retrospect, the notion of a promise was given remarkable importance within philosophical systems put forward by Immanuel Kant or Friedrich Nietzsche, although their emphasis was not so much on language as on the moral aspect of social interaction.

For Kant, expectation of "morality" is based on reason, while Nietzsche binds the act of promise with a discussion of the human unique ability to create obligations which transcend over time with focus on the significance of the act of promising and its consequences in social life ${ }^{136}$. In particular, Nietzsche

${ }^{135}$ Even though saying "I know" (or "I don’t know") may sometimes involve responsibility that some linguists and philosophers would be ready to associate with "promising" in a broad sense, i.e. with accepting responsibility for one's statements.

${ }^{136}$ Nietzsche (2003 [1913]) also discusses the concept of promising as uniquely human and points to its significance for social life and any theory of morality, although he presents the problem in a much different light from Kant. Accepting that "moral" and "autonomous" are "mutually exclusive terms", Nitzsche (2003 [1913]: 36) acknowledges that the man of will, "the sovereign individual", "the lord of free will", unlike other animate creatures in the world is "competent to promise" and that in promising "the object is to provide the promiser with a memory" (p. 40). Nietzsche sketches social aspects of a morally binding promise in a historical context and states the following: "the 'ower', in order to induce credit in his promise of repayment, in order to give a guarantee of the earnestness and sanctity of his promise, in order to drill into his own conscience the duty, the solemn duty, of repayment, will, by virtue of a contract with his creditor to meet the contingency of his not paying, pledge something that he still possesses, something that he still has in his power, for instance his life or his wife, or his freedom or his body (or under certain religious conditions even his salvation, his soul's welfare, even his piece in the grave; so in Egypt, where the corpse of the ower found even in the grave no rest from the creditor-of course, from the Egyptian standpoint, this peace was a matter of particular importance). But especially has the creditor the power of inflicting on the body of the ower all kinds of pain and torture - the power, for instance, of cutting off from it an amount that appeared proportionate to the greatness of the debt; - this point of view resulted in the universal prevalence at an early date of precise schemes of valuation, frequently horrible in the minutness and meticulosity of their application, legally sanctioned schemes of valuation for individual limbs and parts of the body. I consider it as already a progress, as proof of a freer, less petty, and more Roman conception of law, when the Roman Code of the Twelve Tables decreed that it was immaterial how much or how little the creditors in such a contingency cu off, "si plus minusve secuerunt, ne fraude esto". Let us make the logic of the whole of this equalisation process clear; it is strange enough. The equivalence consists in this: instead of an advantage directly compensatory to his injury (that is, instead of an equalisation in money, land, or some kind of chattel), the creditor is granted by way of repayment and compensation a certain sensation of satisfaction - the satisfaction of being able to vent, without any trouble, his power on one who is powerless, the delight "de faire le mal pour le plaisir de la faire", the joy in sheer violence: and this joy will be relished in proportion to the lowness and humbleness of the creditor in the social scale, and is quite apt to have the effect of the most delicious dainty, and even seem the foretaste of a higher social position. Thanks to the punishment of the "ower", the creditor participates in the rights of the masters" (Nietzsche 2003 [1913]: 40). 
points to the fact that a morally binding promise (especially in the legal context of contracts) is sanctioned within a society and that, with time, it becomes institutionalised, which is reminiscent of the most frequently quoted examples of speech act theory in the Austinian tradition. In fact, Reinach, (cf. section 1.6), a 'grandfather' of speech act theory, as early as 1913 also concentrated on the concept of promising in the context of legal and linguistic actions. One of the claims made by Reinach is that a speech action such as a command or a promise, which are inherently social in nature and "in need of being heard" (Reinach 1983 [1913]: 19) to constitute an inner unity of "deliberate execution" and "deliberate utterance". Reinach's understanding of the social act of promising, as discussed by Smith (1984) and represented in Figure 5 below, clearly points to the salient elements of commitment, such as "obligation" and "claim".

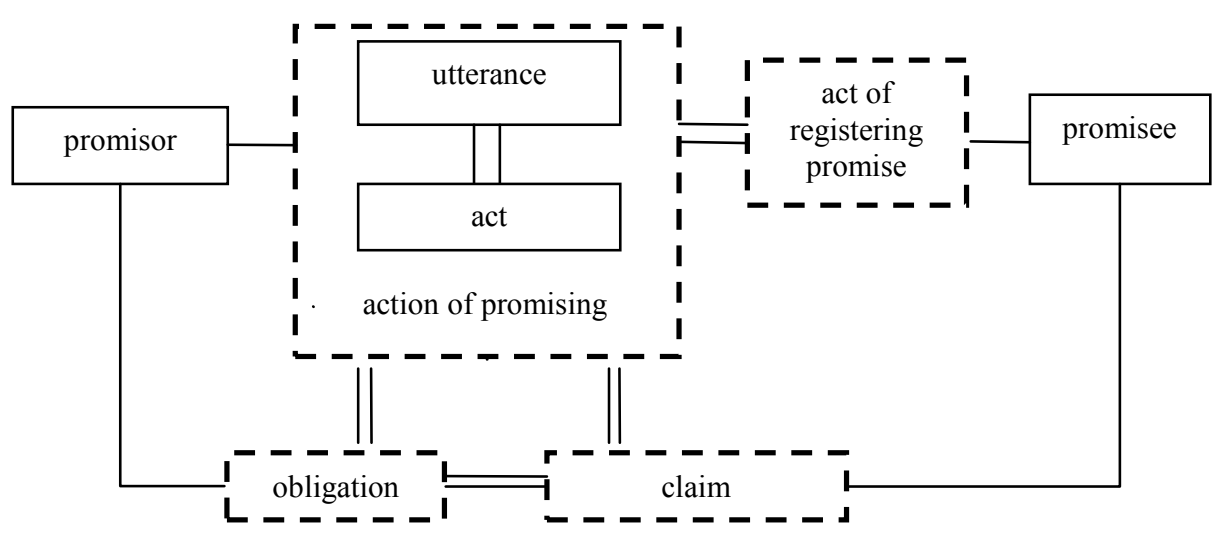

Figure 5: Reinach's model of promising as represented by Smith (1984: 327)

Not only had the notion of promising been present in pre-speech act-theoretic research and was central for Austin when he started his theorising on speech actions but, significantly, many of his reflections are in accord with previously uttered independent opinions. Austin, being White's Professor of Moral Philosophy at the time, appears to have been greatly influenced by H. A. Prichard, who was at first his teacher and then a colleague at Oxford, and with whom he reportedly corresponded on the nature of promising as early as in 1947. Prichard, it is said ${ }^{137}$, was so cautious about the concept of "promise" and related conditions of successful accomplishment of such acts that when invited, for instance, to a meeting and asked whether he would come, would only say "I fully intend", not to abuse the possibility of an unintended failure to perform the action in question. The correspondence between Austin's and Prichard's views can be seen in the latter's definition of promising:

${ }^{137}$ Searle cites this in his Berkley lectures in philosophy available on-line. 
promising resembles asking a question or issuing an order, [...] it consists not in making a statement, but in doing something, in the sense in which we oppose doing to mere talking (Prichard 2002 [1949]: 257)

For Prichard, allowing some simplification, promising can be performed by "uttering certain sounds" which, however, are as if an audible sign for a prior internal act, which "must have been made [...] somehow without language" (Prichard 2002 [1949]: 263). Prichard seems to have struggled with the concept of what could be dubbed as a "trigger" for a moral obligation and the connection between triggering that moral duty and linguistic "noises". Another claim made by Prichard is that such an obligation arises with the utterance because there is an earlier "promise" that one would not utter such words without the intention to perform the action promised.

These views are echoed in Austin's lectures, or possibly Austin's and Prichard's views just significantly coincide. For instance, Austin claims that a promise is only felicitous when it is sincere.

when we think of some of the more awe-inspiring performatives such as "I promise to ...." Surely the words must be spoken 'seriously' and so as to be taken 'seriously'? This is, though vague, true enough in general-it is an important commonplace in discussing the purport of any utterance whatsoever. I must not be joking, for example, nor writing a poem. But we are apt to have a feeling that their being serious consists in their being uttered as (merely) the outward and visible sign, for convenience or other record or for information, of an inward and spiritual act: from which it is but a short step to go on to believe or to assume without realizing that for many purposes the outward utterance is a description, true or false, of the occurrence of the inward performance. The classic expression of this idea is to be found in the Hippolytus (1. 612), where Hippolytus says

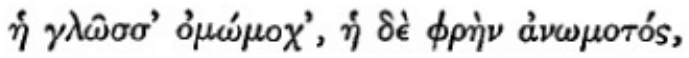

i.e. 'my tongue swore to, but my heart (or mind or other backstage artist) did not'. Thus, 'I promise to' obliges me-puts on record my spiritual assumption of a spiritual shackle.

It is gratifying to observe in this very example how excess of profundity, or rather solemnity, at once paves the way for immodality. For one who says 'promising is not merely a matter of uttering words! It is an inward and spiritual act!' is apt to appear as a solid moralist standing out against a generation of superficial theorizers: we see him as he sees himself, surveying the invisible depths of ethical space, with all the distinction of a specialist in the sui generis. Yet he provides 
Hippolytus with a let-out, the bigamist with an excuse for his 'I do' and the welsher with a defence for his 'I bet'. Accuracy and morality alike are on the side of the plain saying that our word is our bond.

(Austin 1962/1975: 9-10)

Austin further indicates that uttering a promise without a sincere intention to promise does not make the utterance itself "false", but, when revealed, may invalidate the act. And even in such cases, it is more expected that the act in question will be described as "void" or "given in bad faith", or not implemented (p. 10), etc. It follows that for promises, as for other acts, it is "appropriate" that the person uttering the act "should have a certain intention" (here: to keep his word).

Sincerity itself is a contentious issue which has motivated much theorising. Selected voices, departing from Austin, suggest that it is enough to allow that the utterance makes manifest that the speaker accepts the responsibility for his or her utterance's content and that the person's internal feelings and commitments are not so important in communication in general. This is particularly relevant in contexts in which linguistic acts are not entirely "privately" conversational, e.g. when speakers produce commitments on behalf of a company or in highly institutional settings, such as numerous legal contexts. However, in Austin's lectures speech acts are presented as accompanied or lined with "private" sincere states of mind, despite the fact that many of the cited examples come from institutional settings. Other features expected from promises, according to Austin, include the following conditions cited in lecture II:

It is obviously necessary that to have promised I must normally (A) have been heard by someone, perhaps the promisee; (B) have been understood by him as promising. If one or another of these conditions is not satisfied, doubts arise as to whether I have really promised, and it might be held that my act was only attempted or was void.

(Austin 1962/1975: 22)

Thus, for Austin, an act of promising consists in accepting to act in a certain way and in making it explicit for one's audience (at least one other person) that it is the case. In addition, promising relies on people's trust in social cooperation, i.e. also the trust that people are able to recognise what promising is all about and that they are ready to show respect for moral obligation which arises with promising. Accepting Prichard's and Austin's views, an act of promising cannot be understood, performed, in fact it cannot exist without due respect for intention, and this should be true for all acts, i.e. both "private"/intentional and conventional/institutional acts, or both conventional and communicative acts, to use Bach and Harnish's (1979) nomenclature. 
Next to the problem of moral obligation, Austin (1962/1975) also refers to the legal dimension of commitments and mentions that the kind of uncertainty involved in promising is so common that in law, e.g. in the serving of writs or summonses, special precautions are taken to guard against infelicities. Expanding his perspective on promising, Austin seems to merge the very private account of promising with more institutional settings disregarding the possible discrepancy between a person's "private" intentions and that person's social (often professional) role which may involve commitments of an institutional nature, possibly even standing in conflict with private attitudes.

Emphasis on intention can also be heard in Austin's Harvard William James lectures, when he comments on the nature of assertion vis-à-vis a commissive act:

The insincerity of an assertion is the same as insincerity of a promise, since both promising and asserting are procedures intended for use by persons having certain thoughts. 'I promise but do not intend' is parallel to 'it is the case but I do not believe it'; to say 'I promise', without intending, is parallel to saying 'it is the case' without believing.

(Austin 1962/1975: 50)

Austin further relates this to entailment relations, where "I promise" entails "I ought to" and "I promise but I ought not" is parallel to "it is and it is not" (51) and points to the fact that one assertion commits us to another assertion, just like one performance may commit us to another performance (52). This correlation between utterances of promising, uttered in the first person, and personal commitment is also present in Austin's other papers, e.g. in "Other Minds" (Austin 1970: 76-116).

Austin's original account of promising sends the reader in two main directions; one is the problem of sincerity, an "inward act", seen as an essential feature for a successful promise, the other is a social obligation that arises from such an act, which can be most clearly seen in legal contexts. Both these problems are interwoven and lack final clarification. For instance, is a social act in which a speaker is only "an institutional speaker", a "hired performer", sincere? Can it be judged along the lines of sincerity? ${ }^{138}$

As indicated in chapter two, Austin saw law as an especially promising source of inspiration and believed that philosophers of language have much to learn from legal contexts. Significantly, Austin and L.H.A. Hart gave seminar together in Oxford and shared reflections on legal language and its performative dimension. H.L.A. Hart (1961) notably discussed promising as directly related to law through correspondence in exerting power conferred by rules. In the context of law, promising is also widely discussed with reference to Grotius and

\footnotetext{
${ }^{138}$ For instance, when people speak on behalf of the company which employs them, can their acts be judged with regard to sincerity?
} 
Pufendorf, key figures in natural law theories of rights and duties, who both perceived legal duties in terms of a moral thing, a faculty or quality. For instance, Olivecrona $(1962,1971)$, saw the act of promising as central in emergence of legal obligations based on (rather mysterious) moral power being a function of a declaration of will. Such a declaration is supposed to produce psychological effects, i.e. in effect the promisor feels himself bound and the promisee feels entitled to expect the promisor to act relevantly to the promise. In highly institutionalised settings communicators' immediate psychological effects are strengthened. In Olivecrona's words, "all rights are supposed to have their origin in promises made by free individuals" (Olivecrona 1971: 242), and people may also acquire rights and duties by conduct without an explicit linguistic from.

In a more restricted approach, contracts are often defined as sets of related promises (e.g. Fried 1981). However, even among lawyers there has been a vivid debate as to the nature of such "promises", the relation between the institution of making promises and contracts, and the role of voluntary obligation in the theory. Promises are in the titles of works and in the centre of interest for legal theorists such as, inter alia, Atiyah (1981), Fried (1981), or Raz (1977, 1982).

For instance, Raz (1977) argues that promises are made by communicating an intention to undertake, by that very communication, an obligation. In his words, "the normal habitat of promises [is] in the framework of ongoing relations" (Raz 1982: 938). Raz uses the concept to fight the view that contracts are prototypical "promises". He indicates that contracts and legal "promises" are different from prototypical promises which are basically private actions. Instead, legal contracts may be valuable as indications of certain formal explications of elements in promises, but they usually lack the most salient element related to moral values. Raz (1977) makes a distinction between the intention-based conception of promising and the obligation-based conception. In the former case, the essence of the obligation is related to the communication of the intention to act in a certain way; in the latter case, it is the intention to undertake the obligation to act in a certain way by the very act of communicating of this intention that is seen as the main source of obligation which arises as a consequence of a promise. Thus, in the former case voluntary communication of intention is enough for a promise to be valid, while in the other, there should be honest intention on the part of the promisor that his or her communicative act triggers the obligation.

Atiyah (1981) $)^{139}$ also addresses the question of how to compare contracts and promises, i.e. relations shaped by informal social practices. Both Fried (e.g. 1981)

\footnotetext{
${ }^{139}$ Atiyah (1981) discusses promises about action which have been performed in the normal course of events and promises whose benefits for the addressee are questionable or non-existent. $\mathrm{He}$ also points to promises in which there was a manifestation of the intention to proceed in a certain way, nonetheless, there is no moral obligation to keep the promise, i.e. he claims that there are promises which are not binding. He further finds certain reasons why some promises should be held morally binding even though there has been no benefit to the promisor nor any harm caused or likely to be caused to the promisee.
} 
and Atiyah believe that contracts are a special type of promises; they provide insightful comments not only on the nature of law, but on the nature of obligation which has its informal end in private promises and its highly institutionalised form in legal contracts.

[I]t is true that in many cases the verbal formula 'I promise .' cannot, as a matter of language, be easily reduced to anything like 'I consent'. But the fact surely is that an explicit promise is an expressed willingness or consent to the state of affairs which the promisee posits, or which will be required by its performance.

(Atiyah 1981: I78)

Raz $(1977,1982)$ contradicts the view that contracts are promises pointing to the fact that voluntary obligations can be accepted in many different social contexts, and not all contracts should count as promises, because the obligation to which they refer may not be "private" and does not have to arise form the expressed speaker's intention. It is argued that, typically, promises rely on social norms and shared, often tacit, moral considerations and values, which is why most of the intentions behind promises remain unspecified and invisible in the lexical form of the promise. Legal systems attempt to articulate the element which is implicit in the network of social relationship, to make it explicit and evaluable, in this way translating individualistic phenomena into public, generalised, conventional sphere.

Other authors also frequently emphasise that "promising" is a type of action which involves a "joint" decision, not just one dependent on the promisor's intentions, and argue that as an act a promise is heavily dependent on social rules and norms, according to Austin ${ }^{140}$.

As mentioned above, Searle also positions promising in the centre of his speech act theory and his exemplary description of a speech act (Searle 1969: 54ff.) is based on this notion. The act of promising is chosen as the most representative example for the illustration of Searle's model as promising, in Searle's opinion, is "fairly formal and well articulated; like a mountainous terrain, it exhibits its geographical features starkly" (Searle 1969: 54). Explaining "how to promise" Searle cites necessary and sufficient conditions which should be satisfied in order for the act to be successful:

I. Normal input and output conditions obtain.

2. Propositional content: $S$ expresses the proposition that $p$ in the utterance of $T$.

3. In expressing that $p, S$ predicates a future act $A$ of $S$.

4. (Preparatory) $H[\mathrm{H}=$ Hearer $]$ would prefer $S$ 's doing $A$ to his not $\operatorname{doing} A$, and $S$ so believes;

${ }^{140}$ Cf. Kannetzky’s (2007) discussion of "promising” in a holistic approach. 
5. (Preparatory) It is not obvious to both $S$ and $H$ that $S$ will do $A$ in the normal course of events.

6. (Sincerity) $S$ intends to do $A^{141}$

7. (Essential) $S$ intends that the utterance of $T$ will place him under an obligation to do $A$.

8. $S$ intends ( $i$-I) to produce in $H$ the knowledge $(K)$ that the utterance of $T$ is to count as placing $S$ under an obligation to do $A$. $S$ intends to produce $K$ by means of the recognition of $i$-I, and he intends $i$-I to be recognised in virtue of (by means of) $H$ 's knowledge of the meaning of $T$.

9. The semantical rules of the dialect spoken by $S$ and $H$ are such that $T$ is correctly and sincerely uttered if and only if conditions I-8 obtain.

where $\mathrm{S}$ stands for the speaker who utters a sentence $\mathrm{T}$ in the presence of a hearer $\mathrm{H}$ and means his message as literal and sincere.

(cf. Searle 1969: 57-61)

Searle's account in terms of preparatory, sincerity and essential conditions allows for a systematic and elegant description of indirectness (cf. Searle 1975a). The clarity of Searle's model can also be seen in the fact that, to use Austin's nomenclature, any violation of Searle's preparatory conditions produces a misinvocation, while a violation of the sincerity conditions produces an abuse which would not render the act in question entirely infelicitous.

For Searle, promising is an institutional act par excellence (Searle 1969: 51ff) and "institutions" are systems of constitutive rules. Such rules, in contrast to mere regularity, can be summarised in the formula " $X$ counts as $Y$ ", or more often, " $X$ counts as $Y$ in context $C$ ". The inclusion of "I (hereby) promise" in an utterance is recognized as one of the strongest illocutionary force indicating devices (IFIDs) in the English language (Searle 1969: 58), which projects the notion of commitment even over utterances that are not themselves "promises" proper (e.g. threats, emphatic assertions).

In an earlier paper- "How to derive 'Ought' from 'Is"', Searle (1964) presents promising as an act in which we deal with the creation of (an) obligation. Later obligations created in such contexts may function as reasons for actions performed by the speaker. In other words, according to Searle, in making a promise the speaker creates "a desire-independent reason for an action" (Searle 2002b: 5), in which the institution of promising provides "a vehicle", i.e. functions as a device, but not a source, for the action. Here, Searle's attitudes are convergent with numerous legal approaches, but also with externalist general approaches to linguistic communication, which place emphasis on visible signs of certain intentions rather than sincere internal states bearing in mind that it is

\footnotetext{
${ }^{141}$ Originally, condition "6" was more strict, "S wants to do A"; the introduction of "intends" makes room for analysis of insincere speech acts. Kalisz (2001, cf. Kalisz \& Kubiński 1993) indicates that such a modification is not needed in a cognitive analytical framework, where speech acts are seen as radial categories and conditions are understood in terms of prototypes.
} 
only visible or audible signs, and not inner psychological states, that hearers can access.

Searle's account and his conception of the promise has been criticised along various lines, e.g. among the conditions whose necessity has been questioned there is the very concept that a linguistic promise itself serves to commit the speaker. It has been suggested instead (cf. Hare 1964) that the linguistic form may serve as a confirmation or just a sign of some pre-existing commitment. Hare (1964) uses this point in his attempt to refute Searle's analysis in which the deontic "ought to" is derived from the epistemic "is".

At another point Searle indicates that there is no perlocutionary effect which could differentiate promising from firm statements of intentions and emphatic predictions (Searle 1969: 46). Although what they have in common is the intention to create in the hearer some expectations about the future, their meanings are basically different and not at all synonymous ${ }^{142}$.

In Searle's model of promises, the speaker appears to be the master of both his voluntary action of promising and its consequences. However, illustrative examples, especially related to law, have been suggested to prove that the voluntary character of promising is relevant to only selected acts. It has also been indicated (cf. e.g. Raz 1982) that marriage, for instance, is a kind of voluntary obligation which people are free to impose on themselves, but which, subsequently, they have very limited power to modify or shape. Such "extended promises", it may seem, are fixed by principle and the interested parties, despite their status as "promisors", have very little, if any, control over the contents of the promissory obligation ${ }^{143}$.

Searle's account motivated many further discussions, including the debate between Bogusławski (1983a, 1983b) and Verschueren (1983). Gibbs (2004: 52ff.), in turn, reviews other doubts as to the necessary character of conditions relating to promising, e.g. Peetz's (1977) example of promises whose contents, under some circumstances, may not be welcome by the hearers despite the fact that they are not perceived as "negative", as, e.g., threats would be.

Alston (2000) modifies Searle's account of the act of promising arguing that Searle's conditions should be limited. He follows Searle's concentration on the notion of speaker's obligation, which he calls the key characteristic of the illocution and defines speaker's "taking responsibility" in producing an utterance as the dimension which allows that the utterance could at all count as an illocutionary act. Alston's proposal (Alston 2000: 70) is as follows:

\footnotetext{
${ }^{142}$ Here Searle criticises Grice's model and especially the concept of reflexive intention, claiming that it suggests that in communication speakers attempt to produce perlocutionary acts.

${ }^{143}$ Raz, contrary to Atiyah (1981), believes that promises arise through communication of intention to promise and to accept promissory obligation, but agrees with Atiyah that people have limited control over the content of promissory obligation.
} 
[Preparatory]

It is possible for $U$ to do $A$.

H would prefer $U$ 's doing $A$ to $U$ 's not doing $A$.

$U$ intends to do $A$.

[Normative Effect] In uttering $U, S$ places himself under an obligation to do $A$

[Communicative] In uttering $S, U$ intended that $H$ realize that condition $A$ and $B$ are satisfied.

Alston also criticizes Searle's model of sincere and non-defective promises, indicating multiple ways in which a promise may indeed be defective. In his entire account, Alston emphasizes his belief in the normative character of illocutionary acts, their universal reliance on changes in the normative situation and positions of interlocutors. As Alston suggests: "An utterance is most basically made into an IA [illocutionary act] of a certain type by virtue of a normative stance on the part of the speaker" (Alston 2000: 171). In this respect Alston's externalist account is in a way parallel to models explicitly accepting ostensive behaviour as central in communication, including, e.g., much distant post-Gricean relevance theoretic approaches (cf. Sperber \& Wilson 1986/1995, Carston 2002). In a still different perspective, Žagar (1991) uses the speech act of promising as an example to show a polyphonic aspect of utterances ${ }^{144}$.

\footnotetext{
144 The argument includes a discussion of the differences between the following exchanges:

(i)

A: Are you coming?

(ii)

A: Are you coming?

B: I am coming.

B: I promise to come.
}

In example (i) a direct answer is given, while in (ii) the answer is not direct in the sense of matching the question. However, 17a is shown to be even stronger than $17 \mathrm{a}$, which is a canonical performative, but in many contexts could be judged as rather unnatural. Interpreting the explicit promise as a less natural response, Žagar argues that the choice of form is certainly motivated by its function, recalling Austin's respect for Leibniz's view that whenever there is a difference in natural language expressions, there be a change in meaning involved. In summary, Žagar suggests a template as below for arriving at an explicit form by evoking the notion of (monologic) polyphony as used by Ducrot:

A: We are throwing a surprise party tomorrow evening. Are you coming?

B: Yes, I am.

C: That would be a surprise! You never come!

B: I promise to come.

Such an interpretation invites a perspective where most utterances exhibit a polyphony of voices (or technically_- "utterers"), which are seen as implicit or backgrounded in the act. In other words although there is only one "speaker", many voices in the sense of attitudes and (potential) arguments, and hidden opinions, are shown as inherent or embedded in the utterance. Žagar's main point here is that the scale of different forms of promising, from an explicit performative canonical form, to indirect ones, differ accordingly in their argumentative force. Thus, "I promise to come". is argumentatively stronger than "I am coming". 
It is evident that "promise" as a category is remarkably capacious. It may include examples of private, "communicative", purely "intentional" acts, and examples classified as conventional and institutional. For instance, taking an oath in institutional settings is classified as a kind of promise, but allows little (or no) room for any variety in form ${ }^{145}$, while conversational promising can be performed in many diverse ways.

There are many original alternative approaches to the speech act of promising. In an intercultural perspective, Wierzbicka (1987: 205ff.) explicates the concept of "promise" through her reductive paraphrase into lingua mentalis ${ }^{146}$. The definition for the verb promise is as follows:

$$
\begin{aligned}
& \text { promise: } \\
& \text { I know that you want to me to do A; } \\
& \text { I want to do it because you want me to do it; } \\
& \text { I say: I will do it; } \\
& \text { I want us to think that if I don't do it, people will not } \\
& \text { believe anything that I say I will do; } \\
& \text { I say this, in this way, because I want to cause you to be } \\
& \text { able to think that; } \\
& \text { I have to do it. }
\end{aligned}
$$

Mey (2001) complements Searle's conditions with another aspect which he imports from anthropological studies. It is suggested that an utterance is also judged as a promise with regard to its ability to maintain the present state of affairs, in which way it shares many characteristics with prediction-like assertions.

In an experimental study, Gibbs and Delaney (1987) examined understanding of promises with focus on the three key dimensions suggested by Searle (1969), i.e. "obligation", "hearer preference", and the promised performance being "nonevident", i.e. the condition that the person who promises is consequently under obligation to act accordingly, that what is promised is desirable to the addressee who wants it to happen, and finally that the action promised would not normally happen in a regular course of events. In an attempt to establish whether people really possessed tacit knowledge which reflects the conditions' enumerated by Searle, a knowledge which should govern how they make promises, in one of the

In addition, by explicitly staging the act of promising the speaker presupposes a need for a stronger speech act, presupposing "negative" attitudes on the part of the audience. This, apparently, may be seen as an instance of grammaticalisation of context, where contextual information is taken as mutually known and "translated" into form through a specific choice of words and a grammatical structure, i.e. applying a pragmatic strategy.

${ }^{145}$ Cf. Obama's repeating the presidential oath in 2009 - a "do-over" to secure validity of the act following Justice John Roberts' verbal flub.

${ }^{146} \mathrm{Cf}$. section 3.4.2.e. for a summary of her methodology in describing lexical meaning. 
experiments Gibbs and Delaney produced stories which participants of the experiment had to read and then respond to them with an utterance. Later participants rated the responses, both theirs and others, as to what extent they constituted promises. In another experiment respondents had to comment on scenarios which included utterances to be rated as promises. The answers were elicited in such a way that respondents had to explicitly state whether a particular utterance was a promise, to give opinion whether the speaker was under obligation to act according to the contents of the utterance, whether the addressee in each scenario wanted the action to be performed or not, and finally, whether the addressee in each story would have preferred that the speaker performed the action in the normal course of events. Still another study focused on the degree of obligation felt by participants with regard to scenarios which they read and to the point whether the obligation was pre-existent in relation to the utterance which counted as a promise or emerged parallel to discourse.

The studies confirm some of Searle's claims, for instance that in making promises speakers predicate a future act (e.g. "I'll take out the garbage"), however, they contradict Searle's claim that uttering the very words "I promise" is crucial for making a promise, as only 2 per cent of all the utterances produced during the experiments used this explicit phrase.

Furthermore, Gibbs and Delaney's studies reveal that participants rated evaluated utterances differently on the "promise" scale depending on the type of violation of their felicity conditions. The data seems to contradict Searle's "nonevident" condition, according to which utterances which refer to activities expected in the normal course of events are not "promises" as they would have been performed anyway. The study shows that respondents rated utterances produced in such contexts as perfect promises despite the alleged violation. It appears that people expect promises in situations where there are high expectations on both the speaker's and the addressee's part that the action being the content of a promise is to (or could) be performed. It has been suggested (cf. Gibbs 2004: 54) that this kind of "natural" expectation is stronger in its generative power to create an obligation to act than the corresponding linguistic speech act of making a promise, which usually just reaffirms the existing state, already strengthened by the speaker's belief that the action is desired by the addressee.

In general, the studies show that utterances which do not violate any of the conditions specified by Searle are rated highest on the promise scale, while utterances which violate conditions of one (or more) of the three areas being investigated receive varied ratings. "Nonevident" violations appear to be least important, which proves that people do not consider the related condition as necessary, while the "obligation" condition turns out to be most important and shows that it is essential for promises that the promisor is under obligation to keep the promise. In addition, the experiments show that typically people understand "promise" utterances not as vehicles for introducing speakers' 
intentions and bases for future obligations, but rather as confirmations of preexisting, in most cases tacit, obligations. Thus, systematically, promises appear to reaffirm obligation rather than to create it. As Gibbs (2004: 54) claims: "The main function of verbal promises is to remind the addressee of the existence of some prior obligation and to specify when an action is to be performed". This evidentiary view is still a contentious issue, but broadens a general perspective on the nature of speech acts of promising.

It has also been shown that comprehension of promises consistently evolves with age. Astington's (1988) study, although based on French, has implications beyond this particular language. It has been reported that on average children do not differentiate between predictions and promises until they reach the age of nine, while the clearer recognition of the difference between a promise and an assertion manifests itself in children aged between eleven and thirteen. Naturally, practice precedes metapragmatic awareness in that children can successfully produce felicitous promises before they are able to label promises successfully and accurately.

In another psycholinguistic experimental study, Bernicot and Laval (2004) extended their previous research (Laval and Bernicot 1999, Astington 1988) and studied promises in children to see how children process promises, how they evolve to comprehend the concept and master relevant linguistic forms, and what cues children use in recognition of promises. In particular, attention was paid to whether children use contextual cues such as the listener's wishes about the accomplishment of the action being promised, or rather base their judgment on textual clues, such as linguistic form and temporal information (e.g. literally grammatical tense). It has been found that children (aged three to ten) can understand promises better in contexts which highlight relevant preparatory conditions. Testing non-verbal behaviour shows that on average children are able to master the sincerity condition at the age of five, but the preparatory condition is mastered about the age of nine and ten. The more evident the speaker's belief and the listener's desire, the easier the comprehension.

It has further been shown that grammatical form of an utterance plays a role and can either enhance or hamper comprehension of promises. Comprehension of textual information is highly dependent on contextual information and its significance changes with age. In contexts where children have to rely solely on "texts", they tend to recognise promises phrased in "immediate future" forms (e.g. French forms parallel to the English "I am going to ...") easier than e.g. promises phrased in "simple future" forms. This starts with children who are six years old and becomes a general characteristic by the age of nine. In other words, "social" information is processed earlier and with greater ease than linguistic information, which is mastered later. When context is known, linguistic form plays a minor role, in the absence of contextual information, i.e. information related to the preparatory condition, children have difficulty in processing "simple future" forms as vehicles for promises. Although from the age of nine 
children seem to give priority to the linguistic features of the utterance, context still seems to be most important in ascription of function to utterances ${ }^{147}$.

Later work in experimental pragmatics, including studies of understanding related to "epistemic vigilance" (cf. Mascaro \& Sperber 2009 and Sperber et al. 2010) and deception, indicate that around the age of four a mind-reading ability appears which enables children to recognise intentions of the communicator. It can be posited that this mind-reading ability will also be functional in recognising the speaker's intentions behind making promises (although this has yet to be proved experimentally). It may further be suggested that there are aspects of promising which seem to be even more dynamic and based on psychological criteria. This line of research can be used to depress the role of linguistic forms in communication in general and to suggest that functional units in communication, i.e. speech acts or events rely more on social conventions and psychological clues than on the recognition of linguistic forms with which they are semantically associated (i.e. in an "out-of-context" approach). For instance, Bernicot and Laval (2004) report on their speech act-theory-based investigation into how children between the ages of three and ten process promises. In the study, the authors concentrate on two aspects of speech act comprehension, i.e. listeners' expectations and textual characteristics. It is claimed that both of these factors play a role in comprehension of promises and children's experience and their trust in the speaker (or lack of such trust) appears to play a more important role than the linguistic form involved.

In summary, experimental pragmatic research generally supports Searle's (e.g. 1965, 1969, 1975a) claims about the speech act of making promises and its necessary and sufficient conditions. However, it emphasises one important aspect of promises, which is the fact that they heavily depend on social institutions and tacit conventions. Even the most explicit promise can only be successful when spoken in the right circumstances in the environment when it can be expected. As Gibbs (2004) indicates, promises do not normally work when addressed to strangers; they are functional only in environments where certain conventions, social relations and institutions with pre-defined patterns of behaviour exist ${ }^{148}$. As a result, Searle's 1964 model example of a promise: "I promise to pay you, Smith, five dollars" can hardly be expected to be taken as a promise with legitimate reliance when uttered to a stranger in the street even if all promise-oriented Searlian conditions are met. Even if the addressee's name is Smith and he would welcome related performance, even if the speaker is sincere and has the right intentions, etc.

\footnotetext{
${ }^{147}$ However, in contexts which involve highly contradictory information, i.e. where contextual (preparatory condition) information is in conflict with the linguistic form used, children have tendency to rely on the linguistic form (cf. Bernicot \& Laval 2004).

${ }^{148}$ As relevance theoretic research on epistemic vigilance shows, children tend to recognise and accept promises offered by people who they have learnt to trust.
} 
A possible lesson from the psycholinguistic experiments mentioned above is that speech acts in general are not at the core of social relations, but rather function as their reaffirmation. Promising may be a prototype of a speech act and yet no form seems to be "enough" to eventually define and constitute a promise. The verbal form may be just most tactile of all aspects of a promise, especially when there is a search for social judgment and speech is given a "forensic" dimension. However, being an accessible sign, it is also the only element in such contexts which is available to "the third party" and the only which gives the promise a visible shape, a "body". In this sense, it allows to refer back to the promise, not only on an intimate interpersonal level, but with a broadly social dimension. Being reaffirmation, the linguistic form is a proof which can later be used for reference, but it is rarely conclusive of the existence of an obligation. This view is consistent with Atiyah's 'legal' perspective on promises:

To make an explicit promise is one way of helping to clear up the doubt which would otherwise arise. The promisor, by explicitly promising, is admitting that (insofar as it is for him to decide) he thinks the promisee will be justified in acting in reliance on him.

(Atiyah 1981: 201)

$[\mathrm{T}]$ he promise is not the reason for the obligation any more than the judge's decision is to him a reason for the law which he declares.

(Atiyah 1981: 192)

To reiterate, the form still possesses a forensic dimension in that it can later be referred to as a proof of the obligation which is believed to exist. In this context Atiyah points to a difference between law and private promises where, in the legal perspective, once a promisor has communicated to the promisee a relevant intention, there is an assumption of an obligation. It is then immaterial whether or not the promisor was sincere in his or her expressed attitudes, although the question remains whether he must at least intend to communicate an intention in order for such an assumption to arise. It is suggested that in law the speaker need not have the sincere (inner and private) intention to perform certain acts and accept certain commitments, but "at any rate [...] the one thing necessary, in addition to the actual performance of the speech act, is that the act communicates the intent to assume an obligation" (Atiyah 1981: 102), i.e. persuades the listener that the speaker intends to assume an obligation. In most legal contexts making a public promise, especially reinforced with documents and signatures, is enough to attach to the act in question a social value.

In summary, it is evident that the act of promising, widely accepted as the most typical speech act, or the most illustrative performative, is also illustrative of the numerous problems that speech act theory has to face. Research based on the act of promising is as varied as research in speech act theory in general. The commissive force can be approached as a feature which permeates all speech acts (in a manner similar to that of assertion which can also be seen as a general 
feature of all utterances) when it is accepted that speech as such would always give rise to responsibility and obligation. Promise can also be seen as just a very central and most salient act of the commissive type, whose other members possess related, but less focal forces. In a comparative perspective, different types of promises and related acts reflect the richness and complexity of social life. Analysed in detail, they show features of family resemblance rather than conformity to certain necessary conditions. There may be apparent promises which are not binding because the bond in between the promisor and the promisee fails to arise for some social reasons. There may also be promises whose content is not perceived as desirable by the addressee. "Promises" sanctioned by law, such as contracts of varied kinds, from marriages to corporate world, are given institutionalised form and can thus be more easily evaluated as to their validity, but such validity is rooted in their particular social and legal system. Evidently, social recognition of promises may differ in degree across contexts. Psycholinguistic research suggests that psychological salience, reception of utterances which count as promises are of prime importance. There are different expectations with regard to highly institutionalised, or even ritualised acts, and different ones for very private moral obligations. In the context of diversity existing in the field, methodological proposals how to account for the act of promising that have been offered after Austin are better seen as situated descriptions which serve particular research needs. They enrich general understanding of promise-related issues, but are unlikely to offer "the only proper" account due to the complexity of the concept.

\subsection{Speech acts and their classifications in a diachronic perspective}

The pragmatic character of speech act typologies is well exposed in intercultural studies, but can also be seen in historical linguistics. In diachronic speech act analysis, the most frequently used categories are those suggested by Searle (1979b. [1975]), which seems to follow from the fact that Searle's taxonomy is indeed "the" taxonomy, a transparent and well established model in contemporary linguistics and the philosophy of language. For instance, using Searle's labels, Jucker and Taavitsainen (2008) found it practical to organise their edited volume with reference to two groups of speech acts: Directives and Commissives (part one) and Expressives and Assertives (part two).

It is worth noting that in the context of historical pragmatics, speech act theoretic research relies on corpus data and empirical research methods as naturally no direct experimental methods, such as, e.g. discourse completion tasks, or interviews, are available. Due to methodological restrictions, diachronic studies tend to focus on accessible iterative routinised forms, illocutionary verbs, or routinized Illocutionary Force Indicating Devices (IFIDs) found in records of past utterances and texts. The oldest available data naturally involve legal and 
religious contexts, i.e. context in which writing was more common. Thus, on the one hand, Bertuccelli-Papi's (2000) titular question "Is a diachronic speech act theory possible?" receives a positive response, but on the other, the speech acts discussed in historical contexts are necessarily fragmentary and concern particularised contexts and events. There have been analyses of speech acts embedded in records of past court proceedings, which, significantly, often include reciprocal patterns suitable for the methodology of conversational analysis. Particular functions that have been investigated range from "singular: insults or promises to complex ones, e.g. flyting and sounding, to produce "illocutionary bibliographies"” (Arnovick 1999). Early Modern English trial records have also been investigated with the aim of building a "speech act network" (Kryk-Kastovsky 2000, 2006a, 2006b, 2009), based on an earlier notion of "pragmatic space" (Jucker and Taavitsainen's 2000), within which a speech act can only be accounted for in relation to the neighbouring acts. For instance, Culpeper and Archer (2008) discuss requests with reference to the structural model developed in the Cross-cultural Speech Act Realization Project (CCSARP), which involves a coding scheme and differentiate between elements such as "head act", "alerter", and "support move" (or "grounder") ${ }^{149}$. Doty and Hiltunen (2009), in turn, discuss an overall structure and different stages of three genres: indictments, depositions, and examination records of the Salem witchcraft documents from the seventeenth century. They search for characteristic formulae in the legal context of the time to find that there already existed systematic features at every stage and in every genre, differentiated according to the person's authority and the stage of the trial. The description of the three genres reveals their scalar nature as relevant speech acts range from an already conventionalized legal register of the indictment (as formal charging developed later), through depositions (mainly acts of initial charging) with narratives "sandwiched" (Doty \& Hiltunen 2009: 468) in a conventional legal frame. A more individualized phrasing is found in examination records which often contain acts of denial and confession. Diachronic speech act analyses stress the role of power as relative to the pairing of form and function. Predictably, in past legal encounters legal professionals are shown to have used formulaic language more frequently than other participants of the proceedings, who used a greater number of varied discourse strategies.

\footnotetext{
${ }^{149}$ Interestingly, Culpeper and Archer's (2008) conclusions concerning the use of requests in Early Modern English include the claim that 17th century England, in contrast to contemporary England, was not a negative politeness culture, but a positive one. They draw a parallel between England of the past and the use of directness in contemporary Polish to show that the frequent use of "flat" imperatives does not correlate with a higher level of impoliteness, but is indicative that distance is not a highly positive value in the culture. Furthermore, in a contrastive perspective, they show that requests in courtroom discourse less frequently included "support moves", and quite often what should be classified as a support move was present as a separate element with an illocutionary function of its own.
} 
Interestingly, diachronic speech act analysis exposes the importance of sociocultural factors, such as social background and power relations, but also reciprocity, in defining speech acts of the past. In general, speech acts are presented as "fuzzy notions" which are "not readily amenable to corpuslinguistics" (Jucker et al. 2008: 273) and accessible only through "flashes of past practices" (Taavitsainen \& Jucker 2008: 2). Qualitative assessment of the analysed material must be related to standardised lexis or other recognisable IFIDs. Despite these limitations, speech act theoretic approach turns out to be recognised as both natural and practical as it touches the very fundamental question of how people of the past used language to communicate different functions. Analysing correlations between such functional categories will hopefully allow to chart largely unknown territories of social and linguistic practice, distant in modes of conceptualisation and time.

\subsection{Preliminary conclusions}

Classifications of speech acts, and especially of illocutionary acts, which are (allegedly) minimal meaningful units of linguistic action, may have far-reaching implications. Providing a taxonomy is important for the theory of speech acts per se, being its integral part, but the practice transcends its local relevance being also important for a description of human (verbal) behaviour. As such, it finds application in virtually all social sciences, including anthropology, sociology, and science.

Austin was the first theorist to present a taxonomy of speech act verbs. His agenda, as noted above, was to analyse verbs in order to get insight into the nature of linguistic action and also to identify acts that people perform in speech. There is much diversity in speech act-theoretic taxonomies, even in those produced by Austin's most immediate followers, who chose to directly refer to his classification. The table below presents the best known taxonomies focused on the English language which can be approached as quite direct elaborations of Austin's ideas. A more detailed account of the cited models can be found in earlier sections of the present chapter, but the table below, despite necessary generalisations, serves to show numerous overlaps and shifts of selected labels as well as differences between the categories as defined by different authors. Many of the overlaps happen because the authors concentrate on verbs and correspondence between their syntactic structures. Syntactic-semantic characteristics are also often definitive in sub-dividing selected groups. 


\begin{tabular}{|l|l|l|l|l|l|}
\hline \multirow{2}{*}{ AUTHOR $\downarrow$} & \multicolumn{5}{|c|}{ C A T E G O R Y } \\
\hline $\begin{array}{l}\text { Austin } \\
(1962)\end{array}$ & Expositives & Verdictives & Exercitives & Commissives & Behabitives \\
\hline $\begin{array}{l}\text { Searle } \\
(1969, \quad 1979 \\
[1975])\end{array}$ & $\begin{array}{l}\text { Assertives }= \\
\text { Representatives }\end{array}$ & $\begin{array}{l}\text { Declaratives } \\
\text { Representatives }\end{array}$ & $\begin{array}{l}\text { Directives } \\
\text { Declaratives }\end{array}$ & Commissives & $\begin{array}{l}\text { Expressives } \\
\text { Directives }\end{array}$ \\
\cline { 2 - 4 } $\begin{array}{l}\text { Rlston } \\
(2000)\end{array}$ & Assertives & \multicolumn{2}{|c|}{ Exercitives } & Commissives & $\begin{array}{l}\text { Expressives } \\
\text { Directives }\end{array}$ \\
\hline $\begin{array}{l}\text { Bach \& } \\
\begin{array}{l}\text { Harnish } \\
(1979)\end{array}\end{array}$ & Constatives & $\begin{array}{l}\text { Effectives } \\
\text { Verdictives } \\
\text { (conventional) }\end{array}$ & $\begin{array}{l}\text { Directives } \\
\text { Effectives }\end{array}$ & Commissives & Acknowledgements \\
\hline $\begin{array}{l}\text { Vendler } \\
(1972)\end{array}$ & Expositives & Verdictives & $\begin{array}{l}\text { Exercitives } \\
\text { Operatives }\end{array}$ & Commissives & $\begin{array}{l}\text { Behabitives } \\
\text { Interrogatives }\end{array}$ \\
\hline $\begin{array}{l}\text { Katz } \\
(1977)\end{array}$ & $\begin{array}{l}\text { Expositives } \\
\text { (performative) }\end{array}$ & $\begin{array}{l}\text { Stipulatives } \\
\text { (related to } \\
\text { "naming") } \\
\text { (constives }\end{array}$ & $\begin{array}{l}\text { Admissives } \\
\text { Requestives } \\
\text { Permissives }\end{array}$ & Obligatives & Expressives \\
\end{tabular}

Table 12: Selected speech act-theoretic classifications

In summary, Austin's approach has never been universally recognised as methodologically relevant, and, for instance, Leech (1989/1983) explicitly criticised the assumption "that a careful analysis of the meaning of illocutionary verbs can lead to the understanding of illocutionary force" as a "historical hindsight" (Leech 1989/1983: 176). However, in many research fields Austin's method reveals a salient potential.

Taxonomical attempts motivated by Austin's botanising phenomenological approach led to research that grew to invite contrastive intercultural studies of speech acts and considerations of issues such as politeness and power relations. It proves to be methodologically successful in descriptions of specific social relations in culturally distant groups. There is still a cognitive potential in Austin's original programme, whose application may inform various disciplines. For example, speech act taxonomies and classifications of speech act verbs are used in analyses of language acquisition and learning to prove, inter alia, that "[t]he ontogeny of performative vocabulary is not identical to the development of ability to perform" (Ervin-Tripp 1976: 28, fn.4) and that people's awareness of a social function precedes conventional type of verbal behaviour.

In a different perspective, ethnomethodological research in which Searle's classification of speech acts was tested against natural language data suggests that comprehension and production of speech acts is not dependent on processes related to a complex system of rules and conditions, such as defined by Searle (cf. Reiss 1985: 120-122). Instead, it is claimed that comprehension of speech actions depends on "control of the functions of speech acts as devices for motivating effects" (122). In a neo-Austinian manner, the acts' instrumental functions are foregrounded and, consequently, it is claimed that both the 
conceptual contents and structure of speech acts follow from these functions. Taxonomies and functions conceived of in this dynamic way also laid foundations for speech act theoretic research and application in fairly practical fields such as clinical linguistics contexts (e.g. Cummings ${ }^{150}$ 2007, 2009; Clark \& Lucy 1975; Paul \& Cohen 1985; Kissine et al. 2012), and built a potential for use in business and information science.

Looking at numerous taxonomy-related proposals that have emerged in the field of speech act theory over the decades since Austin, it is evident that no clear match between sentence types and corresponding speech acts can be claimed. Models which presuppose such a correspondence (e.g. Searle 1969, 1979b [1975]; Alston 2000) must exclude much of natural language data in which language is used in a flexible and "ordinary" way, often with much creativity involved. It must also be accepted after Bach (1999: 360, fn.35) that "performative verbs do not encode illocutionary forces" (cf. also Bach \& Harnish 1979: 203-209, Bach \& Harnish 1992), at least not in the way in which form should match function beyond simple conventional potential.

Classifications are important in the context of intercultural differences, where, however, they also import their own problems of culture-dependency. "Local", situated classifications can elucidate actions and relations present in the analysed culture, but such classifications are partly induced by the local reality and, as such, can be far from universal. In turn, trying to impose classifications defined for the English language (or some other language) may distort the picture of linguistic action in the foreign community under investigation ${ }^{151}$.

Austin's original agenda was clearly to theorise about English speech acts and to discover intricacies that the English language had behind the numerous uses to which English verbs were put. Nonetheless, it seems justified to suppose that speech act theory should be of some universal value. The picture of the present-day speech act-theoretic research, especially as practiced in intercultural fields, suggests that the agenda was right and eventually at least partly successful. Speech act-theoretic methodology is able to lead to information about cultural differences in speech acts and, by extension, in the social sphere; it also gives insight into English vis-à-vis other languages through contrastive analysis.

\footnotetext{
${ }^{150}$ On the methodological note, it is interesting that Cummings (2007) discusses several inaccurate, in her opinion, applications of the label "pragmatic" (while also offering a discussion of the scope of pragmatics itself) in the field of clinical pragmatics, but the rich references therein lead to numerous illustrations of applications of pragmatic concepts into language disorderoriented research.

${ }^{151}$ For instance, a common line of criticism related to politeness theory in the tradition of Brown and Levinson (1987) is that it is heavily centered on Anglo-Saxon standards (or possibly middle class Anglo-Saxon standards). For instance, the frequently quoted phrase: "I have been seriously told that 'Poles/Russians, etc. are never polite"' cited by Leech (1983: 84) has been shown to origin from misinterpreting Polish and Russian politeness-oriented standards in speech act use by distorting them through imposing syntactic and semantic English-related criteria.
} 
In summary, it is not realistic that there is one typology of speech acts adequate to all research programmes as speech act taxonomies perform different functions depending on the focus of particular investigations. In linguistics "local" studies, whether on the level of one language, or in intercultural contexts, they serve to show shapes and shades of meaning and practiced patterns of behaviour. In a larger philosophical perspective, even all the main categories may dilute into one as a result of functional and methodological "zooming". As approaches to the act of promising show, all language, as a phenomenon, may be perceived as "commissive" in nature through focus on speakers' taking on responsibility for their utterances. In another bird-eye view perspective, all language is "assertive" 152 , i.e. involving a commitment to a certain state of the world ${ }^{153}$, and in yet another, its nature is "directive" thanks to the prescriptive aspects of communication. Different fields emphasise different aspects. For instance, research related to first language acquisition will necessarily focus on directives, as central to how children use language, but such an approach is not universal. Despite the diversity and necessary limitations, in many fields both applying and constructing speech act taxonomies will prove productive.

The variety and context-dependence is relevant for focusing on verbs and acts. Austin's original proposal is a mixed and underdefined account, but functions as an invitation to phenomenological research of varied nature. Speech acts and verbs, as well as their taxonomies, are thus best approached in a situated perspective, where particular models serve particular needs and help to identify speech-acts, their families and the interrelations between them (cf. Austin 1970: 150). In a perspective known from biological science (e.g. Lenneberg 1967: 387), the categories are not labels for fixed classes of objects, they are better seen as modes of categorisation used in a dynamic process.

\footnotetext{
${ }^{152}$ Cf. the title of Pagin's (2004) paper asking: "Is assertion social?" while the whole of speech act theory is seen as a theory of social interaction based on competences acquired in the course of social grooming. Cf.

${ }^{153}$ Cf. also Hindriks's (2007) "The status of the knowledge account of assertion" with a discussion of "the knowledge rule" and the belief-centered theories of assertion.
} 


\section{CHAPTER FOUR}

\section{SPEECH ACTS AND THE NOTION OF CONVENTION}

"Much of speech act theory is [...] devoted to striking proper balance between convention and intention" Jerrold Sadock (2008: 53)

\subsection{Introduction}

It is implicit in speech act theory that knowing how to perform linguistic acts, e.g. how to ask questions, how to order, and how to accept or deny a suggestion, is part of linguistic knowledge not less necessary for success in a social environment than knowledge of grammar and vocabulary of the language which is being used. It is also widely accepted that although linguistic acts are instances of intentional actions, at the same time they must draw on conventionality. Thus, in a theoretical perspective, both the concept of intention and convention are directly related to linguistic acts. In speech act theory, however, these two concepts, approached either individually or together, have motivated much discussion and contributed to numerous theoretical and methodological divisions.

Conventions are rules of conduct and language, being a social institution, must be conventional. However, what exactly in language is conventional has not yet received a satisfactory definition. Definitely, there is a conventional relation between sound and sense, which makes it possible for users of a particular language to recognise linguistic signs. But is the meaning of words, clauses, sentences and discourse beyond the sentence level conventional in at least similar manner? This problem has never been resolved although there have been many explicit suggestions, as well as many implicit ideas, concerning the conventional nature of linguistic utterances. Speech act theory has its own history of relevant discussions. 
It could appear that the convention-oriented approach should be rooted in formal perspectives on language and meaning, while the intention-based analysis would necessarily be functional through its concentration on the speaker and his or her inner (intentional) states (e.g. Avramides 2005). It should follow that a conventionalist approach must be associated with semantics, with the concept of meaning as maximally abstracted from particular contexts in which utterances are interpreted. In contrast, an intentionalist approach would be associated with pragmatics and utterance meaning, which will naturally go beyond the level of a sentence and which places emphasis on speakers and their wants in performing linguistic acts which are situated, motivated and intentional. However, in the context of speech acts the division has grown to be more complicated and complex.

In speech act theory, there emerged a discussion which offered a wide array of ideas related to conventionality. Furthermore, a proposal of a clear distinction has been put forward, following which there should be a divide between researchers who are "conventionalists" and those who are "intentionalists". The models suggested are characterised by a significant level of terminological confusion. The term "conventional" itself is often used to contrast different types of utterances and different aspects of their meaning. For instance, for some researchers, "conventional" utterances are to rely on social institutions such as marriage, or games such as bridge, while more "private" utterances are called "communicative" or "intentional". The semi-formal division can be traced back to Peter Strawson's seminal article of 1964, "Intention and convention in speech acts", in which the author attempts to amend Austin's original account and explicitly claims that there are two main types of speech acts: speech acts whose understanding requires recognition of a relevant social institution and speech acts whose success is relative to the audience's ability to recognise speaker's intention. Strawson originated the line of research in which "institutional" conventional speech acts are to be excluded from linguistic analysis proper. Moving away from institutional uses, he also integrated speech act theory with the Gricean perspective on how language works.

In the context of speech act theory, Strawson's proposal proved to exert significant influence and gave rise to prolonged discussions on the nature of speech acts and their cognitive aspects. The discussions may be related to many contrasts which have appeared in speech act-theoretic research over the years. Next to the above-mentioned contrast between the conventionalist and the intentionalist orientations, which, allowing some simplification, may be recognized as the Austinian as opposed to the Gricean stance, the division can also be related to the debates between contextualism and minimalism, externalism as opposed to internalism (e.g. Harnish 2009a), mentalism vis-à-vis normativism, to mention just the most widely acknowledged and dominant research standpoints. 
In the present chapter, selected problems and models of speech act theory relevant for the concept of convention will be discussed with the aim of exposing selected areas of both real and apparent disagreements, which are further related to Austin's emphasis on the fact that both locutionary and illocutionary aspects of a speech act must be conventional.

\subsection{The concept of convention in linguistics and philosophy}

In common language of the people, the relation between a linguistic form and its function is often described as "conventional". For instance, it may be said that questions of the form "Shall I ...?" are conventionally used to convey spontaneous offers, while the question "Can you pass me the salt?" is conventionally used as a request. Additionally, all language, having accepted its arbitrary nature, must be perceived as a conventional system, which maps forms and meanings. In this broad perspective conventionality is understood as a relation between form and function. This quality was recognised by Aristotle in De Interpretatione (16a.20-28) and by many philosophers who came after him. It is for instance exposed in Hermogenes's argument in Plato's (1999 [380 BC]) Cratylus ${ }^{154}$. As Lewis, a key figure among theorists of convention, claims: "It is a platitude - something only philosophers would dream of denying - that there are conventions of language" (Lewis 1983b: 166). Language thus appears to be conventional in a similar way as it happens for institutions of social nature such as money ${ }^{155}$. It follows from the definition of language as a system of arbitrary signs used for communication that language is necessarily conventional. It only makes sense in the context of recognisable linguistic signs, it has to be learned and theoretically presupposes a choice, i.e. it is taken for granted that linguistic forms in a language could mean something else, but they just happen not to. This view is both a clear commonsense truth and a source of confusion. Lewis's model, widely accepted in language studies, inter alia, follows in the footsteps of Hume's Treatise of Human Nature, where convention was discussed in terms of "common interest" (e.g. Hume 1896: 490), draws on research by the 2005 Nobel prize winner, T. C. Schelling's (1960), theorizing on "social contract", "common interest" and (tacit or explicit) coordination or bargaining in games of strategy with equilibrium points, as well as the nature of the intellectual process

\footnotetext{
${ }^{154}$ In the dialogue, names are seen as properties of objects and animate entities, according to Hermogenes, names "belong" by convention, while in Cratylus's perspective names "belong" by nature.

${ }^{155}$ In Nicomachean Ethics (Book V: Moral Virtue), Aristotle says: “[...] money has become by convention a sort of representative of demand; and this is why it has the name 'money' (nomisma) - because it exists not by nature but by law (nomos) and it is in our power to change it and make it useless".
} 
in coordination (1960: 54-58; cf. also 92ff.) ${ }^{156}$. The present-day understanding of conventionality in language (and possibly a shift towards a less decisive definition of linguistic arbitrariness) has partly been shaped by Lewis's interaction with Quine and Quine's (1976 [1935], 1969a) denial of the conventional nature of natural language due to its lack of "convening". Quine's main argument was that conventions have to be understood as agreements, while there had never been an "agreement" concerning language use. In turn, Lewis's main point was that conventions were not agreements as such, but emerged in the environment where an agreement, e.g. with regard a coordination problem, was needed, but nearly impossible to reach, for example due to a great number of people involved.

Lewis's (1983a [1975]) definition of convention is as follows:

A regularity $R$, in action or in action and belief, is a convention in a population $P$ if and only if, within $P$, the following six conditions hold. (Or at least they almost hold. A few exceptions to the "everyone"s can be tolerated.)

(1) Everyone conforms to $R$.

(2) Everyone believes that the others conform to $R$.

(3) This belief that the others conform to $R$ gives everyone a good and decisive reason to conform to $R$ himself. [...]

(4) There is a general preference for general conformity to $R$ rather than slightly-less-than-general conformity -in particular, rather than conformity by all but any one. (This is not to deny that some state of widespread nonconformity to $R$ might be even more preferred.) [...]

(5) $R$ is not the only possible regularity meeting the last two conditions. There is at least one alternative $R^{\prime}$ such that the belief that the others conformed to $R^{\prime}$ would give everyone a good and decisive practical or epistemic reason to conform to $R^{\prime}$ likewise; such that there is a general preference for general conformity to $R^{\prime}$ rather than slightly-less-than-general conformity to $R^{\prime}$; and such that there is normally no way of conforming to $R$ and $R^{\prime}$ both. [...]

(6) $[\ldots](1)$ to (5) are matters of common (or mutual) knowledge: they are known to everyone, it is known to everyone that they are known to everyone, and so on. The knowledge mentioned here may be merely potential: knowledge that would be available if one bothered to think hard

\footnotetext{
${ }^{156}$ As Schelling (1960/1980) points out, coordination is not just about guessing what other people, i.e. average people, would do. Many games do not rely on repetition in individual experience, in fact many will be played just once in a lifetime so "players" cannot draw on their life experience and history. Instead, especially in contexts where there are multiple equilibria, they must rely on introspection and inference with regard other players' probable behaviour. In Schelling's words "[c]oordination is not a matter of guessing what the 'average man' will do. One is not, in tacit coordination, trying what another will do in an objective situation; one is trying to guess what the other will guess one's self to guess the other to guess, and so on ad infinitum" (Schelling, 1960/1980: 92-93).
} 
enough. Everyone must potentially know that (1) to (5) hold; potentially know that the others potentially know it; and so on. [...]

$$
\text { (Lewis } 1983 \text { [1972]: 164-166) }{ }^{157}
$$

Lewis's exposition of how to understand convention is in agreement with much linguistic and philosophical theorising in the field, where convention is understood as a quality of behaviour which presupposes a choice, is based on repetition and can best be phrased in terms of rules and norms. For instance, in Gilbert's view, people's “everyday concept of a social convention is that of a jointly accepted principle of action" and "a group fiat" (Gilbert 1989/1992: 377, 399,394 , et passim) with respect to how one is to act in a specific situation. With language being social in nature, all linguistic conventions are housed as a subset within a broader category of social conventions, which in turn are an indispensible part of social life.

Conventions are thus species of norms which possess certain qualities. It is usually claimed that all social conventions must have features such as contingency, path dependency, and underdetermination by reason (cf. e.g. Marmor 2009, 2008, 1996). Most theorists (e.g. Lewis 1969, Gilbert 1990, Marmor 2009, Searle 1969, Millikan 2005a) agree that conventions are social rules and norms which regulate human conduct, but they differ as to particular characteristics of such norms and their motivation.

Lewis (1969), as can be seen above, suggests that conventions arise as alternatives to social agreements and are meant to solve recurrent coordination problems. In situations when there are large numbers of participants with particular interests and reasons for action, in order to coordinate mutual conduct an agreement is needed. However, in recurrent situations where there are exceptionally many participants involved, negotiations are not possible, and, under the circumstances, conventions emerge as solutions and participants act in a conventional way on the assumption that others will also conform to the same type of conduct. In his original account, Lewis (1969) suggests that when conventions emerge, people, assuming other people would do the same, tend to choose the most salient option which becomes a convention. Marmor (2009), in turn, suggests that many conventions originated in an accidental manner ${ }^{158}$ and the salience model is just one of many plausible speculations. Furthermore, it has also been claimed that conventions may be better seen as responses to numerous kinds of common social needs than as responses to coordination problems. To avoid commitment to the concept of social agreements, Gilbert

\footnotetext{
${ }^{157}$ This account of the concept of convention has been quoted after the 1983 edition of the article "Languages and language".

${ }^{158}$ Marmor (2009: 21f.) illustrates the point with the example of an origin of the army salute and the greeting "Hallo" as used on the phone, reportedly distorted form of "hallod", i.e. "do you hear" in Hungarian.
} 
(1989/1992) finds it practical to approach conventions as norms of "quasiagreements".

In summary, Lewis's model is vulnerable in a number of respects. For example it presupposes that conventions emerge where there are problems to be solved. However, at least some conventions seem to be constitutive of what they relate to. A very straightforward and much quoted example is that of chess. It only makes sense to refer to the conventional rules in the context of the game, which, however, had no existence prior to the rules. Thus, there could be a separate species of conventions - constitutive conventions, next to coordination conventions (cf. Marmor 2009: 31-57). In a speech act theoretic perspective a similar point has been expressed by Searle, who distinguishes between constitutive and regulative rules (cf. section 2.8) underlying speech acts.

There are also doubts as to the scale of conformity of behaviour. Although conventions do not require that all members of a given society conform to certain predefined forms of conduct, it is naturally expected that any norm must be followed by some members, or at least recognized as a norm that could or should be followed. It is problematic how many members of a given society must conform to (or at least recognize) a norm so that we could define it as a norm and a convention. Marmor (1990: 3 et passim) quotes both Margaret Gilbert (1990) and Ruth Millikan (1998 [2005d] $)^{159}$ to illustrate the scalar nature of social convention and a possibility that there might exist conventions without conformity of behaviour, of which Gilbert $(1989 / 1992)^{160}$ actually makes a point in her criticism of Lewis.

There are further problems with Lewis's approach to social conventions when the role of practical reasoning is taken into consideration. It appears that conventional norms should find their place in human practical reason, which seems a threat for their status as arbitrary. Norms are typically motivated, but the status of reason in constituting and maintaining a norm may be understood in different ways depending on one's theoretical commitments. Lewis (1969) explicitly claims that conventions are relative to reason, Marmor (2009), however, contradicts this suggesting that reasoning does not normally admit of alternatives as in common sense world there often appears to be only one best and right solution to a problem. In addition, Burge (2007 [1975]) points to numerous "unconscious" instances of patterned forms of behaviour.

There is also a distinction between a rule and a belief and the two may be confused when they provide reasons for action. Conformity of behaviour is regarded as rooted in convention, while action is motivated by a recognised norm. However, beliefs, which can also be widely shared within a community are not conventional, which can be illustrated with the fact that believing

\footnotetext{
${ }^{159}$ Cf. e.g. Gilbert's (1990) example of sending a thank-you note after being invited to a dinner party and Millikan's (2005d [1998]) example of handing out cigars when a boy is born

${ }^{160}$ Cf. Gilbert's claim that "social conventions can exist in the absence of expectations of conformity” (Gilbert : 1989/1992: 348).
} 
something just and only because other people believe it is nonsense. In contrast, to behave in a certain socially predefined way just because other people behave that way makes perfect sense ${ }^{161}$. As a result, beliefs appear to be nonconventional in nature, just like moral judgements, rules of moral behaviour, or rules related to rational thinking and reasoning.

Social norms, being arbitrary and unique, cannot by definition embrace norms which do not allow of an alternative. In other words, that for which there is no alternative cannot be understood as a convention. If it is believed that norms of rationality are always one-way paths with only one value and do not admit of alternatives, consequently, they cannot be "conventional". Similarly, all moral norms, which by definition are not relative, cannot be "conventional" as there are no alternatives for them.

An interesting proposal with regard to the nature of convention has been put forward by Burge (2007 [1975]), who suggests that linguistic conventions are largely "unconscious" and historically accidental. Sustaining a positive attitude towards Lewis' work, he, however, challenges some of his claims. In particular, Burge expresses his dissatisfaction with the opinion that for all conventional behaviour there must exist a possible alternative. One of Burge's examples is a critique of Poincaré's discussion with regard to Kant, Newton and geometry. Kant claimed that his and Newton's practice of using Euclidean geometry to map physical space was nonconventional due to the fact that there were no conceivable alternatives. However, at a later time, Poincaré suggested that this view was mistaken as there were Reimannian and other geometries. In the perspective of this story, it could be concluded that the same practice was conventional at one time, but nonconventional at another when different classifications would arise due to the difference in knowledge of geometry exhibited between the eighteenth century and the twentieth century. However, recognition of a change in the status of the practice would violate our intuitions about the nature of the very practice. Consequently, Burge suggests that human beings are not totally conscious and reason-guided when they perform conventional practices. There may be conventional regularity of behaviour for which there are no directly available alternatives, which is clearly visible in linguistic performance. As Burge (2007 [1975]: 33) claims, there may be linguistic conventions similar in nature to Kant's and Newton's practice of using Euclidean geometry, i.e. conventions which are applied without the speaker realising that there may be alternatives, but "[t]he fact that we currently lack reason to believe (or even disbelieve) that a given regularity is a convention does not preclude us from deciding later that it is and was such" (Burge 2007 [1975]: 33). To provide an example, speakers of some totally isolated language may not realize that there are other languages in the world which they could potentially

\footnotetext{
${ }^{161}$ Marmor (2009: 17) illustrates the point with the example of driving on the right side of the road as opposed to beliefs which are related to the idea of truth and falsehood although naturally people may use other peoples' authority as justification for their beliefs.
} 
speak, nor that the rules present in their language are not natural. In consequence, they may mistakenly regard their practice of using their language as nonconventional in the technical sense even though, as Burge (2007 [1975]: 250) claims, despite their belief, the language would still be arbitrary in nature. In this argument Burge refutes Lewis's (1969: 58) claim that participants share "common knowledge" with regard to the arbitrary nature of the rule(s), being a necessary condition for any social convention. Marmor (2009: 6f.) suggests there may also be non-conventional forms of behaviour which some people may regard as conventional, e.g. some people may believe moral rules are merely conventions.

Burge also challenges Lewis' concept of a "rational assembly", i.e. his suggestion that conventions are relative to reason. Having acknowledged Lewis's advancement in freeing the notion of convention from a commitment to an explicit agreement, he proceeds to show that the role of reason has been much overestimated in theorizing on conventions and that there has been "overzealousness in distinguishing human rational systems from mere regularities of nature" (Burge 2007 [1975]: 37). This overzealousness may have stemmed from an over-interpretation of the Cartesian idea of self-consciousness and self-reference in the rational system, i.e. the belief that experience itself presupposes rationality.

As Burge (Burge 2007 [1975]: 35) claims, "[t]he stability of conventions is safeguarded not only by enlightened self-interest, but by inertia, superstition, and ignorance", which results in the fact that arbitrary conventional practices may not be represented in the participants' beliefs and preferences, just because these participants do not consciously realize them. Instead, the arbitrariness of conventions "resides somehow in the 'logic of the situation' rather than in the participants' psychological life". Thus, in Burge's perspective, the arbitrariness of conventions has two significant aspects. One is that conventions are "historically accidental", i.e. they are not determined by biological, psychological or sociological laws, even though psychological and other aspects may play a role in conventions (e.g. certain patterns of behaviour may be functional in putting people at ease). The other aspect is that they are not necessarily the best conceivable candidates for fulfilling a given social function, but they just happen to be the ones used.

Although there has been much discussion focused on problems found in approaches associated with Quine and Lewis ${ }^{162}$, the concept of conventionality is commonly used in linguistics and philosophy of language and taken for granted despite its methodological and theoretical underdetermination. It is in fact rarely explicit or clear what particular theorists mean by "convention", even though it is clear that the label "conventional" is often used to refer to a quality

\footnotetext{
${ }^{162}$ Lewis's account was later followed by much theorising focused on game theory rather distant from a general linguistic approach and speech act theory.
} 
beyond the trivial attribute of language. This lack of explicitness induces confusion and, as a result, subsequent problems cannot be easily solved, e.g. when specific types of "convention", e.g. social conventions, institutional conventions, established conventions, etc., are discussed. In general, "social" conventions are associated with particular social functions (such as questioning, ordering, etc. mentioned above) and situations which are close to cultural customs and habits. They may for example specify how people can and should be introduced and what linguistic (conventional) responses are allowed within certain contexts. Frequently, such forms may be judged along the lines of politeness (as polite or not), but whichever dimension is explored, it has to be learnt to what particular uses utterances of certain forms are (conventionally) put in a given community. Socially predefined functions of utterances are part of linguistic knowledge of native speakers, but in contexts where non-literal or non-explicit language plays a role, they often require a relatively high level of expertise; such expressions are also more difficult to master by learners of the language in question.

In a speech act theoretic perspective it is significant that conventions, being social norms, may replace first-order reasons for action. In a broad view, a conventional form of conduct makes it possible that people do not deliberate what to do under certain circumstances, instead, they just follow the (tacit) convention.

In conclusion, the received view suggests that social conventions, including linguistic conventions, are norms which are relative to reason, they may arise as alternative to agreements where there are large numbers of agents involved (cf. Lewis 1969, Marmor 2009), they are arbitrary, and can admit of degrees. Such conventions are practice-dependent and conditioned by compliance dependent reasons. Conventionality may then be re-defined in a simpler form in the following way:

A rule, $\mathrm{R}$, is conventional, if and only if all the following conditions obtain:

i. There is a group of people, a population, $\mathrm{P}$, that normally follow $\mathrm{R}$ in circumstances $\mathrm{C}$.

ii. There is a reason, or a combination of reasons, call it $\mathrm{A}$, for members of $\mathrm{P}$ to follow $\mathrm{R}$ in circumstances $\mathrm{C}$.

iii. There is at least one other potential rule, $\mathrm{S}$, that if members of $\mathrm{P}$ had actually followed in circumstances $\mathrm{C}$, then A would have been a sufficient reasons for members of $\mathrm{P}$ to follow $\mathrm{S}$ instead of $\mathrm{R}$ in circumstances $\mathrm{C}$, and at least partly because $\mathrm{S}$ is the rule generally followed instead of $\mathrm{R}$. The rules $\mathrm{R}$ and $\mathrm{S}$ are such that it is impossible (or pointless) to comply with both of them concomitantly in circumstances $\mathrm{C}$.

(Marmor 2009: 2) 
The definition given above is a useful approximation which highlights commonly recognised aspects of (modern) conventionality. Point (i) emphasizes conformity of behaviour, point (ii) stresses rationality involved in conventional behaviour, which includes compliance-dependent reasons, while point (iii) addresses arbitrariness, availability of a conceivable alternative form of conduct. All these values are scalar in nature: conformity of behaviour may apply to only a fraction of a given society, reasons to perform in a certain way may not be explicit, for example performers may not realise why they follow certain patterns of behaviour, and finally, they may not realise that the behaviour itself is conventional and that there are, or could be, alternatives.

In retrospect, these points can be found in theories related to speech action. Wittgenstein, who can be considered a forefather of speech act theory, seems to forward an implicitly conventionalist view of language in its entirety. Convention seems implicit in his idea of "meaning as use", which naturally relates to iterative forms of linguistic behaviour, and seems to embrace all meaning that can be defined as linguistic.

In a different deconstructionist perspective, but in a similar semiotic vein, it has been suggested that utterances, and especially their illocutionary forces can be analysed in a way which mirrors analysis of meaning found in structuralism. For example, in "Convention and Meaning: Derrida and Austin", Culler (1981) suggests that Austin's system is parallel to de Saussure's system (as mentioned in chapter two), only repeated at a different level of signification. As Culler suggests,

Just as we account for the meaning of sentences by analyzing the linguistic system, so we should account for the meaning of utterances (or as Austin calls it, their illocutionary force) by analyzing another system, the system of speech acts.

(Culler 1981: 15)

Culler emphasises the fact that the performative is successful by virtue of a possibility that it can go wrong and that nothing can be considered a performative unless it can go wrong. Explicitly, it is claimed that to explain illocutionary force is "to set forth the conventions that make it possible to perform various illocutionary acts" (Culler 1981: 18). The view may be stretched so that infelicity is taken to be a sign of conduct or defect in circumstances which marks a departure from a relevant convention (whether conscious or tacit). In this perspective, felicity conditions, and especially failure, appear not to be external, but internal to the act; they are much more than mere context ${ }^{163}$. For Culler, as for Austin, all illocutionary acts must be conventional

\footnotetext{
${ }^{163}$ Culler (1981) defines this approach as "semiotic" and refers to Umberto Eco's idea that a sign is something enabling to tell a lie (Eco's "theory of the lie"), cf. Eco's definition of semiotics: "[S]emiotics is in principle the discipline studying everything which can be used in order to lie. If
} 
in the sense that there are predefined schemata which secure their success, while failure is internal to the performative and "a point of departure for investigating it" (Culler 1981: 18).

Marmor $(2008,2009)$, however, takes a different perspective and suggests that only elements of language are conventional in nature and argues that literal meaning is not readily conventional. What is conventional is the boundaries within which literal meaning may be recognised.

Theorists also point to the problem of a definition of a rule vis-à-vis a convention. Marmor (2009) suggests that all conventional conduct involves rules, in which he contradicts an earlier account by Lewis (1969), who distinguished between explicit rules and "understandings", i.e. unwritten and informal rulelike entities. Lewis explicitly pointed out that in common language of the people both categories can often be contrasted as when it is colloquially pointed out that some forms of conduct are not "rules", but simply "conventions" (cf. Lewis 1969: 104-105). Addressing the problem, Marmor (2009: 15) finds this view mistaken, but it is significant that the belief is repeated by Searle (1995: 28) in The Construction of Social Reality ${ }^{164}$. It seems right to believe that rules are scalar and involve dynamicity. When there is a social need for that, they may be codified and explicated in detail, they also may, and in fact do, fade and disappear while new conventions emerge, which can be illustrated with reference to games.

A related view on normativity and convention is associated with the concept of "communities of practice" (Lave \& Wenger 1991, Wenger 1998). A community of practice is a more recent label to refer to a group of people with an identity and competences, within which people share interests and may perform concerted actions. Such practices often motivate learning and lead to emergence of norms. The view supports the idea that norms arise in groups where people have to cooperate or just happen to perform some tasks together (cf. also Davies 2005). In another perspective, the concept of communities of practice emphasises that communication and interaction motivate specialisation and emergence of arbitrary patterns of behaviour.

The concept of convention and the understanding of its nature is thus of special relevance to speech act theory, where yet another distinction is often posited - that of "semantic convention" as opposed to "pragmatic inference". The following sections discuss selected speech act theoretic ideas concerning conventionality of utterances and their varied aspects.

something cannot be used to tell a lie, conversely it cannot be used to tell the truth; it cannot in fact be used 'to tell' at all." (Eco $1978: 7)$

${ }^{164}$ For a more detailed account of Searle's position see section 2.8 . 


\subsection{Convention and intention in the context of speech act theory}

In the context of speech act theory the concept of convention has often been put as against the concept of intention. In an approximation, intentionalist speech act theoretic approaches are based on Grice's (1975) concept of meaning and especially on his notion that meaning is best accounted for with reference to Speaker's communicative intentions.

Although Grice, a great advocate of logic and normativity, put forward his model to account for both what he called "conventional" (i.e. what-is-saidrelated meaning) and Speaker's meaning (which includes implicature, i.e. meaning beyond words), his concepts have been elaborated so that to differentiate between "intentional" in the sense of referential, mind-readingrelative meaning and "conventional", i.e. institution-oriented meaning. This approach is, inter alia, exemplified by Bach and Harnish (1979). Following the path of reasoning in which intention was juxtaposed to convention resulted in a terminological twist, leading to the situation in which performative utterances could be classified as either "conventional" or "intentional" depending on circumstances of their use.

This shift, although directly related to the Gricean programme (cf. Strawson 1964), may be seen as a violation of Grice's original account because it suppresses the fact that all linguistic expressions are conventional in a very basic sense, and that they are all at the same time "intentional" because communication as such presupposes making sense of utterances, for instance in the form of inferring intentions and beliefs behind them.

The split into conventional and intentional acts is underlined with quite strong intuitive force as indicated in Burge's extremist critical comments,

Individualistic assumptions about the mental have infected theorizing about the relation between mind and meaning. [...] The Gricean program analyzes conventional meaning in terms of subtle 'mutual knowledge', or beliefs and intentions about each others' beliefs and intentions, on the part of most or all members of a community. Seen as a quasi-definitional enterprise, the program presupposes that the notion of an individual's believing or intending something is always 'conceptually' independent of the conventional meaning of symbols used to express that something. Insofar as 'conceptually' has any intuitive content, this seems not to be the case. Our subject's belief or intention contents can be conceived to vary simply by varying conventions in the community around him. The content of individuals' beliefs seems sometimes to depend partly on social conventions in their environment.

(Burge 2007: 140-141) 
[...] in certain senses, 'use', socially conceived, necessarily 'fixes' conventional linguistic meaning; but 'use' (individualistically or socially conceived) does not necessarily 'fix' cognitive value. This general schema comprehends a variety of specific instantiations.

(Burge 2007: 273)

Speech act theory is a domain in which the confusion related to the intentional and the conventional, and the relation between the two, can be particularly clearly seen. To reiterate, the distinction, accepted in an explicit or implicit way, is often exploited in theorising on the nature of speech acts and often adds to the metalinguistic terminological confusion. It is often presupposed without clear exposition of how such metalanguage is to be taken that speech acts can be classified as either "conventional" or "intentional", with additional entanglement invited by the fact that terms such as "conventional", "intentional", or "institutional", etc. can be used to name trivial attributes of linguistic utterances, and to describe language in general. The following sections present how the concept of convention has been approached and exploited by selected speech act theorists.

\subsubsection{Austin on convention in speech acts}

Considering Austin's position with regard to convention and speech acts, a disclaimer seems necessary. As in relation to many other problems, a contemporary reader may have doubts whether Austin's use of the lexical item "convention" may be readily juxtaposed with views expressed in the later discussion explicitly addressing both convention and intention, as well as the relation between the two. When Strawson (1964) discusses convention he clearly uses the word in opposition to "intention" and the notion is saturated with rather fresh at the time Gricean (and occasionally anti-Gricean) ideology. However, when Austin uses "convention" and its kinship terms in his lectures, he evidently addresses a more flexible notion, a concept which is not fully fleshed theoretically, possibly not mature in its theoretical stance, and definitely not complementary to "intention". This is not to say that Austin is negligent in using the word, but it seems a fact that his use is a loose use. However, it also appears that Austin's original words can be used in a somewhat post-Austinian debate thanks to the clear distinction which he makes while discussing the internal architecture of speech acts. Consistently through his lectures, Austin emphasises the fact that both locutionary and illocutionary acts are conventional, while the perlocutionary act is not. Conventionality, although not simply contrasted with intentionality, is clearly important in his account.

In a contemporary perspective, Austin presents a mixed orientation, merging institutional acts with "private" acts. As his lectures unfold, he seems to 
concentrate on convention and most of his examples of performative utterances involve institutionalised, even ritualised, and socially conventional, fossilised utterances $^{165}$. His most frequent examples of speech acts include acts of christening, naming a ship, marrying, pleading, or giving a verdict. However, all through the lectures Austin emphasises conventionality as a crucial aspect of any speech act; he also points to the fact that some performatives can be "more" conventional than others ${ }^{166}$, for example in Lecture VIII, he remarks,

Speaking of the "use of "language" for arguing or warning' looks just like speaking of "the use of "language" for persuading, rousing, alarming'; yet the former may, for rough contrast, be said to be conventional, in the sense that at least it could be made explicit by the performative formula; but the latter could not.

(Austin 1962/1975: 103; original emphasis)

The difference receives no detailed explanation, but it seems that what Austin is referring to may be successfully related to the distinction between illocutionary and perlocutionary verbs (accepted by selected later researchers), as "the latter" categories (i.e. "persuading, rousing, alarming") are indicative of some kind of "result" rather than merely current performance. This point, i.e. that illocutionary acts are necessarily conventional, but perlocutionary acts are not, is elaborated further on in the lectures. At another point Austin explicitly declares,

We must notice that the illocutionary act is a conventional act: an act done as conforming to a convention.

(Austin 1962/1975: 105)

and later continues:

The illocutionary act and even the locutionary act too involve conventions: compare with them the act of doing obeisance. It is obeisance only because it is conventional and it is done only because it is conventional. Compare also the distinction between kicking a wall and kicking a goal.

(Austin 1962/1975: 107)

\footnotetext{
${ }^{165}$ As Searle points out with regard to the distinction between constatives and performatives, here again Austin's special cases "swallow" the general case (Searle 1971: 7).

${ }^{166}$ In his paper entitled "Truth", Austin (1970: 117-133) also indicated the distinction between "descriptive conventions" and "demonstrative conventions", where the former related to the restrictions on the use of words and the latter would regulate the use of referring expressions, such as "this" (89-90).
} 
He also emphasises that

the whole apparatus of 'explicit performatives' [...] serves to obviate disagreements as to the description of illocutionary acts. It is much harder in fact to obviate disagreements as to the description of 'locutionary acts'. Each, however, is conventional and liable to have a 'construction' put on it by judges.

(Austin 1962/1975: 116, fn I)

Austin continues that using a formula of the kind, "In saying so-and-so I was warning" makes the act callable by a different name (cf. Austin 1962/1975: 127). However, for illocutionary acts, as Austin claims, "the act is constituted not by intention or by fact, essentially, but by convention (which is of course a fact)" (Austin 1962/1975: 127; original emphasis).

This last statement seems reflective of the tentative character of the theory at the time. Austin exposes the problem and suggests the direction where a solution could be found, i.e. in convention, but does not offer a definition of the term, nor its (technical) relation vis-à-vis intention. It seems reasonable to suppose that Austin refers here (at least primarily) to a linguistic convention and not institution-oriented extralinguistic type of predefined patterns of behaviour.

Although he claims (as can be seen above) that "the act is constituted not by intention" (Austin 1962/1975: 128), while discussing conditions of a successful performance, Austin does admit that

being serious consists in [... the words'] being uttered as (merely) the outward and visible sign [...] of an inward and spiritual act".

(Austin 1962/1975: 9)

Furthermore, Austin concludes that the outward utterance is a description, true or false, of the occurrence of the inward performance and makes several further references to "inward" and "spiritual" action (cf. Austin 1962/1975: 13 \& passim) marked with "outward" and "audible" signs.

The fragment above testifies that Austin's perspective on speech acts was in fact more holistic than it is at present usually acknowledged. To some extent his presentation of a performative utterance being "a sign" of action (also of an inward action), is reminiscent of the notion of ostensiveness understood as part of communicative behaviour, widely discussed in Gricean, neo-Gricean, and post-Gricean models (cf. e.g. Sperber and Wilson 1986/1995, Carston 2002). Furthermore, even though Austin's theory which is accessible to present-day readers was clearly a model still in the making, Austin did direct some attention to "intentional" problems, e.g. moral issues ${ }^{167}$. In overall, in his lectures, Austin was introducing a topic which turned out to be broad and complex and it is thus

${ }^{167} \mathrm{Cf}$. his references to Kant and analogy between moral judgements and speech acts (e.g. in Lecture I) 
not surprising that in the initial sketch of the theory of speech acts - the only one that he managed to present during his lifetime - a variety of data is provided without a fully-fleshed theory able to anticipate and accommodate all details elaborated later. Still, it is evident that despite his emphasis on convention, Austin believed in an interplay of both intention and convention in all speech acts.

It is also evident that the exact meaning of "convention" as used in the lectures is significantly underdetermined and may send the reader in different directions. Even immediate commentators who knew Austin and his original work, as e.g. G.L. Warnock, were not able to explicate the notion and tended to find a fault in it. That conventions as commented on by Austin were taken to simply be social extralinguistic conventions is evident in Warnock's (1973) criticism of the notion and his conclusion that "illocutionary forces $[\ldots]$ are not in general convention constituted" (1973: 76). Inter alia, Warnock criticises the notion referring to utterances which do not involve "social" conventions in the institutional sense and finds that conventionality is not a good candidate for a description of explicit performatives. In Warnock's view, the illocutionary force of explicit performatives of the form "I promise...", etc., "for the most part", is recognised thanks to their "standard meaning" which cannot be identified as "convention"; as a result they are not operative "by convention" (Warnock 1973: 86). Warnock believes that there are two main types of performatives in Austin's theorising: conventionally operative utterances and explicit performative utterances with only the former group involving (social) convention.

Warnock's analysis brings him to conclude that eventually Austin is right in that all utterances are speech acts, but he argues for a recognition of "a legitimate sub-class of utterances called 'performative"' (Warnock 1973: 87), further sub-divided with the criterion of conventionality. Considering the evident discrepancy between Austin's and Warnock's approaches, it is not surprising that the notion remains a contentious issue in later theoretical debates.

In summary, it seems that Austin's claim that both locutionary and illocutionary acts are conventional rests on the assumption that the locutionary act depends on some general linguistic convention, which, as later acknowledged by Strawson in 1964, would be a trivial comment. However, it turns out to be more important if two types of conventions are to be differentiated. Locution is crucial for understanding the "meaning" of the utterance on the (more) semantic ${ }^{168}$ level ("sense and reference" according to Austin 1962/1975: 94, 95), making use of general conventions of language-we may call this type "convention ${ }_{\mathrm{L}}$ "- associated with the use of any linguistic form. Illocutionary acts, in turn, must rest on a different type of convention-let us call it "convention,". Conventions operative on the illocutionary level, according to

\footnotetext{
168 "Semantic" as used here subscribes to a simplified view, which ignores the fact that any linguistic meaning is necessarily underdetermined and there are inherently pragmatic inferential processes on all levels of linguistic analysis.
} 
Austin (cf. the citations above) are of the same, or very similar, nature for both verbal and non-verbal acts. It seems right then to identify them (even when limited to linguistic utterances) as social conventions which rely more heavily on knowledge how a particular society works and less on generalised (dictionary meaning-oriented) conventions.

Illocutionary conventions are of much varied and a rather puzzling nature, both on the more formal level of language and the more "social" level of speech actions defined within a broad context of culture and society.

With regard to linguistic forms, locutions and illocutions, Allwood (1977) pointed out that the nature of convention that Austin might have had in mind varied with the verbs used in particular utterances. For instance, for

It is snowing.

it seems right to conclude that the locutionary aspect "says something about the weather", while the illocutionary aspect involves the force of a statement. However, the picture gets more complex and complicated in the case of explicit performatives such as (50):

I promise to buy you a drink.

It is suggested that the illocutionary force in such utterances seems to arise at least partly from the meaning of the verb, thus its nature (however conventional) is profoundly different from the force associated with (49). For (50), both the fact that the verb "promise" is used and the form of the utterance as a statement are important. Although the meaning of (50) can vary across contexts, at least part of this meaning, in the sense of function, is construed thanks to the convention associated with the verb "promise", i.e. input on the locutionary level. This varying degree of "lexical meaning" intervention may be seen as a good indication that the illocutionary level is at least to a certain degree dependent on the locutionary and, to reiterate, that the conventions operative on both levels are varied and possibly mixed across different categories of speech acts. Still, just as it is possible to conceive of locution and illocution, it seems right to conceive of conditions which constrain both aspects of a speech act, and as such conventions which are operative on both "levels" of a speech act. Typically, illocutionary conventions - conventions $s_{\perp}$ can be associated with public actions and their functions within a society; more specifically, they can be seen as conditions which contribute to the definition of such acts and which define their felicity.

In this context, it is worth remembering that locution and illocution (together with perlocution) are not distinct acts, but just useful approximations which mark important aspects of one linguistic act. In Austin's words, "the locutionary act as much as the illocutionary is an abstraction only: every genuine speech act is both" (Austin 1962/1975: 146). Thus, within limits, a way of referring to them 
is arbitrary and indicative of certain theoretical commitments because other configurations might also be possible. In particular, the distinction is relative to the construal of context envisaged for a potential utterance or experienced in the case of particular token utterances.

Context itself may be approached in various ways. Fetzer (2007a: 5), with focus on speech action, distinguishes between four main categories: linguistic context, cognitive context ${ }^{169}$, sociocultural context, and social context ${ }^{170}$. All these categories can be successfully relativised to the types of conventions operative at each level, e.g. conventions $\mathrm{L}_{\mathrm{L}}$ are thus linguistic in nature and can be associated with linguistic context and co-text, while conventions $S_{I}$ are more readily relativised to socio-cultural and social context. In this model, cognitive context invites notions relative to intentions and beliefs. Naturally, it is not possible to enforce a clear borderline between linguistic and social, cognitive (and other types of) contexts, and it is not possible to clear-cut different types of conventions. However, there seem to be salient and non-counterintuitive means to differentiate between the linguistic and other types even if only in an approximate manner.

An independent interpretation of Austin's thoughts comes from Sbisà, who firmly asserts that "illocutionary acts are conventional, first of all, because they have conventional effects" (Sbisà 2009: 33), which, as evidenced in Austin's lectures, are essential to illocution. Sbisà further argues that the bringing about of conventional effects is associated with the indispensability of uptake.

Sbisà's arguments are supported with (however vague) Austin's own words and as such bring clarity to the discussion of convention, illocution, intention and related notions. However, a through definition of "conventional effects" has not been given, either by Austin or researchers working within his framework. As a result, at least some of the vagueness inherent in the notion of "conventional acts" has been inherited by the notion of "conventional effects". The closest interpretation that can be attempted here seems to be that "conventional effects" are "public" or "social-conventional effects", i.e. effects that can be "socially" expected and "socially" ("publicly") defined. In this way, conventionality of illocutionary acts can be defined as different from perlocution, which also embraces effects which cannot be easily envisaged and often lack a "social" definition. This reading seems to be supported with Austin's words:

\footnotetext{
${ }^{169}$ The category of cognitive context is an extension introduced into Fetzer's earlier (2004) threepartite model.

${ }^{170}$ There are evident differences which do not allow treating convention in exactly the same manner as context, however, there are also salient correspondences in between the two notions as demonstrated in further sections of the present chapter.
} 
The illocutionary act 'takes effect' in certain ways, as distinguished from producing consequences in the sense of bringing about states of affairs in the 'normal' way, i.e. changes in the natural course of events.

(Austin 1962/1975: 116)

According to Sbisà (2009), conventionality of illocutionary acts resides in the conventional status of the effects which they bring about. Consequently, it is not important that (or whether) an illocutionary act is performed "through" conventional means ${ }^{171}$, rather, it is important that it brings conventional effects. Furthermore, uptake is seen an indispensable, but it is not taken as evidence for the intentional character of illocutionary acts. In this approach it indeed results from the fact that illocutionary acts are conventional and have conventional effects.

Sbisà's perspective on Austin revives his model as inherently social. The force of the utterance is not so much in its form, which of course plays a role, but in the audience's ability to recognise a relevant social convention behind the form. It is a model in which there is a lot of trust in social expertise of speakers, and one which presents language as a means for making things happen, while the "things" being done are dynamic in nature and form. It is also interesting that in contrast to many current approaches, Sbisà does not believe that Austin's and Grice's frameworks can in fact be compatible (cf. Sbisà 2009: 34ff.) and denies that reformulations of speech acts in terms of Gricean pragmatics have any sound theoretical potential.

In conclusion, in Austin's account there is much discussion of both convention and intention. They are not juxtaposed, but it is emphasized that all locutionary and illocutionary acts are by definition conventional. The points that Austin suggests are different from later arguments put forward by other theorists and also his conception of convention, even though under-defined is evidently different from what was to follow.

\subsubsection{Strawson, conventionality of linguistic acts and Gricean intervention}

Strawson has had an immense impact on the development of speech act theory after Austin, first of all due to the fact that he originated the divide into intention-based and convention-based speech act theoretic 'schools'. In an attempt to refine Austin's model, Strawson introduces Gricean, at the time new, approach to meaning, in which the focus is on speaker intentions which are made manifest and then recognised by the hearer. Thus, Strawson's position is a

${ }^{171}$ It may be noted that the concept of "conventional means" is another underdetermined notion. 
combination of Austin's concepts of "uptake" and conventionality with Grice's concept of "nonnaturally meaning something".

In summary, Strawson suggests that there are two main types of speech acts: "conventional" speech acts and "intentional" speech acts. The former, amply illustrated in Austin's lectures, rely for their felicity on adherence to social conventions and rules; they are institutional, while the latter type, according to Strawson, more frequently performed in natural language, rely on the hearer's recognition of what the speaker intended to communicate. "Conventional" speech acts fall outside the scope of language studies because their recognition is primarily dependent on familiarity with relevant institutions. It is also presented as essential that the "real meaning" of words uttered in performance of such conventional, institutional acts is rarely important. Instead, they function as (not typically linguistic) signs for the recognition of their institutional functions. For instance (as also later claimed by relevance theorists, cf. Sperber \& Wilson 1986/1995: 244-245), bidding while playing bridge does not really belong to linguistic communication proper, at least not as much as it belongs in the institution of bridge, and by extension, in the theory of institutions rather than the theory of language.

Strawson very clearly departs from Austin's position and while discussing conventional speech acts, he says:

the speaker's utterance is not only intended to further, or affect the course of the practice in question in a certain conventional way; in the absence of any breach of the conventional conditions for furthering the procedure in this way, it cannot fail to do so. (Strawson 1964: 612)

The fragment shows that Strawson here interprets convention as a trivial quality. This type of convention is omnipresent, just like language has to be conventional to a certain degree if it is to be language at all. He also rejects the supposition that "calling" an act a certain name is an indication of convention:

we must dismiss as irrelevant the fact that it can properly be said to be a matter of convention that an act of, for example, warning is correctly called by this name. For if this were held to be a ground for saying that illocutionary acts were conventional acts, then any describable act whatever would, as correctly described, be a conventional act.

(Strawson 1964: 442)

In general, Strawson seems to interpret the "convention" that Austin referred to as relevant only in either very general sense or as "institutional" (i.e. referring to a social institutional predefined patterns of behaviour). Suggesting a more finegrained analysis of linguistic acts, he proposes that a distinction should be 
introduced between two broad classes of such acts. Explicitly addressing Austin's claims, Strawson argues:

It seems perfectly clear that, if at least we take the expressions "convention" and "conventional" in the most natural way, the doctrine of the conventional nature of the illocutionary act does not hold generally.

(Strawson 1964: 445)

He continues to explicitly claim that "some illocutionary acts are conventional; others are not (except in so far as they are locutionary acts)" (Strawson 1964: 445), pointing out that the persistence with which Austin would "repeatedly affirm the contrary" cannot be understood as his being mistaken in generalising from some cases to all. In Strawson's opinion,

it is much more likely that he [i.e. Austin] is moved by some further, and fundamental, feature of illocutionary acts, which it must be our business to discover. Even though we may decide that the description "conventional" is not appropriately used, we may presume it worth our while to look for the reason for using it. Here we may recall that oddly qualified remark that the performance of an illocutionary act, or the use of a sentence with a certain illocutionary force, "may be said to be conventional in the sense that at least it could be made explicit by the performative formula" (p. 103). On this we may first, and with justice, be inclined to comment that there is no such sense of "being conventional", that if this is a sense of anything to the purpose, it is a sense of "being capable of being conventional." But although this is a proper comment on the remark, we should not simply dismiss the remark with this comment. Whatever it is that leads Austin to call illocutionary acts in general "conventional" must be closely connected with whatever it is about such acts as warning, entreating, apologizing, advising, that accounts for the fact that they at least could be made explicit by the use of the corresponding first-person performative form.

(Strawson 1964: 445)

Strawson evidently associates conventionality with the means via which illocutionary acts are performed and does not read it to be part of their inherent nature as could be expected (and also interpreted) from Austin's lectures ${ }^{172}$. He further addresses in more detail two points made by Austin: the first is the possibility to "explicate" an illocutionary act in a canonical form, the other is the point that an illocutionary act means "doing" something "in" saying particular words. The first point, in Strawson's opinion involves Austin's "unconventional"

172 Cf. Sbisa's (2009) discussion of Strawson's and Searle's reinterpretation (or rather misinterpretation) of Austin's ideas. 
use of the word "conventional" (451). The other point is discussed with reference to "never-explicit" acts, such as insinuating and showing off (cf. also section 3.2).

Eventually, Strawson concludes that in natural linguistic communication, i.e. in situations in which people do not turn to using predefined formulaic language by which they may perform institutional formal acts, what really matters is interlocutors' ability to read each other's intentions (although certain illocutionary acts, such as redoubling in bridge may be performed unintentionally). For Strawson, recognition of the speaker's intention behind an utterance is directly connected with uptake (cf. also section 2.7), while "securing uptake is essentially a standard, if not an invariable, element in the performance of the illocutionary act" (Strawson 1964: 449). Linguistic acts come on a scale ranging from private and based on the intention-recognition procedure, sometimes underdetermined (cf. Strawson's discussion of "Don't go") to acts belonging to "convention-constituted procedures" (459). In institutional setting, such as that of an umpire giving a batsman out, a jury bringing in a verdict of guilty, a judge pronouncing sentence, etc. speakers' intentions are not foregrounded and conventional meaning "exhausts" the illocutionary force. However, it would be a mistake to treat processing of such utterances as a model for how linguistic communication in general works. Strawson's reinterprets Austin suggesting that in natural (not convention-consitituted) communication an illocutionary act is not "essentially" conventional, instead "it may be that the act is conventional, done as conforming to a convention, only in so far as the means used to perform it are conventional" (456-457). What all acts have in common is the necessity of a kind of uptake, or rather a recognition of their meaning, understanding of their force, or understanding of "an audience-directed intention" on the part of the particular audience.

Strawson's position has proved to be of great influence and has defined further developments of the theory of speech acts. In particular, even though Strawson admits that speech acts come on a scale and they cannot be readily classified into one or the other category, the publication of his 1964 article marks the beginning of a view that "conventional", i.e. institutional, social institution-oriented acts are of minor, if any, importance in language studies as they may not involve any mindreading, any elaborate interpretational activity. Thus, in many models, most notably in Bach and Harnish's (1979) analysis and later neo- and post-Gricean approaches, "conventional" acts are left aside as irrelevant for the question of how language works and how speech acts function.

In their influential model, Bach and Harnish (1979; cf. section 4.3.5) indeed divide acts into "conventional" and "communicative", pointing to the fact that only the latter group is worth attention in language studies. 


\subsubsection{Searle on convention and intention in speech acts}

The most visible of Austin's followers, Searle, also addresses conventionality on many occasions and takes a rather independent position, which has evolved over the years. Initially, in his early model of speech act theory, Searle (1969) mostly follows Austin by defending a conventional account of illocutionary acts. However, it is significant that promoting a broad social perspective, Searle considers language as a special kind of social institution, an institution which makes complex social world possible at all (cf. section 2.8). Thus, his notion of conventionality and the idea of social institutions are more general. The concepts of "convention" and "institution" are omnipresent, indispensable elements, and form foundations of culture in its entirety. In his initial model (Searle 1969), which is both clear and practical, Searle renames Austin's felicity conditions as necessary and sufficient conditions and suggests that such conditions can be best explained in terms of explicated rules. For any social institution, whether language, marriage, or cocktail parties, as Searle suggests, it is necessary that there be rules which exist in two main types: constitutive rules and regulative rules:

regulative rules regulate antecedently or independently existing forms of behavior; $[. .$.$] constitutive rules do not merely regulate, they create$ or define new forms of behaviour.

(Searle 1969: 33)

It has been argued that Searle's rules are of rather vague nature ${ }^{173}$. Constitutive rules not only constitute, but also regulate behaviour, while regulative rules can also be constitutive of forms of conduct with which they are followed. As a result, it may seem that the functions are shared by both types of rules. However, as later pointed by Marmor (2009), Searle seems to anticipate the problem, when he further explains:

Where the rule is purely regulative, behavior which is in accordance with the rule could be given the same description or specification (the same answer to the question "What did he do?") whether or not the rule existed, provided the description or specification makes no explicit reference to the rule. But where the rule (or system of rules) is constitutive, behavior which is in accordance with the rule can receive specifications or descriptions which it could not receive if the rule or rules did not exist.

(Searle 1969: 35)

${ }^{173}$ Cf. Marmor's (2009: 32ff.) remarks on Warnock’s (1971) criticism of Searle 
The difference can be illustrated by examples such as:

(51a) X drove on the left side of the road.

(51b) X appointed $\mathrm{Y}$

(51c) $X$ christened $Y$

(51d) X scored checkmate in just fifteen moves

where the verb in (51a) describes an action in an explicit way, but the verbs in (51b) to (51d) refer to concepts which need further specification and presuppose some knowledge of relevant institutions on the part of the audience.

The distinction is further mirrored in the syntax associated with both kinds of rules. As Searle suggests, constitutive rules are most naturally phrased in the formula "X counts as $\mathrm{Y}$ " or "X counts as $\mathrm{Y}$ in context $\mathrm{C}$ ", while regulative rules are most naturally phrased with the use of the imperative mood, e.g. "Do X" or "If you do X, then Y". Although there are constitutive rules which may be phrased in the form ascribed to regulative ones and vice versa ${ }^{174}$, the syntactic implications are very strong.

Searle's account of social reality and speech acts involves an interesting perspective on both conventionality and intentionality. There is hardly any tension between the notions because for Searle, convention is always a function of intention. Naturally, intention may receive different definition in different contexts. In Searle's broad social perspective, all institutions are created and maintained through collective intentionality, whose nature is rather vague. On a less general level, all rules which secure felicity are phrased in terms of speaker's intentions, beliefs and attitudes (cf. Searle 1969: 57ff.). For instance, a promise will only be successful if the speaker has an intention to act in a certain way and believes that what is being promised should be beneficial for the hearer. In addition, intentionality in the philosophical sense, i.e. related to "directness" and attitude, is present in all speech acts, even if in such speech acts the speaker does not express his or her sincere individual intentional states (cf. Searle 1979a: 4; 1983: 9-10), i.e. when what the speaker says is not what he or she believes to be true or sincere, etc $^{175}$.

With regard to semantics, Searle (1965 [1996: 135] et passim) stresses the fact that meaning "is more than a matter of intention, it is also a matter of

\footnotetext{
${ }^{174}$ Cf. Marmor's (2009: 33) example of instructing one's students that "sending an essay assignment by e-mail counts as (or does not count as) timely submission", which has appearance of a constitutive rule, but clearly expresses a regulative one.

${ }^{175} \mathrm{Cf}$. “... to say that the Intentional state which constitutes the sincerety condition is expressed in the performance of the speech act is not to say that one always has to have the Intentional state that one expresses. It is always possible to lie or otherwise perform an insincere speech act. But a lie or other insincere speech act consists in performing a speech act, and thereby expressing an Intentional state, where one does not have the Intentional state that one expresses." (Searle 1983: 9-10). Searle further indicates that "the parallelism between illocutionary acts and their expressed Intentional sincerity conditions is remarkably close" (10).
} 
convention", in which he addresses the issue of specific independence of linguistic expressions, independence with regard to speaker's intention. It follows that people cannot just make their words mean what they want, instead, the meaning of what they say is constrained by convention ${ }^{176}$. The point is illustrated with a passage from Philosophical Investigations in which Wittgenstein says: "Say 'it's cold here' and mean 'it's warm here". Wittgenstein's line is used to show that meaning is a function of what is said ${ }^{177}$. In other words, speakers are not really free in conveying their private meanings via any utterances.

Searle also discusses illocutionary force indicated devices (after Searle 1969 known as IFIDs) in terms of conventionalised markers of illocutionary force. Naturally, the most straightforward IFID is the very form of an explicit performative, i.e. a performative utterance in its canonical form, but IFIDs include markers of very different kinds, only some of which are syntactic in nature. Before Searle, Austin (1962/1975: 58-9; 71-72) mentioned markers of illocutionary force such as performative verbs, i.e. illocutionary markers par excellence, and words such as "guilty", "offside", and "the second and the third person, and impersonal passive". Urmson (1963), after Austin, also pointed to parenthetical constructions as markers of illocutionary force, others concentrated on adverbs such as "hereby" or "please" (cf. Sadock 1974) ${ }^{178}$.

Searle (1965), and later Vanderveken (Searle and Vanderveken 1985, Vanderveken 1990, 1991a), among IFIDs list: word order, stress, intonation contour, punctuation signs, the mood of the verb (which is also sometimes presented as just an "aspect" of sentence meaning, cf. Holdcroft $1978^{179}$ ), sentential type, and performative verbs. In turn, Infantidou-Trouki (1993) discusses sentential adverbials and presents "illocutionary" adverbs as one of the four groups of discourse markers, the other three being: attitudinal, evidential and hearsay adverbials. It is understood that such discourse markers are non truth-conditional in that they do not contribute to the propositional content of the utterance of which they are part, but serve to indicate the type of speech act which is being performed. Illocutionary adverbials of that kind include, among others: frankly, confidentially, honestly, and seriously and they are understood to modify "an implicit illocutionary verb" (Infantidou-Trouki 1993: 69; cf. also

\footnotetext{
${ }^{176}$ A similar idea is present in Korta and Perry's $(2007,2011)$ concept of a forensic aspect of meaning.

${ }^{177}$ Cf. also Searle's hypothetical example with a soldier pretending to be German (Searle 1965 [1996: 135]).

${ }^{178}$ IFIDs may be used to explain how, if not all, then at least some utterances (or potentially sentences) have their illocutionary force. For instance, Faller (2002) points to Cuzco Quechua evidentials as illocutionary modifiers to indicate that IFIDs may relate only to the illocutionary force of an utterance/sentence, which without their presence would function as an assertion. Such evidentials are shown to modify the sincerity conditions of the act in question.

${ }^{179}$ Holdcroft (1978) suggests that mood restricts the range of acts which May be performed by uttering a certain sentence.
} 
Bach \& Harnish 1979). The examples cited by Infantidou-Trouki (1993: 70) have been presented below. The (52 a-c) sample sentences show illocutionary adverbials, while examples $(53 \mathrm{a}-\mathrm{c})$ present their paraphrases.

(52a) Frankly, I'm bored.

(52b) Mary has, confidentially, failed the exam.

(52c) Seriously, your argument is fallacious.

(53a) I tell you frankly that I'm bored.

(53b) I inform you confidentially that Mary has failed the exam

(53c) I tell you seriously that your argument is fallacious.

In her relevance-theoretic analysis, Infantidou-Trouki confirms that "illocutionary" adverbials are non-truth-conditional.

There is so much variety among conventionalised markers of that type that in later research the list has been significantly extended. For instance, in an intercultural perspective, among the markers of the imperative Aikhenvald (2010: 20ff.) cites varied features such as: a special clitic or a suffix, including subtraction; a tone pattern, and a special set of pronominal cross-referencing affixes.

Consequently, although illocutionary force is conventionally associated with particular linguistic forms, it seems that the number of IFIDs cannot be defined as they are not only language-dependent, but also culture-dependent ${ }^{180}$. Speech acts are always social in nature, which means that different forms may carry the same or very similar force, while one type of force may also be shared across different forms. The problems of matching forms and forces multiply in intercultural perspectives, both between different nations and within a nation, between different social groups in the context of one language. It is also a fact about language that meaning of sentences is always underdetermined and even though utterances are produced in particularised contexts, they will usually inherit this quality. To provide a rather straightforward and much quoted example, even within the English language, the utterance "The ice is thin" may function as a warning, a piece of information, an encouragement to break the ice on the lake, or in a number of other ways ${ }^{181}$.

\footnotetext{
${ }^{180}$ IFIDs, predictably, lose their force when performative utterances are embedded (e.g. "If I hereby promise to paint the room pink, then it is a promise") or reported, which is another sign that illocutionary force is different from meaning (or sense) in general.

${ }^{181}$ Among the attempts to account for a relation between language forms and their illocutionary force there is Alston's (1994) model which suggests that meaning of sentences can be explicated in terms of their illocutionary act potential (IAP). This means being able to enumerate all functions which may be performed in uttering a particular sentence. Alston's model is elegant, but it can only be accepted as an approximation due to the dynamic social factors mentioned above.
} 
In conclusion, as Searle (1969: 31) suggested, it is probable that "in natural languages illocutionary force is indicated by a variety of devices, some of them fairly complicated syntactically". Even conventional markers, as IFIDs indicated by Searle, do not guarantee a thorough theory of illocutionary acts and forces and are best seen as descriptions of much "local" phenomena, related to various discourse fields not necessarily across languages, but also across semantic domains.

As noted above, Searle's (1969) original model is read as a come-back to Austin through its reliance on convention. What is accepted as "conventional" in this account is related closely to the mechanism of making sense of a speech act. Hearers make sense of a speech act because they can recognise, by convention, how an act should be interpreted, which is summarised in Searle's formula " $\mathrm{X}$ counts as Y in context C". There is an "intention" present in the process, but in the sense that the speaker's intention to conform to a certain convention must be recognised if communication is to succeed. In other words, speakers manifest their intention to satisfy a certain convention, but it is their satisfying the convention in question that "informs" what kind of speech act is performed. In explicit performatives, the intention to perform the act which is named by the performative verb is "encoded" in the literal form of the utterance (Searle 1989). Searle emphasises, however, that the performative character of the utterances is primary and, inter alia, the truth value of an utterance derives from this particular performative character of the utterance and not vice versa. Explicit performatives have values as assertions, but assertion is derived from their character as performatives, as declarative acts, and it is not the case that declarations are derived from assertions (cf. Searle 1989: 553ff.). This position places Searle on the conventionalist side.

\subsubsection{Morgan on conventions and speech acts}

Searle's reflection on the interplay between intention and convention was taken up by Morgan (1977/1978), who suggested a more refined model for speech actoriented conventions. Morgan puts forward his interpretation and elaboration of Searle $(1975 a)^{182}$, placing emphasis on the fact that literal meaning plays a role in understanding utterances even where such utterances are not explicit and direct. Morgan's starting point is that utterances of the kind "Can you pass me the salt?" are conventional, but not idioms. He accepts Searle's, and earlier Austin's, distinction between meaning and use, but suggests that there are two

\footnotetext{
${ }^{182}$ In the paper, Morgan emphasises that his starting point in approaching understanding of indirect language, such as uttering "Can you pass me the salt?" was to argue against Searle's (1975a) standpoint and in favour of either Gordon and Lakoff's (1975) or Sadock's (1974) ideas, but that in the course of his analysis he gradually approached Searle's position, or what he subjectively interpreted to be Searle's point of view.
} 
main types of convention: "conventions of language" and "conventions about language".

Morgan concentrates on a brief remark given by Searle (1975a: 76),

It is by now, I hope, uncontroversial that there is a distinction to be made between meaning and use, but what is less generally recognized is that there can be conventions of usage that are not meaning conventions.

Distinguishing between these two types of convention, Morgan claims, can help provide a better account of all speech acts, but proves especially fruitful in the context of indirect utterances. For instance, conventions of usage ("about language") could explain how standardised indirect acts work, while conventions of meaning ("of language") could account for literal utterances, but also idioms. The model accepts that Gricean maxims are roughly "a set of rules for inferring the intentions behind speech acts" (Morgan 1977: 3) and it is suggested that processes of grammaticalisation of implicature are active in conventionalising implicature into literal meaning and in the production of idioms $^{183}$.

In summary, conventions of language are "simple" meaning conventions, "matters of literal meaning" (Morgan 1977: 22), but conventions about language are conventions of the culture that uses the language. The point can be easily illustrated with greetings, whose literal meanings can differ across languages and cultures:
a. How are you?
b. 你吃飯了嗎? [ni chi fanle ma; Chinese; “Have you eaten?”]
c. Comment ça va? (French; "How is it going?")
d. "Jak się masz?" (Polish; "How do you have yourself?")

As Morgan points out referring to greetings, despite the differences present across languages and communities, there are obvious constraints on what may be grammaticalised as a greeting, for instance, it is not likely that the phrase whose literal meaning is "you hair is missing" could become one in any conceivable culture. Thus, on the one hand, literal meanings of such greetings (and other speech acts) must play a role, but, on the other hand, users of particular languages would reject it as "the" meaning, or "a proper meaning" of the utterance; it cannot be equalled with "I greet you". Similarly, uttering expressions such as "God be with you", most speakers would simultaneously conventionally use it as a farewell phrase and mean it literally. In a vast majority,

${ }^{183}$ Cf. Morgan's example: "The dog went to the bathroom on the living room rug". 
such phrases are motivated by a cultural convention, but their literal meaning has direct relevance in the context of their use.

According to Morgan, conventions about language contain three important elements: purpose, occasion (optionally), and means. It is emphasised that "there is a naturalness to the convention in that there is a natural connective chain between the (most general) purpose [...] of the convention and the specification of the means" (Morgan 1977: 18) in terms of particular sentences of a natural language. Such purpose-meaning connections between the occasion of usage and expression to be used is what language learners have to master in order to be proficient in a foreign language. In general, concentration on the means, and its refinement, correlates with a higher level of literalness and a move where the convention involved approaches conventions of language. Also when the relation between purpose and means becomes less transparent, there is a tendency to interpret it as arbitrary and, in consequence, conventions about language may be reinterpreted as conventions of language. In such cases, the chain between occasion and expression is seen as direct (e.g. when greeting someone, say: "How are you?") and literal meaning does not seem to play a role; indeed, e.g. a language learner may not even be aware of the connection between the literal meaning of the expression and the purpose in the context of greetings.

Morgan's framework may lead to a further refinement of Austin's concepts of meaning and use, and convention. For instance, in his approach, which is explicitly focused on how linguistic utterances are interpreted, Morgan points out that, in comprehending language, users may differ as to their interpretation of the form-meaning connection, and, in particular, as to the level of conventionality involved. This may be clearly illustrated by assumptions that language learners may form about the use of the expression "God be with you", which according to Morgan might be interpreted in the following ways:

1) Upon parting, one invokes the good will of God toward the other person by saying the English sentence "God be with you."

2) Upon parting, one expresses one's regard for the other person by saying the English sentence "God be with you."

3) Upon parting, one says the English sentence "God be with you."

(cf. Morgan 1977: 20)

When applied to a native language comprehension, the presence of differences of that kind may be indicative of cultural differences, e.g. a believer may treat the phrase as a conventional way of saying good-bye, but also mean it explicitly and literally. The differences can also be related to different levels of conventionalisation of certain (different) linguistic forms whose literal meanings are of varied significance; in other words it makes space for the fact that certain linguistic forms are more arbitrary than others as more purpose-means links have been lost in their case. 
Another interesting point that Morgan includes in his discussion is that conventions may be related to historical reference. By quoting a famous (or a relatively famous) line, such as:

\section{Am I my brother's keeper?}

I'd rather be in Philadelphia.

the speaker invites the hearer to form a certain implicature related to the previous uses of the sentence. Including this type of conventionality in a research programme should allow to better account for conversational moves and, as such, extends the traditional Austinian approach. This aspect is further strengthened by Morgan's reference to the "conventionalization of the rules of conversation". For instance, expressions such as:

\section{Are you crazy?}

Have you lost your mind?

\section{Are you out of your gourd?}

are "conventionally" used to question the sense of the speaker's interlocutor's actions. There is some creativity allowed in such contexts as other obvious questions, including newly created ones, can also be used. It is thus suggested that it is a conversational implicature schema that is conventionalised in such contexts (also in, e.g., colloquial answers to obviously false assertions) rather than the use of particular sentences.

In general, Morgan's theorising on conventions suggests a scalar approach and in this way works against a general juxtaposition of conventional acts with intentional acts.

In many ways Morgan's account also anticipates the findings of experimental pragmatics research, which proved that standardized indirect speech acts are "short-circuited" and, as such, do not take longer to comprehend ${ }^{184}$. It is also convergent with Bach and Harnish's (1979) comments on "illocutionary standardization" (what is "standardly used"), directly related to processes of generalization and conventionalization ${ }^{185}$, and Clark's (1979; cf. also Clark \& Schunk 1980; Clark 1992, 1996) claim that indirect speech acts, and especially indirect requests, differ in how (conventionally) they are used within a community. In general, the difference between Morgan's "conventions of use"

\footnotetext{
${ }^{184}$ Morgan (1977: 25), whose claim had not been based on experimental measurements, still admits that his suggestion is counter-intuitive and may be doubted by many readers. The conventionalisation of expressions such as "Can you pass me the salt?" and the primacy of their non-literal and non-linear interpretation had not been proved until much later (cf. e.g. contributions in Noveck \& Sperber 2004).

${ }^{185}$ Cf. Morgan's (1977/1978) distinction between the "natural approach" and the "conventional approach".
} 
and trivial "meaning conventions" can be illustrated with the fact that, for instance, a question of the form "Can you $v .$. ?" in most contexts is readily interpreted as a request and not a literal question concerning abilities. As Morgan (1977: 25) suggests arguing for the "short-circuited implicature" interpretation, the literal meaning seems to be latent in such expressions, which, in relevant contexts, are readily recognised as requests. The speed with which the meaning of such utterances are grasped by hearers suggests that their processing does not involve a step-by-step, from the literal to the non-literal, "traditional" Gricean procedure.

Interestingly, Levinson (2000) points out that such speech acts result from compression by precedent and routinisation and when approached as instances of implicature are different from heuristically worked out "default implicatures" (e.g., in interpretation of scalar concepts).

In summary, Morgan's contribution to the "convention debate" is significant, but it also serves to show that convention here (despite direct reference to Searle and speech act theory) is approached in an independent way and does not show direct relevance to the concept of convention as discussed by Austin.

\subsubsection{Selected cognitive approaches including Bach and Harnish (1979) and Levinson (2000)}

As indicated above, Bach and Harnish (1979; cf. section 4.3.5) divide speech acts into "conventional" and "communicative", claiming that only "communicative" speech acts are worth attention in linguistic and philosophical studies.

In their rich analysis, Bach and Harnish (1979, esp. chaps. 9 and 10) generalise the standardisation thesis to a wide range of other cases besides simple performatives, including hedged and embedded performatives. They perceive performativity as a regularity of use that goes beyond literal meaning.

The concept of convention is also central in the debate between Bach and Harnish vis-à-vis Searle, conducted at the end of the twentieth century (cf. Bach and Harnish 1979, 1992, Searle 1969, 1989), which has already been mentioned in earlier sections.

Bach and Harnish's (1979) position is different from that represented by Searle in that they believe the mechanism described by Searle is operative for "institutional speech acts", but less adequate for a description of "communicative" acts. For institutional acts, hearers indeed need to recognise the speaker's intention to satisfy a convention, but such conventions, Bach and Harnish argue, are not of linguistic nature. They normally involve institutional reality as, e.g. when a clergy pronounces a couple married, or a judge gives a legal verdict in pre-defined institutional settings. The main criticism coming from Bach and Harnish is that most speech acts function in a different way, with 
no or very little involvement of convention, i.e. without involving any extralinguistic convention.

In Bach and Harnish's model, speakers express their "attitudes" (e.g. an attitude of ordering, requesting, etc.) and "reflexively intend" that their utterances are to be taken to express such attitudes. Any speech act involves four main "intimately related" levels or acts:

- $\quad$ Utterance Act: $S$ utters $e$ from $L$ to $H$ in $C$;

- $\quad$ Locutionary Act: $S$ says to $H$ in $C$ that so-and-so;

- $\quad$ Illocutionary Act: $S$ does such-and-such in $C$;

- $\quad$ Perlocutionary Act: $S$ affects $H$ in a certain way

(where $S$ is the speaker, $H$ the hearer, $e$ an expression [typically

a sentence] in language $L$, and $C$ is the context of utterance)

(Bach \& Harniah 1979: 3).

Bach and Harnish link the illocutionary act with hearer's uptake, by which its conventional meaning is identified with what the speaker is intending to convey. Meanings not envisaged by the speaker should be treated as "perlocutionary" and not directly related to uptake.

The model follows Grice's ideas of ostensive stimuli, which involve a chain of expectations, viz. the speaker intends that the hearer should interpret his or her linguistic behaviour as intended and that the hearer will base his or her interpretation on this recognition. It is in this sense that the intention is "reflexive".

In contrast to Searle, at least at the stage of the discussion being referred to, Bach and Harnish argue that an explicit performative is first recognised and understood as a statement, and only later as a speech act of a certain type. There is a visible strife for explicitness and clarity in Bach and Harnish's $(1979,1992)$ formulation of speaker's intention and steps leading to making sense of a speech act, although the division into institutional and communicative acts is not thoroughly justified in their discussion.

The concept of convention in linguistic communication in the tradition of Bach and Harnish (1979) may be related to "the overall picture of a general communication" as envisaged by Levinson (2000: 22). According to Levinson, in a presupposed rather than asserted picture, there are two levels of communication: a level of sentence-meaning (which is to be accounted for by grammar "in the large sense") and a level of speaker-meaning (to be explicated by a theory of pragmatics rooted in Grice). Consequently, speaker-meaning and utterance-token-meaning must be understood in this model as emergent in particular circumstances and context-specific. It is nonce meaning based on "once-off inferences". Levinson points to the fact that such a picture severely underestimates the regularity, recurrence, and systematicity of pragmatic inferences and claims that a third aspect, or a third layer, must be recognised. 
The third layer is a layer of pragmatic inferential systematicity, which could be labelled as "utterance-type meaning" (or "statement-or-utterance-meaning" to follow Atlas 1989: 34). This third level, Levinson claims, is based "not on direct computations about speaker-intentions, but rather on general expectations about how language is normally used" (Levinson 2000: 22; original emphasis). Such expectations, in turn, allow to infer information concerning both the content and force of utterances. It follows that speech act comprehension, along with processing of phenomena such as presupposition or implicatures, are processed at this "third" level.

Although Levinson's "third level" bears striking similarity to, for instance, Morgan's (1977/1978) conception of the conventions of use (as opposed to conventions of language; cf. section 4.3.4), it is at the same time a basket in which both semantic and pragmatic elements can be found. By Levinson's admission, "the systematicity of reference" found on this level "might be deeply interconnected to linguistic structure and meaning" (Levinson 2000: 23), which may lead to problems in deciding which of such elements are semantic, and which are pragmatic in nature. Thus, although the inclusion of the third level creates space for conventions "of normal use" of language, the level seems to criss-cross the other levels focusing on contextual, situated inferences.

It is significant that Levinson relates his notion of "the third level" directly to Austin (1962/1975), and especially to Austin's tri-partite account of a speech act in terms of locution, illocution and perlocution. In his interpretation,

The locutionary level corresponds to the level of sentence-meaning, the illocutionary to our intermediate layer formed of conventions or habits of use, and the perlocutionary (partly) to the level of speaker-meaning (i.e., the speaker's intentions to get the addressee to believe or do something as consequences of the utterance). (Levinson 2000: 23)

It is also evident that the correspondence between Levinson's and Austin's original account is just that of approximation. Both models emphasise the salience of contextualised and at the same time conventional meaning without a final definition of the phenomenon being referred to.

Levinson further refers to selected other notions that have been put forward in the context of speech act conventionality, including Morgan's (1977/1978) distinction between "convention of use" and "convention of language", as well as Bach and Harnish's (1979: 192-202) concept of "standardisation" standing in opposition to their concept of "conventionalisation" of non-literal use.

Other researchers attempted to account for what may be recognised as "illocutionary" conventions by referring to "short-circuited" readings of speech acts. For instance, Recanati (2004: 12) cites Robin Campbell's typology of pragmatic processes, indicating that automatic short-circuited interpretation 
depends on micropragmatic inferences rather than macropragmatic ones (cf. Campbell 1981: 101):

A macropragmatic process is one constituted by a sequence of explicit inferences governed by principles of rational cooperation. A micropragmatic process develops a cryptic and heuristic procedure which partially replaces some macro-pragmatic process and which defaults to it in the event of breakdown.

(Campbell 1981: 101)

Under this interpretation, it follows that conventionalised indirect speech acts are understood automatically, their (grammatical) form is directly associated with their illocutionary force and that inference does not have to proceed through literal interpretation. Hearer's understanding of the illocutionary force in question is triggered by a "conventional" form, which evidently relies on "conventions of use" in Morgan's (1977/1978) sense, and not just trivial and omnipresent linguistic conventions. This view has been supported with the results of pragmatic timing experiments, where frequent conventionalised indirect speech act are shown to be processed in no longer time in comparison to direct and literal acts (cf. e.g. selected articles in Noveck \& Sperber 2004).

Since Austin then, the concept of convention in speech acts has been linked to the problem of the meaning of utterances whose functioning involves a combination of their literal meaning and their "appropriateness" as linguistic devices used in everyday rituals, as well evidenced by Morgan (cf. section 4.3.4) and later researchers.

\subsubsection{Millikan's biological model of language and conventions}

Another approach to linguistic conventionality directly related to Austin's work is represented by Ruth Millikan. One of the 'special' uses into which Millikan (e.g. 2004, 2005a) puts the label "conventional" in her teleosemantic theory of language is to present it as antonymous to "innovative" 186 . She recognises "conventional usages" as "reproduced usages" based on precedents. Millikan (e.g. 1984, 2004, 2005a) explains speech act conventions in terms of stabilising and standardising proper functions and recursive patterns of behaviour through which they proliferate. These are directly related to the biological functions of body organs and the functions of mechanisms that produce tropistic behaviours, which are presented as "prime examples of proper functions". It is suggested that "derived proper functions" evolve on the basis of more primitive ones in the environment of adapted productions. According to Millikan, human intentions,

\footnotetext{
${ }^{186}$ Millikan (2007: 658-659) points to this distinction as "the most helpful" in distinguishing semantics and pragmatics.
} 
which should be understood as goal representations harboured within a human being, represent their own purposes, which are derived proper functions and help produce their own fulfilments. In turn, human artefacts have as proper functions the purposes for which they were designed. In this explicitly "biological" model, it is accepted that there are both purposes of cooperative linguistic forms and the purposes of the people who use such forms producing actual utterances.

In Varieties of Meaning, Millikan (2004) addresses the distinction between intention and convention on a larger scale. She attempts to describe the relation between "natural signs" and "conventional signs", and the similarity between "locally recurrent natural signs" (LRNS) and "intentional signs". She further attempts to describe how animals' instinctive intentional signals evolve and, in particular, how natural "signs of impending behaviour" evolve into "conventional intentional signs" that people use. It is emphasised that differences in conventionality of signs are of gradable nature and that conventional signs can also function as LRNSs, while interpreting LRNSs is strikingly similar to perception.

Millikan also explicitly addresses speech act-oriented conventions. Having asked "Why should we care about the conventionality of natural language?" (Millikan 2005d: 2), she immediately responds: "Because understanding it is essential for understanding many aspects of pragmatics: for example, questions in speech-act theory and about how natural-language demonstratives work" (2). In the first part of this statement Millikan also shows that she takes speech acts for granted; that they are regarded as well established entities in linguistics theorizing.

In Millikan's approach, linguistic conventions are indeed "made simple"187. Having admitted that conventionality is an exceptionally broad notion and that there might be non-conventional (e.g. inherited) languages, Millikan narrows her interest to focus on linguistic and natural conventions perpetuated by reproduction. She explicitly rejects the position that conventions in general necessarily require coordination, regular conformity of behaviour, and/or rationality, which were all part of Lewis's theory. With Millikan, these features may often be present, but they are by no means necessary, although she also asserts that "[c]onventional linguistic forms are memes of a particular sort, memes ${ }^{188}$ that are selected for because they are serving coordinating functions" (2005a: 188). Linguistic conventionality is explained in terms of patterns which "proliferate" thanks to the "weight of precedent" (e.g. Millikan 2005a: 2-10, 3040, 57ff., et passim). Thus, all conventions are arbitrary, while a form may be arbitrary and still not conventional if it is not copied by weigh of precedent.

\footnotetext{
${ }^{187} \mathrm{Cf}$. the provocative title of Millikan's paper (2005d): "Language conventions made simple" included in Millikan 2005a, pp. 1-23.

${ }^{188}$ There is a link between Millikan's approach to meaning in language and other cognitive approaches which recognise the concept of memes as introduced by Dawkins (1989 [1976]); cf. chapter five.
} 
Weight of precedent conceived of in this way is seen as more than just mere reproduction as it relies on patterns being derived from previously used items, possibly with some modulation. Any form to become conventional must first be motivated by reproduction (and not merely by coincidence) ${ }^{189}$.

Reproduction involves complex structures. Just like there are paired structures in the world at large, e.g. men and women dancing, bolts and nuns being adjusted, speech acts too happen in the "handshake reproduction" manner, i.e. as paired patterns or matched units ${ }^{190}$. Language is then "a tangled jungle of overlapping, crisscrossing traditional patterns" (2005d: 18), while "a conventional act is an act of reproducing or helping to reproduce, in whole or in part, a conventional pattern" (18). In addition, linguistic utterances can be conventional in many different ways ${ }^{191}$.

As the conventional function of a linguistic form will stay stable if it continues to serve the interests of speakers and hearers, it is called a "stabilising function", a "survival value". In summary, a linguistic convention consists in a pattern that includes two types of contributions: a conventional contribution of the speaker and a conventional contribution of the hearer. Both contributions belong in the same convention. In Millikan's view, convention which shows coordination between speaker and hearer includes a perlocutionary act in Austin's sense. Indeed, it appears that, for Millikan, perlocution is internal to the act and to the convention involved.

\footnotetext{
${ }^{189}$ Millikan points to the fact that behaviour is conventional only when it is motivated by precedent. For instance there are conventions of wearing black to a funeral and shaking hand with the right hand, but "instances falling under these descriptions are conventional only when done as following convention; that is when reproduced rather than accidentally instantiated" (Millikan 2005a: 147)

${ }^{190}$ (Millikan (2005d: 12) mentions Niko Tinbergen, an ethologist, who discusses "ritualized versions of intention movements", where "intention movements" allow for inference of what an organism in question will do next. Such movements may be further exaggerated and become communicative.

Millikan also says that there are natural conventions and "regulated" conventions and that both types may be sanctioned, but it is just an illusion that natural conventions are de jure.

${ }^{191}$ As Millikan claims: "Not just position in linguistic context, but position in extra-linguistic context may also be copied by speakers. Saying 'hit me!' when playing blackjack to ask the dealer for another card is copied whole. That is, what is copied, hence what has a conventional meaning, is saying — 'hit me!'—while-playing-blackjack. Similarly, saying —'break-a-leg!'- to-an-actorbefore-a-performance is copied whole by speakers in order, conventionally, to wish the actor luck. These phrases-in-context are reproduced items, replicators, each with a special memetic purpose or meaning. Contrast the case of 'This is N' used to introduce oneself on the phone. Its use in a particular context is also copied, but saying 'This is N' does not have a separate meaning in that context. It does not mean what it means because it is said on the phone (Millikan 2005a: 199-200).

Millikan claims that such utterances involve "a conventional use of context" (2005a: 200), which range from simple sticking a label on a product to more sophisticated institutional uses of conventional formulae. She emphasises that fact that there is hardly any limit on context which might be needed to interpret an utterance.
} 
To illustrate Millikan's approach, the concept of proper function in relation to the concept of mood is that, for example, to produce a "true" belief in the hearer is a dominant function of the indicative mood (e.g. Millikan 1984: 58ff.), while the "proper" function of the indicative mood is to convey information. This function makes other uses of indicative mood possible ${ }^{192}$.

In general, conventional coordination patterns need to succeed only often enough to avoid extinction (2005a: 59). They may differ in their complexity. For example, parliamentary debates or playing chess are performed according to complex relational patterns in which not only "shapes" (forms), but also relations that hold in between them are reproduced. Complex conventions are conveniently described with the use of rules, which, in turn, are most often conveniently phrased as conditional sentences. In addition, many of such rules may be sanctioned in some socially recognised way. Such conventions may include legal norms, although purely imposed rules do not have to be all conventional (cf. Millikan 2005a: 148ff). Relevant to speech act theoretic research is also Millikan's concept of "conventional moves" which produce "conventional outcomes", i.e. voluntary patterns of behaviour which induce certain effects and constrain the development of the situation in the future. Millikan's examples include a conventional Protestant marriage ceremony and a chess game, where in both cases performing the conventional act (of marrying or moving a figure on the board) effectuates relevant constraints on what may happen later; they involve "free actions" which trigger (or make possible) predictable effects.

Millikan (2005a) claims that a majority of rules and conventions of language are of non-evaluative nature. Instead, they are perceived as means of survival, i.e. norms of function and survival which help biological species survive and proliferate. All Millikan's norms are biological in nature. Linguistic norms, it should be taken, emerge in interaction, they are reproduced, they survive backed with interlocutors' responses for biological reasons, i.e. because in a broad scale they would benefit interlocutors. Each linguistic convention has its own lineage, although the same form may of course be shared by (or belong to) two or more lineages, resulting in different meanings. Conventions may be identified with lineages of patterns and, in this light, conformity to linguistic patterns of behaviour can be seen as nature's way to help organisms co-exist, develop and survive. It should also be informative for models of linguistic conventionality that (when Millikan's perspective is accepted) such conformity need not be absolute; it is only necessary that there is conformity in a critical mass of cases. In fact, Millikan suggests that in some cases conformity of linguistic behaviour may be well below average, but still very relevant. In addition, the rules underlying conventional patterns of behaviour are not prescriptive in nature.

\footnotetext{
${ }^{192}$ For Millikan's early discussion of four types of imperatives, which correspond to the illocutionary acts of giving orders, making requests, giving advice, and giving directions, and their potential in performing a stabilising function, see Millikan (1984: 57-9).
} 
"These rules describe conventional patterns; they do not prescribe them. The bare existence of a convention neither mandates, nor gives permission for anything" (Millikan 2005d: 15).

Interaction is of prime value in this model as completed speech acts of a kind that have survival value are not the work of a particular speaker alone, but of a hearer purposefully cooperating with a speaker. According to Millikan, "'meaning', in the most basic sense, simply is function; [...] 'proper' or 'stabilising' function" (Millikan 2005a: 90; cf. 1984: ch. 1-6; 2004: ch. 2 and $11)^{193}$. The functions of complete linguistic forms are to perform complete speech acts, i.e. cooperative acts accomplished by speaker and hearer together. The performance of cooperative acts is what keeps speakers using certain forms in consistent ways and keeps hearers responding to them in consistent ways, hence keeps them in circulation.

On a methodological note, it is interesting that Millikan (2005a: 90) explicitly mentions that she reserves the term "pragmatics" for "the study only of how nonconventional speech acts are performed, acts which do not express conventional functions because [they are] not directly derived from precedent" (Millikan 2005a: 90).

Millikan (2005d: 19) presents speech act theory as a theory in which conventional acts require existence of conventional rules. In her discussion, she refers to speech act theorists such as Searle (1969), Schiffer (1972), Bach and Harnish (1979), and also Davidson (2001a, 2001b). It is significant that referring to these authors she appears to presuppose that a rather common perception of conventionality is pervasive in speech act theory. However, her own position is explicitly against dividing speech acts into conventional and intentional ${ }^{194}$. Instead, she offers a unitary and a general account in which all speech acts are conventional in a broad sense and related to intentionality which (biologically) emerged along with social life ${ }^{195}$.

It is further interesting that acts such as voting, christening someone, or giving orders are dubbed by Millikan as "seemingly extraordinary acts" (2005d: 20) and that she suggests that most of the classifications of speech acts are presented in terms of intentions with which the words were uttered rather than constructed with reference to their outcomes. In Millikan's view, spoken words have two main aspects; they involve 1) speakers' intentions, and 2) proper

\footnotetext{
${ }^{193}$ Millikan $(2005,2008)$ explicitly identifies such a function with Sellars' "survival value". She also points to the fact that, according to Sellars, linguistic rules are "fraught with ought"; they prescribe norms rather than describe them. In Millikan's view, Sellars' understanding of linguistic rules "made contact with theories of speech acts that take these to be wholly conventional in the sense that acts of this sort could not be performed at all were there no conventions for performing them. The relevant norms are essentially social in origin and function" (Millikan 2005a: 79).

${ }^{194}$ Even though she admits that there may be non-conventional, "pragmatic" acts, i.e. speech acts which are not derived from precedent, as mentioned above (cf. Millikan 2005a: 90).

${ }^{195} \mathrm{Cf}$. "There is no such thing as intentionality without attitude" (Millikan 2005a: 90 referring to Sellars), while convention may be followed prior to (or in absence of) intentional action.
} 
functions (or purposes) in the public language. It is only in central cases, it is claimed, that both of these aspects coincide, in others they would not. In "On meaning, meaning, and meaning" (Millikan 2005a: 53-76), it is claimed that a convention, in the sense that a natural language contains conventions, is

merely a pattern of behavior that is (1) handed down from one person, pair, or group of persons to others - the pattern is reproduced - and (2) is such that if the pattern has a function, then it is not the only pattern that might have served that function about as well.(Millikan 2005a: 56)

Millikan indicates that if a different precedent had been set instead, a different pattern of behaviour would probably have been handed down. The examples of conventions perceived in this way which she quotes include, for instance, putting a wreath on the door at Christmas time, dyeing eggs for Easter, and drinking green beer on St. Patrick's Day. The possible differences are illustrated by the fact that in Japan the convention is to eat with chopsticks, while in America, with a knife and fork.

Unlike Lewis, Millikan accepts that such conventions do not necessarily have to solve coordination problems and that they do not have to be universally followed even though some of them can have both of these features. For instance, driving on the right in the United States does solve coordination problems and is mandatory, but this fact does not make it a convention. Similarly, although linguistic conventions do solve coordination problems, they are neither universally followed, nor mandatory (Millikan 2005a: 56) ${ }^{196}$.

In her rather loose, not to say vague, model, Millikan (2005d [1998]) asserts that she follows Lewis's account of arbitrariness, but she also believes, against Lewis, and then Marmor (2009), that conventionality just can be relative to reasons. In her view, what makes tokens of words or sentences tokens of the same word or sentence is, in the first instance, history (cf. Millikan 1984: $73 \mathrm{ff}.)^{197}$.

In summary, Millikan accepts Sellars' concept of pattern-governed behaviour (not just "regular" behaviour), and suggests a single mode of explanation with reference to proper functions that are stabilised selectionally through consistent repetition. It is also while addressing the terminological confusion among intentionalists and conventionalists in speech act theory that Millikan suggests a solution by referring to purposes and (proper) functions (cf. Millikan 1984,

\footnotetext{
${ }^{196}$ Cf. also: "Not all conventions solve coordination problems, however. And for those that spread because they do, the 'because' is almost never a reasoned because but some more mundane kind of causal because. The rest of us conform to linguistic conventions in exactly the same unreasoned way that the idiot and the child do" (Millikan 2005a: 56-57).

${ }^{197}$ Millikan's "natural" dimension is sometimes taken as a reason for rejecting her model altogether, especially by linguists with a more traditional approach to language analysis (cf. e.g. Collins 2007).
} 
2005a). In particular, she believes there are three important and closely related aspects of speech acts, three kinds of purposes, which add to the confusion, viz.:

- the speaker's purpose in speaking;

- the purpose (function) of the public-language expression used;

- the conventional extralinguistic move made, if any, classified by its conventional outcome (which typically accords with its conventional purpose) (Millikan 2005a: 140).

According to Millikan, Austin, Strawson, Grice and Searle, all fail to recognise that there are different purposes, in particular that there are purposes of the second type, i.e. independent functions of public language expressions. She also suggests that they fail altogether to even mention purposes of the third type and, by ignoring them, they distort the picture and are unable to produce an adequate theoretical model. In Austin's (1962) theory, reportedly, there is a mixture of purposes hidden behind one label and an allegedly simplistic approach to speech acts as "moves" in a game, with the result that they should be classified according to their conventional outcomes, or potential effects. Strawson (1964), in turn, roughly, mixes group one and two under the label of intentional acts, discusses purposes of the third group as "conventional", and poses a firm divide between his two categories, which, according to Millikan, are better conceived of in terms of a continuum.

In summary, Millikan first suggests that not only speakers have their intentions and purposes, but linguistic forms come loaded with functions (purposes) which they carry quite independently of speakers who utter such forms. Millikan argues that purposes of the second group, i.e. alienated from speakers, may sometimes coincide with speakers' purposes, but they may also fall into the first group, i.e. roughly speaking, into Strawson's "intentional" category when there is no corresponding purpose on the part of the speaker. Millikan further indicates that instances of conflict between purposes of group one and two (i.e. between speaker's intention and "formal" linguistic purposes) correspond to examples which would pose problems in Strawson's account.

Acts may thus be classified according to purposes of different kind. Classifying speech acts by their general purpose (and not for instance their conventional outcomes) gives more leeway. In terms of speech acts, e.g. promising could be compared to Millikan's example of hunting. Such a general purpose may provide a label for many diverse patterns of behaviour, consequently, many different speech acts. On the other hand, purposes mentioned by Austin and then specified by Strawson are also "conventions" in Millikan's model because they are types of purposes; as a result, speaker's intentions (being instances of purposes) are also "conventional" in Millikan's sense.

In this view, the tension between Austin and Strawson (and many others) manifests itself as a terminological confusion rather than as an interesting 
difference in theoretical orientations. Austin is given justice for his account of explicit performatives because under Millikan's interpretation such performatives are indeed "conventional" and "self-verifying" (e.g. what is said is believed, i.e. the hearer believes that the speaker is performing the act), being embodiments of "conventional moves", while Strawson is praised for his analysis of intention-based acts (which are also "conventional", but in a different way, through different set of purposes). Indeed, where there is no explicit form which grants a "conventional move", speakers have to rely on conveying their intention, i.e. on the hearer's recognition of the speaker's intention in producing an utterance.

It is noteworthy that in Millikan's model there is a distinction between "conventional moves" and "regulated moves", the latter being codified in law or some other type of an explicit regulation. Thus, patterns which are reproduced not just because of a precedent but according to a description or prescription are not "conventional" in the prototypical sense. They involve "regulated conventions", "regulated moves", and produce "regulated outcomes" (cf. Millikan 2005a: 161ff.). These include instances which Strawson defined as "some cases, [in which the speaker] may be seen as the mouthpiece, merely, of another agency" (Strawson 1964: 614).

Another salient aspect of Millikan's views is that her account of convention in speech acts suggests a reciprocal model. Millikan is more explicit than for instance Austin, Strawson or Searle in presenting speech acts as interactive phenomena. Her models of conventional patterns of behaviour related to speech acts include both the speaker and the hearer. As has been noted above, in a typical speech act, the speaker's input induces the hearer's response. Hearers respond in a normal cause of events, they respond "conventionally" when their responses are motivated by what the speaker said, while the responses themselves happen "because of" what the speaker said. As Millikan emphasises,

The speaker's production of the expression and the hearer's cooperative response to it constitute a reproduced pattern whose form is arbitrary relative to its coordination function. That is all that is needed for convention.

(Millikan 2005a: 152)

Millikan juxtaposes such correlative speech acts with "merely conventional means of expressions" such as conventional exclamations "Outch!" or "Hurrah!", which do not presuppose a conventional response from the hearer.

Typical correlative speech act patterns, as suggested by Millikan, have been illustrated in the diagrams below. The first diagram presents the structure for directives: 


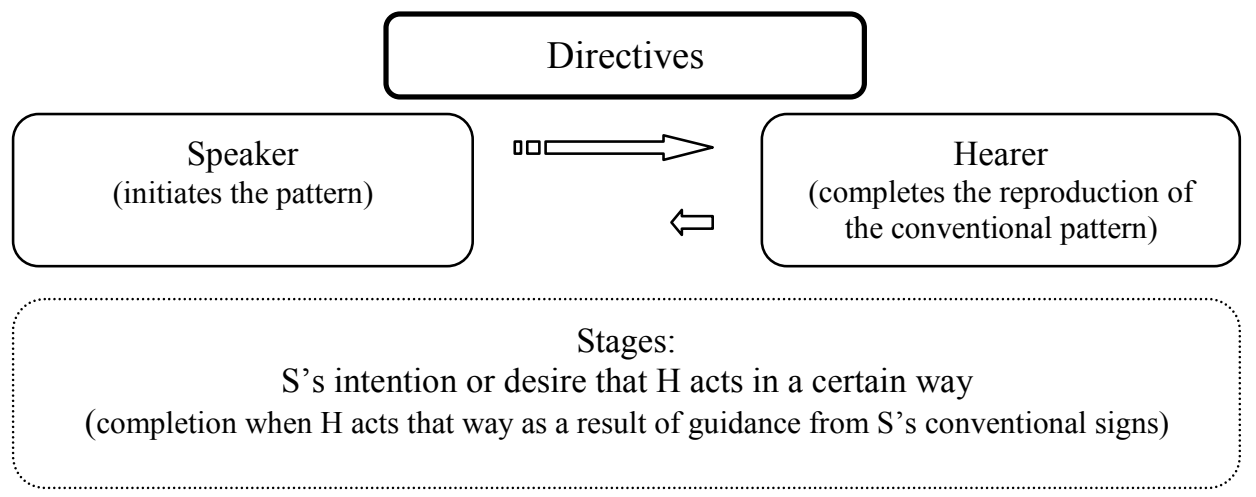

Figure 6: Conventional pattern for Directives according to Millikan (2005a)

To reiterate, it is significant that Millikan's models for speech act types do not presuppose universal or even common conformity of behaviour. It is in fact their conventional nature that defines what speech acts are, thus, for example the model for directives has an element of completion because the completion is exactly the motivation behind a typical directive. Such patterns of behaviour are said to include a "cooperative proper function" because if such acts are fulfilled "in the normal way", they are fulfilled through a cooperating response, a response whose proper function includes a form of completion of the initiating act's proper function. Millikan points to a correspondence that this model has with Grice's reciprocal intentions and its relevance with regard to his claim that the hearer does what the speaker intends partly because the speaker intends it. In Millikan's "biological" approach, if directives (in just sufficient a number) were not followed by desired responses, they would cease to exist as their patterns are reproduced by weigh of precedent. In a parallel manner, for assertions, it is conventional for the hearer to believe what the speaker says as can be seen in the conventional pattern for assertive speech acts summarised in the diagram below:

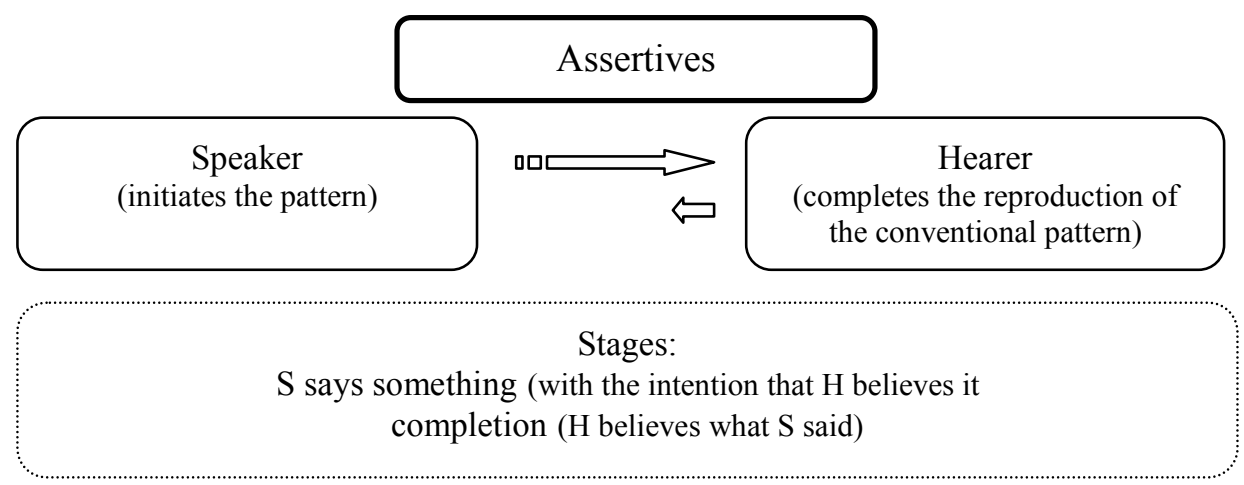

Figure 7: Conventional pattern for Assertives according to Millikan (2005a) 
In summary, according to Millikan, a proper function of the imperative is to induce the action described, while a proper function of the indicative mood is to induce belief in the proposition expressed. It should follow that such proper functions of the grammatical moods coincide with conventional outcomes of the equally conventional moves which serve as vehicles for them, in a much similar manner as it happens in the case of explicit performatives (as discussed above); conventional moves (conventionally) produce conventional outcomes.

Millikan allows for an indeed "biological" variety in speech acts, but she only discusses a few relatively simple cases. For instance, she claims that "the survival value" of the formula "I warn you that p" should be that there are at least some instances in which utterances of this form may cause the hearer to be alarmed about relevant dangers, while the survival value of "I order you to do A" seems to rest upon the fact that it sometimes (conventionally) results in causing the hearer "to $A$ ", by which, in turn, the hearer may avoid negative sanctions.

Convention is also said to play a role in contexts where the speaker's intention is in conflict with the proper function carried by the utterance, i.e. it could be paraphrased as a case where conventions of language are not in accord with the speaker's purpose in using them. Strawson's position was that in such cases it is the formal act that is being performed. For instance, if someone says "I promise that $P$ ", even though he lacks the intention to promise, or intends to be taken as joking, hearers may report on the event as that of promising. In institutional settings this can often be evident and, as indicated in chapter two, Korta and Perry (2007) refer to this feature as a "forensic" dimension of language as common practice suggests that linguistic forms (may) carry meanings of their own. This should do justice to the fact that witnesses to an act may form opinion on the act's function at least partly, and sometimes entirely, on the basis of its form and available circumstances, while their interpretations may in reality stay in conflict with the speaker's communicative intentions. Linguistic forms differ in their level of conventionality, but most of them, and especially those which have been frequently reproduced, exhibit a high level of specialisation.

Millikan seems to back Austin in his emphasis on explicitness and the possibility of (explicit) reformulations for speech acts. In her theory, explicit speech acts are "conventional" because they are instantiations of conventional moves; they function as "moves" which carry their own strength through explicitness. Thus, in discourse they appear stronger than their non-explicit counterparts. They assert their own nature and in this way activate different levels of conventions.

Millikan also accepts instances of conflict induced by a discrepancy between proper functions active in a context. One such example is when the speaker uses an alienated expression, but his function in doing it is cooperative because he or she wants the hearer to understand that he or she does not mean what his or her 
words mean. Among the examples cited by Millikan (2005a: 160ff.) there are the following (the real purpose of each utterance, i.e. the speaker's intention, is given in brackets):

(60a) the armed robber smiles and says: 'I entreat you to hand over your money' (directive)

(60b) Anytus threatens Socrates: 'I advise you to be careful' (a threat)

(60c) Mom orders: 'I am asking you for the last time whether you are going to take out the garbage!'(a warning)

(60d) The friend who has matched Jim with a blind date says: 'I warn you that she is exceedingly charming'(an encouragement)

(60e) Father warns: 'If you aren't back by twelve I promise that you will regret it'(a warning)

Such examples are not used as literal, but in an intuitive judgment by the audience they will most probably be classified according to the speaker intention and not their apparent form. The speaker intention in each case here is "cooperative", but it is divergent with regard to the expression's (independent) proper function.

Millikan also seems to endorse the claim voiced by Sperber and Wilson (1986/1995: 244ff.) that most of speech acts do not even have to be recognised with regard to their type to be communicated. For example, one may warn, boast, predict, even assert, hypothesise, demand or threaten, without the hearer's classifying what kind of act has just happened. In such cases, acts are not cooperative, instead of cooperation on the part of the hearer, they require a kind of reaction. In such acts the speaker's intention "overrides" the words spoken in that they are indeed communicated even without being explicated in terms of their function. This type of speech act, for Millikan, serves as grounds for rejecting Strawson's (1964: 458) claim that for "intentional" acts "wholly overt intention $[\ldots]$ lies at the core". Apparently, for such acts, the speaker's intention cannot be seen as "overt" as it does not even have to be explicitly identified by the speaker.

Millikan's scale of speech acts according to the type of convention involved is a complex one. It is also a thought-provoking attempt to produce a functional account by embracing all manifestations of language which are motivated, rooted in reproduction and interactive in nature.

In general, Millikan's model is attractive in its methodological transparence and persuasiveness. It is backed with scientific research and ideas from the theory of evolution and, as such, projects a touch of certainty which is not too common in social sciences or art. It places a lot of trust in a natural evolution of things and seems to suggest a rather contentious idea that whatever is reproduced is also in some way practical. Linguistic conventions and speech acts appear to be built in a framework governed by holistic and universal 
mechanisms operative in a world inhabited by people who live their lives to achieve their purposes and who strive to rationally cooperate. However, it is also a model which gives a very general picture in which the very basic tenets of speech act theory are taken for granted and used rather selectively to strengthen Millikan's model of linguistic communication.

On the other hand, Millikan's argumentation emphasises the reciprocal nature of speech acts, whose performance is a kind of joint venture of interlocutors. In a way distinct from Austin, Millikan also points to the fact that there are many different ways in which a speech act may be performed and that linguistic action is of "natural" kind, of "natural" nature. She advertises a view that uniformity in linguistic patterns of behaviour cannot be expected even on an average scale and talks about satisfaction conditions for "distal objects and properties"; thus her perspective is "naturalistic" rather than "rationalistic". To reiterate, it is enough if a particular function and the ways of performing this function are frequent enough by some natural selection. In this approach, illocutionary force is given priority and is seen as constitutive of a speech act, even constitutive of its content. Thus, 'semantic' meaning of an utterance is at least partly constituted by force intervention. A necessary methodological side effect of such a perspective is that utterances cannot be judged through conceptual analysis; in order to be understood, their social contexts, including psychological and situational data, must be taken into consideration. As it is claimed (e.g. Millikan 2004), linguistic conventions often involve contexts and it is often the case that the sign which is reproduced may in fact be composed of a narrow linguistic part unified with much of non-linguistic context. Without information on this nonlinguistic part, interpretation can hardly be successful and the sign is indeed "incomplete". Allowing so much context into theoretical investigation makes Millikan's model semiotic and ambitious, but not readily formalisable. Although Millikan (2005a: 111) explicitly claims that "[t]he modern debate about which if any speech acts are performed conventionally arises from [... a] confusing overlap (coupled with inadequate theories about what language 'conventions are' $[\ldots])$ ", she does not provide much data as to how this confusion could be eradicated.

With regard to the concept of convention it is noteworthy that for Millikan only conventional moves with proper functions are worthy of true theorising. As Millikan says:

Not every conventional move has a proper function. Conventional patterns may sometimes be imitated for no particular reason rather than due to some function they are performing. Functional convention blurs into the pointlessly convention-bound and into mere habit.

(Millikan 2005a: 158) 
Evidently, in this naturalistic model, conventions with proper function are "biological" and natural, while other types of conventions are mere side-effects, patterns of behaviour in a way void, empty of the meaning which they might potentially possess in more successful contexts.

In a way, Millikan is a direct descendant of Austin with his idea of investigating "the total speech act in a total situation" (Austin 1962/1975: 147) and enriches the original account by putting emphasis on communicative cooperation and interactiveness. She even extends this picture to include apparent acts, such as acts devoid of proper function as mentioned above. In a different perspective, she departs from Austin by her emphasis on general issues with limited attention paid to particular utterances and their forms. Against the background of the intentionalist/conventionalist debate, Millikan has its own position as evidently her approach is cognitive and at the same time it is a variant of a code model of language. The very concept of convention, associated in the context of language with proper functions, serves in Millikan's biological model to distance the theory from the referential model of communication, which is more readily accepted in cognitive studies ${ }^{198}$. In Millikan's account, reaching a meaning of a speech act means recognition of its lineage, and possible ambiguity may be present when one form exists in more than one lineages ${ }^{199}$. Thus, convention as a category important for speech acts is conceived of in Millikan's theory in a specific way. Above all, her model serves to show that attempts to elucidate the concept of convention in communication, as well as attempts to account for how conventions work and what their role is in speech act production, pose a real challenge.

\subsubsection{Brandom and linguistic conventions in a normative perspective}

Brandom's (1994, 2000) perspective on language is by his own admission normative. Just as Millikan, Brandom has been influenced by their mentorSellars, but accepting the lines stretched by Richard Rorty dividing Sellars' disciples into a right and a left wing, Brandom should be found in the opposite camp. Although Brandom does not deal with speech act theory per se, his approach is relevant in that he sees language in terms of action and places assertion in the centre of his theory. Brandom's assertion is a social act which

\footnotetext{
${ }^{198}$ For a recent discussion of the nature of speech acts, moving towards integrating Millikan's interactive model of linguistic communication with approaches in the tradition of Bach and Harnish (1979), the contextualist approach (e.g. Recanati 1987) and Austin's theory, see Witek's (2011) study.

${ }^{199}$ Cf. discussion of Millikan's model in Origgi and Sperber (2000) and their criticism of the "massive ambiguity" that her model involves and their argument that linguistic utterances provide "evidence" for meaning construction that the hearer's recognises in his or her processing of such utterances, which in a lesser degree depends on decoding the meaning (cf. also Sperber \& Origgi 2012).
} 
involves "commitments and entitlements" defined in the context of uttering a sentence, i.e. justifications and evidential reasons for acts.

Brandom defends a particular conception of language "use" which concentrates on normative aspects and asserts to be interested in pragmatics "in terms of scorekeeping" (Brandom 1994: xiv). In his perspective, by producing an assertion a speaker engages in a social act and commits oneself to defend and support such an assertion in case it is challenged by a hearer. Defending an assertion, the performer may provide reasons which will support the act by exposing inferences from other utterances. Producing an assertion will also confer certain entitlements on the speaker, in particular the right to draw further inferences from his or her utterance.

In this way, linguistic communication is presented as a kind of game in which interlocutors engage in asserting and asking for reasons and keep score of what is going on. This game, it is claimed, is rule-governed and subject to socially accepted norms.

Brandom (1994) explicitly attributes contemporary understanding of normativity to ideas discussed by Kant, Frege, and Wittgenstein and places heavier emphasis on normativity in contrast to thinkers whose main interest was the social element of "private" interaction. In this rather complicated theory, rules and norms are central to inferential processes. This new normative perspective places Austin's speech acts in a different light. Once again, they are seen as a mixture of conventional patterns backed with intentional states; however, it is explicitly accepted that speakers' intentional states are not accessible to hearers. Brandom's and related positions may be seen as a link between "traditional" speech act theory and later theoretical divagations related not so much to "speech acts" as "speech actions", such as the ones discussed in chapter five.

Although Brandom presents himself as a pragmatist, his concentration on assertion has been criticised by Kukla and Lance (2009) as a "narrow focus" and "a serious error", which "leads not only to missing out on philosophically important dimensions of language, but to hopelessly distorting [... people's] understanding of language as a normative phenomenon, including [...] understanding of assertion and how it works" (Kukla \& Lance 2009: 9). Significantly, Kukla and Lance criticise Brandom for treating assertion as "the sole building block for his entire theory of the pragmatic and semantic structure of language and the connection between language and the world recreates and instantiates a failure of vision and methodology that is nearly universal in analytic philosophy" (9-10). In other words, Brandom is accused of bringing back the verificationist image of language as a system of propositionally structured declarative assertions with truth-values ${ }^{200}$.

\footnotetext{
${ }^{200}$ Kukla and Lance (2009: 10) also put forward a contentious opinion that both Austin's (1962)
} account of "how to do things with words" and Grice's (1989) discussion of the many "ways of 
To remedy the picture, Kukla and Lance (2009) extend Brandom's discussion from assertion to other speech acts. They show that utterances including vocative hails and calls of shared attention, such as "Yo!" and "Lo!", which they chose for a title of their book, are on a par with assertions with regard to the significance of their communicative, and thus, performative, value. They concentrate on entitlements and commitments both on the side of the speaker and the hearer, which enables them to classify speech acts into four main groups (cf. section 3.4.2.d). In general, by their own admission, they make "heavy use of the distinction between input and output - that is, between the normative statuses constitutive of entitlement to a given speech act and the normative changes (in the status of the speaker, or of others in the discursive community) that the act strives to produce" (Kukla \& Lance 2009: 15). What is also emphasised is that "the function of a speech act should not be confused with either the intention of the speaker in uttering it, or the standard use of that string of words in the community" (Kukla \& Lance 2009: 13). It is asserted that the normative structure of the system of discourse cannot be entirely divorced from speakers' intentions and conventional uses. There must be some defeasible concordance between function, intention and convention, i.e. standard use. However, such a connection is not devoid of semantic dynamicity.

From their normativist perspective, Kukla and Lance are thus able to explicitly address many issues related to, inter alia, normative conventions and inferential processes, but they also treat convention as a general notion without attempting to elaborate on it in the Austinian tradition.

\subsection{8. (Preliminary) Classification of intentionalists and conventionalists}

There have been attempts to classify speech act theorists, both explicit and implicit ones, according to their theoretical stance with regard to the intention and convention debate, as well as with regard to related criteria, such as internalism as opposed to externalism, or normativism as opposed to mentalism.

Outside speech act theory, internalism and externalism are theoretical positions in the philosophy of language and the philosophy of mind which relate to the "location" of propositional and mental contents. Predictably, internalists believe that the content of thought and also the proposition expressed by an utterance can be grasped independently of the "real world" in the (internal) mind, while externalists defend the view that many (if not all) such contents must be

words" take declaratival assertion as the basic form of language and examine other forms as marginal uses and a departure from, or permutation of the norm. 
identified in the (external) things in the real world. Consequently, such contents are referred to as "narrow content" and "wide content", respectively ${ }^{201}$.

Internalist and externalist positions among speech act theorists bear relevance for investigation of the concept of convention as well as intention. For instance, Harnish (2009a) claims that speech act theory has its own version of the externalist-internalist debate, although this version is implicit rather than explicit. In an attempt to classify selected influential models of speech act theory, Harnish presents the following classification (the table has been extended here to include the authors discussed in the chapter - the added researchers' names are written in italics):

\begin{tabular}{|c|c|c|c|}
\hline$\frac{\text { Internalist }}{\text { Grice }(1968)}$ & $>$ & $\frac{\text { Mixed }}{\text { Austin }}(1962)>$ & $\frac{\text { Externalist }}{\text { Gazdar }(1981)}$ \\
\hline Schiffer (1972) & & $\begin{array}{l}\text { Austm }(1902) \\
\text { Searle }(19691975)\end{array}$ & \\
\hline SCIIIIE $(19 / 2)$ & & गeante (1909, 19/J) & \\
\hline Holdcroft (1978) & & Bach \& Harnish (1979) & \\
\hline Alston (2000) & & Searle \& Vanderveken (1985) & \\
\hline & & Strawson (1964) & \\
\hline & & Morgan (1977/1978) & \\
\hline & & Millikan (2005) & \\
\hline & & Brandom $(1994,2000)$ & \\
\hline
\end{tabular}

Table 13: The internalism-externalism spectrum in Speech Act Theory according to Harnish (2009a: 11)

In the classification above a theory is classified as internalist if in analysing speech acts it predominantly refers to psychological states; it is classified as externalist if it methodologically focuses on non-mental phenomena, and it is labelled as mixed if both states (psychological and non-psychological) are used in its apparatus.

It is evident that there is a salient convergence between what Harnish (2009a) identifies here as Convention-Rule-Norm (C-R-N) theories, as opposed to Intention Inference (I-I) based theories and what since Strawson's (1964) publication has been dubbed as conventionalist and intentionalist approach to speech acts. However, Harnish (2009a: 12) presents another classification to specifically refer to the C-R-N and I-I dimensions, quoted in Table 14.

\footnotetext{
${ }^{201}$ For a more detailed discussion of internalism and externalism, its history and varied models embracing Russell and Frege's debate, see e.g. Farkas 2006.
} 


$\begin{array}{lll}\text { C-R-N } & \text { I-I } & \text { Mixed } \\ \text { Austin } & \text { Grice } & \text { Bach \& Harnish } \\ \text { Searle (1969) } & \text { Schiffer } & \text { Searle (1975) } \\ \text { Alston } & \text { Holdcroft } & \text { Searle \& Vanderveken (1985) } \\ \text { Gazdar } & & \end{array}$

Table 14: The rules versus intentions spectrum according to Harnish (2009a: 12)

As the labels suggest, externalist (C-R-N) theories concentrate on norms, rules and conventions which guide performance and recognition of illocutionary acts. Norms, rules and conventions are thus used for classification of acts and for explanation how they function within a given community. In turn, I-I theories advocate the view that illocutionary acts are best analysed with reference to speakers' intentions. Reference to intentions and intentional states is used in such theories for a description of an act and for explaining how it is comprehended.

In a speech act theoretic perspective, when conditions for a successful illocutionary act involve states in the "real" world, the model can be classified as externalist, and when felicity conditions restrict mental states of either (or both) the speaker and the hearer, the models are recognised as internalist models.

Tsohatzidis (2010) provides a related taxonomy whose purpose is to classify speech theorists in terms of their commitment to mentalism and normativism. Having recognised that the nature of illocutionary acts can be explained with reference to two main aspects that they may involve, approaches to speech act analysis are divided into: 1) those that concentrate on the mental states that speakers must possess to successfully perform relevant speech acts, and 2) those that concentrate on the normative features that are characteristic of the speech acts being performed.

Mentalist approaches can be sub-classified into those that focus solely on the speaker's frame of mind, and those that, in a Gricean manner, take into consideration also the hearer's recognition of the speaker's mental state. Tsohatzidis suggests that speech act-theoretic approaches begin with Strawson's seminal article of 1964, whose ideas were further developed by, inter alia, Schiffer (1972) and Bach and Harnish (1979). Despite evident differences in the theoretical commitments accepted by all these researchers, they are recognised as mentalists through their concentration on the frame of mind that speakers, or, alternatively, both speakers and hearers, need to have in order for a speech act to be successful. An independent mentalist camp is that of Searle (1983), from the time of his publication of Intentionality, in which he heavily relies on mental states, but, unlike Schiffer (1972) and Bach and Harnish (1979), he does not 
theoretically envisage in his 1983 model any space for cooperation on the part of the audience.

With regard to his later publications, Searle (e.g. 2007) is also presented as a key figure in the transition between mentalism and normativism due to the amount of gravity that he places on deontic consequences of utterances (cf. section 2.8), which finds a full recognition in his other works (e.g. Searle 2001, 2010).

Among normativists, Tsohatsidis further places Alston (e.g. 2000) and Gauker $(1994,2007,2008)$. Alston is classified as a normativist due to his concentration on the notion of responsibility; Gauker, in turn, is a normativist as he takes an extreme position and suggests that "[ $[\mathrm{t}] \mathrm{he}$ proposition that a speaker's words express in context never depends at all on what the speaker intends in speaking" (2008: 359). Although Gauker's focus is not on speech acts, his understanding of language has clear implications for the theory. Most immediately, it suggests that explaining linguistic behaviour in terms of intentions cannot be theoretically sound. What can be noticed, however, is that any utterance of a sentence constitutes an illocutionary act if there is a "discourse norm" that can be applied to its evaluation. Such a norm is significant in indicating the degree in which the utterance in question helps promote the practical aim of the conversation. In turn, such a practical aim is identified as securing inter-personal coordination so that the interlocutors could successfully pursuit their extra-linguistic goals ${ }^{202}$. Among other normativists, there are Brandom (1994, 2000; cf. section 4.3.7) and Kukla and Lance (2009), who develop Brandom's ideas on assertion and his conception of entitlements and commitments involved in speech acts, and expand the discussion by including other types of speech acts beyond assertion. Millikan (e.g. 2005a) may also be placed on the normativist side thanks to her concentration on conventions which "naturally" proliferate by weigh of precedent (cf. section 4.3.6). In her account of performativity, conventions seem to grant speech acts some independence in the sense that many of them can be externally judged by general public without attempts at mindreading in situated contexts.

Naturally, there are numerous intermediate positions between mentalism and normativism. Significantly, Searle's theoretical path from the "simple" analysis of speech acts (e.g. Searle 1969, 1975a) towards a theory of the social world for which speech acts which involve deontic values provide a foundation (e.g. Searle 1995, 1999, 2010), is a good example of combining the two perspectives.

The table below presents a classification of speech act approaches into normativist, mentalist, and mixed positions, which has been partially based on Tsohatzidis' s (2010) discussion.

\footnotetext{
${ }^{202}$ Gauker's picture of language is very general, for instance he suggests that imperative sentences are usually used to set goals pursued by interlocutors, while the function of assertive (sentences in indicative mood) is mainly to identify the means to achieve such goals.
} 


\begin{tabular}{|c|c|c|c|c|c|}
\hline \multicolumn{2}{|c|}{ Mentalists } & Mixed & \multicolumn{3}{|c|}{ Normativists } \\
\hline $\begin{array}{l}\text { recognition } \\
\text { of S's } \\
\text { intention in } \\
\text { focus }\end{array}$ & $\begin{array}{l}\text { not interested } \\
\text { in recognition } \\
\text { of S's } \\
\text { intention }\end{array}$ & & $\begin{array}{l}\text { deontic values } \\
\text { in social } \\
\text { reality } \\
\text { constructed } \\
\text { through SAs }\end{array}$ & $\begin{array}{l}\text { no possibility } \\
\text { of } \\
\text { mindreading }\end{array}$ & $\begin{array}{l}\text { social world } \\
\text { of } \\
\text { entitlements } \\
\text { and } \\
\text { commitments }\end{array}$ \\
\hline $\begin{array}{l}\text { Strawson } \\
(1964) \\
\text { Schiffer } \\
(1972) \\
\text { Bach and } \\
\text { Harnish } \\
(1979)\end{array}$ & $\begin{array}{l}\text { Searle } \\
(1983)\end{array}$ & $\begin{array}{l}\text { Austin } \\
(1962) \\
\text { Morgan } \\
(1977 / 19 \\
78) \\
\text { Searle } \\
(2007 a)\end{array}$ & $\begin{array}{l}\text { Searle, } \\
(1995,2001, \\
2010)\end{array}$ & $\begin{array}{l}\text { Alston } \\
(1994, \\
2000) \\
\text { Gauker } \\
(1994, \\
2000,2007)\end{array}$ & $\begin{array}{l}\text { Brandom } \\
(1994, \\
2000) \\
\text { Kukla \& } \\
\text { Lance } \\
(2009)\end{array}$ \\
\hline & & & $\begin{array}{l}\text { Millikan (198 } \\
\text { normativity: co } \\
\text { functions and p } \\
\text { precedent] }\end{array}$ & $\begin{array}{l}2004,2005) \\
\text { ventions related } \\
\text { liferation by w }\end{array}$ & $\begin{array}{l}\text { paturalistic" } \\
\text { proper } \\
\text { h of }\end{array}$ \\
\hline
\end{tabular}

Table 15: Selected approaches to speech act classified according to their mentalist/normativist orientation (partially based on Tsohatzidis 2010).

It is significant that in all the classifications mentioned above, Austin is placed in a mixed position. In particular, his reliance on the notion of convention is not defined in a way which would allow to elect him as a conventionalist, or a normativist. Instead, it appears that Austin combines (and integrates) all abovementioned approaches by referring to certain aspects associated with each of them. As a result, any attempt to classify him as a theorist of a certain kind can only function as a useful approximation. This feature is inherited by the theory itself. It is clear that speech act theory as such is neither mentalist, nor normativist in orientation, but possesses both aspects. The same is true about the internalist and the externalist approach, and, finally, the conventionalist as opposed to the intentionalist school. The classifications indicate the many directions in which Austin's though was elaborated, but it is also revealed that none of the researchers were able to provide (and few were interested in providing) an explication of Austin's original account of conventionality of speech acts.

\subsubsection{Convention, semantic minimalism, contextualism, and short- circuited meanings}

The problem of convention, which directly refers to how meaning is processed, in the context of speech acts has its own theoretical and methodological history 
in the debates between the schools recognised as semantic minimalism and contextualism, including numerous intermediate positions. The debates have produced a vast amount of literature and ideas, and there is only space to refer to the most visible ones and directly relevant to the problem of convention in speech acts, i.e. selected ideas put forward by Cappelen and Lepore (2005), Bach (e.g. 1995, 1998, 2001, 2006), and Recanati (e.g. 2003b, 2004).

In Insensitive semantics, Cappelen and Lepore defend "a positive theory", advocating the view that there is a minimal semantic content in all utterances and even though this semantic content is context sensitive, its context sensitivity can be systematically distinguished from other kinds of context sensitivity if only theoreticians are ready to work hard enough. In other words, the authors defend a view that a substantial amount of linguistic material possesses conventional meaning which is independent of a particular context of use, simultaneously claiming that their approach can sufficiently explain how ordinary language works.

Cappelen and Lepore's position has relevance for speech acts analysis and for investigation into the concept of convention as a very important claim behind insensitive semantics is that the study of speech act content and semantic content are two distinct fields of investigation. It is explicitly indicated that it is certain researchers' inability to see the distinction that leads such thinkers to follow contextualism. In other words, mixing speech act content analysis with the study of semantic content is presented as a methodological error. On the other hand, responding to potential criticism of their ideas, Cappelen and Lepore point out that even following contextualists' way of thinking about meaning construction, it should be concluded that the starting point for constructing the meaning of an utterance is sentence meaning, i.e. a search for relevant information which "looks like a convention associated with our use of sentences" (Cappelen \& Lepore 2005: 135). Furthermore, accepting that this is a frequent, or even a universal procedure, "there is no reason to deny that it attaches to the use of words as a matter of convention, and hence, to their conventional meaning" (135).

In general, there are two main arguments presented by Cappelen and Lepore: Semantic Minimalism and Speech Act Pluralism. Semantic Minimalism claims that it is possible to define a level of semantic content which is minimally influenced by context. For example, in order to define the minimal semantic content of an utterance $U$, being an utterance of a well-formed sentence $S$ in a context $C$, it is necessary to fix relevant referents for all indexical or demonstrative components of that sentence, as well as to disambiguate all ambiguous components and precisify the vague ones. It is suggested that semantic context sensitivity should stop on Kaplan's Basic Set and should never go beyond the $\operatorname{set}^{203}$ (cf. Cappelen \& Lepore 2005: 150ff.).

${ }^{203}$ Cappelen and Lepore are critical of numerous proposals to treat components beyond Kaplan's set as semantically context-sensitive, positions richly represented among philosophers of language 
The other argument, or rather the other part of their argument, Speech Act Pluralism, claims that every utterance of a sentence $S$ may communicate a plurality of meanings. This type of meaning is not minimally, but massively context sensitive. As minimalism claims: "No one thing is said (or asserted, or claimed, or ... ) by any utterance: rather, indefinitely many propositions are said, asserted, claimed, stated, etc." (Cappelen \& Lepore 2005: 199). "What is said" depends on factors beyond the proposition which is semantically expressed and different kinds of context play a role in utterance interpretation, the most direct ones being the context of the utterance and the context of the interpreter, but virtually all conceivable information may be important.

There are three main corollaries on which the theory and the two main arguments are based. The first one is Surprising Semantic Invariability, i.e. the view that even terms such as "tall" or "fast" are semantically insensitive. The second one is Denial of Context of Utterance Centrism, which claims that the context in which an utterance of a sentence is interpreted is at least as important as the context of the utterance. In other words, the context of the utterance is no longer in a focal position. Finally, the third corollary, Denial of First Person Authority over what's said, says that normally speakers cannot control contexts in which their utterances are interpreted. It follows that they do not have access to all of what they say in their utterance; some part of what "they say" will rest with the interpreter.

Cappelen and Lepore indicate that, at least since Frege, most philosophers of language had been mistakenly, and often unwittingly, committed to Speech Act Monism, i.e. a view that there is just one meaning for every utterance. Implicitly, this claim may also be attributed to Austin.

The concepts of Semantic Minimalism and Speech Act Pluralism suggest a modified perspective on speech acts and convention. First of all, semantic minimalism divides perception of utterances into two levels. On the semantic level, the meaning of utterances is to be understood as fairly stable. However, there is ample space left for variety in their interpretation, which makes it possible that an utterance may "mean" virtually anything as its speech act meaning will be determined by the hearer, or an audience who may import their own contexts and purposes. The interpretation may happen as distant in time and space, while interpretants may use in their comprehension circumstances which were nonexistent at the time of the utterance (or action) or of which the speaker was not aware.

Cappelen and Lepore justify their position by evoking a general theory of action which allows that any ostensive form of behaviour can naturally evince a plurality of acts, or, in its more restricted form, at least allows for a variety of descriptions. Seeing a general philosophical theory of action as one that should embrace speech act theory, semantic minimalists claim that it provides grounds for their claim of Speech Act Pluralism. This claim is to be valid irrespective of the internal orientation within the theory. For instance, both Kimeans' and 
Davidsonians' views are supportive of minimalism. In other words, whether it is believed that there is a number of acts which are co-incidental with a bodily movement, as Kim's (Kim 1976) followers would say, or that there is a single action constituted by a bodily movement, which, however allows for a number of independent action descriptions, as Davidson's followers claim, the argument of Speech Act Pluralism will be supported.

In summary, Cappelen and Lepore heavily rely on conventional meaning of sentences, and words themselves, in understanding utterances, but their discussion of the concept of convention is general and, although they treat speech acts as legitimate categories, they do not find it practical to discuss Austin's distinctions.

There are varieties of minimalism and, for example, in a version of semantic minimalism proposed by Kent Bach, commonly referred to as radical Semantic Minimalism, there is, in turn, space for sentences which do not express propositions, even as relative to contexts of use. Instead, sentences can be seen as semantically incomplete. Semantic incompleteness in Bach's (e.g. 2006) sense is thus different from context sensitivity, which may pose further challenges for convention-related accounts.

Naturally, context-sensitivity stays in the centre of contextualists' attention. Contextualism, advocated by many relevance theorists (e.g. Sperber \& Wilson 1986/1995, Carston 2002) and, prominently, by François Recanati (e.g. 2003a, 2003b, 2004, 2007), is a school which claims that there is pragmatic intrusion on all levels of meaning construction. Contextualists vary among themselves as to the degree in which this intrusion is allowed, but in a general view they are in favour of context sensitivity and the linguistic underdeterminacy thesis ${ }^{204}$ (cf. Carston 2002).

Thus, it may seem that contextualists, who recognise dynamicity of linguistic meaning, will be particularly good candidates for elucidating the problem of convention in speech acts.

In relevance theory, there is a strong commitment to the view that meaning is always constructed in an on-line manner and a firm distinction between decoding and inference, which, possibly, should evoke different types of conventions. Naturally, it is often understood that decoding plays the minor role in comparison with inferential processes. Relevance-theoretic perspective on utterance interpretation focuses on unitary description of phenomena such as metaphor, narrowing and loosening, which, whether in the context of explicit or implicit input, are always governed by the same Principle of Relevance (theoretically defined in Sperber and Wilson 1986/1995). Despite the fact that relevance theory is rather critical of speech act theory (cf. Sperber \& Wilson

${ }^{204}$ Carston (2002) convincingly argues that all utterances are underdermined. 
1986/1995: 243-254 $)^{205}$, its framework could be used to explain speech act comprehension.

The criticism which speech act theory received from relevance theory may well be related to the concept of convention. Relevance theorists tend to exclude speech acts which are "institutionally" conventional from the domain of studies on utterance comprehension, but "institutional conventionality" itself invites confusion; now it is not only the notion of conventionality that is in need of further explication, but the notion of "institutionality" as well. In a broad perspective, all linguistic acts are social in nature, and, thus, "institutional" in the most general sense ${ }^{206}$. In a general approach, playing bridge would be "institutional" just as promising and asking about preferences are. As it is evidently not the case that Sperber and Wilson, just as Bach and Harnish (1979) before them, use the concept of "institutional" in this broad sense, the problem of conventionality in communication in general remains underdefined.

In the relevance-theoretic perspective, in their interpretation of utterances hearers are guided by a general expectation of relevance (cf. Wilson \& Sperber 2002; 2012: 5-6, 65-6) and in a communicative situation, they search for the most accessible and "relevant" interpretation considering a particular context. Most of relevance theoretic research has been devoted to lexical pragmatics, but it may be claimed that speakers proceed along similar lines in their recognition of an illocutionary force in a context. Just like lexical meaning of "to drink" can be extended to cover "to drink alcohol" and the meaning of "secretary" can be narrowed to mean "a female secretary" (cf. Levinson 2000), the meaning of performative utterances may be understood beyond the exact form with which hearers are confronted.

In cognitive lexical pragmatics such interpretations can be explained with reference to "default" rules, which are to be responsible for short-circuited processing. This view is related to Campbell's (1981) suggestion (cited earlier, cf. secion 4.2.2.) that there are two main types of pragmatic processes found on a

\footnotetext{
${ }^{205}$ Historically, the relation between speech act theory and relevance theory has not been easy. Although today there is much literature which may be identified as relevance theoretic speech acts accounts (e.g. Jary 2011), there has been much criticism voiced by relevance theorists and addressed at speech act theory. In the first seminal book on relevance theory, Relevance: Communication and Cognition (Sperber \& Wilson 1986/1995), Wilson and Sperber admit that "perhaps the single most uncontroversial assumption of modern pragmatics is that any adequate account of utterance comprehension must include some version of speech-act theory" (Sperber \& Wilson 1986/1995: 243), but just a few lines later explicitly state that they "would like to question this assumption" (Sperber \& Wilson 1986/1995: 243). However, they also refer to "speech acts" and "illocutionary" phenomena while discussing natural language processing (e.g. Sperber \& Wilson 2012: 261; Wilson \& Sperber 2012b:163; cf. section 2.9 herein). Relevance theory suggests that much of the material that has been presented as speech act-theoretic will be better accounted for by a theory of institution and not a "linguistic" theory. The most promising field of speech act theory that relevance theorists identify is a study of the correlation between mood and function.

${ }^{206}$ Cf. Searle's conception of institutional reality; section 2.8 .
} 
macro- and micro-level. In Campbell's view, macropragmatic processes are understood as sequences of explicit inferences, while a micropragmatic process is to be "cryptic and heuristic" (Campbell 1981: 101), a developed short-cut (cf. also section 4.3.9.). Next to the default model and the underspecification model (cf. DM vs. UM in Bezuidenhout \& Morris (2004: 261ff)), there is a related discussion of implicature as contrasted with default interpretation. There are evident differences between the relevance-theoretic notion of interpretive procedure and, for instance, Campbell's approach, as relevance theory argues in favour of a unitary principle, but at the same time the latter seems to grasp some problems which stay in the centre of relevance-theoretic research (e.g. iconic readings of utterances). In this sense Campbell's default interpretation may be seen as parallel to "automatic" search for relevance in RT and "conventions of use” in Morgan's (1978) sense.

On the extreme contextualist side, Recanati claims that "what defines contextualism is the generalisation of context-sensitivity" (2009 ms: 1). Such context-sensitivity, in other words, context-dependence, is the property thanks to which a linguistic expression whose conventional meaning is fixed by the rules of language, may still "carry different contents in different contexts".

Comparing three models of contextualism, viz. Methodological Contextualism (MC), Modulation Based Contextualism (MBC), and Radical Contextualism (RC), Recanati points out that none of them stays in conflict with systematic semantics despite the fact that they significantly differ with regard to how meaning and propositions, or senses, are conceived of.

Having accepted that the basic Fregean assumption is that every utterance simultaneously with its use contributes its literal sense, i.e. the sense which "it independently possesses in virtue of the conventions of language" (Recanati 2009ms: 2), Recanati shows that different types of contextualism differ in their orientation towards this untenable Fregean idea. He points to the fact that the Austinian propositions consist of the lekton together with the situation in which it is to be evaluated. In this sense, any utterance is processed in context and is judged in a free pragmatic process which allows to find the most salient or relevant, or appropriate interpretation. Contextual free enrichment is free in that it is not associated with any particular part of the sentence which is uttered. Through free enrichment, contextual meaning of a lexical item becomes more specific than its literal (conventional) meaning.

It appears that Recanati also accepts different levels of conventions, which can be related to different levels of context-dependency. In his version of contextualism, there appear to be evidently trivial conventions of language or, rather, conventions of literal meaning in language. However, the conventions of use, which allow for non-literal or enriched interpretations are merged in the notion of context. As Recanati claims, against Searle's Principle of Expressibility, 
According to contextualism, the sort of content that utterances have (in virtue of the speech acts that they serve to perform) can never be fully encoded into a sentence; hence it will never be the case that the sentence itself expresses that content solely in virtue of the conventions of the language. Sentences, by themselves, do not have determinate contents. What gives them the determinate contents that they have (in context) is the fact that they are used in performing meaningful actions. In brief, contextualism says that the gap between sentence meaning and speaker's meaning can never be closed. (Recanati 2003b: 194)

In a model dubbed as Meaning Eliminativism, Recanati forms an extreme claim that linguistic meaning is not even needed as input to the meaning construction process (cf. Recanati 2004: 146-153). In his words, "[t]he senses that are the words' contribution to contents are constructed, but the construction can proceed without the help of conventional, context-independent word meanings" (Recanati 2004: 147). It is further claimed that the contextual sense of an utterance can be computed directly without any intervention at the linguistic (literal) meaning level. This is possible because language users draw on their knowledge of the previous uses of such linguistic forms. The model merges the abstraction of meaning from use and the modulation of meaning in use into one complex process as is graphically represented in Figure 8.

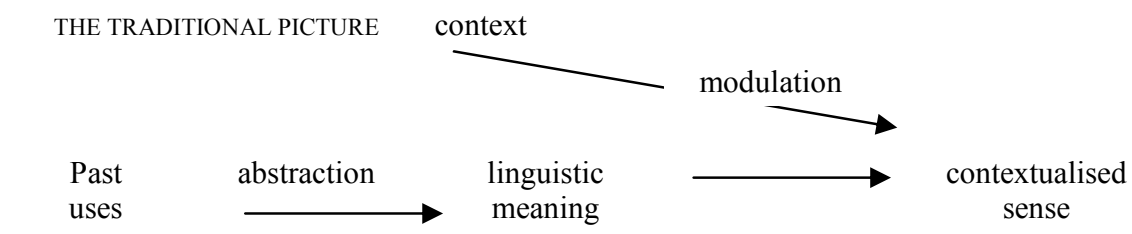

MEANING ELIMINATIVISM

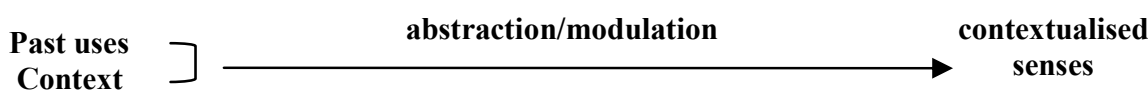

Figure 8: A single process of abstraction and modulation according to Recanati 2004: 148

It is suggested that words are not associated with their "conventional meanings", instead, their application and understanding must be context-dependent. This is also characteristic of the process of learning a language, where learners are first confronted with linguistic evidence, i.e. language in use, and not some "preformatted linguistic meanings". In general, the model suggests that language 
users draw on their knowledge of a sufficient number of "source-situations", and they can apply this knowledge in "target-situations".

In this context, speech acts must operate on conventions beyond trivial linguistic conventions, which themselves may be conceived of as abstractions from past uses, or, as relative to "lineages", as Millikan would put it (cf. section 4.3.6). An utterance plays a role as "evidence" for a function and on-line meaning construction ${ }^{207}$. Another interesting point in this picture is that sense depends on the relations of similarity, related to features with "diagnostic values" 208 and contrast sets. It is a complex configuration of contextual foregrounded features that determine which senses will emerge as salient. The model is problematic in that it places emphasis on particularised meanings rather than types, although types are presupposed in the concept of "past situations" which project the potential of words' meanings.

Recanati indicates that the stability with which words are applied and with which meanings are recognised within a language community suggests that words contribute a "meaning potential", which in combination with context allows for successful communication. There is an implicit suggestion with regard to conventionality of speech acts. Just like meaning, which is always situated meaning, conventionality of an act will be related to a varied configuration of lexical meaning and context, where "lexical meaning" need not be identified with dictionary meaning. As utterances function as signs in particular contexts, their semantic value, i.e. even the value of the same surface form, may differ across contexts of use. The level of abstraction, in Recanati's (2004) sense, may differ. As a result, the notion of conventionality must stay underdefined as it is both clear that there is conventionality at work, and that the label applies to a wide array of different phenomena.

In summary, the problem of convention in speech acts has not received a sufficient explication in either contextualist or minimalist theoretical models. In fact, researchers on both sides, whether explicitly or implicitly, suggest that conventions responsible for understanding the force of particular utterances cannot be readily (or even at all) systematically accounted for. The relevant research programmes seem to concentrate more on the particular mechanisms which people use in understanding utterances ${ }^{209}$.

\footnotetext{
${ }^{207}$ Recanati cites psychological literature in support of Meaning Eliminativism (cf. Recanati 2004: 147; fn 44 and the references within).

${ }^{208}$ Recanati explicitly borrows this idea from Tversky.

${ }^{209}$ The problem of conventionality in speech acts, and especially the tension between the concepts of convention and intention as operative in speech acts is also implicit in Austin's Hippolytus example, already mentioned in section 3.7 on promising. In lecture One, Austin (1962/1975: 1112) quotes Eurypides' character Hippolytus saying:
}

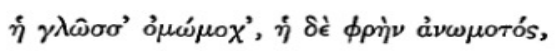

which translates into "my tongue took an oath, but my mind (or heart) remained unsworn". Evidently, if speech acts could only be private acts, i.e. they could rely on inner feelings, beliefs 


\subsubsection{Convention and iterability - Derrida and his legacy}

A common way of approaching linguistic convention is by reference to repetitiveness of certain forms and this perspective is focal in Derrida's reading of speech act theory, which can itself be seen as an exercise in iterativity, and, by extension, an exercise in an analysis of the concept of convention.

Derrida puts a lot of emphasis on the fact that speech acts are understood thanks to their iterativity. An utterance is meaningful only in context and through the context in which it is produced, but at the same time it may function as a sign due to the fact that it can recur in different contexts.

Could a performative utterance succeed if its formulation did not repeat a 'coded' or iterable utterance, or in other words, if the formula I pronounce in order to open a meeting, to launch a ship or a marriage were not identifiable as conforming with an iterable model, if it were not thus identifiable in some way as 'citation?'

(Derrida 1977; quoted from Derrida 1988: 18: 18)

There is an echo of Austin's idea that in performing a speech act a speaker "conforms to a convention" 210 (Austin 1962/1975: 105) and Derrida also emphasises a special conventional nature of speech acts which can be understood as their (relative) independence from speaker's particular intentions.

In a much quoted text, Derrida (1977) comments on the nature of signature and claims that a signature "works" independent of the intentions which accompanied the act of signing. There is an invitation to believe that spoken language and utterances may work in a similar way, by virtue of repetition, a "conventional" repetition in which intention plays a role, but is not foregrounded. Derrida suggests "a typology of forms of iteration" in which intention could also find its place:

In such a typology the category of intention will not disappear: it will have its place, but from that place it will no longer be able to govern the entire scene and system of utterance [l'énonciation]. Above all, at that point we will be dealing with different kinds of marks or chains of iterable marks and not with an opposition between citational utterances,

and secret commitments, speech act theory would be useless. Focusing on functions of language, conceived of in terms of typical mechanisms in social life, only makes sense in normative situations and contexts which presuppose a possibility of objective verification, i.e. contexts in which utterances meet social convention in that they can be legitimately assessed by hearers and not only performers.

${ }^{210} \mathrm{Cf}$. "We must notice that the illocutionary act is a conventional act: an act done as conforming to a convention" (Austin 1962/1975: 105) 
on the one hand, and singular and original event-utterances, on the other.

(Derrida 1977/quoted from Derrida 1988: 18)

Derrida uses Austin's example of a signature to show a relative independence of the sign from the speaker's, or rather writer's intention. In Derrida's view iterativity of a signature creates a situation in which the author's intentions at the time of signing are not very important. Apart from extreme cases of, for instance, coercion, the signature would be recognised as valid in the social world. In a similar way, linguistic expressions will be alienated from their users and can "mean" independently.

In an interesting semiotic account already mentioned above, Culler (1981) links the richness of the Austinian approach with later Derrida's developments. In particular, Culler stresses Austin's exposition of a potential failure, which is an essential feature in defining a performative. In this light, a performative utterance has its conventional force thanks to the potential that it could go wrong; in fact, "something cannot be a performative unless it can go wrong" (Culler 1981: 18; cf. also Austin 1962/1975: 14). As performative utterances are best defined by specification of their felicity conditions, in other words, by listing potential infelicities, Culler (1981) presents Austin (rather contentiously) as an implicit deconstructionist and, simultaneously, exposes Austin's implicit commitments with regard to conventionality.

While referring to normativity, Derrida also mentions "performative powerlessness" (e.g. Derrida 2000). It is suggested that wherever performative acts are given an ethical, juridical, or political space, it is the case that such performative communications both produce and neutralise events. In Derrida's view, to produce performative acts means to produce events, and, consequently, give rise to institutions. In such performance, and the resulting institutions, responsibility is naturally assumed. In Derrida's words: "Wherever there is the performative, whatever the form of communication, there is a context of legitimate, legitimizing, or legitimized convention that permits it to neutralize what happens, that is, the brute eventness of the arrivant" (Derrida 2000: 467). In other words, "if in a certain manner performativity encounters the event produced by language, it is also that which neutralizes the eventness of the event" (467).

In summary, iteration is not understood as a simple repetition that "fixes" what is being performed, but rather as a dynamic scene where it may invite its own alteration. It is emphasised that "iterability alters, contaminating parasitically what it identifies and enables to repeat itself" (Derrida 1988: 62) and "limits what it makes possible, while rendering its rigour and purity impossible" exercising "a law of undecidable contamination" (1988: 59).

It is clear that convention is given a new significance in this light. On the one hand, iterativity stabilises meaning, but, on the other, it enables novelty. Linguistic meaning is never "fixed", but emerges among the constantly changing 
relations between linguistic signs. Derrida's ideas has had significant influence on how convention and meaning are understood in fields such as critical political theory, critical race theory, construction of identity (e.g. Butler 1997, Langton 1993), gender studies (e.g. Hornsby 2000, Butler 1990, 1993), and research related to hate speech ${ }^{211}$ (e.g. McGowan 2009, Butler 1995).

Significantly, although both Derrida and later researchers who followed in his footsteps, e.g. Butler, explicitly refer to Austin's speech act theory and appear to find it more applicable than, for example, Searle's model ${ }^{212}$, their perspective on convention, as well as on many other tenets of the theory is much different from what can be found in Austin's lectures. It seems that Austin's indeterminate discourse, together with the richness of his reflection on the nature of actional language, allows researchers in the tradition of Derridean deconstruction to better, and freely, formulate their own hypotheses. Nonetheless, they selectively use the material and build their own models without explicit elucidation of how they determine the original concepts ${ }^{213}$. In particular, the concept of convention, although being explicitly referred to, remains a blurred notion.

\subsection{Preliminary conclusions}

In summary, despite the fact that in Austin's model convention is explicitly presented as one of the firmest tenets of the theory of speech acts, and as a salient feature of their illocutionary aspect - all illocutionary acts are defined as necessarily conventional acts - the nature of the notion remains underdetermined. As a result, various researchers address, whether explicitly or implicitly, their more or less arbitrary understanding of such conventionality to the effect that a serious discussion between their views is often necessarily impaired.

The conventionalist and intentionalist debate may well be the most visible sign of one of the existing interpretations of convention although it also possesses its own internal problems. In the broadest possible picture, intentionalists argue that the function of speech acts, i.e. their meaning, should be accounted for in Gricean framework, i.e. with reference to mindreading and speakers' intentions ${ }^{214}$. But intentions and mental acts cannot be readily

\footnotetext{
${ }^{211}$ Cf. section 2.6.2.e.

${ }^{212}$ Although, naturally, there had also been a well-known lengthy debate between Derrida and Searle, cf. Searle 1977.

${ }^{213}$ Derrida's (1977) comments on non-serious speech acts may be seen as an exception here.

${ }^{214}$ It is significant that while the intention/convention debate still continues and most of terminological confusion has not been erased, numerous pragmatic handbooks seem to promote a simpler view, in which usually the two concepts are interwoven. For instance, Huang's (2007: 281) glossary includes the following definition: "illocutionary act: an act or action intended to be performed by a speaker in uttering a linguistic expression, by virtue of a conventional force associated with it, either explicitly or implicitly" (Huang 2007: 281).
} 
identified with speech acts and are not directly accessible. Since philosophers such as Husserl, Brentano and Marty at least, intentions are better seen as aspects of speech acts as they involve psychological reality which is easily distinguished from social reality ${ }^{215}$. In other words, mental acts are (at least sometimes) part of linguistic action, but linguistic action (speech acts), being social acts, are first of all "conventional" (also in a trivial sense as their recognition depends on iterativity).

In a different way, the psychological element has also saturated philosophy after Descartes with the foregrounded idea of self-consciousness and selfreference following from the rule: "Knowing implies knowing that one knows". However, as Burge argues, following rules does not need to mean that one knows them, while our "overuse" of the rule-centered approach may well lead to "an exaggerated view of our present self-understanding" (Burge 2007 [1975]: 37). It follows that performance of speech acts does not need to be as rational (and backed with conscious intention) as it is often expected.

The juxtaposition of intentional and conventional acts, significantly marked with Strawson's (1964) paper, evokes a different type of distinction, a distinction between "more private", and "more social ("thus-less-private')" acts, while in general, the labels "intentional" and "conventional" produce confusion with regard to mental, as opposed to "social" activity, which itself opens the arena for analysis of speech acts which are insincere, manipulative, "political",etc. and also for those which transcend the bipersonal dimension ${ }^{216}$. Indeed, the answer to the questions whether such acts are "speech acts" also depends on researchers' theoretical orientation. A similar (terminological) confusion can be sensed with regard to the concept of "institutional" acts. Just like in the case of conventionality, in a trivial sense, all social acts are "institutional", although some of them involve institutional settings of a more elaborate type (e.g. naming a ship, declaring war, etc.), a setting which will detach the person who acts as the speaker/performer from the speech action being performed. In other words, personal attitudes and feelings of a person who, for instance, perfoms naming of a ship, are not directly relevant.

In the context of institutionality, Harris (1988) sees the games analogy as appropriate because, as Wittgenstein put it in lectures edited as Remarks on the Foundations of Mathematics: "A game, a language, a rule is an institution"

\footnotetext{
${ }^{215}$ Korta and Perry (2011: 4) indicate that communicative intentions are reported in the same grammatical structures as beliefs, desires and other mental states, which can be a good indication that they are perceived as mental actions and that meaning and contents of utterances arise from human intentions. The form in which reports on saying tend to be phrased is that of the thatclauses as in "John said that he was happy to see the students".

${ }^{216}$ Transcending the bipersonal dimension may involve utterances whose performance is aimed at achieving a more distant purpose, for instance a political end, or building an image to serve a purpose beyond the interaction which is happening at the time. Many of such utterances will be better accounted for in terms of speech or communicative events than "speech acts", which traditionally focus on "local" interactions.
} 
(Wittgenstein 1978: 334; also cited in Harris 1988: 97). The "institutionality" perspective is further strengthened in Wittgenstein's remark that "[i]n order to describe the phenomenon of language, one must describe a practice, not something that happens once, no matter of what kind" (Wittgenstein 1978: 335). It can be noticed that institutionality conceived of in this way can be identified with the "institutionality" of speech acts as, for instance, discussed by Searle (cf. section 4.3.3 and 2.8) only to some degree, despite the surface terminological convergence.

In summary, it is difficult, or impossible, to characterise speech acts in terms of their conventionality until the concept receives a sufficient definition, or until it is at least explicated how the notion is used in particular models of speech act theory. The terminological divergence across different approaches has been illustrated in Table 16 with reference to just four influential models.

The comparison of accounts of different perspectives on illocutionary acts in relation to their conventionality shows that various research programmes concentrate on different conceptions of conventionality. The reference here is limited to illocutionary acts and not just speech acts because while some authors (e.g. Millikan 2005a) tend to merge the distinction between illocutionary acts and speech acts, others (notably Austin 1962, but also many of his followers, e.g. Strawson 1964) emphasise that illocutionary acts are necessarily conventional, but perlocutionary acts (i.e. technically some aspects of speech acts) are not, or need not always be. In turn, locutionary acts are always seen as conventional ${ }^{217}$, but usually their conventionality is seen as trivial linguistic conventionality, a feature necessarily shared by all language and, as such, not directly relevant to the problem under discussion unless in the context of indirect or vague acts ${ }^{218}$.

Methodologically, the distinctions posed by different models may appear contentious in a modern cognitive perspective. Conventionality is usually understood as a result of iterative use of certain linguistic forms and, as such, appears to be a function of intention in a broad (and technically cognitive) way. It is not just a feature of straightforwardly institutional use, as in naming a ship or christening, where people are expected to recite formulae which may well be devoid of communicative meaning and interpersonally may sound as just empty words. Illocutionary convention (in the Austinian sense) is also supposed to be something more than a trivial feature of language, which allows that linguistic expressions are understood. Austin's conventions, and especially illocutionary conventions, appear to be both common and dynamic. They allow for performance of acts which are publicly recognised, but they include both depleted institutional formulae, recited by authorised speakers, and more interpersonal speech acts, such as promises, invitations, and requests. This

\footnotetext{
${ }^{217}$ For a critical discussion of this view see e.g. Bach and Harnish 1979: 132-134.

${ }^{218}$ Paraphrasing Sadock's "I love chocolates" example, saying "I love roses" on receiving a bunch flowers will in most cases be received as a "thank you", but it may also be an expression of other functions, for instance of criticism.
} 
perspective has been lost in most of the models of speech act theories that have been put forward after Austin's theory.

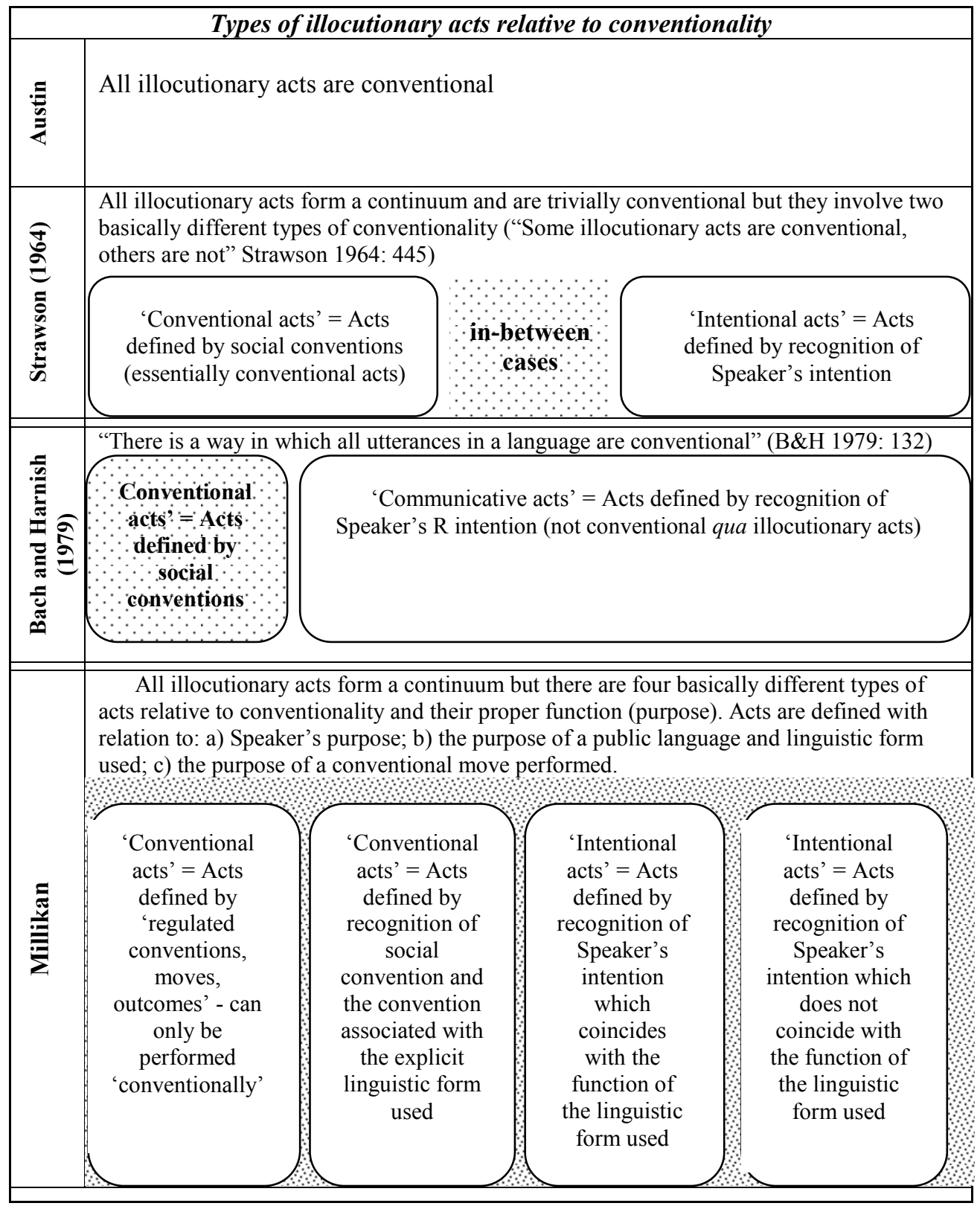

Table 16: "Conventional" acts juxtaposed to other acts in selected models of speech act theory 
Returning to the concept itself, due to the fact that linguistic conventions are necessarily relevant both to speakers and hearers, the relation between intention and convention is even more complex. For instance, the received view of speech act theory suggests that for the (probably) most prototypical act of promising, the object of the promise has to be something desired, or at least in the interest of the addressee (cf. Austin 1962/1975; Searle 1969). In addition, the speaker should "mean well", i.e. should have the intention to fulfil the promise. However, as well illustrated by Culler (1981), there may be cases in which the addressee apparently wants the promise to be fulfilled, but internally dreads what is to happen. Similarly, an intended threat may be turned into a promise if what is to happen is in fact part of the addressee's desires, however unconscious. Context plays a major role in speech act processing and it may not always (or not at all) be possible to specify a priori all sufficient conditions for a successful performance of an act. There are thus further dimensions of the relation between intention and convention in speech acts in need of investigation.

The existing theories, or rather different models of speech act theory, discuss a number of conventions relating them to speech acts. It is generally accepted that language is necessarily conventional in a trivial sense as otherwise it would not be understood by interlocutors and that totally private languages cannot exist in a social world; certainly not as systems intended for communication. There are then locutionary conventions, which in Austin's theory are shown to relate to sense and reference of utterances, i.e. semantic matching of words used and their 'objective' meanings and referents. Beyond the locutionary conventions, there appear to be illocutionary conventions, which can be conceived of as norms and rules for functional moves in the social world. Such illocutionary conventions may be (partially) identified with Morgan's (1977/1978) conventions of usage which secure a function. Locutionary and illocutionary conventions may merge, which is well exposed in the case of idioms. Austin's insistence on conventionality of illocutionary acts as distinct from conventionality of the locutionary aspect of a speech act, may be perceived as an attempt to elucidate the functional dimension of language with focus on how society defines functional units in communication. There is a need then for rethinking the conventionalist vis-à-vis the intentionalist debate and, possibly, on a more metalinguistic level, for a clearer classification of speech act theorists with regard to their understanding (and application) of the notions of convention and intention that they exercise in their theoretical models.

One possible starting point for a further discussion may be the idea that linguistic conventions and speech act, or illocutionary conventions are not absolute. As Millikan (2005a: v, et passim) points out, linguistic rules in general cannot be seen as "mere uniformities", which is richly manifested in the frequency with which people break them, whether on lexical, syntactic, or other levels. It seems reasonable that speech acts inherent in language should be similar in this respect. Speech act conventions cannot be separated from purely 
linguistic conventions (if such conventions may be conceived of), and from social or cultural conventions. Language, a social phenomenon, merges distinctions between these facets related to social life and both Austin's illocutionary conventions, and Millikan's speech act conventions, are better thought of as norms of relatively dynamic nature. Actions can be recognised only with reference to established patterns of behaviour, whether by abiding by explicit or implicit norms, or by violating them. As most aspects of social life, they are accessible only in approximation, and can be characterised (and exist) as dynamic entities with fuzzy boundaries.

Different theoretical models show varied ways in which researchers pursue stabilising the position of illocutionary force. Such attempts are labelled in various ways, as for instance "conventions of use" (Morgan 1978), "default rules" in relevance theory, conventionalisation by precedent (Millikan 2005a), "illocutionary standardisation" (Bach and Harnish 1979, Harnish 2010). All such notions usually involve a combination of both convention- and intention-related factors.

In summary, in many ways the juxtaposition of convention and intention is an oversimplification as all communicative acts involve both aspects, albeit in much varied configurations. Mastering a language involves learning how to understand intentions behind utterances and how the social world defines its institutions with all complexities involved. There is an evident parallel interplay of decoding and inferencing. Both these processes are interwoven and the difficulty in processing meaning is more directly associated with familiarity of a certain form/function relation than with surface explicitness, as well documented in experimental pragmatic research ${ }^{219}$. Linguistic utterances can be recognised as signs of action parallel to non-linguistic forms of behaviour ${ }^{220}$, which are (at

\footnotetext{
${ }^{219} \mathrm{Cf}$. research results related to indirect speech acts, from Morgan (1977/1978) to relevance theorists (e.g. contributions included in Noveck \& Sperber 2004) and research on formulaic language (e.g. Wray 2002 and the edited volumes: Corrigan et al. 2009a/b; Wood 2010), or the most quoted example of "Can you pass me the salt?", which has been shown to be direcly processed as a request.

${ }^{220}$ To some degree, this view is in agreement with the general relevance theoretic perspective on communication (Sperber and Wilson 1996/1995, Carston 2002), in which language is just one of the many systems which make communication possible, albeit the most explicit one. Producing utterances speakers make ostensive stimuli which their audiences have to process, but there seem to be no reason why processing of linguistic stimuli should be significantly different from processing of other signals, for instance gestures. In this post-Gricean model, language is special as the most effective system of detailed communication, but inference, and not decoding, is in the very centre of communicative phenomena, and especially natural everyday communication. It would be interesting to try and confront Austin's understanding of conventionality of illocutionary acts vis-à-vis the relevance-theoretic decoding/inference distinction. Austin's interests in speech act theory are at least partially convergent with Gricean and neo-Gricean approaches to nonnatural meaning and meaning "beyond words" (e.g. for many speech act, the illocutionary aspect is identified with meaning "beyond" the literal meaning). Significantly, where Grice and his followers would concentrate on intention (inferences guided by the Cooperative Principle and the
} 
least according to Austin 1962/1975) also "conventional", i.e. people can understand both linguistic and parallel non-linguistic actions through recognition of relevant conventions.

One of the aspects of conventionality that Austin mentions, but dies not elaborate, is reciprocity of speech acts. Although he asserts that "many illocutionary acts invite by convention a response or sequel" (Austin 1962/1975: 116), most of the examples that he discusses are approached as "little orphans", to use Goffman's (1976: 276) phrase which originally referred to non-dialogic approaches. Neglecting reciprocity seems important in the context of illocutionary conventionality. Some aspects of such conventionality has been accounted for by Millikan, who advocates coordination patterns for speech acts. The interactive perspective on speech acts shows conventionality as an aspect of biologically-motivated functional units, which memetically proliferate by imitation.

In summary, conventionalisation is a scalar phenomenon, selected utterances, as Strawson (1964) suggested, may "exhaust" their meaning by being explicit, but it must also be noted that even nonce meaning can be understood thanks to convention. The mechanisms of processing nonce meaning (possibly a function of regularities present on varied occasions) and its reliance on convention still remains to be elucidated.

As Morgan pointed out (in a self-critical manner), there has been "a hallowed linguistic tradition in carefully avoiding saying what $[\ldots$ is] meant by 'convention'" (Morgan 1977: 31). As a result, Austin's convention, possibly in the sense that an act "could be made explicit by the performative formula" (Austin 1962/1975: 103), or his examples of verbal actions parallel to conventional non-verbal behaviour (e.g. doing obeisance), as well as his distinction between "kicking a wall and kicking a goal" (Austin 1962/1975: 107), can today be juxtaposed with general concepts such as "knowledge of shared habits" or "common knowledge of the way things are done" (Morgan 1977: 31), or " a great body of language lore" (Levinson 2000: 23). It remains yet to be discovered whether Austin's conception of conventionality of illocutionary acts, having been analysed against other notions, will be finally elucidated and will prove methodologically important.

maxims), Austin would discuss the function for the utterance with the use of the notion of convention. 


\title{
CHAPTER FiVe
}

\section{From SPEech ACTS To SPEech ACTIONS (AND BACK)}

\begin{abstract}
"Good morning!" said Bilbo, and he meant it. "What do you mean?" [Gandalf] said. "Do you wish me a good morning, or mean that it is a good morning whether I want not; or that you feel good this morning; or that it is morning to be good on?" "All of them at once," said Bilbo. (Lord of the Rings by J.R. Tolkien)
\end{abstract}

\subsection{Introductory remarks}

Research into speech acts has followed varied paths. One way to look at its development, next to the "convention-to-intention" approach is to follow a shift from a more sociological and philosophical perspective, through focus on linguistic expressions, their form and illocutionary potential, and back to a broad socio-pragmatic approach analysing speech events rather than singular acts. The final all-embracing perspective may in turn be seen as a come-back to, or a renewal of Austin's original agenda to elucidate "the total speech act in the total speech situation" (Austin 1962/1975: 147). This circle from single utterances to situated speech events is reinforced with an interest in cognitive science and a view of language in terms of a biological phenomenon. A touch of such a perspective, with an ambition to be a full-fleshed science, is present in Millikan's model of speech acts, and in perspectives on language taken by, inter alia, Burge (e.g. 2007 [1975]), as well manifested in his understanding of linguistic convention (cf. section 4.2). In the present chapter, further models suggested for speech act-theoretic accounts which include broad contextual information are discussed with focus on the concept of pragmemes. 
Although pragmemes should not be readily identified with speech acts, in linguistics and the philosophy of language, there is a rather independent discussion of memes and pragmemes as relevant for speech act theory. The biological concept of memes is explicitly present in Millikan's theory of language (cf. e.g. Millikan 2005a: 199), has been developed into a functional linguistic model with "pragmemes" by Mey $(2001,2006)$, and elaborated by researchers in different fields of language studies (e.g. Capone 2010c and the papers within $\left.{ }^{221}\right)$. This renewed perspective on linguistic action commonly refers to cognitive concepts, such as memes, situatedness, and affordance.

\subsection{The concept of situatedness and affordance}

The concept of situatedness arose in the 1980s, mainly in cognitive studies, initially as a reaction towards what is now known as a classical view of mind, an orientation dominant at the time. The classical approach can be traced back to the science tradition, and especially to logic and mathematics. At the core of the idea of situatedness there lies the belief that cognition should not be understood as just "individual", "rational", "detached", and "abstract". In other words, cognitive issues should not be focused on a solitary person, a conceptual thought should not be approached as the best exemplar of cognition, thinking should not be considered as detached from perception, and the immediate physical environment, first of all should be taken into account, and then should not be considered as only of secondary significance. The novel approach associated with the label of situatedness argues that in consideration of human cognition, physical environment is of primary importance and plays an essential role in shaping cognition and experience. The renewed approach is also much more modest in that it recognises limitations which may indicate that cognitive science at large may not be able to provide a thorough description of all universal principles which govern cognition and which would be relevant in the context of all individuals ${ }^{222}$.

The concept of an affordance, in turn, was coined ${ }^{223}$ by the perceptual psychologist James J. Gibson $(1977,1979)$ and introduced in 1977 in his article "The theory of affordances", later elaborated in his book The Ecological Approach to Visual Perception. Gibson's original explanation of the concept points to the mutual complementarity between an animal and the environment,

\footnotetext{
${ }^{221}$ All contributions in the edited collection (Capone 2010c) are focused on the concept of pragmemes as analysed with regard to different linguistic and anthrophological issues, cf. a critical introduction by Capone (2010b) and further articles, especially: Seymour (2010), Mey (2010), Kecskes (2010), Jaszczołt (2010), Montimy (2010), Allan (2010), Capone (2010a), and others.

${ }^{222}$ Cf. e.g. MITECS, entry: "situatedness".

${ }^{223}$ As Gibson (1979: 127) explains: "The verb to afford is found in the dictionary, but the noun affordance is not. I have made it up."
} 
i.e. between an individual entity and what the environment in which the entity lives "offers", "provides", or "furnishes". Physical affordances in the natural world can be represented by, for instance, a floor or ground being "stand-on-able" and permitting un upright posture for some animals and human beings, with other its affordances being "walk-on-able" and "run-on-able", but not "sink-toable" as water could be (cf. Gibson 1979: 127-128). Air "affords" breathing and, more generally, respiration, a stone affords its being a missile, but also a paperweight. According to Gibson,

The different objects of the environment have different affordances for manipulation. The other animals afford, above all, a rich and complex set of interactions, sexual, predatory, nurturing, fighting, playing, cooperating, and communicating. What other persons afford, comprises whole realm of social significance for human beings. We pay the closest attention to the optical and acoustic information that specifies what the other person is, invites, threatens, and does.

(Gibson 1979: 128)

Gibson's affordances are action possibilities available in the environment to an individual; possibilities independent of the individual's ability to perceive them, but relative to the potential actor's capabilities. Thus, in relation to human beings, a scene's affordances are the limits of our actions. It is significant that Gibson's affordances are neither objective, nor subjective, but cross-cut the dichotomy and, as Gibson points, "helps us to understand its inadequacy" (1979: 129). Affordances "are always there" in the world, although they may pass unnoticed or may not be attended to.

In general, the theory of affordances rejects rigid classifications. Gibson emphasises that to learn or know how to use a thing, i.e. to know its affordances, does not mean to (be able to) classify that thing. He directly refers to Wittgenstein to praise his concept of "family resemblance" (Gibson 1979: 134), in the context of which there are no necessary and sufficient features which could define a class. Instead, there are various links between entities without any imposition of clear-cut taxonomies. Focusing on visual perception, Gibson shows that perception in general is economical, only features recognised as important, for instance to distinguish an object from other objects, are clearly perceived. In this aspect, Gibson's ideas are convergent with contemporary contextualist positions, for instance with the perspective accepted by relevance theorists, who understand linguistic perception in a similar way (cf. Sperber \& Wilson 1986/1995).

Gibson's ideas offer much, and have proved formative, also in the context of speech acts. The orientation is also presented as a radical departure from "existing theories of value and meaning" (140) and as an exposition of the two 
notions in a new light ${ }^{224}$. In this perspective, meaning and value are not just associated; perception itself, when it happens, is a perception of a "value-rich ecological object" (140). Perception presupposes that all that is perceived has some affordance for benefit or injury to someone, just because perception and affordances belong in ecology, and not just physics. They are said to be neither physical, nor phenomenal; affordances are properties taken with reference to the observer.

Behaviour affords behaviour, and human speech is inherently connected with "nested" sequences of events, produced by people. Understanding such nested sequences should thus allow an insight into why in certain contexts, "the outcome of an event sequence is implicit at the outset - how the end is present at the beginning - so that it is possible to foresee the end when the observer sees the beginning" (Gibson 1979: 102).

The concept of an affordance can be of crucial importance in speech act theory because affordances, being the product of perception, are not just internal representations (beyond the trivial sense of the expression). Perceiving them, human beings may bridge the gap between perception and action as they involve a kind of "functional colouring". Action possibilities are presented as latent in the environment, objectively measurable, and independent of an individual's ability to recognise them. However, at the same time, they are always related to the actor and therefore dependent on particular actors' capabilities.

In language studies, situatedness, often referred to as sociocultural situatedness, usually refers to the way in which individual language users process information. In other words, it denotes "the way(s) in which individual minds and cognitive processes are shaped by their being together with other embodied minds, i.e. their interaction with social and cultural structures, such as other agents, artifacts, conventions, etc. and, more particularly $[\ldots]$ with language itself" (Frank 2008:1).

In speech act theoretic studies, the "situated" perspective has been propagated by Jacob Mey. As has been indicated in earlier sections, Mey (2001: 219) claims that "[s]peech acts in order to be effective have to be situated. That is to say, they both rely on, and actively create, the situation in which they are realized" (original emphasis). Mey emphasises the intuitively known fact that speech acts, "in themselves, are not 'real'; they have to be situated in reality, that is, in the context in which they were produced" (Mey 2011: 171). In this perspective, there is a kind of strong and inherent dynamicity in the relation between the context and the words uttered, which influence each other. The words create and co-create context, while the context may give particular significance to the words (whether spoken or written). The active influence of context is particularly visible in the case of indirect speech, when words acquire

\footnotetext{
${ }^{224}$ Gibson also points to the inadequacy of the Shannon-Weaver model of communication, which may serve as a useful framework for measuring telephone exchanges, but is insufficient as a model for natural communication and perception of information in the world (cf. Gibson 1979: 242-243).
} 
context-dependent meaning thanks to the environment in which they function, but it is also an omnipresent factor in defining the function of an utterance.

Mey (2011) emphasises the fact that the present-day concept of situatedness is in agreement with Austin's (1962) original thought as expressed in the 1950s in his lectures. This approach shows that words may "create", or trigger the (right) context, or may be semantically saturated by the context (as in the case of many indirect expressions). As Mey suggests,
A so-called indirect speech act is what the context makes it to be - not necessarily what the words spoken express by themselves; vice versa, a speech act (broadly: an utterance) may create the context for which it is appropriate. In international negotiations, for instance, the diplomatic speech acts are the instruments creating the final document, the communiqué or diploma, on which further negotiations are deemed to build; the felicity conditions for such acts cannot be captured by simplistic principles such as 'sincerity' or by universal maxims such as 'quantity' or 'quality' [...].
(Mey 2011: 171)

Thus, situatedness respects both the conventional force of words, phrases and utterances and the creative power of context. There is a wide array of relevant examples. On the one hand, an illustration of an extreme context in which words are ascribed essentially literal power, is, for instance, taking the presidential oath as demonstrated in the situations when Barack Obama was sworn as President. Significantly, on both occasions when the event took place (in 2009 and in 2013), Barack Obama repeated the ceremony in order to avoid any contention with regard to felicity conditions of the ceremony indicating the social power of the exact formula. Another example of the presupposed connection between words and reality can be seen in security measures which dictate that even joking about terrorism on the part of travellers must be taken as serious matter by American airport authorities ${ }^{225}$.

In the case of selected indirect speech acts, in turn, it may be the case that although the verbal input is scarce, or formally imperfect as an utterance or a sentence, as, for instance often happens in requests, the words can be significantly powerful and invite immediate inference of the "right" meaning, despite that in other cases related expressions may have very strong "intrinsic" meaning and can "override the situational aspects" (Mey 2011: 174) 226 . There are further situations in which people are "instructed" about the meaning of linguistic forms, as in contexts of subordination, such as in the church or in the

\footnotetext{
${ }^{225}$ A related example is discussed by Mey (2011).

${ }^{226}$ Mey (2011) illustrates the point by referring to a situation in which knowledge of contextual factors, such as, for instance, that our interlocutor confuses 'right' and 'left', may lead to a nonliteral interpretation of certain utterances (e.g. "Turn right") which in other contexts would immediately be processed as literal.
} 
army, even though, naturally, these two contexts may differ in their axiological aspects. In politics and diplomacy, also, it is not expected that interlocutors will apply standards recognised for everyday conversation, and in formulating their judgment of such exchanges the critics must take this fact into consideration. For instance, international negotiations, if they are to be rightly interpreted, must be understood within a broader frame of a relevant political situation within which speakers' communicative intentions may be multifold and "layered", different for the "local", and for the more "global" contexts with "messages" transcending the most immediate settings.

In general, thus, situatedness reminds us that context is dynamic and crucial in inferring meaning in general, and in interpreting speech acts in particular. It is stressed that no speech act can be real until is it "situated" in reality. It seems that this emphasis on the role of context in (situated) speech act recognition motivated Mey's (e.g. 2001) emphasis on the fact that they are "pragmatic acts" (rather than "speech acts"). This quality may seem self-evident, especially when it is remembered that Austin called speech acts phrased in the canonical form "masqueraders" (1962/1975: 4), but, in reality, it has been often ignored by researchers over the years. In linguistics, and in speech act theory in particular, there may still be felt a tacit belief that it is possible to give a through and a universal account of speech acts with a transparent match between certain forms and meanings in a (maximally) decontextualised account.

Situated speech acts are "situated" in context. In turn, context is understood as a dynamic structure, "an active and creative, indeed proactive portion of the entire situation" (Mey 2011: 178), which itself is simultaneously permeated and co-created by relevant societal conditions.

One of the advantages envisaged in the context of approaching speech acts as situated speech acts, being "pragmatic acts", is that this perspective invites interpreters to perceive such acts not only in terms of the immediate conditions associated with the form of the utterance in question, such as for instance sincerity conditions and relevant speaker's intentions, but within a wider context in which the utterance itself, and the speaker are part of the situation being considered. In such situations, speakers, as animals in natural habitat, can exercise some freedom, but are also constrained in what they can achieve; they have to face their affordances.

\subsection{Speech acts, pragmemes and linguistic communication}

Another concept built on ideas adopted from natural sciences is that of pragmemes. A pragmeme is a type of act and its name is derived from the concept of the meme as introduced by the British evolutionary biologist, Richard Dawkins, and elaborated in his book The Selfish Gene (1976). Incidentally, Dawkins explains the origin of the name for a unit of cultural transmission in a 
way which is somewhat reminiscent of Austin's justification of adopting his metalanguage $^{227}$ :

We need a name for the new replicator, a noun that conveys the idea of a unit of cultural transmission, or a unit of imitation. 'Mimeme' comes from a suitable Greek root, but I want a monosyllable that sounds a bit like 'gene'. I hope my classicist friends will forgive me if I abbreviate mimeme to meme* If it is any consolation, it could alternatively be thought of as being related to 'memory', or to the French word meme. It should be pronounced to rhyme with 'cream.'

(Dawkins 1989 [1976]: 192) 228

Originally, memes, being units of cultural transmission, include "tunes, ideas, catch-phrases, clothes fashions, ways of making pots or of building arches" (192). Memes are presented as self-replicating brain structures similar to selfreplicating genes being DNA structures and gave rise to a study known as memetics. They propagate within their meme pools once planted in the brains of particular people and can be realised physically (cf. the belief in afterlife which is physically "realised" in the brains of many people). It is also being indicated that "[c]ultural transmission is analogous to genetic transmission in that, although basically conservative, it can give rise to a form of evolution" (Dawkins 1989 [1976]: 189), which suggests that pragmatic competence may be passed to further generations in a manner which can be similar in some aspects to genetic transmission, even though "[1] anguage seems to 'evolve' by nongenetic means, and at a rate which is orders of magnitude faster than genetic evolution" (189). Fecundity of particular records, rather than their longevity, will define the propagation success of the meme.

A theoretical model which allows for situated speech acts, seems to basically invite two-level analysis, or in other words, it imports a new higher level of interpretation. On the basic level, an utterance is interpreted as a speech act, and the focus is on its form, while the higher level will place it in a wider frame of a relevant socio-cultural situation. As May suggests, "an act of promising" may be construed as a promise, or as a threat, depending on the situation.

It may be tempting to see this higher level interpretation as corresponding to Austin's notion of perlocutionary act, but it seems that there is more to its

\footnotetext{
${ }^{227}$ Cf. Austin's passages on his choice of speech act-theoretic metalanguage in lecture one, e.g. "Formerly I used 'performatory': but 'performative' is to be preferred as shorter, less ugly, more tractable, and more traditional in formation." (Austin 1962/1975: 6, fn.3).

${ }^{228}$ In 1988 the word meme joined the official list of words being considered for future editions of Oxford English Dictionaries (Dawkins 1989: 322); the word was followed by its derivatives, e.g. memeplexes or memeoids. Now dictionaries include also the concept of the internet meme, which is defined as a typically humorous image, video, piece of text, etc., copied and spread rapidly by Internet users, often with slight variations.
} 
definition and the difference between the two concepts is significant. First of all, it is claimed that pragmemes may be both of illocutionary and perlocutionary type (cf. Mey 2001, Capone 2005, Allan 2010). In addition, according to Austin, perlocutionary effects are supposed to be non-conventional and, as such, largely unpredictable, while situated speech acts still seem to focus on what is expected (and the meaning that can be worked out) when a broader context enters the scene. Thus, situated speech acts are better seen as an alternative model for speech act analysis, or better: "speech act-theoretic" analysis, which enriches their description by introducing a consideration of speaker's affordances, affordances defined by the context in which utterances are produced. The context of an utterance will define, and in fact will pre-determine what the speaker can say and in which form. The context is "pro-active" because it endows the speech act with its value and validity. Next to being "in" context, linguistic acts are also actively "situated" and "conditioned" by it, as especially evident in indirect speech acts. All speech acts are both situated and situating. To reiterate, "[s]peech acts in order to be effective have to be situated. That is to say, they both rely on, and actively create, the situation in which they are realized" (original emphasis) (Mey 2001: 219).

The model which accepts pragmemes can also be seen as an elaboration of earlier attempts to embrace "more detailed" contextual information in speech act-theoretic studies. As can be seen in Figure 9, selected elements present in the new approach were also quoted in Verschueren's (1987: 132) chart for a holistic analysis of LAVs (i.e. Linguistic Action Verbs, cf. chapter three), which lists both psychological, and socio-institutional elements which combine to produce the situation in which the act in question is interpreted. The mirrored structure of the speech event is to represent the conditions or properties $(\mathrm{C})$, under which a verb $\mathrm{V}$ can be appropriately used in a description $\mathrm{D}$ (the right-hand side) of a linguistic action A (the left-hand side of the diagram). Theh conditions are marked as $\mathrm{C}$ if they bear on $\mathrm{A}$, and as $\mathrm{Cd}$ if they are related to $\mathrm{D}$.

The categories enumerated in the 1987 account include the "physical and social world", communicative intentions on the part of the speaker and communicative effects on the part of the hearer, as well as both the speaker's and the hearer's beliefs, attitudes and (general) intentions, i.e. culture-related factors. In addition, the model makes reference to the linguistic choices on the part of the speaker, which mediate between communicative intentions and communicative effects, and include the (potential) use of elements such as communication type, sentence structure, propositional content, etc. The sociocultural factors are integrated in the description with elements which are traditionally discussed in grammar-oriented accounts (e.g. sound feature, phoneme, morpheme, phrase). It should also be marked that elements such as "location" or "time" have been excluded as being of minor importance in conceptualisations of linguistic action in English and mainly active in metaphorical uses (cf. Verschueren 1987: 131). 


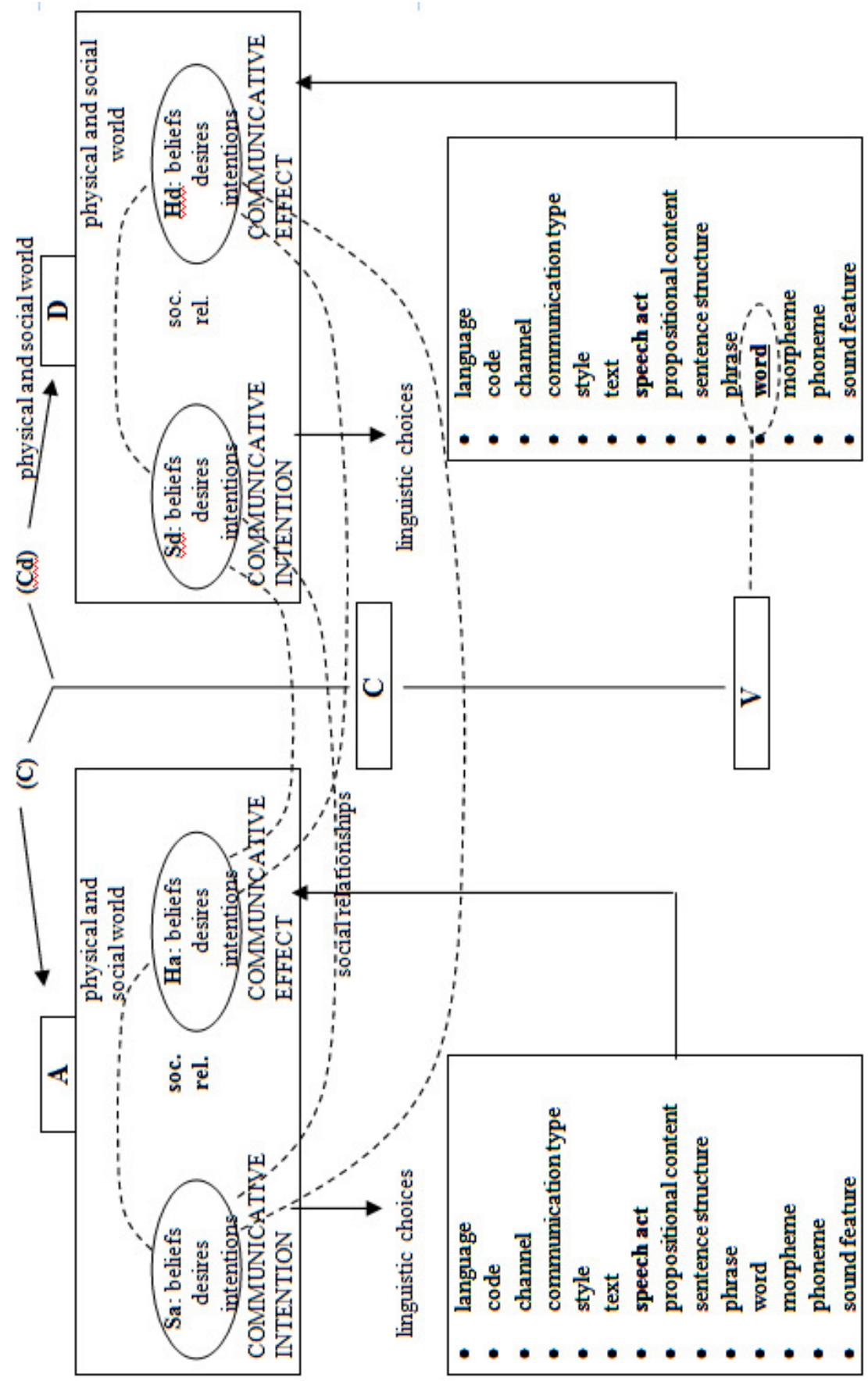

Figure 9: A general framewprk for a discussion of the meaning of linguistic action verbs (represented after Verschueren 1987: 132) 
Significantly, the "speech act" is mentioned among the metalinguistic categories, indicating that communicative action can "make use" of different speech acts in order to achieve particular goals.

It must be recognised that Verschueren's agenda in producing the chart was to provide "a workable, though partial, framework within which the meaning of LAVs can be discussed in a cross-linguistically and cross-methodologically comparable way" (1987: 131). However, this very approach would also place the model near Austin's original plan to account for speech actions through a meticulous analysis of how particular verbs are used in producing speech acts.

Verschueren's account also anticipates a description of speech acts in terms of their abstract equivalents, i.e. pragmemes as they are being referred to in the new model, and makes room for speech act pluralism, thus providing a link to modern theories in the philosophy of language (significantly both to semantic minimalists, and contextualists). Although Verschueren (in the discussed account) is primarily interested in verbs, while Mey's emphasis in analysing pragmemes is on linguistic action possibly in a more abstract sense, there are significant correspondences between their theoretical positions with regard to the problem of how to incorporate context-related information in a theoretical model. Their approaches are also convergent in perceiving "speech acts" as internal to speech actions (cf. Fig. 9 and Fig. 10).

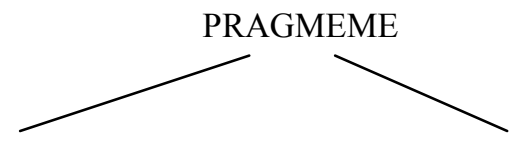

SPEECH ACTS

ACTIVITY PART

(iNTERACTANTS

INDIRECT SPEECH ACTS

CONVERSATIONAL ('DIALOGUE') ACTS

PSYCHOLOGICAL ACTS (EMOTIONS)

PROSODY (INTONATION, STRESS)

PHYSICAL ACTS:

BODY MOVEMENTS (INCL. GESTURES)

PHYSIOGNOMY (FACIAL EXPRESSIONS)

(BODILY EXPRESSIONS OF) EMOTIONS

$\ldots$

$\varnothing($ NULL)

PRACT
TEXTUAL PART

$(\mathrm{CO}(\mathrm{N}) \mathrm{TEXT})$

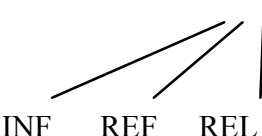

REL

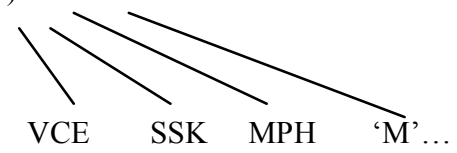

\section{ALLOPRACT}

Figure 10: A schematic representation of pragmeme, pract and allopract

(adapted from Mey 2001: 222) 
In Figure 10, the list included on the left-hand side of the diagram corresponds to various choices, options which a language user may exercise (or not) in a communicative situation. If the speaker decides not to use any of the listed options, the situation may be that of "silence", possibly meaningful silence. The abbreviations on the right correspond, subsequently to "inferencing" (INF), establishing reference (REF), relevance (REL), voice (VCE), "shared situation/dialogue knowledge" (SSK), metaphor (MPH), and "metapragmatic joker" (M), which, when present, indicates something taking place on the metapragmatic plane. In Mey's configuration (Fig. 10), the concept of pragmemes, just like that of situatedness and an affordance, is also derived from natural science and treated as a natural science category, while the terminology used corresponds to the distinctions made in phonology (cf. phone, allophone, phoneme) and morphology (cf. morph, allomorph, morpheme). A particular way of apologising, an instance of it, a token, constitutes a "pract", which shares certain characteristics with all the "allopracts" of the same abstract "pragmeme", the pragmeme of apology. As Capone (2005) put it,

A pragmeme is a speech act - an utterance whose goal is to bring about effects that modify a situation and change the roles of the participants within it or to bring about other types of effect, such as exchanging/assessing information, producing social gratification or, otherwise, rights/obligations and social bonds. [. . . ]

A pragmeme is a situated speech act in which the rules of language and of society synergize in determining meaning, intended as a socially recognized object sensitive to social expectations about the situation in which the utterance to be interpreted is embedded.

(Capone, 2005:1357)

Thus, understanding a pract (which shares certain characteristics with its allopracts) and recognising it as a pragmeme requires both linguistic (if there is linguistic input) and broader, extra-linguistic, social skills. For instance, to understand

I am sorry, my car broke down.

as an apology, the understanding of the literal meaning of the sentence must be enriched. Success in such enrichment will depend on the audience's knowledge of relevant social and cultural conventions as well as on the cognitive principles which govern human thinking. In order to explain the phenomenon, Allan (2010) suggests that understanding of speech acts involves a kind of "social default",229.

\footnotetext{
${ }^{229}$ Allan (2010) imports the idea from Jaszczołt's theory of default semantics (cf. e.g. Jaszczołt 2005, 2009). In fact, Allan's proposal is by his own admission contentious, as the concept of "social default", when applied at this level, may altogether oust the notion of the pragmatic act.
} 
In other words, speech acts may be seen as actions which propel the potentially indefinite transformations of context. It may be claimed that it is only within the dynamic structures of context that both the speaker and the interpreter can skilfully manage and make convergent certain elements of their context so that successful communication can take place.

On a different note, it is debatable whether Mey's is an intentionalist approach. For instance, Montminy (2010) judges it as anti-intentionalist, but Capone (2010a: 2865) expresses a contradictory view and claims that the pragmeme approach does not involve an anti-intentionalist perspective. In the context of pragmemes, the intentionalist perspective may in fact be presented as entirely inadequate. As other people's minds and their intentions are not directly accessible to us, in ascribing certain intentions to our interlocutors, we necessarily proceed from the situation to the speaker's intentions. The view has certain consequences. So when Stanley $(2007: 44)^{230}$ argues that a cry:

Water!

is an utterance whose illocutionary force is indeterminate, not "a genuine linguistic speech act" in fact, Capone (2010a) would suggest that it is indeed accessible thanks to the fact that the utterance is performed in a particular context, for instance in a desert situation. A side effect of such a perspective is that pragmemes may save speech act theory from being usable only for limited data, providing room for embracing non-sentential utterances.

In cases of situated meaning, the clues which hearers have to use in order to understand an utterance are many and of varied nature. However, as the meaning of linguistic forms, such as "Water !" as discussed above, are heavily contextdependent, there is, in consequence, no way of securing the purity of the relation between a particular form and one meaning. Seemingly fossilised standard forms may invite their own internal "othering".

There is a touch of (social) institutionality in Mey's account of pragmemes, while in Millikan's model (cf. chapter four), the concept of the meme is elaborated in a more "biological" way with emphasis on "lineage". As Millikan suggests,

[w]ider context may always suddenly be needed for interpretation-needed in order to make it clear from which lineage of tokens this token has been copied, hence which is its true memetic function. Understanding the semantics of a linguistic form never reduces merely to decoding.

(Millikan 2005a: 202)

\footnotetext{
${ }^{230}$ Cf. Putnam's (1975) Twin Earth and his version of externalism; cf. also Burge (1979); For Stanley (2007: 44-45), only speech acts with determinate (non-ambiguous) illocutionary force are genuine speech acts.
} 
There are numerous other researchers who emphasise that the meaningful match between the form and the function of linguistic utterances is a product of imitation of memes (e.g. Blackmore 1999), who typically, like Millikan, elaborate on Dennett (1991), but in the context of the Austinian theory, the most significant feature in this direction of research seems the renewed emphasis on the "total speech act in the total situation".

\subsection{Pragmemes and the ethnomethodological approach}

Pragmemes seen as abstractions of acts of communications, integrate the ethnomethodological perspective with the traditional approach to speech acts, and with modern cognitive theories. The explicitly "situational" turn in speech act analysis is best seen as convergent with ethnomethodological tradition (e.g. Turner's 1974 collection; Garfinkel 1967/1984; 1972) in linguistics research, which itself, by emphasis on interactional context, motivated research in the framework of conversational analysis. Next to the focus on interaction, there is also a methodological commitment to the effect that data culled from natural discourse can suggest categories relevant for analysis of that particular discourse. Thus, in ethnomethodology, it is only natural that a researcher should identify rather than "invent" relevant categories which will manifest themselves in how participants in a discourse use their language to perform different deeds while managing and reconstructing their social world.

There is a creative dimension in such an approach, linked to the "discovery" procedure. Significantly, nearly a hundred years ago, Sapir (1929) pointed out to the promising perspective of integrating linguistics with psychology ${ }^{231}$.

Linguistics may $[\ldots]$ hope to become something of a guide to the understanding of the "psychological geography" of culture in the large. In ordinary life the basic symbolisms of behavior are densely overlaid by cross-functional patterns of a bewildering variety. It is because every isolated act in human behavior is the meeting point of many distinct configurations that it is so difficult for most of us to arrive at the notion of contextual and non-contextual form in behavior. Linguistics would seem to have a very peculiar value for configurative studies because the patterning of language is to a very appreciable extent self-contained and not significantly at the mercy of intercrossing patterns of a non-linguistic type.

(Sapir 1929: 2012)

\footnotetext{
${ }^{231}$ It may be noted, however, that Sapir concentrated at the time on possible prospects in the field of Gestalt psychology (cf. Sapir 1929) and the input that the study of language might offer. Significantly, in Sapir's opinion, "of all forms of culture, [...] language is that one which develops its fundamental patterns with relatively the most complete detachment from other types of cultural patterning" (1929: 212).
} 
Sapir thus sketches a positive view in which linguistic performance is seen as most structured, endowed with most ordered and transparent patterning of all symbolic systems that human beings use. There is thus a potential to arrive at the emic picture of linguistic action, which should emerge on the basis of etic analyses of particular instances of linguistic behaviour. This picture may well be applied to analyses of speech acts in their situational frames with the use of categories such as speech situations, speech events, and, traditionally, speech acts. The programme of integrating culture, language and thought in one analytic framework in order to elucidate, to use Austin's term, how people do things with words, may however, be as interesting, as difficult a task. If speech acts are seen in the broadest possible perspective, and their meaning is to be the function of convention, conceived of in terms of a social disposition, the number of variables in a relevant research study may be too high. In turn, the most basic assumption behind ethnomethodology, and indeed, explicitly in Sapir's approach, is that the "lawlessness" of social phenomena is only apparent. Thus, abandoning a narrowed perspective, and opening research programmes to dynamic data (and categories) of social, ethnic, political, etc. kind, may prove effective and inform our understanding of the internal and relational structure of linguistic actions.

\subsection{Preliminary conclusions}

The concept of pragmemes was introduces in order to renew the speech act theoretic perspective and to provide a more holistic account of functional uses of language with a direct reference to Austin's programme to elucidate "the total speech act in the total speech situation" (Austin 1962/1975: 147). This holistic programmes, apart from the lectures edited as How to Do Things with Words, was also strongly emphasised in Austin's other papers, e.g. in "How to Talk" (1970: 134-153), which explicitly addressed the concept of the "speech situations" as important in understanding and classifying speech acts.

A description in terms of pragmemes emphasises elements of context (cf. Fig. 10) which, in other accounts, are taken for granted, understood as background information, shared information, or common ground. Such a description also points to contextual factors such as power relations and speakers' plans which transcend the "local" domain, external influences, and emotions. However, including theses elements in the descriptive schema does not automatically allow for a better theoretical description of speech acts, or "pragmatic acts" as they are being referred to.

It is not always clear how pragmatic acts differ from speech acts, although the pragmatic act is presented as a wider concept, which may include a speech act, or a number of (internal) speech acts. The distinction remains to be defined 
in more detail and it may be difficult to accommodate it within the original approach.

Against the background of Austin's theory, pragmemes are better seen as reconfirmation of the basic assumptions voiced in the Austinian account with its emphasis on dynamicity, sensitivity to context, and mereology of forms and acts. In particular, pragmemes will not help to elucidate either the internal architecture of the speech act in general, its three-fold nature, not will they clarify more detailed classifications. What they successfully do is show speech acts in the context of the social world with emphasis on the biological constraints on communication. Thanks to the reference to natural sciences, acts of speech are presented as natural products of evolution, and language as one of many interacting elements in nature. This "natural" view embraces the "social", unlike "pure biological" perspectives which emerged, for instance, within generative linguistics.

It is a contentious issue whether speech acts should be locked for solely linguistic analysis, or whether they should be approached in a broader sociolinguistic and anthropological linguistics context. The scope of linguistics itself is sensitive to researchers' choices and commitments, and a pure linguistics analysis can well be a myth or, at least, (occasionally) a useful approximation. Speech act theory itself emerged along with the idea that language should be accounted for in terms of action performed in the socio-cultural frame.

A memetic (pragmemetic) perspective suggests that linguistic behaviour is copied in a broader semiotic manner and that the patterns which proliferate in most cases are already elaborate coordinate patterns, received and imitated as functional distinguishable units.

With regard to the problem of the choice between the intentionalist and the conventionalist approach, pragmemetic analysis naturally suggests a path from the external to the internal, i.e. within this approach, speaker intention is accessed through experience of available ostensive data, viz. the linguistic form of the utterance and its (non-petrified) context. Analysing context, interpreters need to deal with all kinds of uses, both more conventional, institutionalised uses and less conventional ones, for which they need more "creative" cues and clues (cf. Dascal 2003: 169ff).

In a way, the theory of pragmemes, being a return to "the total speech act in the total speech situation", is a reaffirmation of the functional approach in language studies. The approach elevates pragmatics to the highest position in communication studies, presenting it as an all-embracing field, which is reminiscent of Dik's positioning pragmatics as a framework within which semantic and syntactic problems should be studied (cf. Dik 1978: 4-5). In the context of pragmemes, Dik's functional perspective, despite the time that has passed from its formulation, still sounds relevant: 
In the functional view a language is regarded as an instrument which human beings use in order to achieve certain goals and purposes. These goals and purposes are taken to lie in the first place in the establishment of complex patterns of social interaction. Speakers use linguistic expressions to communicate messages to interpreters so as to change these interpreters in certain ways. The intended changes may be purely mental or emotional (as when the knowledge, the convictions, or the feelings of interpreters are modified), or they may be directed at effecting further changes in the projected practical activity patterns of the interpreters. [...] There is no point [...] in dissecting competence from performance, and study it in isolation (if that would be at all possible); for competence is competence-to-perform-incommunicative-situations, in other words: communicative competence (Hymes 1972), i.e. the ability to act and perform in given ways, with respect to given interpreters in given settings, and in relation to given communicative goals and purposes.

(Dik 1987: 83)

In this context it is interesting that speech act theoretic problems are typically classified as "micropragmatic" issues (e.g. Verschueren 1999), implicitly indicating that speech act theory focuses on particular utterances and speech act theoretic potential that individual sentences may have. Pragmemes, in turn invite a macropragmatic perspective. Another shift invited by the pragmemetic approach is that, encorporating speech acts into the theory of "pragmatic acts" and pragmemes, we produce a heavy-handed approach (cf. Neale's (2007) conception of "heavy-handed pragmatics"), which would tower over other disciplines. In summary, the speech action approach, which replaces "lighthanded" speech act theory in one way marks abandoning speech act theory, or its conception as it is commonly advertised in linguistics handbooks, but in a different way, it also marks a return towards Austin's original agenda to analyse "the total speech act in the total situation" (Austin 1962/1975: 147).

Characteristically, Austin's concept of the speech act once more proves influential in generating varied approaches, and in multiplying distinctions. The impact of Austin's speech act theory is not seen directly in what it offered as a full-fleshed model at the time of its formulation, but is more readily found in the paths of research that it suggested. 


\section{Concluding Remarks: Speech act theory: retrospects and prospects}

Taking Austin's formulation of speech act theory as central in speech acttheoretic research, it is evident that while the theory itself is taken for granted, its integrity across linguistics and philosophical studies is only alleged. As has been shown above, none of the tenets of speech act theory as formulated in Austin's works has been maintained as certain in a general picture. In fact, the only idea which has been able to survive over time is the very conception of linguistic performance, the belief that language can be used to perform (extralinguistic) actions. This, however, does not appear to be contentious nowadays and even at the time when Austin was formulating his theory, it was criticised as a doubtful discovery ${ }^{232}$.

As evidenced in chapter one, reflections on the actional nature of language have been present in theories as old as philosophy. It is also evident that neither Austin's theory, nor the models following his account, have been able to fully account for the nature of the actional character of language, which may also be related to the Austinian initial distinction between constative and performative utterances. If, as Austin eventually concluded, all utterances are performative in nature, then how to account for those which are evidently "more performative" than others? Does the actional character remain a methodologically important characteristic feature, which could at all be accounted for in a systematic way?

A similar question may be posed with regard to conventionality of illocutionary acts and, by extension, of speech acts $n$ general. The conception of conventionality as discussed by Austin has not been given a full definition, thus, it is not applied in a systematic way. Even when used in order to distinguish between different types of processing of speech acts, as it is the case in the

\footnotetext{
${ }^{232}$ Cf. e.g. Simpson's (2006: 1439, fn.10) astonishment at how H.L.A. Hart felt impressed by Austin's theory of the performative use of language, "in accordance to which certain actions (for example, promising) were performed by "speech acts," which he himself found an "obvious point".
} 
models suggested by Strawson (1964) and Bach and Harnish (1979), to name just the two best known applications, the concept is known only in approximation. Any attempt at widening the theoretical and methodological perspective results in a picture in which the notion is used in a variety of ways which suit particular "local" research needs.

Other key notions of speech act theory, such as that of uptake, of the speech act verb, or locution, illocution, and perlocution, have also been used freely to refer to different concepts across different speech act-theoretic models. Moreover, even the most explicit form of performative utterances cannot secure a stable and successful match between form and meaning because language, and consequently speech acts, are social and dynamic in nature.

It may thus appear that speech act theory, despite being referred to in all linguistics handbooks and in many research plans, is in fact non-existent and, if its existence is asserted, then (possibly even worse) the theory may appear to be of no methodological value. However, a much different perspective can also be adopted.

Instead of concentrating on how what we know as "speech act theory" fails as a holistic theory of speech acts, i.e. a theory able to neatly classify and account for how things are done with language, it should be more productive to see what a speech act-theoretic approach can offer, and what it does. First of all, speech act theory exposes interesting and important issues about language. It exposes the tension between the view which presents language as a defined system with clear-cut categories and recursive conventional elements, and the view of a system which is naturally dynamic and context-dependent. Accepted as an albeit imperfect, even incomplete, "meandering and chequered" (Loxley 2007: 10) research tool, speech act theory invites considerations of the functions of language not only to show what language is for in general, but it is also offers its potential to reveal complex differences in how people perceive the world and the differences in how they (constantly) structure and restructure social reality. Starting with linguistic utterances, this perspective opens the view on culture and social interaction in all its richness. Speech act theory is then a theory of social action, but also an ethnomethodological tool, where the data submitted for analysis may suggest relevant analytic categories. The freedom in adopting such varied categories is limited, but the flexibility which is involved, invites efficient research. As has been indicated in chapter three, the suitability of speech act theory conceived of in this way has already been proven in fields such as historical linguistics, intercultural studies, ethnolinguistics, and analyses of speech acts in semantically restricted domains, such as medicine or law.

The relevance of Austin's speech act-theoretic legacy can also be evidenced in different perspectives. In more extreme (and contentious) a view, Dawkins's concept of meme proliferation and his ideas related to copying fidelity may themselves be used to explain the history of speech act theory. As Dawkins claims (1989 [1976]: 189), "cultural transmission is analogous to genetic 
transmission in that, although basically conservative, it can give rise to a form of evolution". As a result, it could happen that Darwin would not be able to recognise Dawkins's theory as his, i.e. as being Darwinian, because of the evolution of the relevant meme which happened over time. In a similar manner, within this naturalistic perspective, speech act theory can be perceived as progressing and inviting some meme mutation, with only the core idea incorporated in the meme being preserved.

In conclusion, it is more efficient, and probably more accurate, to see Austin's legacy as posing questions and exposing ideas to be elaborated in different directions than in terms of a holistic theory of speech acts, which should either be praised or rejected. Just like the study of language in general, as suggested by Seuren (2009: xi), speech act theory has "a long past but not one that has been cumulative in the sense that results, once attained, become accepted doctrine".

In Austin's theory, too, some valuable and interesting insights have sometimes been lost, while more "blinkered" views would take over. Eventually, the speech act-theoretic perspective invites an intelligent view with emphasis on language as determined and constrained by the conditions of society. Speech acts (or actions), in turn, may be of different scope and impact. There are conventionalised forms whose functions tend to remain stable across varied contexts, and creative utterances with nonce meaning and force. There are also wide speaker plans which go beyond one utterance, or even one speech event with an "illocutionary" (or rather "perlocutionary") aims beyond particular local contexts. Whether approach "locally" or "globally", such actions can be subject to serious and reliable research with the use of speech act-theoretic methodology.

It seems justified to believe that Austin's interest was ultimately in speech acts of all scope, including "global" speech "actions", as his reference to elucidating "the total speech act in the total speech situation" (Austin 1962/1975: 147) would suggest. However, as he mainly cited isolated utterances (or sentences), related to conventional and institutional contexts, the notion of communicative acts, for which speech acts form a sub-class, has been developed alongside (lower rank) speech acts to mark interest in broader contexts. Following the discussion in chapter five, it must be accepted, however, that theoretical models which focus on actions rather than acts do not mark a real departure from Austin's agenda.

Eventually, linguists are confronted with speech act theory "dispersed" across different models, but able to produce an interface between different perspectives on how utterances and their meanings are managed by people who endow them with socially binding force. As the nature of the emergent performative force in linguistic utterances is as complex as the nature of social reality and culture, there are different "ununited" speech act-theoretic approaches suitable for different interests and research programmes. 
To reiterate, most of the tenets of Austin's speech act theory can be challenged and such challenges may produce interesting and valuable research results. This quality is relative to the fact that the theory operates on naturally dynamic social reality. Indeed, Austin's phenomenological formulation of speech act theory is a good illustration for Niels Bohr's aphorism (Bohr 1967: 328) that it is only for trivial truths that their opposites are obviously absurd; in contrast, it is the hallmark of any profound truth that its negation can also be a profound truth. 


\section{REFERENCES}

Aikhenvald, Alexandra Y. (2010) Imperatives and Commands. [Oxford Studies in Typology and Linguistic Theory] Oxford: Oxford University Press.

Alexander, Jeffrey C. (2004) "Cultural pragmatics: Social performance between ritual and strategy". Sociological Theory, Vol. 22, No. 4, pp. 527-573.

Allan, Keith (2010) "Referring as a pragmatic act" Journal of Pragmatics, Vol. 42, pp. 2919-2931.

Allen, James F. \& C. Raymond Perrault. (1980). "Analyzing intention in utterances". Artificial Intelligence, Vol. 15, pp. 143-178.

Allwood, Jens (1977) "A Critical Look at Speech Act Theory" In Logic, Pragmatics and Grammar, ed. by Dahl, pp.53-99. Lund: Studentlitteatur.

Allwood, Jens (1980) "On power in communication". In: ALVAR: a Festshift to Alvar Ellegård [SPELL I], ed. by J. Allwood \& M. Ljung. University of Stockholm, Department of English, pp. 1-20.

Allwood, Jens (1995) "An activity based approach to pragmatics", Gothenburg Papers in Theoretical Linguistics, 76, pp. 1-38.

Allwood, Jens (2001) "Capturing differences between social activities in spoken language" In: Perspectives on Semantics, Pragmatics, and Discourse: a Festschrift for Ferenc Kiefer, ed. by István Kenesei \& Robert M. Harnish. Amsterdam \& Philadelphia: John Benjamins, pp. 301319.

Alston, William P. (1963) "Meaning and Use" The Philosophical Quarterly, Vol. 13, No. 51, pp. 107-124.

Alston, William P. (1964) "Linguistic Acts" American Philosophical Quarterly, Vol. 1, No. 2, pp. 138-146.

Alston, William. P. (1994) "Illocutionary acts and linguistic meaning”. In: Tsohatzidis (ed.), pp. 29-49.

Alston, William P. (2000) Illocutionary Acts and Sentence Meaning. Ithaca, NY: Cornell University Press.

Anderson, Stephen R. (1971; reprinted 1976) "On the linguistic status of the performative/constative distinction" (ms; Harvard University \& Indiana University Linguistics Club, Bloomington, Indiana) Reproduced by Indiana University Press.

Anscombre, Jean-Claude, François Létoublon \& Alain Pierrot (1987) "Speech act verbs, linguistic action verbs, and delocutivity". In: Verschueren (ed.), pp. 45-67.

Aristotle (350 BC.) De Interpretatione, On Interpretation, translated by E. M. Edghill. Available online at The Internet Classic Archive http://classics.mit.edu/Aristotle/interpretation.1.1.html (accessed 27 June 2010). 
Aristotle. (1908) Nicomachean Ethics. [translated by William David Ross] Oxford: Clarendon Press. Available on-line at: http://nothingistic.org/library/aristotle/nicomachean/nicomachean 34.html (accessed May 2012).

Arnovick, Leslie K. (1999) Diachronic Pragmatics: Seven Case Studies in English Illocutionary Development. Amsterdam/Philadelphia: John Benjamins.

Asher, Nicholas \& Alex Lascarides (2001) "Indirect speech acts" Synthese, Vol. 128, pp. 183-228.

Astington, J.W. (1988) "Children's understanding of the speech act of promising”. Journal of Child Language. 15, pp. 157-173.

Atiyah, P.S. (1981) Promises, Morals and Law. Oxford: Oxford University Press.

Atkins, Beryl T., Judy Kegl \& Beth Levin (1988) "Anatomy of a verb entry: From linguistic theory to lexicographic practice". International Journal of Lexicography. Vol.1, No. 2, pp. 84126; doi: 10.1093/ij1/1.2.84

Atlas, Jay David (1989) Philosophy without Ambiguity. Oxford: Clarendon Press.

Austin, John Langshaw (1962/1975 2nd ed.) How to Do Things with Words. Oxford: Oxford University Press.

Austin, John Langshaw (1964) Sense and Sensibilia (Reconstructed from the manuscript notes by G.J. Warnock). Oxford: Clarendon Press.

Austin, John Langshaw (1970) Philosophical Papers $2^{\text {nd }}$ ed. [first published in 1961; ed. by J.O. Urmson \& G.J. Warnock] Oxford: Oxford University Press.

Avramides, Anita (2005 [1997]) "Intention and convention" In: A Companion to the Philosophy of Language, ed. by Bob Hale \& Crispin Wright. Oxford: Blackwell, pp. 60-86.

Bach, Kent (1975) "Performatives are statements too" Philosophical Studies: An International Journal for Philosophy in the Analytic Tradition, Vol. 28, No.4, pp. 229-236.

Bach, Kent (1994a) "Conversational impliciture". Mind and Language, Vol. 9, pp. 124-162.

Bach, Kent (1994b) "Semantic slack: What is said and more". In Foundations of Speech Act Theory: Philosophical and Linguistic Perspectives, ed. by S. L. Tsohatzidis. London: Routledge, pp. 267-291.

Bach, Kent (1995) "Standardization vs. conventionalization". Linguistics and Philosophy, Vol. 18, pp. 677-686.

Bach Kent (1997) "The Semantics-Pragmatics Distinction: What It Is and Why It Matters" In: Pragmatik: Implikaturen und Sprechakte, ed. by Eckard Rolf. Westdeutscher Verlag, pp. 3350.

Bach, Kent (1998) "Standardization revisited". In: Pragmatics: Critical Assessment, ed. by Asa Kasher. London: Routledge.

Bach, Kent (1999) "The myth of conventional implicature". Linguistics and Philosophy, Vol. 22, Issue 4, pp. 327-366.

Bach, Kent (2001) “You don’t say?”. Synthese, Vol. 128, No.1/2: Pragmatics, pp. 15-44.

Bach, Kent (2005) "Context ex Machina” In: Semantics versus Pragmatics, ed. by Zoltán Gendler Szabó. Oxford: Clarendon Press, pp. 15-44.

Bach, Kent (2006) "The excluded middle: Semantic minimalism without minimal propositions". Philosophy and Phenomenological Research, Vol. 73, pp. 435-442.

Bach, Kent \& Robert M. Harnish (1979) Linguistic Communication and Speech Acts. Cambridge, MA: MIT Press.

Bach, Kent \& Robert M. Harnish (1992) "How Performatives Really Work" Linguistics and Philosophy. Vol. 15, No.1, pp. 93-110.

Bakewell, Liza. (1998) "Image acts". American Anthropologist, Vol. 100, No. 1., pp. 22-32.

Bakhtin, Mikhail M. (1986 [reprint of 1975]). "The problem of speech genres". In M. Bakhtin, Speech Genres and Other Essays (ed. by Caryl Emerson and Michael Holquist). Austin: University of Texas Press, pp. 60-102.

Ballmer, Thomas T. \& Waltraud Brennenstuhl (1981) Speech Act Classification: A study in the lexical analysis of English speech activity verbs. Berlin/New York: Springer Verlag. 
Barker, Stephen (2004) Renewing Meaning: A Speech-Act Theoretic Approach. Oxford: Clarendon Press.

Barker, Stephen (2007) "Semantics without the distinction between sense and force". In John Searle's Philosophy of Language: Force, Meaning and Mind, ed. by Savas L. Tsohatzidis, pp.190-210. Cambridge: Cambridge University Press.

Bates, Elisabeth (1976). Language and context: The acquisition of pragmatics. New York: Academic Press.

Bates, Elisabeth, Luigia Camaioni, \& Virginia Volterra (1975) “The acquisition of performatives prior to speech". Merrill-Palmer Quarterly, Vol. 21, No. 3, pp. 205-226. [Reprinted in E. Ochs \& B. Schieffelin (eds.) Developmental pragmatics. New York: Academic Press (1979), pp. 111-128 and in Pragmatics: Critical concepts, edited by Asa Kasher. London: Routledge, 1998, pp. 274-295.]

Bauman, Richard (1977) Verbal Art as Performance. Rowley, Mass.: Newbury House.

Beaney, Michael (1997) The Frege Reader. Oxford: Blackwell.

Bell, David. (1997) "Innuendo". Journal of Pragmatics 27: 35-59.

Benveniste, Émile. (1971) [The original French version, under the title Problèmes de linguistique générale, was published in Paris by Editions Gallimard, 1966] Problems in General Linguistics [translated by Mary Elizabeth Meek]. Coral Gables, Florida: University of Miami Press.

Berlin, Brent \& Paul Kay (1969) Basic Color Terms: Their Universality and Evolution. Berkeley, CA: University of California Press.

Berlin, Isaiah (1973) "Austin and the Early Beginnings of Oxford Philosophy" In: Berlin et al., pp. 1-16.

Berlin, Isaiah et al. (1973) Essays on J.L. Austin. Oxford : Clarendon Press.

Bernicot, Josie \& Virginie Laval. (2004) "Speech acts in children: The example of promises" In: Noveck, Ira \& Dan Sperber, pp. 207-227.

Bertuccelli-Papi, Marcella (2000) "Is a diachronic speech act theory possible?" Journal of Historical Pragmatics, Vol.1, No.1, pp. 57-66.

Bezuidenhout, Anne L. \& Robin K. Morris. (2004) "Implicature, relevance and default pragmatic inference” In: Noveck, Ira \& Dan Sperber (eds.), pp. 257-282.

Biber, Douglas (1988) Variation across Speech and Writing. Cambridge: Cambridge University Press.

Bird, Alexander (2002) "Illocutionary silencing”. Pacific Philosophical Quarterly. Vol. 83, pp. 115.

Black, Max (1963) “Austin on performatives”. Philosophy Vol. 38, pp. 217-263.

Blackmore, Susan (1999) The Meme Machine. Oxford: Oxford University Press.

Blum-Kulka, Shosana, Juliane House \& Gabriele Kasper (eds.) (1989) Cross-Cultural Pragmatics: requests and Apologies. Norwood, NJ: Ablex.

Boër, Steven \& William G. Lycan (1980) "A performadox in truth-conditional semantics". Linguistics and Philosophy, Vol. 4, No. 1, pp. 71-100.

Bogusławski, Andrzej (1983a) "An analysis of 'promise'”. Journal of Pragmatics, Vol. 7, pp. 607-627.

Bogusławski, Andrzej. (1983b) “A reply to Jeff Verschueren” Journal of Pragmatics, Vol. 7, pp. 633-635.

Bohr, Hans (1967) "My Father" In: Niels Bohr: His Life and Work as Seen by His Friends and Colleagues, ed. by Stefan Rozental. Amsterdam: North-Holland, pp. 325-399.

Brandom, Robert (1994) Making it Explicit: Reasoning, representing, and discursive commitment. Cambridge, MA: Harvard University Press.

Brandom, Robert (2000) Articulating Reasons: An introduction to inferentialism. Cambridge, MA: Harvard University Press. 
Bratman, Michael E. (1994) "Moore on Intention and Volition". University of Pennsylvania Law Review, Vol. 142, No. 5, pp. 1705-1718.

Briggs, Richard (2004) Words in Action: Speech Act Theory and Biblical Interpretation. London: Continuum.

Brown, Gillian \& George Yule (1983) Discourse Analysis. Cambridge: Cambridge University Press.

Brown, Penelope \& Stephen Levinson. (1987) Politeness: Some Universals of Language Usage. Cambridge: Cambridge University Press.

Bühler, Karl (2001) Theory of Language: The representational function of language. [Sprachtheorie] Translated by Donald Fraser Goodwin. Amsterdam \& Philadelphia: John Benjamins B.V.

Burge, Tyler (1979) "Individualism and the mental". In: Midwest Studies in Philosophy, ed. by Peter French, Theodore Uehling \& Howard Wettstein. Minneapolis: University of Minnesota Press, pp. 73-121; available on-line; doi: 10.1111/j.1475-4975.1979.tb00374.x.

Burge, Tyler (2007 [1975]) “On knowledge and convention" In: Tyler Burge (2007) Foundations of Mind. Oxford: Oxford University Press, pp. 32-37. [originally published in The Philosophical Review, vol. 84 (1975), pp. 249-355]

Butler, Judith. (1990) Gender Trouble: Feminism and the Subversion of Identity. New York: Routledge.

Butler, Judith (1993) Bodies That Matter: On the Discursive Limits of "Sex". Routledge, New York, London.

Butler, Judith (1995) "Burning Acts - Injurious Speech" In: Performativity and Performance, ed. by Andrew Parker \& Eve Kosofsky. London: Routledge, pp. 197-227.

Butler, Judith (1997) Excitable Speech: A Politics of the Performative. Routledge, New York, London.

Campbell, Robin (1981) "Language acquisition, psychological dualism and the definition of pragmatics". In: Possibilities and Limitations of Pragmatics, ed. by Herman Parret, Marina Sbisà \& Jeff Verschueren. Amsterdam: John Benjamins, pp. 93-104.

Cappelen, Herman \& Ernie Lepore (2005) Insensitive Semantics. A defence of Semantic Minimalism and Speech Act Pluralism. Oxford: Blackwell.

Cappelen, Herman \& Ernie Lepore (2006) "Précis of Insensitive Semantics". Philosophy and Phenomenological Research, Vol. LXXIII, No. 2, pp. 424-433.

Capone, Alessandro (2005) "Pragmemes: a study with reference to English and Italian". Journal of Pragmatics, Vol. 37, pp. 1355-1371.

Capone, Alessandro (2010a) "Barack Obama's South Carolina speech" Journal of Pragmatics, Vol. 42, pp. 2964-2977.

Capone, Alessandro (2010b) "Introduction”. Journal of Pragmatics, Vol. 42, pp. 2861-2869.

Capone, Alessandro (2010c) (ed.) Journal of Pragmatics: Pragmemes [special issue], Vol. 42, Issue 11, pp. 2861-3162.

Carston, Robyn (2002) Thoughts and Utterances: The Pragmatics of Explicit Communication. Oxford: Blackwell.

Carston, Robyn (2008) "Linguistic Communication and the semantics/pragmatics distinction" Synthese. Vol. 165/3, pp.321-346; doi: 10.1007/s11229-007-9191-8.

Cavell, Stanley (2002a) Must We Mean What We Say? A Book of Essays. [Updated Edition]. Cambridge: Cambridge University Press.

Cavell, Stanley (2002b) “Austin at criticism” In: (Cavell 2002a), pp. 97-114.

Cavell, Stanley (2002c) "Must we mean what we say?” In: Cavell (2002a), pp. 1-43.

Chapman, Siobhan (2008) Language and Empiricism: After the Vienna Circle. Houndmills, Basingstoke, Hampshire: Palgrave Macmillan.

Chapman, Siobhan (2011) Pragmatics. Houndmills, Basingstoke, Hampshire: Palgrave Macmillan. 
Chapman, Siobhan \& Christopher Routledge (2005) Key Thinkers in Linguistics and the Philosophy of Language. Edinburgh: Edinburgh University Press.

Charnock, Ross (2009) "Overruling as a speech act: Performativity and normative discourse" Journal of Pragmatics 41: 401-426.

Chrzanowska-Kluczewska, Elżbieta (2004) Language-games: Pro and against. Kraków: Universitas.

Chudzik, Anna (2002) Mowne zachowania magiczne w ujęciu pragmatyczno-kognitywnym. Kraków: Universitas.

Clark, Herbert H. (1987) "Four dimensions of language use". In: The Pragmatic Perspective, ed. by Jef Verschueren \& Marcella Bertuccelli-Papi. Amsterdam: John Benjamins, pp. 9-25.

Clark, Herbert H. (1992) Arenas of Language Use. Chicago: Chicago University Press.

Clark, Herbert H. (1996) Using Language. Cambridge: Cambridge University Press.

Clark, Herbert H. (1979) "Responding to indirect speech acts". Cognitive Psychology, Vol. 11, pp. 430-477.

Clark, Herbert H. \& T. B. Carlson (1982) "Hearers and speech acts". Language, Vol. 58, pp. 333373.

Clark Herbert H. \& Peter Lucy (1975) "Understanding what is meant from what is said: A study in conversationally conveyed requests". Journal of Verbal Learning and Verbal Behavior, Vol. 14, pp. 56-72.

Clark, Herbert H. \& Dale H. Schunk (1980) "Polite responses to polite requests". Cognition, Vol. 8, pp. 111-143.

Cohen, L. Jonathan (1964) “Do illocutionary forces exist?” The Philosophical Quaterly, Vol. 14, No. 55, pp. 118-137.

Cohen, L. Jonathan. (1973) "The non-existence of illocutionary forces: A reply to Mr. Burch." Ratio, Vol. 15(1), pp. 125-131.

Cole, Peter \& Jerry L. Morgan (eds.) (1975) Syntax and Semantics, Vol. 3: Speech Acts. New York: Academic Press.

Collins, John (2007) "Review of Language: a Biological Model-Ruth Garret Millikan". The Philosophical Quaterly, Vol. 57, Issue 226, pp. 142-145; doi: 10.1111/j.14679213.2007.476_5.x.

Corrigan, Roberta, Edith A. Moravcsik, Hamid Ouali \& Kathleen M. Wheatley (eds.) (2009a) Formulaic Language, Volume 1: Distribution and historical change. Amsterdam \& Philadelphia: John Benjamins.

Corrigan, Roberta, Edith A. Moravcsik, Hamid Ouali \& Kathleen M. Wheatley (eds.) (2009b) Formulaic Language, Volume 2: Acquisition, loss, psychological reality, and functional explanations. Amsterdam \& Philadelphia: John Benjamins.

Croft, William (1994) "Speech act classification, language typology and cognition". In: Tsohatzidis (ed.), pp. 460-477.

Culler, Jonathan (1981) "Convention and Meaning: Derrida and Austin". New Literary History, Vol. 13, No. 1, On Convention: I, pp. 15-30 (Published by: The Johns Hopkins University Press) Stable URL: http://www.jstor.org/stable/468640; an excerpt from On Deconstruction: Literary Theory in the 1970s).

Culpeper, Jonathan \& Dawn Archer (2008) "Requests and directness in Early Modern English trial proceedings and play-texts, 1640-1760". In: Speech Acts in the History of English, ed. by Andreas H. Jucker \& Irma Taavitsainen. Amsterdam/Philadelphia: John Benjamins, pp. 45-84.

Cummings, Louise (2007) "Clinical pragmatics: a field in search of phenomena?" Language and Communication, Vol. 27, pp. 396-432.

Cummings, Louise (2009) Clinical Pragmatics. Cambridge: Cambridge University Press.

Danet, Brenda (1980) "Language in the legal process". Law and Society Review 14, pp. 445-564.

Dascal, Marcelo (2003) Interpretation and Understanding. Amsterdam: Benjamins. 
Davidson, Donald (1963) "Actions, Reasons and Causes" Journal of Philosophy, Vol. 60, pp. 685-700 (reprinted in Davidson 2001, pp. 3-19).

Davidson, Donald (1979 [2001b]) “Moods and Performances" In: Davidson (1984/2001b), pp. 109-122.

Davidson, Donald (2001a; $2^{\text {nd }}$ ed.) Essays on Actions and Events. Oxford: Clarendon Press.

Davidson, Donald (1984/2001b) Inquiries into Truth and Interpretation. Oxford: Oxford University Press.

Davies, Bethan (2005) "Communities of practice: Legitimacy not choice". Journal of Sociolinguistics, Vol. 9: 4, pp. 557-581.

Davies, Martin (2003) "Philosophy of language" The Blackwell Companion to Philosophy, $2^{\text {nd }}$ ed., ed. by Nicholas Bunnin \& Eric P. Tsui-James. Oxford: Blackwell, pp. 90-146.

Davies, Martin (2006) "Foundational Issues in the Philosophy of Language". In: The Blackwell Guide to the Philosophy of Language, ed. by Michael Devitt \& Richard Hanley. Oxford: Blackwell, pp. 19-40.

Davis, Steven (1979) "Perlocutions". Linguistics \& Philosophy, Vol. 3, Issue 2, pp. 225-243. [reprinted in: Speech Act Theory and Pragmatics, ed. by J. R. Searle, F. Kiefer \& M. Bierwisch. Dordrecht, The Netherlands: Reidel, pp. 37-55].

Dawkins, Richard (1989 [1976]) The Selfish Gene. Oxford: Oxford University Press.

de Beaugrande, Robert (1988) "Performative soeech acts in linguistic theory: The rationality of Noam Chomsky". Journal of Pragmatics, Vol. 29, No. 6, pp. 765-803.

de Beaugrande, Robert (1991) Linguistic Theory: The discourse of fundamental works. London \& New York: Longman (converted to web pages and uploaded 2002; references in the text to the web-based edition http://www.beaugrande.com/LINGTHERLinguistic\%20Theory\%20Title. htm).

de Beaugrande, Robert. (1998) "Performative speech acts in linguistic theory: The rationality of Noam Chomsky". Journal of Pragmatics, Vol. 29, pp. 765-803.

de Saussure, Ferdinand. (1966 [1916]) Course in General Linguistics, ed. by Charles Bally \& Albert Sechehaye in collaboration with Albert Riedlinger, translated and with an introduction and notes by Wade Baskin. New York, Toronto \& London: McGraw-Hill Book Company [earlier published in 1959; New York: Philosophical Library].

de Saussure, Ferdinand (1983 [1916]) Course in General Linguistics (ed. by Charles Bally \& Albert Sechehaye in collaboration with Albert Riedlinger; translated and annotated by Roy Harris). New York: London: Duckworth.

Dennett, Daniel (1991) Consciousness Explained. London: Penguin.

Derrida, Jacques (1977/1982) "Signature Event Context" ["Signature évnément context"] Glyph, [Baltimore, MD: Johns] Vol.1, pp. 191-192, Reprinted in Jacques Derrida. Margins of Philosophy. Trans. Alan Bass. Chicago: University of Chicago Press, pp. 307-330.

Derrida, Jacques (1988) Limited Inc. Evanston, IL: Northwestern University Press. Hopkins Press, pp. 172-97. Reproduced in Jacques Derrida, Margins of Philosophy, trans. by Alan Bass. Brighton: Harvester Press, pp. 307-30.

Derrida, Jacques (2000) "Performative powerlessness-A response to Simon Critchley". Constellations, Vol. 7, pp. 466-468.

Dik, Simon C. (1978) Functional Grammar. Amsterdam: North Holland.

Dik, Simon C. (1987) "Some principles of functional grammar" In: Functionalism in Linguistics, ed. by René Dirven \& Vilém Fried, Amsterdam: John Benjamins, pp. 81-100.

Dore, John (1979) "Conversational acts and the acquisition of language". In: E. Keenan \& B. Schieffelin (eds.), Developmental pragmatics. New York: Academic Press, pp. 339-62.

Doty, Kathleen L. \& Risto Hiltunen (2009) "Formulaic discourse and speech acts in the witchcraft trial records of Salem, 1692". Journal of Pragmatics, Vol. 41, pp. 458-469.

Dosse, François (1997) History of Structuralism, Vol. 2: The Sign Sets, 1967-present. Translated by Deborah Glassman. Minneapolis, MN: University of Minnesota Press. 
Drabik, Beata (2004) Komplement i komplementowanie jako akt mowy i komunikacyjna strategia.

[Book series: Pragmatyka i semantyka mowy, No.3] Kraków: Universitas.

Dummett, Michael (1981) The Interpretation of Frege's Philosophy. London: Duckworth.

Eco, Umberto (1978) Theory of Semiotics. Bloomington: Indiana University Press.

English, Parker (2007) "Performative speech acts, ethnography and fiction". Journal of Pragmatics, Vol. 39, pp. 1624-1637.

Ervin-Tripp, Susan (1976) "Is Sybil there? The structure of some American English directives" Language in Society, Vol. 5, No. 1, pp. 25-66.

Everett, Daniel (2012) Language: The Cultural Tool. New York: The Panthenon Books.

Faller, Martina T. (2002). Semantics and pragmatics of evidentials in Cuzco Quechua. PhD dissertation, Stanford University; available on-line: http://personalpages.manchester.ac.uk/ staff/martina.t.faller/documents/thesis-a4.pdf (July 2013).

Farkas, Katalin (2006) "Semantic internalism and externalism". In The Oxford Handbook of Philosophy of Language, ed. by Ernest Lepore \& Barry Smith. Oxford: Oxford University Press, pp. 323-340.

Fauconnier, Gilles (1985) Mental Spaces: Aspects of Meaning Construction in Natural Language. Cambridge, MA: MIT Press.

Fauconnier, Gilles (1997) Mappings in Thought and Language. Cambridge: Cambridge University Press.

Fauconnier, Gilles (1999) "Methods and generalisations" In: Scope and Foundations of Cognitive Linguistics, ed. by Theo Janssen \& Gisela Redeker, pp. 96-127.

Fauconnier, Gilles \& Mark Turner (1996 [2001]) "Blending as a Central Process of Grammar" In: Conceptual Structure, Discourse and Language, ed. by Adele Goldberg, Stanford: CSLI, 1996, 113-130 (an updated version of the text was published in: Wojciech Kubiński \& Danuta Stanulewicz (eds.) (2001) Językoznawstwo kognitywne II. Zjawiska pragmatyczne. Gdańsk: Wydawnictwo Uniwersytetu Gdańskiego, pp. 173-211.

Fein, Ofer \& Asa Kasher (1996) "How to do things with words and gestures in comics". Journal of Pragmatics, Vol. 26, 793-808; doi: 10.1016/S0378-2166(96)00023-9.

Felman, Shoshana (2003) The Scandal of the Speaking Body: Don Juan with J. L. Austin, or Seduction in Two Languages. Stanford, CA: Stanford University Press.

Fetzer, Anita (2004) Recontextualizing Context: Grammaticality meets Appropriateness. Amsterdam/Philadelphia: John Benjamins.

Fetzer, Anita (2007a) “Context, contexts and appropriateness” In Fetzer (2007b), pp. 3-27.

Fetzer, Anita (ed.) (2007b) Context and Appropriateness: Micro meets macro. Amsterdam/Philadelphia: John Benjamins.

Feyereisen, Pierre \& Jacques-Dominique de Lannoy (1991) Gestures and speech. Cambridge: Cambridge University Press.

Fillmore, Charles J. (1977a) "Topics in lexical semantics”. In: Current Issues in Linguistic Theory, ed. by Roger W. Cole, Bloomington \& London: Indiana University Press, pp. 76-138.

Fillmore, Charles J. (1977b) "Scenes-and-frames semantics". In: Linguistic Structures Processing, ed. by Antonio Zampolli. Amsterdam: North Holland, pp. 55-81.

Fillmore, Charles J. (1977c) “The case for case reopened”. In: Grammatical Relations [Syntax and Semantics 8], ed. by Peter Cole \& Jerrold M. Sadock, New York: Academic Press, pp. 59-81.

Finnegan, Ruth (1992) Oral Traditions and Verbal Arts. London: Routledge.

Firth, John R. (1964) The Tongues of Men and Speech. [Language and Language Learning 3] London: Oxford University Press.

Fish, Stanley (1989) Doing What Comes Naturally: Change, Rhetoric, and the Practice of Theory in Literary and Legal Studies. Durham, NC: Duke University Press.

Forguson, L.W. (1973) “Locutionary and illocutionary acts” In: Berlin et al. (eds.), pp. 160-185. 
Frank, Roslyn M. (2008) "Introduction: Sociocultural situatedness" In: Cognitive Linguistics Research: Sociocultural Situatedness, Volume 2, ed. by Roslyn M. Frank, René Dirven \& Tom Ziemke. Berlin: Mouton de Gruyter, pp. 1-18.

Fraser, Bruce (1974a) "An examination of the performative hypothesis". Papers in Linguistics Vol.7, pp. 1-40.

Fraser, Bruce (1974b) "An analysis of vernacular performative verbs". In: Towards Tomorrow's Linguistics, ed. by Roger W. Shuy \& Charles-James N. Bailey. Washington: Georgetown University Press, pp. 139-158.

Fraser, Bruce (2001) "An account of innuendo" In: Perspectives on Semantics, Pragmatics, and Discourse: a Festschrift for Ferenc Kiefer, ed. by István Kenesei \& Robert M. Harnish. Amsterdam \& Philadelphia: John Benjamins, pp. 321-336.

Frege, Gottlob. 1892/1994. "On Sense and Reference" In: Translations from the Philosophical Writings of Gottlob Frege, ed. by P. Geach \& M. Black. 1960, Oxford: Blackwell, pp. 56-78. [Reprinted in: Basic Topics in the Philosophy of Language, ed. by Robert M. Harnish. Englewood Cliffs, N.J.: Prentice-Hall, pp. 142-160.]

Fried, Charles (1981) Contract as Promise: A Theory of Contractual Obligation. Cambridge, MA: Harvard University Press.

Furberg, Mats (1963) Locutionary and Illocutionary Acts: A main theme in J. L. Austin's Philosophy [Gothenburg Studies in Philosophy]. Gothenburg: Almqvist \& Wiksell [Reprinted in an extended version in 1971 by Basil Blackwell as Saying and Meaning: A main theme in J. L. Austin's philosophy].

Garfinkel, Harold (1967) Studies in Ethnomethodology. Englewood Cliffs, NJ: Prentice-Hall (Reissued 1984, Cambridge: Polity).

Garfinkel, Harold (1972) "Remarks on ethnomethodology" In: Directions in Sociolinguistics, ed. by John J. Gumperz \& Dell H. Hymes, pp. 301-324.

Gass, S.M. \& J. Neu (1995) Speech Acts across Cultures: Challenges to Communication in a Second Language. Berlin: Mouton de Gruyter.

Gauker, Christopher (1994) Thinking Out Loud. Princeton NJ: Princeton University Press.

Gauker, Christopher (2007) "On the alleged priority of thought over language". In John Searle's Philosophy of Language: Force, Meaning, and Mind, ed. by Savas L. Tsohatzidis. Cambridge: Cambridge University Press, pp. 125-142.

Gauker, Christopher (2008) "Zero tolerance for pragmatics" Synthese, Vol. 165, pp. 359-371; doi: 10.1007/s11229-007-9189-2.

Gazdar, Gerald (1981) "Speech act assignment" In: Elements of Discourse Understanding, ed. by Aravind Joshi, Bonnie Webber \& Ivan Sag. Cambridge: Cambridge University Press, pp. 6483.

Gibbs, Raymond W. (2004) "Psycholinguistic experiments and linguistic-pragmatics" In: Noveck, Ira \& Dan Sperber (eds.), pp. 50-71.

Gibbs, Raymond W. \& Suzanne M. Delaney (1987) "Pragmatic factors in making and understanding promises". Discourse Processes, Vol. 10, pp. 107-126.

Gibson, James J. (1977) "The Theory of Affordances". In: Perceiving, Acting, and Knowing: Toward an Ecological Psychology, ed. by Robert Shaw \& John Bransford. Hillsdale, NJ: Erlbaum, pp. 67-82.

Gibson, James J. (1979/1986) The Ecological Approach to Visual Perception. Hillsday, NJ: Lawrence Erlbaum Associates, Inc (first edition: Boston: Houghton Mifflin).

Gilbert, Margaret (1989/1992) On Social Facts. Princeton, N.J.: Princeton University Press [reprinted after New York: Routledge, 1989].

Gilbert, Margaret (1990) "Rationality, Coordination and Convention". Synthese, Vol. 84, pp. 1-21.

Ginet, Carl. (1979) "Performativity". Linguistics and Philosophy. Vol. 3, No. 2, pp. 245-265; doi: 10.1007/BF00126512 . 
Glendinning, Simon. (2011) "Unmasking the Tradition” In: M. Gustaffson \& R. Sørli (eds.), pp. 32-50.

Goffman, Erving (1974) Frame Analysis: An Essay on the Organization of Experience. Cambridge, MA: Harvard University Press.

Goffman, Erving (1976) "Replies and responses". Language in Society, Vol. 5, pp. 257-313.

Gordon David \& George Lakoff (1975) "Conversational postulates". In: Syntax and Semantics, Vol. 3: Speech Acts, ed. by Peter Cole \& Jerry L. Morgan, pp. 83-106.

Grice, Herbert P. (1975) "Logic and conversation.” In Cole \& Morgan (eds.), pp. 41-58. [Reprinted in Grice (1989), pp. 22-40.]

Grice, Herbert P. (1989) Studies in the Way of Words. Cambridge, Mass: Harvard University Press. Gu, Yueguo (1993) “The Impasse of Perlocution.” Journal of Pragmatics, Vol. 20, pp. 405-32.

Gustaffson, Martin (2011) “Introduction: Inheriting Austin” In: M. Gustaffson \& R. Sørli (eds.), pp. 1-31.

Gustaffson, Martin \& Richard Sørli (eds.) (2011) The Philosophy of J.L. Austin. Oxford: Oxford University Press.

Habermas, Jürgen (1984 [1981]) The Theory of Communicative Action, Vol. 1: Reason and the Rationalization of Society (translated by Thomas McCarthy). London: Heinemann.

Habermas, Jürgen (1987 [1985]) The Philosophical Discourse of Modernity: Twelve Lectures (translated by Frederick Lawrence). Cambridge, MA: MIT Press.

Habermas, Jürgen (1998) "Actions, Speech Acts, Linguistically Mediated Interactions, and the Lifeworld"; In: Jürgen Habermas, On the Pragmatics of Communication, ed. by Maeve Cooke. Cambridge, MA: MIT Press, pp. 216-255 [first published in German in 1988].

Hagen, Rose-Marie \& Rainer Hagen (2005) "Counsel for the afterlife" In: What Great Paintings Say. From Bayeux Tapestry to Diego Rivera - Vol.1. (English translation), ed. by Rose-Marie Hagen \& Rainer Hagen. Köln: Taschen, pp. 8-13.

Haiman, Franklyn Saul (1993) "Speech acts” and the First Amendment. Carbondale \& Edwardsville: Southern Illinois University Press.

Hall, Edward T. (1976) Beyond Culture. New York: Doubleday.

Hancher, Michael (1979) "The classification of cooperative illocutionary acts". Language in Society, Vol. 8, pp. 1-14.

Hare, Richard Mervyn (1964) "The promising game". Revue Internationale de Philosophie, Vol. 70, pp. 389-404.

Hare, Richard Mervyn (1970) "Meaning and speech acts" The Philosophical Review, Vol. 79, No. 1, pp. 3-24 [also reprinted in Hare (1971)].

Hare, Richard Mervyn (1971) Practical Inferences. Berkeley \& Los Angeles, CA: University of California Press.

Hare, Richard Mervyn (1989) "Some subatomic particles of logic". Mind, Vol. 98, pp. 23-37.

Harnish, Robert M. (1994) "Mood, meaning and speech acts" In: Tsohatzidis (ed.), pp. 407-459.

Harnish, Robert M. (2001) "Frege on mood and force" In: Perspectives on Semantics, Pragmatics, and Discourse: a Festschrift for Ferenc Kiefer, ed. by István Kenesei \& Robert M. Harnish. Amsterdam \& Philadelphia: John Benjamins, pp. 203-228.

Harnish, Robert M. (2006) "Mood and inference”. Research in Language, Vol. 4, pp. 57-75.

Harnish, Robert M. (2009a) "Internalism and externalism in speech act theory". Lodz Papers in Pragmatics. Special Issue on Speech Actions, ed. by Iwona Witczak-Plisiecka \& Maciej Witek. Vol.5, No.1, pp. 9-31; doi: 10.2478/v10016-009-0001-2.

Harnish, Robert M. (2009b) "The problem of fragments: Two interpretive strategies" Pragmatics and Cognition 17 (2), pp. 251-282.

Harnish, Robert M. (2010) "Fragments and speech acts" In: Pragmatic Perspectives on Language and Linguistics 2009. Volume 1: Speech Actions in Theory and Applied Studies, ed. by Iwona Witczak-Plisiecka, Newcastle upon Tyne: Cambridge Scholars Publishing, pp. 3-38. 
Harris, Roy (1988) Language, Saussure and Wittgenstein: How to play games with words. London $\&$ New York: Routledge.

Harrison, Bernard (1979) An Introduction to the Philosophy of Language. London \& Basingstoke: Macmillan.

Hart, Herbert Lionel Adolphus (1961/1994; $2^{\text {nd }}$ ed.) The Concept of Law. Oxford: Oxford University Press.

Heinz, Adam (1978/1983) Dzieje językoznawstwa w zarysie. [History of Linguistics: An Outline.] Warszawa: Państwowe Wydawnictwo Naukowe.

Higginbotham, James (2002) "On linguistics in philosophy, and philosophy in linguistics" Linguistics and Philosophy, Vol. 25, pp. 573-584.

Hindriks, Frank (2007) "The status of the knowledge account of assertion" Linguistics and Philosophy, Vol. 30, pp. 393-406.

Hofstede, Geert (1997) Cultures and Organizations: Software of the Mind. New York: McGrawHill.

Holdcroft, David (1974) "Performatives and statements". Mind, Vol. LXXXIII (329), pp.1-18; doi: $10.1093 / \mathrm{mind} / \mathrm{LXXXIII.329.1.}$

Holdcroft, David (1978) Words and Deeds: Problems in the Theory of Speech Acts. Oxford: Oxford University Press.

Holtgraves, Thomas (2007) "Second Language Learners and Speech Act Comprehension" Language Learning. Vol. 57, No. 4, pp. 595-610.

Horn, Laurence R. (2006) "More issues in neo- and post-Gricean pragmatics". Intercultural Pragmatics. 3.1, pp.81-93; doi: 10.1515/IP.2006.004.

Horn, Lawrence R. \& Samuel Bayer (1984) "Short-circuited Implicature: A Negative Contribution", Linguistics and Philosophy Vol. 7, No. 4, pp. 397-414.

Horn, Lawrence R. \& Gregory Ward (eds.) (2004) Handbook of Pragmatics. Oxford: Blackwell.

Hornsby, Jennifer (1993) "Speech acts and pornography". Women's Philosophical Review, [November] pp. 38-45.

Hornsby, Jennifer (1994) "Illocution and its significance". In: Tsohatzidis (ed.), pp. 187-207.

Hornsby, Jennifer (1995) “Disempowered speech”. Philosophical Topics 23, pp. 127-147.

Hornsby, Jennifer (2000) "Feminism in Philosophy of Language: Communicative Speech Acts". In: The Cambridge Companion to Feminism in Philosophy, ed. by Miranda Fricker \& Jennifer Hornsby. Cambridge: Cambridge University Press, pp.87-106.

Hornsby, Jennifer (2006), "Speech Acts and Performatives". In: The Oxford Handbook of Philosophy of Language, ed. by E. Lepore \& B. C. Smith. Oxford: Oxford University Press, pp. 893-909.

Hornsby, Jennifer \& Rae Langton (1998) "Free speech and illocution". Legal Theory, Vol. 4, pp. 21-37.

Householder, F.W. (1981) The Syntax of Apollonius Dyscolus, translated and with commentary by Fred W Householder. Amsterdam \& Philadelphia: John Benjamins.

Huang, Yan (2007) Pragmatics. Oxford: Oxford University Press.

Huang, Yan (2012) The Oxford Dictionary of Pragmatics. Oxford: Oxford University Press.

Hume, David. (1896 [originally published 1739-1740]) A Treatise of Human Nature; Reprinted from the original edition in three volumes and edited, with an analytical index, by L. A. SelbyBigge. Oxford: Clarendon Press. (available on-line at: http://files.libertyfund.org/files/ 342/0213_Bk.pdf (May 2012))

Husserl, Edmund (2001) The Shorter Logical Investigations (translated by J. N. Findlay from the Second German edition of Logische Untersuchungen with a new "Preface" by Michael Dummett and edited and abridged with a new "Introduction" by Dermot Moran). London $\&$ New York: Routledge.

Hutton, Chris (2009) Language, Meaning and the Law. Edinburgh: Edinburgh University Press. 
Hymes, Dell (1967) "Models of the interaction of language and social setting". Journal of Social Issues, Vol. 23, No.2, pp. 8-28.

Hymes, Dell (1972) "On communicative competence" In: Directions in Sociolinguistics: The ethnography of communication, ed. by John Gumperz \& Dell Hymes. New York: Holt, Rinehart \& Winston, pp. 35-71.

Infantidou-Trouky, Elly (1993) "Sentential adverbs and relevance". Lingua, Vol. 90, Issue 1/2, pp.69-90.

Jackendoff, Ray S. (1990) Semantic Structures. Cambridge, Mass.: MIT Press.

Jackson, S. (2004) Professing Performance: Theatre in the Academy from Philology to Performativity. Cambridge: Cambridge University Press.

Jakobson, Roman (1960) "Closing Statement: Linguistics and poetics" In: Style in Language, ed. by Thomas A. Sebeok. Cambridge, Mass.: MIT Press, pp. 350-377.

Jary, Mark (2011) Assertion. Houndmills: Palgrave.

Jaszczołt, Katarzyna M. (2005) Default Semantics: Foundations of a Compositional Theory of Acts of Communication. Oxford University Press, Oxford.

Jaszczołt, Katarzyna M. (2009) Representing Time: An Essay on Temporality as Modality. Oxford: Oxford University Press.

Jaszczołt, Katarzyna M. (2010) "Situated temporal reference: A case for compositional pragmatics?” Journal of Pragmatics, Vol. 42, pp. 2898-2909.

Johnson, Barbara (1980) The Critical Difference: Essays in the contemporary rhetoric of reading. Baltimore, MD: John Hopkins University Press.

Jucker, Andreas H. \& Irma Taavitsainen (2000) "Diachronic speech acts analysis: Insults from flyting to flaming". Journal of Historical Pragmatics, Vol. 1, pp. 67-95.

Jucker, Andreas H., Gerold Schneider, Irma Taavitsainen, \& Barb Breustedt (2008) "Fishing for compliments: Precision and recall in corpus-linguistic compliment research". In: Andreas H. Jucker \& Irma Taavitsainen (eds.), pp. 273-294.

Jucker, Andreas H. \& Irma Taavitsainen (eds.) (2008) Speech Acts in the History of English. Amsterdam/Philadelphia: John Benjamins.

Jurafsky, Daniel (2004) "Pragmatics and Computational Linguistics"; In: Horn, L.R. \& G. Ward (eds.), pp. 578-604.

Kadmon, Nirit. (2001) Formal Pragmatics: Semantics, Pragmatics, Presupposition and Focus. Oxford: Blackwell.

Kalisz, Roman (1989) "On representatives as a class of illocutionary acts". In: Contrastive Pragmatics, ed. by Wiesław Oleksy. Amsterdam: John Benjamins, pp. 37-54.

Kalisz, Roman (1993) Pragmatyka językowa. Gdańsk: Wydawnictwo Uniwersytetu Gdańskiego.

Kalisz, Roman (2001) "Pojęcia pragmatyki językowej w świetle językoznawstwa kognitywnego" In: Językoznawstwo kognitywne II: Zjawiska pragmatyczne, ed. by Wojciech Kubiński \& Danuta Stanulewicz. Gdańsk: Wydawnictwo Uniwersytetu Gdańskiego, pp. 13-21.

Kalisz, Roman \& Wojciech Kubiński (1993) "Speech act as a radial category". In: Images from a cognitive scene, ed. by Elżbieta Górska. Kraków: Universitas, pp. 73-88.

Kant, Immanuel (1978/1798) Anthropology from a Pragmatic Point of View, translated by V.L. Dowdell, rev. \& ed. by H.H. Rudnick. Carbondale, IL: Southern Illinois University Press.

Kannetzky, Frank (2007) "What Makes Cultural Heredity Unique? On Action-Types, Intentionality and Cooperation in Imitation" Mind and Language, vol. 22, No. 5, pp. 592-623.

Kasher, Asa (1994) "Modular speech act theory: Programme and results" In: Tsohatzidis (ed.), pp. 312-322.

Kasper, Gabriele (1984) "Pragmatic comprehension in learner-native speaker discourse". Language Learning, Vol. 4, pp. 1-20.

Katz, Jerrold J. (1972) Semantic Theory. New York: Harper \& Row.

Katz, Jerrold J. (1977) Propositional Structure and Illocutionary Force: A Study of the Cntribution of Sentence Meaning to Speech Acts. Sussex: Harvester Press. 
Kearns, John T. (2006) "Conditional assertion, denial, and supposition as illocutionary acts". Linguistics and Phillosophy 29 (4), pp.455-485; doi: 10.1007/s10988-006-0007-y.

Keck, Gabriele \& Michael Stubbs (1984) "Koschmieder on speech act theory: A historical note". Journal of Pragmatics, Vol. 8, pp. 305-320.

Kecskes, Istvan (2010) "Situation-bound utterances as pragmatic acts". Journal of Pragmatics, Vol. 42, pp. 2889-2897.

Kendon, Adam (1995) "Gestures as illocutionary and discourse structure markers in Southern Italian conversation." Journal of Pragmatics, Vol. 23, pp. 247-279.

Kenesei, István \& Robert M. Harnish (eds.) Perspectives on Semantics, Pragmatics, and Discourse: a Festschrift for Ferenc Kiefer. Amsterdam \& Philadelphia: John Benjamins.

Kim, Jaegwon (1976) "Events as property exemplifications". In: Action Theory. Proceedings of the Winnipeg Conference on Human Action, ed. by Myles Brand \& Douglas Walton. Dordrecht: Reidel, pp. 159-177.

Kissine, Mikhail (2009) "Illocutionary forces and what is said". Mind and Language, Vol. 24, No. 1, pp. 122-138.

Kissine, Mikhail, Philippe De Brabanter \& Jacqueline Leybaert (2012) "Compliance with requests by children with autism: the impact of sentence type". Autism, Vol. 16, No. 5, pp. 523-531.

Klemke, Elmer Daniel (ed.) (1968) Essays on Frege. Champaign, IL: University of Illinois Press.

Korta, Kepa \& John Perry (2007) "How to say things with words". In John Searle's Philosophy of Language: Force, Meaning and Mind, ed. by Savas L. Tsohatzidis. Cambridge: Cambridge University Press, pp.169-189.

Korta, Kepa \& John Perry (2011) Critical Pragmatics. Cambridge: Cambridge University Press.

Koschmieder, Erwin (1934) Nauka o aspektach czasownika polskiego w zarysie. Próba syntezy. [„,Rozprawy i Materjały Wydziału i Towarzystwa Przyjaciół Nauk w Wilnie”, tom V, zeszyt 2] Wilno : Nakładem Towarzystwa Przyjaciół Nauk w Wilnie, Skład Główny w Księgarni św. Wojciecha w Wilnie.

Kryk-Kastovsky, Barbara (2000) "Orality in Early Modern English trial records". Journal of Historical Pragmatics, Vol. 1, pp. 201-230.

Kryk-Kastovsky, Barbara (2006a) "Impoliteness in Early Modern English courtroom discourse". Journal of Historical Pragmatics, Vol.7, pp. 213-243.

Kryk-Kastovsky, Barbara (2006b) "Historical courtroom discourse. Introduction". Journal of Historical Pragmatics [Special Issue: Historical Courtroom Discourse], Vol. 7, pp. 163-179.

Kryk-Kastovsky, Barbara (2009) "Speech acts in Early Modern English court trials". Journal of Pragmatics, Vol. 41, pp. 440-457.

Krzeszowski, Tomasz P. (1997) Angels and Devils in Hell: Elements of Axiology in Semantics. Warszawa: Energeia.

Kukla, Rebecca \& Mark Lance (2009) 'Yo!' and 'Lo!': The Pragmatic Topography of the Space of Reasons. Cambridge, MA: Harvard University Press.

Kurzon, Dennis (1986) It is Hereby Performed .... Explorations in legal speech acts. Amsterdam $\&$ Philadelphia: John Benjamins.

Labov, William (1970) "The study of language in its social context". Studium Generale, Vol. 23, pp. 30-87.

Laderman, Carol \& Marina Roseman (ed.) (1996) The Performance of Healing. New York: Routledge.

Langton, Rae (1993) "Speech Acts and Unspeakable Acts". Philosophy and Public Affairs, Vol. 22, pp. 305-330.

Laval, Virginie \& Josie Bernicot (1999) "How French-speaking children understand promises: The role of future tense". Journal of Psycholinguistic Research, Vol. 28, pp.179-195.

Lave, Jean \& Etienne Wenger (1991) Situated Learning: Legitimate peripheral participation. Cambridge: Cambridge University Press.

Leech, Geoffrey (1989/1983) Principles of Pragmatics. London: Longman. 
Lenneberg, Eric (1967) Biological Foundations of Language. New York: John Wiley.

Levinson, Stephen (1983) Pragmatics. Cambridge: Cambridge University Press.

Levinson, Stephen C. (2000) Presumptive Meanings: The Theory of Generalized Conversational Implicature Language, Speech, and Communication. Cambridge, Mass.: MIT Press.

Lewandowska-Tomaszczyk, Barbara (1996) Depth of Negation: A Cognitive Semantic Study. Łódź: Łódź University Press.

Lewis, David (1969) Convention: A philosophical study. Oxford: Blackwell.

Lewis, David K. (1983a [1975]) "Languages and language" In: Lewis (1983b), pp. 163-188 [originally published in Minnesota Studies in the Philosophy of Science, ed. by Keith Gunderson, Volume VII. University of Minnesota Press (1975), pp. 3-35.].

Lewis, David K. (1983b) Philosophical Papers, Vol. I. Oxford: Oxford University Press. (Oxford Scholarship Online 2003; doi: 10.1093/0195032047.001.0001)

Loxley, James (2007) Performativity. London \& New York: Routledge.

Lycan, William, G. (2008; $2^{\text {nd }}$ ed.) Philosophy of Language: A contemporary introduction. New York: Routledge.

Mackenzie, I. E. (1977) Introduction to Linguistic Philosophy. Thousand Oakes: SAGE Publication.

MacKinnon, Catherine (1989) Towards a Feminist Theory of the State. Cambridge, MA: Harvard University Press.

MacKinnon, Catherine (1991) "Pornography as defamation and discrimination. Boston University Law Review, Vol. 71, pp. 793-815.

MacKinnon, Catherine (1993) Only Words. Cambridge, MA: Harvard University Press.

Malinowski, Bronisław (1965 [1935]) Coral Gardens and their Magic. Bloomington: Indiana University Press.

Marcu, Daniel (2000) "Perlocutions: The Achilles' Heel of Speech Act Theory". Journal of Pragmatics, Vol. 32, pp. 1719-1741.

Marmor, Andrei (1996) “On convention”. Synthese 107: 349-371.

Marmor, Andrei (2008) "Is literal meaning conventional?" Topoi, Vol. 27, pp. 101-113; doi 10.1007/s11245-008-9027-2.

Marmor, Andrei (2009) Social Conventions: From language to law. Princeton \& Oxford: Princeton University Press.

Martland, T. R. (1970) "Austin, Art, and Anxiety". The Journal of Aesthetics and Art Criticism, Vol. 29, No. 2, pp. 169- 174. Published by: Blackwell Publishing on behalf of The American Society for Aesthetics; Stable URL: http://www.jstor.org/stable/428597 (Accessed: 16 January 2010; 14:49).

Martinich, Aloysius P. (ed.) (1996) Philosophy of Language. $3^{\text {rd }}$ edition. Oxford: Oxford University Press.

Mascaro, Olivier \& Dan Sperber (2009) "The moral, epistemic, and mindreading components of children's vigilance towards deception". Cognition, Vol. 112(3), pp. 367-380.

McCawley, James, D. (1977) "Remarks on the Lexicography of Performative Verbs"; In: [Proceedings of the Texas Conference on] Performatives, Presuppositions, and Implicatures, ed. by A. Rogers, R. Wall \& J. Murphy. Arlington, VA: Center for Applied Linguistics, pp. 13-25. [Reprinted in J.D. McCawley (1979) Adverbs, Vowels, and Other Objects of Wonder. Chicago: University of Chicago Press, pp. 151-164].

McGowan, Mary Kate (2003) "Conversational exercitives and the force of pornography". Philosophy and Public Affairs, Vo. 31, pp. 155-189; doi: 10.1111/j.1088-4963.2003.00155.x.

McGowan, Mary Kate (2009) "On pragmatics, exercitive speech acts and pornography". Lodz Papers in Pragmatics. Special Issue on Speech Actions, ed. by Iwona Witczak-Plisiecka \& Maciej Witek. Vol. 5.1, pp. 85-106; doi: 10.2478/v10016-009-0002-1.

McGuinness, Brian (ed.) (1984) Gottlob Frege: Collected Works. Oxford: Basil Blackwell.

McHoul, Alec (1996) “Kant's pragmatics”. Journal of Pragmatics 25: 587-592. 
McHoul, Alec. (1997) "The philosophical grounds for pragmatics (and vice versa?)". Journal of Pragmatics 27: 1-15.

Meijers, Anthonie (2007) "Collective speech acts" In: Intentional Acts and Institutional Facts: Essays on John Searle's Social Ontology, ed. by Savas L. Tsohatzidis. Dordrecht: Springer, pp. 93-110.

Meilijson, Sara R. \& Asa Kasher (2004) "Language Performance in Chronic Schizophrenia" Journal of Speech, Language, and Hearing Research, Vol. 47, pp. 695-713; doi: 10.1044/1092-4388.

Mey, Jacob L. (2006) "Pragmatic acts". In: Encyclopedia of Languages and Linguistics. 2nd ed., ed. by Keith E. Brown. Oxford: Elsevier, pp.(10) 5-11.

Mey, Jacob (2001) Pragmatics: An Introduction. Oxford: Blackwell.

Mey, Jacob (2010) "Reference and the pragmeme." Journal of Pragmatics, Vol. 42, pp. 2882 2888.

Mey, Jacob (2011) "Speech acts in context" In: Context and Contexts: Parts meet whole?, ed. by Anita Fetzer \& Etsuko Oishi, pp. 171-180. Amsterdam/Philadelphia: John Benjamins.

Millikan, Ruth Garrett (1984) Language, Thought and Other Biological Categories. Cambridge MA: MIT Press.

Millikan, Ruth Garrett (2004) Varieties of Meaning. Cambridge MA: MIT Press.

Millikan, Ruth Garrett (2005a) Language: A Biological Model. Oxford: Oxford University Press; doi: 10.1093/0199284768.003.0008.

Millikan, Ruth Garrett (2005b) "The Son and the Daughter: 'On Sellars, Brandom, and Millikan"' (chapter 4 in Millikan 2005, pp. 77-91 [also published in Pragmatics and Cognition, 13.1 (2005)].

Millikan, Ruth (2005c) "Proper function and convention in speech acts." In: Language: $A$ Biological Model, pp.139-165. Oxford: Oxford University Press; doi: 10.1093/ 0199284768.003.0008.

Millikan, Ruth (2005d [1998]) "Language conventions made simple." In: Language: A Biological Model, pp. 1-23. Oxford: Oxford University Press; doi: 10.1093/0199284768.003.0008.

Millikan, Ruth Garrett (2007) "Précis of Varieties of Meaning" Philosophy and Phenomenological Research, Vol. LXXV, No. 3, pp. 655-662.

Millikan, Ruth Garrett (2008) "The father, the son, and the daughter: Sellars, Brandom, and Millikan" In: The Pragmatics of Making it Explicit, ed. by Pirmin Stekeler-Weithofer. Amsterdam \& Philadelphia: Benjamins, pp. 53-64 [published earlier in 2005: in a Special Issue of Pragmatics \& Cognition, vol. 13:1 and Millikan 2005 (chapter four)].

MITECS. MIT Encyclopaedia of the Cognitive Sciences (1999), ed. by Robert A. Wilson \& Frank C. Keil. Cambridge, Mass.: MIT Press. Available on-line at: http://ai.ato.ms/MITECS/ Entry/seifert.html (accessed January 2013).

Mitchell, W. J. T. (1994) Picture Theory: Essays on Verbal and Visual Representation. Chicago: University of Chicago Press.

Mittwoch, Anita (1977) "How to Refer to One's Own Word: Speech-Act Modifying Adverbials and the Performative Analysis." Journal of Linguistics, Vol. 13, pp. 177-189.

Montminy, Martin (2010) "Context and communication: A defense of intentionalism". Journal of Pragmatics, Vol. 42, pp. 2910-2918.

Morgan, Jerry L. (1977) "Two types of convention in indirect speech acts". Technical Report No. 52. University of Illinois at Urbana-Champaign. (later published as: Morgan, Jerry L. (1978) "Two types of convention in indirect speech acts". In: Syntax and semantics, Vol. 9: Pragmatics, ed. by Peter Cole, pp. 261-280. New York: Academic Press; Reprinted in Pragmatics: A reader. (1991), ed. by S. Davis. New York: Oxford University Press, pp. 242-53.)

Morris, Charles H. (1938 [ $3^{\text {rd }}$ reprint, 1944]) "Foundation of the theory of signs". In: International Encyclopedia of Unified Science, Vol. 2, No. 1. Chicago: University of Chicago Press, pp. 1-59. 
Morris, Desmond, Peter Collett, Peter Marsh \& Marie O’Shaughnessy (1979) Gestures. London: Jonathan Cape.

Mulligan Kevin (1987) "Promisings and other social acts: Their constituents and structure". In: Kevin Mulligan (ed.), pp. 29-90.

Mulligan, Kevin (ed.) (1987) Speech act and Sachverhalt: Reinach and the Foundations of Realist Phenomenology. Dordrecht: Martinus Nijhoff Publishers.

Navarro-Reyes, Jesus (2013) "Intention and Responsibility in Speech Acts". In: Cognitive and Pragmatic Aspects of Speech Actions, ed. by Iwona Witczak-Plisiecka. Frankfurt am Main: Peter Lang, pp. 169-188.

Neale, Stephen (2007) "Heavy hands, magic, and scene-reading traps". European Journal of Analytic Philosophy (EUJAP), Vol. 3, No. 2, pp. 77-132.

Nerlich, Brigitte \& David D. Clarke (1994) "Language, action, and context: Linguistic pragmatics in Europe and America". Journal of Pragmatics, Vol. 22, pp. 439-463.

Nerlich, Brigitte \& David D. Clarke (1996) Language, Action, and Context: The early history of pragmatics in Europe and America, 1780-1930. Amsterdam/Philadelphia: John Benjamins Publishing Company.

Nietzsche, Friedrich (2003 [1913]) The Genealogy of Morals. [Translated by Horace B. Samuel]. Mineola, N.Y.: Dover Publications, Inc.

Noveck, Ira \& Dan Sperber (eds.) (2004) Experimental Pragmatics. Houndmills: Palgrave Macmillan.

Ohlsson, Stellan (2007) "The separation of thought and action in Western tradition" In: The Prehistory of Cognitive Science, ed. by Andrew Brook. Basingstoke, UK: Palgrave Macmillan, pp. 17-37.

Olivecrona, Karl (1962) "Legal Language and Reality". In Essays in Jurisprudence in Honor of Roscoe Pound, ed. by R. A. Newman,. Indianapolis, IN: Bobbs-Merrill, pp. 151-91.

Olivecrona, Karl (1971) Law as Fact. London: Stevens \& Sons.

Origgi, Gloria \& Dan Sperber (2000) "Evolution, communication and the proper function of language". In: Evolution and the human mind: Modularity, language and meta-cognition, ed. by Peter Carruthers \& Andrew Chamberlain. Cambridge: Cambridge University Press, pp. 140-169.

Pagin, Peter (2004) “Is assertion social?” Journal of Pragmatics, Vol. 36, pp. 833-859.

Paul, Rhea \& Donald J. Cohen (1985) "Comprehension of indirect requests in adults with autistic disorders and mental retardation”. Journal of Speech and Hearing Research, Vol. 28, pp. $475-479$.

Peetz, Vera (1977) "Promises and threats". Mind, Vol. 86, pp. 578-81.

Perrault, C. Raymond (1990) "An application of default logic to speech act theory" In: Intentions in Communications, ed. by Philip R. Cohen, Jerry Morgan \& Martha E. Pollack. Cambridge, MA: MIT Press, pp. 161-186.

Perry, John (2001) Reference and Reflexivity. Stanford: CSLI Publications.

Pitcher, George (1973) “Austin: a personal memoir” In: Berlin et al., pp. 17-30.

Plato (1999 [380 BC]). Cratylus [translated by Benjamin Jowett]. The Pennsylvania State University. http://www.free-ebooks.net/ebook/Cratylus/pdf/ (accessed May 2012).

Porter, Andrew P. (1993) "When Failure is Success: Counter-Performative Speech Acts". On-line article: http://www.totse.com/en/technology/science-technology/porter.html (accessed 2 May 2008).

Post, Michał (2001) "Efekty i akty perlokucyjne”. In: Językoznawstwo kognitywne II: Zjawiska pragmatyczne, ed. by Wojciech Kubiński \& Danuta Stanulewicz. Gdańsk: Wydawnictwo Uniwersytetu Gdańskiego, pp. 136-147.

Prichard, Harold A. (2002 [1949]) "The obligation to keep a promise" In: H. A. Prichard Moral Writings, ed. by Jim MacAdam. Oxford: Oxford University Press, pp. 257-265. 
Proost, Kristel (2009) "Speech Act Verbs". In: Concise Encyclopedia of Semantics, ed. by Keith Allan. Amsterdam: Elsevier, pp. 912-917.

Prutting, Carol A. \& Diane M. Kirchner (1987) "A clinical appraisal of the pragmatic aspects of language". Journal of Speech and Hearing Disorders, Vol. 52, pp. 105-119; doi: 10.1044/ jshd.5202.105.

Putnam, Hilary (1975) “The Meaning of 'Meaning"'. Minnesota Studies in the Philosophy of Science, Vol. 7, pp. 131-193.

Quine, Willard V. (1965 [1969]), “J. L. Austin: Comment”, Journal of Philosophy, Vol. 62 (19), pp. 509-10 [reprinted in full in Fann (1969), pp. 86-90].

Quine. Willard V. (1969a) "Foreword.” In Lewis (1969), pp. xi-xii.

Quine, Willard V. (1969b) "Natural kinds" In: W.V. Quine. Ontological relativity and other essays. New York: Columbia University Press, pp. 114-138.

Quine, Willard V. (1976 [1936]). “Truth by Convention.” 1936. (In Philosophical Essays for A. N. Whitehead, ed. by O. H. Lee, New York: Longman, pp. 90 - 124 [reprinted in W. V. Quine (1976) The Ways of Paradox and Other Essays, 2nd. ed. Cambridge: Harvard University Press].

Quirk, Radolph, Sidney Greenbaum, Geoffrey Leech \& Jan Svartvik (1985/1992) A Comprehensive Grammar of the English Language. London/New York: Longman.

Ramsay, Allan (2000) "Speech act theory and epistemic planning" In: Abduction, Belief and Context in Dialogue: Studies in Computational Pragmatics, ed. by Harry Bunt \& William Black. Amsterdam: John Benjamins, pp. 293-310.

Raz, Joseph (1977) "Promises and Obligations". In: Law, Morality and Society: Essays in honour of H.L.A. Hart, ed. by Peter M. Hacker \& Joseph Raz. Oxford: Oxford University Press, pp. 210-228.

Raz, Joseph (1982) "Promises in Morality and Law: Review of Promises, Morals, and Law by P. S. Atiyah". Harvard Law Review, Vol. 95, No. 4, pp. 916-938.

Recanati, François (1987) Meaning and Force: The Pragmatics of Performative Utterances. Cambridge: Cambridge University Press.

Recanati, François. (2003a) "Embedded implicatures". Philosophical Perspectives, Vol. 17, No.1, pp. 299-332.

Recanati, François (2003b) "The limits of expressibility". In: John Searle, ed. by Barry Smith. Cambridge: Cambridge University Press, pp. 189-213.

Recanati, François (2004) Literal Meaning. Cambridge: Cambridge University Press.

Recanati, François (2007) Perspectival Thought: A Plea for (Moderate) Relativism. Oxford: Oxford University Press.

Recanati, François. (2009; ms) "Contextualism and Systematic Semantics" A handout for a paper delivered at "Pragmatics, Semantics and Systematicity", a workshop organized in Stockholm, 8-9- May 2009.

Reeder Kenneth (1980) "The emergence of illocutionary skills". Journal of Child Language, Vol. 7, No.1, pp. 13-28.

Reinach, Adolf (1983 [1913]) The A Priori Foundations of Civil Law [translated by John F. Crosby]. Aletheia 3: 1-142.

Reiner, Toby (2009) "Texts as Performances: How to Reconstruct Webs of Beliefs from Expressed Utterances”. Journal of Philosophy of History, Vol. 3, pp. 266-289.

Reiss, Nira (1985) Speech Act Taxonomy as a Tool for Ethnographic Description. Amsterdam and Philadelphia: John Benjamins.

Robinson, Douglas (2003) Performative Linguistics: Speaking and translating as doing things with words. New York \& London: Routledge.

Rorty, R. (1967) "Introduction. Metaphilosophical difficulties of linguistic philosophy". In: R. Rorty (ed.) The Linguistic Turn. Recent Essays in Philosophical Method. Chicago and London: University of Chicago Press, pp. 1-39. 
Rosaldo, Michelle Z. (1982) "The Things We Do with Words: Ilongot Speech Acts and Speech Act Theory in Philosophy". Language in Society, Vol. 11, No.2, pp. 203-237.

Ross, A.R. (2003) "Being Lucky—Virtual Performative Speech Acts". Academic Exchange Quarterly, Vol. 7, No.4.; available on-line at: www.questia.com/read/1G1-114168115/beinglucky-virtual-performative-speech-acts (accessed May 2008).

Ross, John Robert (1970) “On declarative sentences". In: Readings in English Transformational Grammar, ed. by R. Jacobs \& P. Rosenbaum. Boston: Ginn \& Co., pp. 222-272.

Ryle, Gilbert (1956) "Introduction” In: The revolution in Philosophy, ed. by Gilbert Ryle, London: Macmillan, pp. 1-11.

Sadock, Jerrold M. (1970) "Whimperatives" In: Studies presented to R. B. Lees by his students, ed.by J.M.Sadock and A.L. Vanek. Edmonton: Linguistic Research, pp. 223-238.

Sadock, Jerrold (1974) Toward a linguistic theory of speech acts. New York: Academic Press.

Sadock, Jerrold M. (1985) "On the performadox, or asemantic defense of the performative hypothesis". University of Chicago Working Papers in Linguistics, Vol. I, Chicago: University of ChicagoDepartment of Linguistics, pp. 160-69.

Sadock, Jerrold (1994) "Toward a grammatically realistic typology of speech acts" In: Tsohatzidis (ed.), pp. 393-406.

Sadock, Jerrold (2008) "Speech Acts”. In: The Handbook of Pragmatics, ed. by Lawrence R. Horn \& Gregory Ward. Oxford: Blackwell, pp. 53-73.

Sadock, Jerrold M. \& Arnold M. Zwicky (1985) "Sentence types"; In: Language Typology and Syntactic Description, Vol. 1: Clause Structure, ed. by T. Shopen. Cambridge: Cambridge University Press, pp. 155-196.

Saeed, John I. (2009; $3^{\text {rd }}$ ed.) Semantics. Oxford: Wiley-Blackwell.

Sapir, Edward (1929) "The Status of linguistics as a science". Language, Vol. 5, No. 4, pp. 207214 (the text available on-line at http://www.bible-researcher.com/sapir1.html; May 2013).

Sbisà, Marina (1984) "On illocutionary types”. Journal of Pragmatics, Vol. 8, pp.93-112.

Sbisà, Marina (2001) "Illocutionary force and degrees of strength in language use". Journal of Pragmatics, Vol. 33, pp.1791-1814; doi:10.1016/S0378-2166(00)00060-6.

Sbisà, Marina (2002) "Speech acts in context." Language and Communication 22, pp.421-436; doi: 10.1016/S0271-5309(02)00018-6.

Sbisà, Marina (2007) "How to read Austin". Pragmatics, Vol. 17, Issue 3, pp.461-473.

Sbisà, Marina (2009) "Uptake and conventionality in illocution". Lodz Papers in Pragmatics. Special Issue on Speech Actions, ed. by Iwona Witczak-Plisiecka \& Maciej Witek. Vol.5, No.1, pp.33-52; doi: 10.2478/v10016-009-0003-0.

Schelling Thomas C. (1960/1980) The Strategy of Conflict. Cambridge, MA: Harvard University Press.

Schiffer, Stephen R. (1972) Meaning. Oxford: Oxford University Press.

Schiffrin, Deborah (1980) "Meta-Talk: Organizational and Evaluative Brackets in Discourse" Sociological Inquiry, Vol. 50, Issue 3-4, pp. 199-236; doi:10.1111/j.1475682X.1980.tb00021.x

Searle, John R. (1964) "How to derive 'ought' from 'is'”, The Philosophical Review, Vol. 73, No. 1 (Jan. 1964), pp. 43-58.

Searle, John R. (1965) "What is a speech act?" In: Philosophy in America, ed. by Max Black. Ithaca: Cornell University Press, pp. 221-239 [Reprinted in: Martinich, A. (1996), pp. 130140].

Searle, John R. (1968) "Austin on locutionary and illocutionary acts" The Philosophical Review, Vol. 57, No. 4, pp. 1405-1424.

Searle, John R. (1969) Speech Acts. An Essay in the Philosophy of Language. Cambridge: Cambridge University Press.

Searle, John R. (1971) “Introduction”. In: Philosophy of Language, ed. by John R. Searle. Oxford: Oxford University Press, pp. 1-12. 
Searle, John R. (1975a) "Indirect speech acts". In Peter Cole \& Jerry L. Morgan (eds.) Syntax and Semantics, vol. 3, pp. 59-82.

Searle, John R. (1975b) “The Logical Status of Fictional Discourse" New Literary History, Vol. 6, No. 2 [On Narrative and Narratives], pp. 319-332.

Searle, John R. (1977) "Reiterating the differences: A reply to Derrida" Glyph, Vol. 1, pp. 204-205.

Searle, John R. (1979a) Expression and Meaning. Cambridge: Cambridge University Press.

Searle, John R. (1979b. [1975]) “A Taxonomy of Illocutionary Acts.” Reprinted in John R. Searle (1979a) Expression and Meaning, Cambridge: Cambridge University Press, pp.1-29.

Searle, John R. (1983) Intentionality: An essay in the philosophy of mind. Cambridge: Cambridge University Press.

Searle, John R. (1984) Interview [with G. Heyer \& D. Munch]: Von der Sprechakttheorie zur Intentionalitiit. Information Philosophie (Jan. 1984), pp. 2-30.

Searle, John R. (1989) "How Performatives Work", Linguistics and Philosophy, Vol. 12, pp. 535-558.

Searle, John R. (1992a) “Conversation”. In: Searle at al. (eds.), pp. 7-29.

Searle, John R. (1992b) “Conversation reconsidered”. In: Searle at al. (eds.), pp. 137-148.

Searle, John R. (1995) The Construction of Social Reality. New York: Free Press.

Searle, J. R. (1999) Mind, Language, and Society: Doing Philosophy in the Real World. New York: Basic Books.

Searle, J. R. (2001) Rationality in Action. Cambridge, MA: MIT Press.

Searle, John R. (2002a) "How performatives work" In: Essays in Speech Act Theory, ed. by Daniel Vanderveken \& Susumu Kubo. Amsterdam \& Philadelphia: John Benjamins, pp. 535-558.

Searle, John R. (2002b) "Speech Acts, Mind, and Social Reality". In: Speech Acts, Mind, and Social Reality: Discussions with John Searle, ed. by Günter Grewendorf \& Georg Meggle. Dordrecht/Boston/London: Kluwer Academic Press, pp. 3-16.

Searle, John. R. (2007) Freedom and Neurobiology: Reflections on Free Will, Language, and Political Power. New York: Columbia University Press.

Searle, John R. (2010) Making the Social World: The Structure of Human Civilization. Oxford: Oxford University Press.

Searle, John R., Ferenc Kiefer \& Manfred Bierwisch (eds.) (1980) Speech Act Theory and Pragmatics. Dordrecht: Reidel.

Searle, John R., Herman Parret \& Jef Verschueren (eds.) (1992) (On) Searle on Conversation. Amsterdam/Philadelphia: John Benjamins.

Searle, John R. \& Daniel Vanderveken (1985) The Foundations of Illocutionary Logic. Cambridge: Cambridge University Press.

Seuren, Pieter A. M. (1985) Discourse Semantics. Oxford: Blackwell.

Seuren, Pieter A.M. (1998) Western Linguistics: An Historical Introduction. Oxford: Blackwell.

Seuren Pieter A. M. (2009) Language in Cognition. Volume I: Language from Within. Oxford: Oxford University Press.

Seymour, Michel (2010) "Speech act pluralism, minimal content and pragmemes." Journal of Pragmatics, Vol. 42, pp. 2870-2881.

Sharifian, Farzad (2011) Cultural Conceptualisations and Language: Theoretical framework and applications. Amsterdam/Philadelphia: John Benjamins Publishing Company.

Shuy, Roger W. (1994) "Deceit, distress, and false imprisonment". Forensic Linguistics, Vol.1, pp. 133-149.

Shuy, Roger (2001) "Discourse analysis in the legal context". In: The Handbook of Discourse Analysis, ed. by Deborah Schiffrin, Deborah Tannen \& Heidi E. Hamilton. Oxford: Blackwell, pp. 437-52.

Shwayder, David S. (1994) “A semantics of utterance, formalized” In: Tsohatzidis (ed.), pp. 80-98.

Siegel, Muffy E. A. (2006) "Buiscuit conditionals: quantification over potential literal acts" Linguistics and Philosophy, Vol. 29, pp. 167-203. 
Simpson, A. W. Brian (2006) "Herbert Hart elucidated". Michigan Law Review, Vol. 104, No. 6, pp. 1437-1459. Stable URL: http://www.jstor.org/ stable/40041443 (accessed 19 February 2010).

Smith, Barry (1984) "Ten conditions on a theory of speech acts". Theoretical Linguistics, Vol. 11, No.3, pp. 309-330.

Smith, Barry (1988) "Materials towards a history of speech act theory” In: Karl Bühler's Theory of Language, ed. by Achim Eschbach. Amsterdam: John Benjamins, pp. 125-152.

Smith, Barry (1990) "Towards a history of speech act theory" In: Speech Acts, Meanings and Intentions: Critical Approaches to the Philosophy of John Searle, ed. by Armin Burkhardt. Berlin \& New York: de Gruyter, pp. 29-61.

Soames, Scott (2010) Philosophy of Language. Princeton \& Oxford: Princeton University Press.

Souza Filho, Danilo Marcondes de (1984) Language and action: A reassessment of speech act theory. Amsterdam \& Philadelphia: John Benjamins.

Sperber, Dan, Fabrice Clément, Christopher Heintz, Olivier Mascaro, Hugo Mercier, Gloria Origgi, \& Deirdre Wilson (2010) "Epistemic vigilance". Mind and Language, Vol. 25(4), pp. 359-393.

Sperber, Dan \& Gloria Origgi (2012) "A pragmatic perspective on the evolution of language" In: Wilson \& Sperber (2012a), pp. 331-338 [originally published in: R. Larson, V. Déprez \& H. Yamakido (eds.) (2010) The Evolution of Human Language: Biolonguistic Perspectives. Cambridge: Cambridge University Press, pp. 124-132].

Sperber, Dan \& Deirdre Wilson (1986/1995) Relevance. Communication and Cognition. $2^{\text {nd }}$ ed. Oxford: Blackwell.

Sperber, Dan \& Deirdre Wilson (2012) "Pragmatics, modularity and mindreading" In: Wilson \& Sperber (2012a), pp. 261-278 [originally published in: Mind \& Language (2002), Vol. 17, pp. 3-23].

Stacey, Robin Chapman (2007) Dark Speech: The Performance of Law in Early Ireland. Philadelphia: University of Pennsylvania Press.

Stainton, Robert J. (1996) Philosophical Perspectives on Language. Peterborough Ontario \& London: Broadview Press.

Stalnaker, Robert (1978) "Assertion.” In: Syntax and Semantics 9: Pragmatics, ed. by Peter Cole, pp. 315-332. New York: Academic Press; doi: 10.1093/0198237073.003.0005.

Stanley, Jason (2007) "Context and logical form" In: Stanley Jason; Language in Context: Selected Essays. Oxford: Oxford University Press, pp. 30-68.

Strawson, Peter F. (1964) "Intention and convention in speech acts." Philosophical Review, Vol. 73, pp.439-460; doi: 10.2307/2183301.

Strawson, Peter F. (1973). “Austin and locutionary meaning”. In Berlin et al., pp. 46-68.

Sweetser, Eve (2002) "Blended spaces and performativity" Cognitive Linguistics 11-3/4, pp. 305333.

Szymura, Jerzy (1982) Język, mowa i prawda w perspektywie fenomenologii lingwistycznej J.L. Austina. Wrocław: Ossolineum.

Taavitsainen, Irma \& Andreas Jucker (2008) "Speech acts now and then". In: Speech Acts in the History of English, ed. by Andreas H. Jucker \& Irma Taavitsainen. Amsterdam/Philadelphia: John Benjamins, pp. 1-23.

Tambling, Jeremy (1988) What is Literary Language? Buckingham: Open University Press.

Taylor, Talbot J. \& Deborah Cameron (1987) Analysing Conversation: Rules and Units in the Structure of Talk. Oxford: Pergamon Press.

Thibault, Paul J. \& Theo van Leeuwen (1996) "Grammar, society, and the speech act: Renewing the connections" Journal of Pragmatics, Vol. 25, pp. 561-585.

Thomas, Jenny (1995) Meaning in Interaction: An introduction to pragmatics. London: Longman.

Trosborg, Anna (1991) "An Analysis of Legal Speech Acts in English Contract Law". Hermes: Journal of Linguistics, Vol. 6, pp. 65-90. 
Trosborg, Anna (1995) "Statutes and contracts: An analysis of legal speech acts in the English language of the law" Journal of Pragmatics, Vol. 23, pp. 31-53; doi: 10.1016/03782166(94)00034-C.

Tsohatzidis, Savas L. (1994) "Ways of doing things with words: An introduction" In: Tsohatzidis (ed.), pp. 1-25.

Tsohatzidis, Savas L. (2010) "Speech Act Theory: Some current options" Intercultural Pragmatics, Vol. 7-2, pp. 341-362; doi: 10.1515/IPRG.2010.010.

Tsohatzidis, Savas L. (ed.) (1994) Foundations of Speech Act Theory: Philosophical and linguistic perspectives. London: Routledge.

Turner, Roy (ed.) (1974) Ethnomethodology: Selected Readings. Harmondsworth: Penguin.

Urmson, J. (1963) "Parenthetical verbs". In: Philosophy and ordinary language, ed. by C. Caton. Urbana, IL: University of Illinois Press, pp. 220-240.

Vanderveken, Daniel (1980) "Illocutionary Logic and Self-Defeating Speech Acts" In: Speech Act Theory and Pragmatics, ed. by John R. Searle, Ferenc Kiefer \& Manfred Bierwisch. Springer Netherland, pp. 247-272.

Vanderveken, Daniel (1990) Meaning and Speech Acts. Vol.1: Principles of language use. Cambridge: Cambridge University Press.

Vanderveken, Daniel (1991a) Meaning and Speech Acts. Vol.2: Formal semantics of success and satisfaction. Cambridge: Cambridge University Press.

Vanderveken, Daniel (1991b) "Non-literal speech acts and conversational maxims". In: John Searle and His Critics, ed. by Ernest Lepore \& Robert Van Gulick. Oxford, Cambridge, M.A.: Basil Blackwell, pp. 371-384.

Vanderveken, Daniel (1994) "A complete formulation of a simple logic of elementary illocutionary acts". In: Tsohatzidis, Savas (ed.), pp. 99-131.

Vanderveken, Daniel (1995) "On the ramification of the fundamental notions of meaning, analyticity, consistency, entailment and commitment to speech acts in formal semantics: A reply to Brassac and Trognon". Journal of Pragmatics, Vol. 23, pp. 563-576.

Vanderveken, Daniel (2001) "Illocutionary logic and discourse typology". Revue internationale de philosophie, Vol. 55, Issue 216, pp. 243-255; text available on-line at http://www.uqtr. ca/ vandervk/DiscourseTypology.pdf (accessed May 2009).

Vanderveken, Daniel (2002a) "Universal grammar and speech act theory". In: Vanderveken, Daniel \& Susumu Kubo (eds.), pp. 25-62.

Vanderveken, Daniel (2002b) "Searle on meaning and action". In: Speech Acts, Mind and Social Reality: Discussions with John R. Searle, ed. by Günter Grewendorf \& Georg Meggle. Dordrecht: Kluwer, pp. 141-161.

Vanderveken, Daniel \& Susumu Kubo (eds.) (2002) Essays in Speech Act Theory. Amsterdam: John Benjamins.

Vendler, Zeno (1957) "Verbs and Times" The Philosophical Review, Vol. LXVI, pp. 143-160.

Vendler, Zeno (1967) Linguistics in Philosophy. Ithaca \& London: Cornell University Press.

Vendler, Zeno (1972) Res Cogitans: An Essay in Rational Psychology. Ithaca: Cornell University Press.

Vendler, Zeno (1976) "Illocutionary Suicide", In: Issues in the Philosophy of Language: Proceedings of the 1972 Obedin Philosophy Colloquium, ed. by Alfred F. MacKay \& Daniel D. Merrill. New Haven: Yale University Press, pp. 135-145.

Verschueren, Jeff. (1977) The Analysis of Speech Act Verbs: Theoretical Preliminaries. Bloomington, Indiana: Indiana University Linguistics Club.

Verschueren, Jeff (1983) "On Bogusławski on 'promise". Journal of Pragmatics, Vol.7, pp. 629632.

Verschueren, Jeff (1985) What People Say They Do with Words. Norwood, N.J.: Ablex Publishing Corporation. 
Verschueren, Jeff. (1987) "Metapragmatics and universals of linguistic action" In: Jef Verschueren (ed.), pp. 125-140.

Verschueren, Jeff. (ed.) (1987) Linguistic Action: Some Empirical-Conceptual Studies. Norwood, N.J.: Ablex Publishing Corporation.

Verschueren, Jeff. (ed.) (1999) Understanding Pragmatics. London \& New York: Arnold.

Warnock, G. J. (1971) The Object of Morality. London: Methuen.

Warnock, G. J. (1973) "Some types of performative utterances” In: Berlin et al., pp. 69-89.

Warnock, G. J. (1989) J.L. Austin. London \& New York: Routledge.

Wee, Lionel (2004) “'Extreme communicative acts' and the boosting of illocutionary force". Journal of Pragmatics, Vol. 36, pp. 2161-2178.

Wenger, Etienne (1998) Communities of Practice: Learning, meaning, and identity. Cambridge: Cambridge University Press.

Wierzbicka, Anna (1972) Semantic Primitives. Frankfurt: Athenaum.

Wierzbicka, Anna (1980) Lingua Mentalis. Sydney: Academic Press.

Wierzbicka, Anna (1985a) "Different cultures, different languages, different speech acts: Polish vs. English". Journal of Pragmatics, Vol. 9, pp. 145-178.

Wierzbicka, Anna (1985b) Lexicography and Conceptual Analysis. Ann Arbor: Karoma.

Wierzbicka, Anna (1987) English Speech Act Verbs: A semantic dictionary. Marrickville: Academic Press Australia.

Wierzbicka, Anna (1991) Cross-Cultural Pragmatics: The Semantics of Human Interaction. Berlin \& New York: Mouton de Gruyter.

Wierzbicka, Anna (1996) Semantics: Primes and Universals. Oxford: Oxford University Press.

Wierzbicka, Anna (1997) Understanding Cultures Through Their Key Words: English, Russian, Polish, German, and Japanese. Oxford: Oxford University Press.

Wierzbicka, Anna (1999) Emotions across Languages and Cultures: Diversity and Universals. Paris \& Cambridge: Cambridge University Press.

Williams, Christopher (2005) Tradition and Change in Legal English. Verbal Constructions in Prescriptive Texts. Bern: Peter Lang.

Wilson, Deirdre \& Dan Sperber (2002) "Truthfulness and Relevance". Mind, Vol. 111, pp. 583632. (also published in UCL Working Papers in Linguistics (2000), Vol. 12, pp. 215- 254).

Wilson, Deirdre \& Dan Sperber (2012a) Meaning and Relevance. Cambridge: Cambridge University Press.

Wilson, Deirdre \& Dan Sperber (2012b) "Linguistic form and relevance" In: Wilson \& Sperber (2012a), pp. 149-168.

Witczak-Plisiecka, Iwona (2001; ms). Semantic and Pragmatic Aspects of Speech Acts in English Legal Texts. PhD dissertation, University of Lodz, Poland.

Witczak-Plisiecka, Iwona (2009a) "Speech acts and the autonomy of linguistic pragmatics". Lodz Papers in Pragmatics. Special Issue on Speech Actions, 5.1: 85-106; doi: 10.2478/v10016009-0008-8.

Witczak-Plisiecka, Iwona (2009b) "Legal Speech Acts in a Cognitive Linguistic PerspectiveFocus on Modality" Comparative Legilinguistics (International Journal for Legal Communication), No. 1 (1), pp. 159-175.

Witczak-Plisiecka, Iwona (2011) "Performatywność jako znaczenie wyłaniające się w kontekście w świetle pojęć emergencji i amalgamatów językoznawstwa kognitywnego". In: Przestrzenie kognitywnych poszukiwań, ed. by Alina Kwiatkowska. Łódź: Wydawnictwo Uniwersytetu Łódzkiego, pp. 195-206.

Witczak-Plisiecka, Iwona (2013) "Speech action in legal contexts". In: Pragmatics of Speech Actions [Handbook of pragmatics; Part 2], ed. by Marina Sbisà \& Ken Turner. Berlin/Boston: Mouton de Gruyter, pp. 613-658.

Witek, Maciej (2011) Spór o podstawy teorii czynności mowy. Szczecin: Wydawnictwo Naukowe Uniwersytetu Szczecińskiego. 
Wittgenstein, Ludwig (1953/1958) ( $^{\text {nd }}$ revised edition). Philosophical Investigations. Oxford: Basil Blackwell.

Wittgenstein, Ludwig (1960) The Blue and Brown Books. New York: Harper.

Wittgenstein, Ludwig (1878) $\left(3^{\text {rd }}\right.$ revised edition) Remarks on the Foundations of Mathematics, ed. by G.H. von Wright, R. Rhees \& G.E.M. Anscombe (transl.). Oxford: Oxford University Press.

Wood, David (ed.) (2010) Perspectives on Formulaic Language: Acquisition and Communication. London \& New York: Continuum.

Wray, Alison (2002) Formulaic Language and the Lexicon. Cambridge: Cambridge University Press.

Žagar, Igor Ž. (1991) "How to Do Things with Words-The Polyphonic Way" In: Speech Acts: Fiction or Reality? Proceedings of the International Conference Ljubljana, Yugoslavia, November 15, 1990, ed. by Igor Žagar. Ljubljana: IPrA Distribution Centre for Yugoslavia, Institute of Social Sciences, pp. 77-88.

Žagar, Igor Ž. \& Matejka Grgič (2011) How to Do Things with Tense and Aspect. Newcastle upon Tyne: Cambridge Scholars Publishing. 


\section{INDEX}

\section{A}

Aikhenvald, Alexandra Y. 212, 275

Alexander, Jeffrey C. 275

Allan, Keith 256, 262, 265-266, 275, 289,

Allen, James F. 108, 275

Allwood, Jens 18, 71, 203, 275

Alston, William P. 15-16, 73-75, 141-142, 174-175, 184-185, 212, 235-238, 275

Anderson, Stephen R. 97, 275

Anscombe, G.E.M. 295

Anscombre, Jean-Claude 124-125, 275

Archer, Dawn 182, 279

Aristotle 1, 7-9, 11, 24, 27, 38, 49, 73, 81, $106,134-135,189,275-276$

Arnovick, Leslie K. 182, 276

Asher, Nicholas $\quad 158-159,276$

Astington, J.W. 178, 276

Atiyah, P. S. 171-172, 174, 180, 276, 290

Atkins, Beryl T. 122, 140, 276

Atlas, Jay David 219, 276

Austin, John Langshaw 1-4, 6, 10, 12-14, 16-18, 21-25, 27, 29-30, 32-33, 36-39, 41-53, 55-80, 82, 86, 99, 101-102, 105$107,110-111,113-117,119-122,124-131$, 133-136, 139-141, 143-146, 148, 152-155, 158, 161-165, 167-170, 181, 183-186, 188-189, 196, 199-209, 211-213, 215-217, 219-220, 222, 226-227, 229, 231-236, 238, 240-241, 243, 245-248, 250-255, 259-262, 264, 267-271, 273, 276, 277279, 281-283, 289-291, 293, 295

Avramides, Anita 188, 276

\section{B}

Bach, Kent $\quad 20,51,54-55,57,76-79,88$ $89,92,96,118,120,129,144,159,169$, 184-185, 198, 208, 212, 216-219, 224,
$232,235,236,238-239,241-242,250-$ 251, 253, 271, 276

Bailey, Charles-James N. 282

Bakewell, Liza 6-7, 276

Bakhtin, Mikhail M. 18, 276

Ballmer, Thomas T. 121, 154, 276

Bally, Charles 280

Barker, Stephen 71, 147-148, 277

Baskin, Wade 280

Bass, Alan 280

Bates, Elisabeth $\quad 122,140,277$

Bauman, Richard 108, 277

Bayer, Samuel $\quad 159,284$

Beaney, Michael 12, 277

Bell, David 92, 277

Benveniste, Émile $10,14,30-33,35-36$, 38, 124, 277

Berlin, Brent 139, 277

Berlin, Isaiah 41-42, 277, 281, 289, 293, 295

Bernicot, Josie $178-179,277,286$

Bertuccelli-Papi, Marcella 182, 277, 279

Bezuidenhout, Anne L. 243, 277

Biber, Douglas 18, 277

Bierwisch, Manfred 280, 292, 294

Bird, Alexander 48, 277

Black, Max 51, 67, 277, 282, 291

Black, William 290

Blackmore, Susan 267, 277

Blum-Kulka, Shosana, 161, 277

Böer, Steven, 48, 277

Bogusławski, Andrzej 174, 277, 294

Bohr, Hans 274, 277

Bohr, Niels 274, 277

Boole, George 8,134

Brand, Myles 286 
Brandom, Robert $14,16,38,149,232-235$, 237-238, 277, 288

Bransford, John 282

Bratman, Michael E. 4, 277

Brennenstuhl, Waltraud 121, 154, 276

Breustedt, Barb 285

Briggs, Richard 108, 278

Brook, Andrew 289

Brown, Keith E. 288

Brown, Gillian 7, 97, 109, 278

Brown, Penelope 185,278

Bühler, Karl 22, 27-29, 37-38, 278, 293

Bunt, Harry 290

Burge, Tyler 192-194, 198-199, 249, 255, 266, 278

Burkhardt, Armin 293

Butler, Judith $\quad 6,86-87,106,248,278$

\section{C}

Camaioni, Luigia 140, 277

Cameron, Deborah 293

Campbell, Robin $\quad$ 219-220, 242-243, 278

Cappelen, Herman $\quad 81,96,113,239-241$, 278

Capone, Alessandro $\quad 256,262,265-266$, 278

Carlson, T.B. $\quad 119,279$

Carruthers, Peter 289

Carston, Robyn $77-78,96,175,201,241$, 253, 278

Caton, C. 294

Cavell, Stanley $18,43,45,278$

Chamberlain, Andrew 289

Chapman, Siobhan 3, 33, 44, 45, 51, 278

Charnock, Ross 47, 279

Chomsky, Noam 48, 58, 145, 280

Chrzanowska-Kluczewska, Elżbieta 14 , 279

Chudzik, Anna 6, 279

Clark, Herbert H. $\quad 119,185,216,279$

Clarke, David D. 7, 33, 43, 46, 289

Clément, Fabrice 293

Cohen, Donald J. 185, 289

Cohen, L. Jonathan 97, 279

Cohen, Philip R. 289

Cole, Peter 279, 281, 283, 288, 291, 293,

Cole, Roger W. 281

Collett, Peter 288

Collins, John 225, 279

Cooke, Maeve 283

Corrigan, Roberta 253, 279
Critchley, Simon 280

Croft, William 130, 279

Crosby, John F. 290

Culler, Jonathan $\quad 62,196-197,247,252,279$

Culpeper, Jonathan 182,279

Cummings, Louise $122,185,279$

\section{D}

Danet, Brenda 133, 279

Dascal, Marcelo 269, 279

Davidson, Donald 4, 92, 224, 241, 279280

Davis, Steven $\quad 66-67,280,288$

De Brabanter, Philippe 286

de Lannoy, Jacques-Dominique $\quad 6,68,281$

de Morgan, Augustus 9, 134

de Saussure, Ferdinand 25, 38, 62, 109, 196, 280, 283

Delaney, Suzanne M. 176-177, 282

Dennett, Daniel 267, 280

Déprez, V. 293

Derrida, Jacques $38,86,93,111,164,196$, 246-248, 279-280, 291

Dik, Simon C. 269-270, 280

Dirven, René 280-281

Dore, John 160, 280

Doty, Kathleen L. $\quad 182,280$

Dosse, François $\quad 30,280$

Dowdell, V.L. 285

Drabik, Beata 42, 280

Dummett, Michael 12, 281, 284

Dyscolus, Apollonius 9, 284

\section{E}

Eco, Umberto $\quad 179,260$

Emerson, Caryl 255

English, Parker 43, 260

Ervin-Tripp, Susan 145, 168, 260

Eschbach, Achim 276

Evans, J.L. 14

Everett, Daniel $\quad 146,260$

\section{F}

Faller, Martina T. 211, 281

Farkas, Katalin 235, 281

Fauconnier, Gilles 133, 281

Fein, Ofer 6, 68-69, 281

Felman, Shoshana 93, 281

Fetzer, Anita 204, 281, 288,

Feyereisen, Pierre $\quad 6,68,281$

Fillmore, Charles J. 141, 281 
Finnegan, Ruth 108, 281

Firth, John R. 25-26, 281

Fish, Stanley 41, 57, 281

Forguson, L.W. 67, 281

Frank, Roslyn M. 258, 281

Fraser, Bruce $\quad 92,97,122,130,282$

Frege, Gottlob 9, 12-14, 19, 39, 64, 134, 137, 233, 235, 240, 243, 277, 281-283, 286-287

French, Peter 278

Fricker, Miranda 284

Fried, Charles 171,282

Fried, Vilém 280

Furberg, Mats 14, 67, 282

\section{G}

Garfinkel, Harold 161, 267, 282

Gass, S.M. 107, 282

Gauker, Christopher 237-238, 282

Gazdar, Gerald 235-236, 282

Geach, P. 282

Gibbs, Raymond W. 174, 176-179, 282

Gibson, James J. 256-258, 282

Gilbert, Margaret 191-192, 282

Ginet, Carl 118-119, 282

Glassman, Deborah 280

Glendinning, Simon 43, 282

Goffman, Erving $\quad 18,119,254,282-283$

Goldberg, Adele 281

Goodwin, Donald 278

Gordon David 213, 283

Górska, Elżbieta 285

Greenbaum, Sidney 272

Grewendorf, Günter 292, 294

Grgič, Matejka 36, 296

Grice, Herbert P. 10, 19, 29, 33, 58, 61, 70, 74-77, 79, 89, 118-119, 137, 158-159, 174-175, 188, 198-199, 201, 205, 208, 214, 217-218, 226, 228, 233, 235-236, $248,253,283-284$

Gu, Yueguo 66, 283

Gumperz, John 282, 284

Gunderson, Keith 287

Gustaffson, Martin 42, 282-283

\section{H}

Habermas, Jürgen $\quad 37-38,283$

Hacker, Peter M. 290

Hagen, Rainer 5, 283

Hagen, Rose-Marie 5, 283

Haiman, Franklyn Saul 85, 283
Hale, Bob 276

Hall, Edward T. 160, 283

Hamilton, Heidi E. 292

Hancher, Michael 119, 130, 283

Hare, Richard Mervyn 67, 92, 174, 283

Harnish, Robert M. 13, 16, 20, 51, 54-55, 64, 88-89, 92, 96, 98, 120, 159, 169, 184-185, 188, 198, 208, 212, 216-219, 224, 232, 235-236, 238, 242, 250-251, $253,271,275-276,282-283,286$

Harris, Roy 18, 25, 249-250, 280, 283

Harris, Zelig 145

Harrison, Bernard 64, 283

Hart, Herbert Lionel Adolphus 106, 170, 183, 271, 284, 290, 292

Heintz, Christopher 293

Heinz, Adam 33, 284

Heyer, G. 292

Higginbotham, James $\quad 110,284$

Hiltunen, Risto 182,280

Hindriks, Frank 186, 284

Hofstede, Geert 160,284

Holdcroft, David 56, 73, 147, 211, 235236, 284

Holquist, Michael 276

Holtgraves, Thomas 107, 284

Horn, Laurence R. 84, 159, 284-285, 291

Hornsby, Jennifer $\quad 4,6,66,88,106,248$, 284

House, Juliane 277

Householder, Fred W. 9, 284

Huang, Yan 51, 89, 117, 248, 284

Hume, David 189, 284

Husserl, Edmund 19-24, 27, 39, 45, 249, 284

Hutton, Chris 43, 284

Hymes, Dell H. 30, 270, 282, 284

\section{I}

Infantidou-Trouky, Elly $\quad 211-212,285$

\section{J}

Jackendoff, Ray S. 140, 285

Jackson, S. 285

Jacobs, R. 291

Jakobson, Roman 27-30, 285

Janssen, Theo 281

Jary, Mark 242, 285

Jaszczołt, Katarzyna M. 256-266, 285

Johnson, Barbara 93, 285

Joshi, Aravind K. 282 
Jowett, Benjamin 289

Jucker, Andreas H. 181-183, 279, 285, 293

Jurafsky, Daniel 139, 285

\section{K}

Kadmon, Nirit 109-110, 285

Kalisz, Roman $\quad 62,133,173,285$

Kant, Immanuel $9-11,14,38,69,106,151$, $166,193,201,233,285,287$

Kannetzky, Frank 172, 285

Kasher, Asa 6, 68-69, 108, 140, 276-277, 281, 285, 288

Kasper, Gabriele $\quad 277,285$

Katz, Jerrold J. 55, 58, 96, 145-147, 184, 285

Kay, Paul 139, 277

Kearns, John T. 140, 285

Keck, Gabriele 33, 285

Kecskes, Istvan 256, 286

Keenan, E. 280

Kegl, Judy 276

Keil, Frank C. 288

Kendon, Adam 68,286

Kenesei, István $\quad 275,282-283,286$

Kiefer, Ferenc $\quad 275,280,282-283,286$, 292, 294

Kim, Jaegwon 240-241, 286

Kirchner, Diane M. 108, 140, 160, 290

Kissine, Mikhail 77, 108, 185, 286

Klemke, Elmer Daniel $\quad 12,286$

Korta, Kepa 62-63, 67, 70, 76, 79-84, 211, 229, 249, 286

Koschmieder, Erwin $\quad 33-38,285-286$

Kosofsky, Eve 278

Kryk-Kastovsky, Barbara 182,286

Krzeszowski, Tomasz P. 133, 286

Kubiński, Wojciech 173, 281, 285, 289

Kubo, Susumu 292, 294

Kukla, Rebecca 149-152, 233-234, 237238, 286

Kurzon, Dennis 119, 286

Kwiatkowska, Alina 295

\section{L}

Labov, William 7, 286

Laderman, Carol 108, 286

Lakoff, George 213, 283

Lance, Mark 149-152, 233-234, 237-238, 286

Langton, Rae $\quad 6,87,106,248,284,286$
Larson, R. 293

Lascarides, Alex 158-159, 276

Laval, Virginie 178-179, 277, 286

Lave, Jean 197, 286

Lawrence, Frederick 282

Lee, O.H. 290

Leech, Geoffrey 184-185, 286, 290

Lenneberg, Eric 169, 268

Lepore, Ernest $\quad 81,96,113,239-241,278$, 281, 284, 294

Létoublon, François 275

Levin, Beth 276

Levinson, Stephen $\quad 51,70,217-219,242$, 254, 278, 286

Lewandowska-Tomaszczyk, Barbara 141, 287

Lewis, David K. 12, 165, 189-195, 197, 221, 225, 287, 290

Leybaert, Jacqueline 286

Loxley, James 57, 272, 287

Lucy, Peter 185, 279

Lycan, William, G. 16, 48, 287

MacAdam, Jim 289

MacKay, Alfred F. 294

Mackenzie, I. E. 108, 287

MacKinnon, Catherine $86-87,106,287$

Malinowski, Bronisław 6-7, 26, 287

Marcu, Daniel 66, 287

Marmor, Andrei 191-197, 209-210, 225 , 287

Marsh, Peter 288

Martland, T. R. $\quad 110,287$

Martinich, Aloysius P. 287, 291

Mascaro, Olivier 179, 287, 293

McCarthy, Thomas 283

McCawley, James, D. 122, 287

McGowan, Mary Kate 6, 129, 248, 287

McGuinness, Brian 12, 287

McHoul, Alec 9-10, 69, 110, 287

Meek, Mary Elizabeth 277

Meggle, Georg 292, 294

Meijers, Anthonie 119, 288

Meilijson, Sara R. 108, 140, 288

Mercier, Hugo 293

Merrill, Daniel D. 294

Mey, Jacob L. $\quad 87,92-93,176,256,258-$ 260, 262, 264-266, 288 
Millikan, Ruth Garrett 106, 165, 191-192, 220-232, 235, 237-238, 245, 250-256, 266-267, 279, 288

Mitchell, W. J. T. 7, 288

Mittwoch, Anita 118, 288

Montague, Richard 134

Montminy, Martin 266, 288

Moore, G.E. 4, 18, 45, 277

Moran, Dermot 284

Moravcsik, Edith A. 279

Morgan, Jerry L. 213-217, 219-220, 235, 238, 243, 252-254, 279, 283, 288-289, 291

Morris, Charles H. $\quad 105,288$

Morris, Desmond 68, 288

Morris, Robin K. 243, 277

Mulligan Kevin 10, 22-24, 289

Munch, D. 292

Murphy, J. 287

\section{$\mathbf{N}$}

Navarro-Reyes, Jesus $\quad 63,289$

Neale, Stephen 270, 289

Nerlich, Brigitte 7, 33, 43, 46, 289

Neu, J. 107, 282

Newman, R. A. 289

Newton, Isaac 193

Nietzsche, Friedrich 166, 289

Noveck, Ira 216, 220, 253, 277, 282, 289

Nowell-Smith, Patrick 15

\section{$\mathbf{O}$}

Ochs, E. 277

Ohlsson, Stellan $\quad 135,289$

Oishi, Etsuko 288

Oleksy, Wiesław 285

Olivecrona, Karl 171, 289

Origgi, Gloria 232, 289, 293

O'Shaughnessy, Marie 288

Ouali, Hamid 279

Pagin, Peter $\quad 186,289$

Paul, Rhea 185, 289

Parker, Andrew 278

Parret, Herman $\quad 278,292$

Peetz, Vera 174, 289

Perrault, Raymond $\quad 108,139,275,289$

Perry, John 62-63, 67, 70, 76, 79-84, 211, 229, 249, 286, 289

Pfänder, Alexander 21
Pierrot, Alain 275

Piskorska, Agnieszka 116

Pitcher, George $\quad 42,289$

Plato 7, 27, 48, 189, 289

Poincaré, Henri 193

Pollack, Martha E. 289

Porter, Andrew P. 47, 289

Post, Michał 66, 289

Pound, Roscoe 289

Prichard, Harold A. 23, 167-169, 289

Proost, Kristel 155-157, 289

Prutting, Carol $108,140,160,290$

Putnam, Hilary 266, 290

\section{Q}

Quine, Willard V. 111, 113, 190, 194, 290

Quirk, Radolph, 4, 123, 290

\section{R}

Ramsay, Allan 108, 290

Raz, Joseph 171-172, 174, 290

Recanati, François $\quad 13,58,67,71,95,118$ $119,232,239,241,243-245,290$

Redeker, Gisela 281

Reeder, Kenneth $\quad 107,290$

Reid, Thomas 11-12

Reinach, Adolf $10,12,22-24,38,131$, $167,289,290$

Reiner, Toby $\quad 48,290$

Reiss, Nira $160,161,184$

Rhees, R. 295

Riedlinger, Albert 280

Robinson, Douglas 110,290

Rolf, Eckard 276

Rogers, A. 287

Rorty, R. 106, 232, 290

Rosaldo, Michelle Z. 160-165, 290

Roseman, Marina 108, 286

Rosenbaum, P. 291

Ross, A. R. 47, 291

Ross, John Robert 96, 98, 115, 291

Ross, William David 276

Routledge, Christopher 33, 278

Rozental, Stefan 277

Rudnick, H.H. 285

Russell, Bertrand 9, 95, 134, 235

Ryle, Gilbert 3, 15, 45, 291

\section{S}

Sadock, Jerrold M. 48, 130, 139, 187, 211, $213,250,281,291$ 
Saeed, John I. 51, 291

Sag, Ivan 282

Samuel, Horace B. 289

Sapir, Edward 267, 291

Sbisà, Marina $\quad 41-42,51-52,62,64,82,89-$ 90, 92, 111, 130, 204-205, 207, 278, 291, 295

Schelling Thomas C. 189-190, 291

Schieffelin, B. 277,280

Schiffer, Stephen R. 55, 224, 235-236, 238, 291

Schiffrin, Deborah 117-118, 291-292

Schneider, Gerold 285

Schunk, Dale H. 216, 279

Searle, John R. 10, 12, 16, 20, 22-25, 30, $38,41,43,47,53-56,67,71-73,80,85-$ 90, 93-94, 96-97, 99-106, 108-109, 113, 119-123, 131-140, 142, 146, 153, 155, $158,162,164-165,167,172-177,179$, 181, 184-185, 191-192, 197, 200, 207, 209-211, 213-214, 217-218, 224, 226227, 235-238, 242-243, 248, 250, 252, 277, 280, 282, 286, 288, 290

Sebeok, Thomas A. 28, 285

Sechehaye, Albert 280

Selby-Bigge, L.A. 284

Seuren, Pieter A. M. 9, 11-12, 26, 94-95, 108-109, 116, 273, 292

Seymour, Michel 256, 292

Sharifian, Farzad 161, 292

Shaw, Robert 282

Shopen, T. 291

Shuy, Roger W. 106, 282, 292

Shwayder, David S. 13, 292

Siegel, Muffy E. A. $\quad 72,292$

Simpson, A. W. Brian 271, 292

Smith, Barry $8,11,15,19-22,24,27,39$, $167,179,281,284,290,292-293$

Soames, Scott 107, 293

Sørli, Richard 282-283

Souza Filho, Danilo Marcondes de 18,67 , 293

Sperber, Dan $109,148,175,179,201,206$, 216, 220, 230, 232, 241-242, 253, 257, 277, 282, 287, 289, 293, 295

Stacey, Robin Chapman 6, 293

Stainton, Robert J. 18, 293

Stalnaker, Robert $\quad 85,293$

Stanley, Jason 266, 293

Stanulewicz, Danuta 281, 285, 289

Stekeler-Weithofer, Pirmin 288
Strawson, Peter F. $\quad 15,67,88-91,188$, 198-199, 202, 205-208, 226-227, 229230, 235-236, 238, 249-251, 254, 271, 293

Stubbs, Michael 33, 285

Svartvik, Jan 290

Sweetser, Eve 133, 293

Szabó, Zoltán Gendler 276

Szymura, Jerzy $\quad 22,293$

\section{T}

Taavitsainen, Irma $\quad 181-183,279,285,293$

Tambling, Jeremy 93, 293

Tannen, Deborah 292

Tarski, Alfred 95, 134

Taylor, Talbot J. 293

Thibault, Paul J. 109, 293

Thomas, Jenny $119,131,293$

Tolkien, J.R.R. 255

Trosborg, Anna 133, 293

Tsohatzidis, Savas L. 67, 236, 237-238, 275-267, 279, 282-286, 288, 291-294

Turner, Ken 295

Turner, Mark 133, 281

Turner, Roy $161,267,294$

\section{$\mathbf{U}$}

Uehling, Theodore 278

Urmson, J.O. $\quad 42,61,211,276,294$

$\begin{array}{ll}\text { V } & \text { Van Gulick, Robert } 294\end{array}$

van Leeuwen, Theo 109, 293

Vanderveken, Daniel 47, 100, 103, 113, 130, 134-140, 211, 235-236, 292, 294

Vendler, Zeno $\quad 107,122,142-146,184$, 294

Verschueren, Jeff $\quad 4,36,115-116,121-123$, 174, 262-264, 270, 275, 277-279, 292, 294

Volterra, Virginia 140, 277

von Wright, G.H. 295

Wall, R. 287

Walton, Douglas 286

Ward, Gregory 284, 291

Warnock, G.J. 15, 51, 53-54, 202, 209, 276, 294-295

Webber, Bonnie 282

Wee, Lionel 48, 295 
Wenger, Etienne 197, 286, 295

Wettstein, Howard 278

Wheatley, Kathleen M. 279

Whitehead, Alfred 9, 134, 290

Wierzbicka, Anna 3-4, 114, 153-154, 161, 176, 295

Williams, Christopher 43, 295

Wilson, Deirdre $109,148,175,201,206$, 230, 241-242, 253, 257, 293, 295

Wilson, Robert A. 288

Witczak-Plisiecka, Iwona $69,80,108,119$, 133, 283, 287, 289, 291, 295

Witek, Maciej 232, 283, 287, 291, 295

Wittgenstein, Ludwig 14-18, 38, 43, 45, 106, 108, 121, 196, 211, 233, 249, 250, $257,283,295$
Wood, David 253, 296

Wray, Alison 253, 296

Wright, Crispin 276

\section{$\mathbf{Z}$}

Žagar, Igor Ž. $\quad 36,175,296$

Zampolli, Antonio 281

Ziemke, Tom 281

Zwicky, Arnold M. 139, 291

Yamakido, H. 293

Yule, George 7, 97, 109, 278 
